\title{
AIR POLLUTION AND CLIMATE FORCING OF THE CHARCOAL INDUSTRY IN AFRICA
}

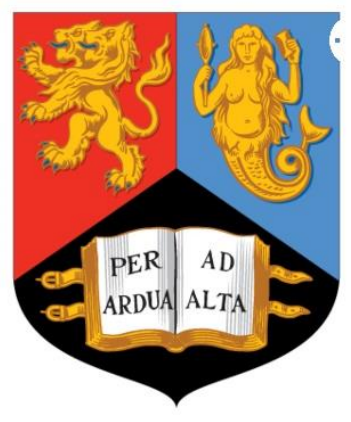

By

Alfred Swaray Bockarie

\section{A thesis submitted to the University of Birmingham for the degree of DOCTOR OF PHILOSOPHY}

School of Geography, Earth and Environmental Sciences College of Life and Environmental Sciences University of Birmingham July 2020 


\section{UNIVERSITYOF \\ BIRMINGHAM}

\section{University of Birmingham Research Archive}

\section{e-theses repository}

This unpublished thesis/dissertation is copyright of the author and/or third parties. The intellectual property rights of the author or third parties in respect of this work are as defined by The Copyright Designs and Patents Act 1988 or as modified by any successor legislation.

Any use made of information contained in this thesis/dissertation must be in accordance with that legislation and must be properly acknowledged. Further distribution or reproduction in any format is prohibited without the permission of the copyright holder. 


\section{ABSTRACT}

Demand for charcoal in Africa is growing rapidly, driven by urbanization and lack of access to electricity and other reliable and clean off-grid energy. Charcoal production and use, including plastic burning to initiate combustion, release large quantities of trace gases and particles that impact air quality and climate. In this work, past (2000-2014) trends in charcoal production and use in Africa are quantified and the dominant drivers identified to forecast the future (2030) of the industry. An inventory of current (2014) and future (2030) emissions from the charcoal supply chain in Africa has also been developed and implemented in the GEOS-Chem chemical transport model to quantify the contribution of charcoal to surface concentrations of $\mathrm{PM}_{2.5}$ and ozone, and direct radiative forcing due to aerosols and ozone. Charcoal production (and use) increased from 2000 to 2014 in Africa by a factor of 2 . In 2014, the charcoal industry required 140-460 Tg fuelwood, depending on efficiency of combustion, to produce charcoal and 260 tonnes plastic for charcoal use to initiate combustion. The variability in wood required is due to variability in combustion efficiency of 9-30\% that depends on kiln type and technology. The plastic use is an educated guess in the absence of statistics on its use and is most prevalent in low-income homes. A rough estimate of forest loss suggests that by 2030, 4.4-15 million hectares of forest will be lost in Africa due to charcoal production. By 2030, charcoal production will almost double which will drive a similar increase in emissions from the industry. Charcoal production makes a substantial contribution to $\mathrm{CH}_{4}$ emissions in Africa. These may outcompete $\mathrm{CH}_{4}$ emissions from open fires in West Africa by 2025. As expected, inefficient combustion emissions of $\mathrm{CH}_{4}, \mathrm{NMVOCs}$, and $\mathrm{CO}$ are predominantly from charcoal production, whereas $\mathrm{BC}$ and $\mathrm{NO}_{\mathrm{x}}$, signatures of efficient 
combustion, are predominantly from charcoal use. An exception is OC that in the inventory is mostly from charcoal use, but should be predominantly from charcoal production, due to the use in the inventory of emission factors that in recent field studies are shown to underestimate OC emissions from charcoal production. In 2014, the largest enhancements in $\mathrm{PM}_{2.5}\left(0.5-1.4 \mu \mathrm{g} \mathrm{m}^{-3}\right)$ and ozone (0.4-0.7 ppbv) occur in densely populated cities in East and West Africa. Cooling due to aerosols ( -100 to $-300 \mathrm{~mW} \mathrm{~m}^{-2}$ ) is concentrated over dense cities, whereas warming due to ozone is widespread, peaking at $4.2 \mathrm{~mW} \mathrm{~m}^{-2}$ over the Atlantic Ocean. Population-weighted $\mathrm{PM}_{2.5}$ exposure increases from $0.34 \mu \mathrm{g} \mathrm{m}^{-3}$ in 2014 to $0.51 \mu \mathrm{g} \mathrm{m}^{-3}$ in 2030 . The air quality and climate impact of charcoal will only worsen with ongoing dependence on this energy source, as most of the future (2100) largest megacities will likely be in Africa. 
I dedicate this work to God Almighty and to all individuals, groups and organisations that are seeking knowledge to make this world a better place 


\section{ACKNOWLEDGEMENT}

I wish to thank a number of people without whom I would not have accomplished this task. First and foremost, I would like to thank my supervisors, Associate Professor Eloise Ann Marais, Professor Angus Robert Mackenzie and Professor Roy Harrison for their guidance, support and expertise throughout my $\mathrm{PhD}$ Research and most importantly for stretching me beyond my own belief.

I am also very grateful to the Islamic Development Bank Group for their financial support during this research project and to Njala University Sierra Leone, for granting me study leave to achieve this milestone in my academic pursuit.

To my family and friends, I wish to thank you for your unconditional support during my time at the university, I could not have done this without you. Most especially, I would like to thank my fiancé, Edna and son, Kpateh, for the patience and peace of mind you gave me during my studies, I am grateful.

Lastly, I must say I am grateful to my laptop and other academic accessories for providing me the requisite service when I need them. Thank you! 


\section{TABLE OF CONTENTS}

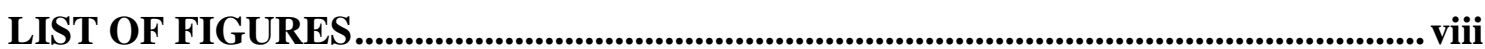

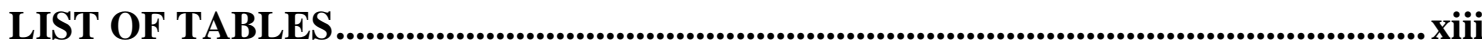

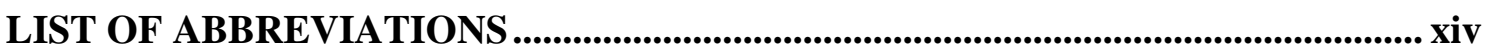

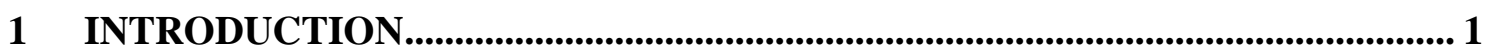

1.1 Overview of Air Pollution and Climate Change ................................................ 1

1.2 Climate and Air Quality Effects of Air Pollutants .............................................. 5

1.2.1 Radiative forcing of short-lived climate forcers ....................................... 11

1.2.2 Chemistry of trace gases and aerosols in the atmosphere............................ 12

1.2.3 Oxidation of volatile organic compounds (VOCs) ..................................... 13

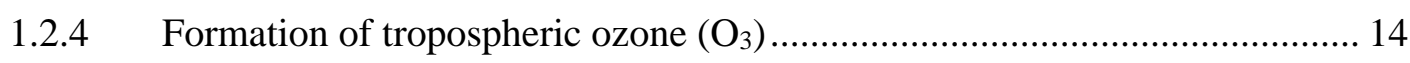

1.2.5 Atmospheric aerosol emission and formation in the atmosphere ...................... 17

1.2.6 The influence of meteorology on air pollutants and short-lived climate

forcers. 18

1.2.7 Weather patterns that influence pollutant transport in Africa........................ 19

1.2.8 Lifetime of pollutants in the atmosphere …............................................. 24

1.2.10 Assessing the impact of pollution sources on air quality and climate .............. 27

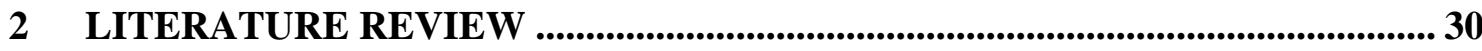

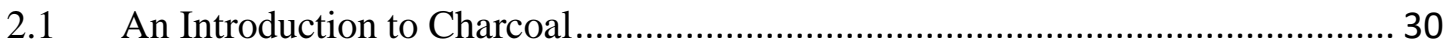

2.2 Charcoal production in Africa....................................................................... 31 
2.3 The Charcoal Supply Chain in Africa

2.4 Aerosols and Trace Gases from the Charcoal Supply Chain ................................ 39

2.5 Environmental Impacts of Charcoal Production ................................................ 44

2.6 Modelling the Effects of Emissions on Air Quality and Climate......................... 46

2.7 Concluding Remarks and Research Gaps ........................................................ 50

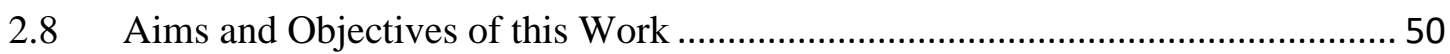

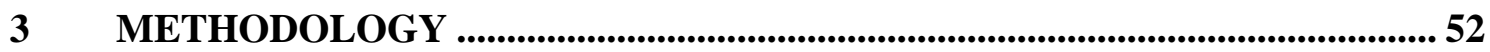

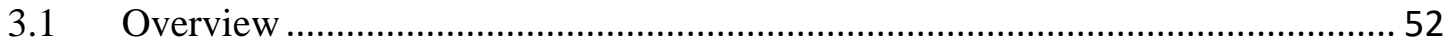

3.2. Trend Analysis in Charcoal Production and Use in 2014 ................................. 52

3.3 Estimating Forest Degradation from Charcoal Production .................................. 56

3.4 Estimating Emissions from the Charcoal Industry in Africa .............................. 57

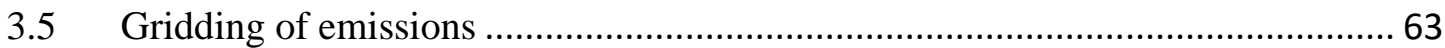

3.6 Estimating future (2030) charcoal production and emissions from the charcoal

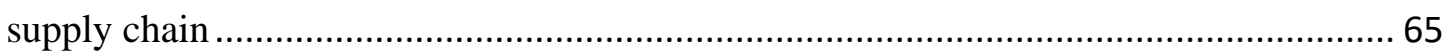

3.7 Assessing Air Quality and Climate Impact of The Charcoal Industry in Africa... 67

3.8 Current and Future Population-Weighted $\mathrm{PM}_{2.5}$ from the Charcoal Supply Chain

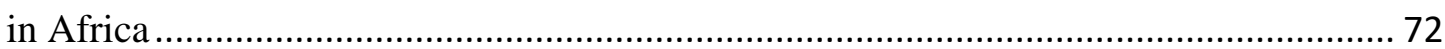

4 CURRENT (2014) AND FUTURE (2030) CHARCOAL PRODUCTION AND USE

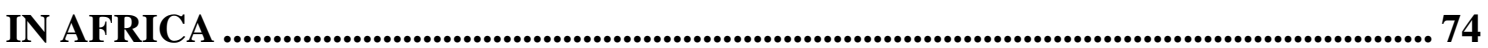

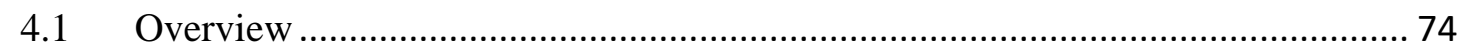

4.2 Past (200-2014) Trends in Charcoal Production and Use in Africa..................... 74 
4.3 Future (2030) Charcoal Production and Use in Africa.....

4.4 Implications for Forest Degradation in 2030

4.5 Summary

84

5 PRESENT-DAY (2014) AND FUTURE (2030) EMISSIONS FROM THE

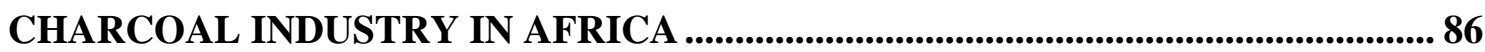

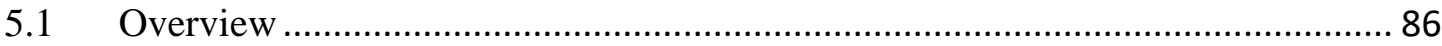

5.2 Current (2014) Charcoal Industry Emissions ................................................... 86

5.3 Future (2030) Emissions from the Charcoal Industry …...................................... 94

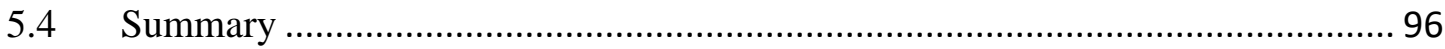

6 AIR POLLUTION AND CLIMATE FORCING OF THE CHARCOAL INDUSTRY IN AFRICA NOW AND IN THE FUTURE ............................................. 97

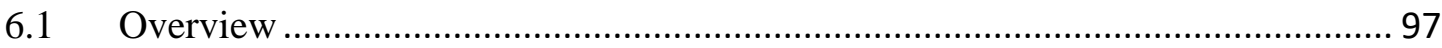

6.2 Air Quality Impacts of Charcoal Emissions in Africa ....................................... 97

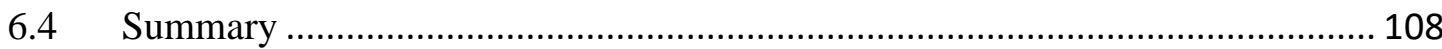

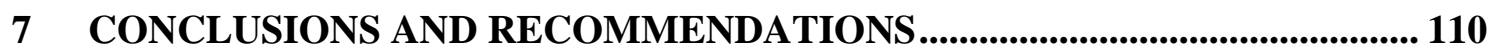

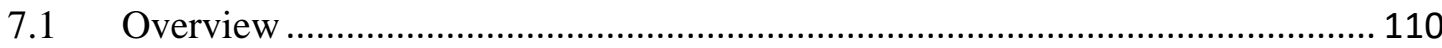

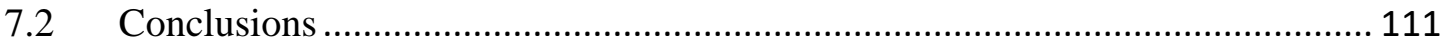

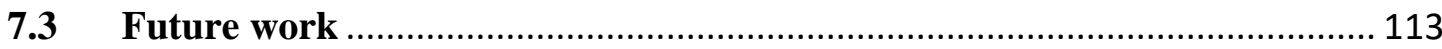

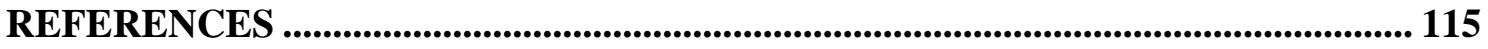

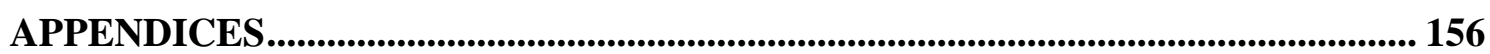




\section{LIST OF FIGURES}

Figure 1.1 Impact of climate change on the economy. Panel shows the global total impact of climate change on welfare-equivalent income. The solid blue dots are estimates of welfare impact of climate change. The dotted red lines represent the $95 \%$ confidence interval and the solid red line represents the best-fit pairwise linear function. Source: Tol (2018)

Figure 1.2 Premature mortality from ambient air pollution. Map shows number of premature deaths attributed to exposure to ambient ozone and $\mathrm{PM}_{2.5}$ per 100,000 people. Source: Ritchie (2019) 4

Figure 1.3 Global population-weighted $\mathrm{PM}_{2.5}$ and ozone in 2017. Top panel shows ambient population-weighted $\mathrm{PM}_{2.5}$ while the bottom panel shows ambient seasonal ozone in countries and regions across the globe. Ozone was data was collected during summer when ozone production is maximum. Source: HEI (2019b). 10

Figure 1.5 Effect of $\mathrm{NO}_{\mathrm{x}}$ and VOC concentrations on ozone abundance. The curved lines or isopleths give the concentration of daily maximum $\mathrm{O}_{3}$ [in ppmv] as a function of $\mathrm{NO}_{\mathrm{x}}$ and VOC concentrations. Equal sensitivity of $\mathrm{O}_{3}$ to VOCs and $\mathrm{NO}_{\mathrm{x}}$ is shown at the 8:1 line (diagonal line through the origin). Source: Melkonyan and Kuttler (2012)

Figure 1.6 Position of the ITCZ and monsoon in July (red line). The other colours signify sea-level pressure. The arrows indicate direction and intensity of surface winds. Source: Pidwirny (2006) 20

Figure 1.7 The two phases of the West African Monsoon. The map shows variation in rainfall and temperature due to the West Africa monsoon. Source: Gu and Adler (2004). 
Figure 1.8 The schematic representation of La Nina (left) and El Nino (right) conditions over Africa. The light-blue areas indicate wet and cool conditions while the orange areas indicate warm and dry conditions. Dashed green lines represent the equator. Source: (Salau et al., 2016)

Figure 2.1 Charcoal production in Africa in 2017. Countries are coloured by subregions as defined by the key on the right of the map. The size of the red circles indicate the amount of charcoal produced in each country from the UN energy statistics database (UN, 2017b). The total for the continent in 2017 is $48.4 \mathrm{Tg}$.

Figure 2.2 Earth-mound kiln commonly used to produce charcoal in Africa. Source: Schure et al. (2019). 35

Figure 2.3 Transportation of charcoal to cities in Africa. Image shows a diesel truck transporting charcoal to cities in Zambia. Note the potholed, unmetalled road and that some of the charcoal is in net bags. Source: Pearson (2020).

Figure 2.4 Charcoal cookstoves used in Africa. Image compares improved charcoal cookstoves (a and b) to a traditional charcoal cookstove (c). Source: Mamuye et al. (2018)

Figure 3.1 Historically revised UN energy statistics data for charcoal production in Kenya, Ghana and Somalia. Left panel (a), shows 2017 UNSD charcoal production data whilst the right panel (b), shows the 2020 UNSD charcoal production data. Panels (a) and (b) are on $\log 10$ scale for charcoal production. .54

Figure 3.2 Geospatial mapping of charcoal supply chain activities for Sierra Leone. Centre map shows charcoal production zones (green), charcoal use (red), and the extent of routes with the greatest density of trucks (blue). Hatchings are protected areas (see text 
for details) that are excluded from charcoal production. The Map on the right shows the distinction between the city centre (grey) and slums (brown).

Figure 3.3 Regression plots for charcoal production $\left(\mathrm{Tg} \mathrm{a}^{-1}\right)$ and urban population for Sierra Leone (left) and Nigeria (right). Plot is extrapolated to 2030. The shaded grey area is the region of uncertainty in the extrapolation at $95 \%$ confidence interval. 67

Figure 4.1 Charcoal production in Africa. Countries are coloured by 14-year mean charcoal production values for 2000 to 2014 . The size of the maroon circles are population densities for large urban centres. Data for charcoal production and use are from the UN (UN, 2017b) and for population density are from CIESIN (CIESIN, 2017). 76

Figure 4.2 Time series of charcoal production and use in Africa for 2000 to 2014. Units are in $\mathrm{Tg} \mathrm{a}^{-1}$. Values inset give average annual increases in charcoal production (left) and use (right).

Figure 4.3 Time series of charcoal production in Africa and East Africa from 2000-2014 (left) and from 2008-2014 (right) using UNSD 2017 data respectively. Units are in $\mathrm{Tg} \mathrm{a}^{-1}$. Values inset gives the p-value and average annual increases. 78

Figure 4.4 Biomass availability for charcoal production in Africa in tonnes $\operatorname{grid}^{-1} \mathrm{a}^{-1}$. Difference between total forest biomass and wood biomass harvested for charcoal production in 2014 (left panel), and available (green) and depleted (red) grids due to tree harvesting for charcoal production (right panel) 80

Figure 4.5 Current and future charcoal production and use in Africa. Plot shows charcoal production (top) and use (bottom) for 2014 to 2030. Units are $\mathrm{Tg} \mathrm{a}^{-1}$. 81

Figure 4.6 Forest degradation from charcoal production in Africa. The yellow bars show forest degradation in 2030. The green bars show forest degradation in 2014. Values are for kiln efficiency at $9 \%$. Unit is million hectare per year (Million ha $\mathrm{a}^{-1}$ ). 83 
Figure 5.1 Emissions of OC from the charcoal industry in Africa in 2014. Emissions are of OC on a $0.1^{0} \times 0.1^{0}$ grid from charcoal production (left), use (centre) and transport (right). Values inset are emission totals for 2014. Inset map is Uganda. 88

Figure 5.2 Same as above, but for NMVOCs. 88

Figure 5.3 Contribution of charcoal activities to emitted charcoal pollutants in 2014. .89 Figure 5.4 Ratios of 2030-to-2014 charcoal production and use for each African country. These are the scale factors used to project charcoal production, use, and transport emissions to 2030. The scale factors are gridded at a horizontal resolution of $0.1^{0} \times 0.1^{0}$. 96

Figure 6.1 The effect of the charcoal supply chain on surface $\mathrm{PM}_{2.5}$ and ozone in 2014 . Panels show the spatial distribution of GEOS-Chem annual mean surface $\mathrm{PM}_{2.5}$ (left) and ozone (right) from all sources (top) and from the charcoal supply chain only (bottom) (see text for details). Black boxes are domains used to generate data shown in Figure 6.2...98 Figure 6.2 Seasonality of $\mathrm{PM}_{2.5}$ and ozone enhancement from charcoal emissions in Africa in 2014. 100

Figure 6.3 Seasonality of $\mathrm{PM}_{2.5}$ and ozone enhancements from the charcoal industry in Africa. Values are seasonal surface $\mathrm{PM}_{2.5}$ (top panel) and surface ozone (bottom) enhancements obtained as the difference in simulations with and without the charcoal industry inventory. 102

Figure 6.4 The effect of the charcoal supply chain on surface $\mathrm{PM}_{2.5}$ and ozone in 2030 . 103

Figure 6.5 Population-weighted charcoal industry $\mathrm{PM}_{2.5}$ in Africa. Maps show population-weighted $\mathrm{PM}_{2.5}$ obtained for $\mathrm{PM}_{2.5}$ from charcoal industry emissions in Africa in 2014 (left) and 2030 (right). 104 
Figure 6.6 Direct radiative forcing in the tropics and subtropics due to the charcoal supply chain in Africa now and in the future. Model simulated annual mean all-sky topof-the-atmosphere direct aerosol shortwave (left) and ozone longwave and shortwave (right) forcing for 2014 (top) and 2030 (bottom) from GEOS-Chem coupled to RRTMG (see text for details). The box in the bottom right panel shows peaks peak ozone radiative forcing over the Atlantic Ocean. 106

Figure 6.7 Vertical distribution of tropospheric ozone attributed to the charcoal supply chain in Africa in 2014. Longitude-pressure plot of GEOS-Chem ozone enhancements in the northern (top) and southern (bottom) hemispheres averaged into $50 \mathrm{hPa}$ bins. The top of the troposphere is diagnosed with tropopause height from the MERRA-2 meteorology. Grey indicates topography. 107 


\section{LIST OF TABLES}

Table 1.1 Pollutants and gases in the atmosphere that are discussed in this thesis.........6

Table 3.1 Trend analysis using Mann-Kendall with Theil-Sen's slope method. Table shows slope and p-values for 14-year (2000-2014) trend analysis on charcoal production and use $\left(\mathrm{Tg} \mathrm{a}^{-1}\right)$ in Africa and its subregions. 55

Table 3.2 Activity data for charcoal production, use and transport in Africa in 2014...59

Table 3.3 Emission factors during charcoal production, use and transport....................64

Table 3.4 Regional timing of the wet and dry seasons in Africa. 70

Table 4.1 Charcoal production and use in Africa. 14-year (2000-2014) mean charcoal production and use in Africa and its subregions. 75 


\section{LIST OF ABBREVIATIONS}

$3 \mathrm{D}$

Three Dimensional

AGB Above Ground Biomass

AOD Aerosol Optical Depth

BC Black Carbon

CEDS Community Emission Database Systems

CFCs Chloro-Floro Carbons

$\mathrm{CH}_{4} \quad$ Methane

CIESIN Center for International Earth Science Information Network

$\mathrm{Cl} \quad$ Chlorine

CO Carbon monoxide

$\mathrm{CO}_{2} \quad$ Carbon dioxide

CTMs Chemical Transport Modelling

DICE Diffuse and Inefficient Combustion Emissions

EDGAR Emission Database for Global Atmospheric Research

EF Emission Factor

EMEP European Monitoring and Evaluation Programme

ENSO El Nino Southern Oscillation

ESRI Environmental Science Research Institute

FAO Food and Agricultural Organisation

GDP Gross Domestic Product

GEF Global Environmental Facility

GEO-FP GEOS-Forward Processing Product

GFAS Global Fire Assimilation System 


\begin{tabular}{|c|c|}
\hline GFED & Global Fire Emission Database \\
\hline GMAO & Global Modelling Assimilation Office \\
\hline GPW & Gridded Population of the World \\
\hline $\mathrm{HCl}$ & Hydrogen Chloride \\
\hline HEMCO & Nasa-Harvard Emission Components \\
\hline HHDVs & Heavy-Duty Diesel Vehicles \\
\hline HTAP & Hemispheric Transport of Air Pollution \\
\hline IBM & International Business Machines \\
\hline IEA & International Energy Agency \\
\hline IPCC & Intergovernmental Panel on Climate Change \\
\hline ITCZ & Intertropical Convergent Zone \\
\hline IUCN & International Union for Conservation of Nature \\
\hline IUPAC & International Union of Pure and Applied Chemistry \\
\hline JPC & Journal of Physical Chemistry \\
\hline KPP & Kinematic Pre-Processor \\
\hline LBLRTM & Line-By-Line Radiative Transfer Model \\
\hline LPG & Liquified Petroleum Gas \\
\hline MEGAN & Model of Emission of Gases and Aerosols in Nature \\
\hline MERRA-2 & Modern-Era Retrospective Analysis for Research and Applications \\
\hline NMVOCs & Non-Methane Volatile Organic Compound \\
\hline NO & Nitric Oxide \\
\hline $\mathrm{NO}_{2}$ & Nitrogen Oxide \\
\hline $\mathrm{NO}_{\mathrm{x}}$ & Nitrogen oxides \\
\hline $\mathrm{O}_{3}$ & Ozone \\
\hline
\end{tabular}


OA Organic Aerosol

OC Organic Carbon

$\mathrm{OH} \quad$ Hydroxyl

PBL Primary Boundary Layer

PM Particulate Matter

$\mathrm{PM}_{2.5} \quad$ Particulate Matter (particles with aerodynamic diameter less than 2.5)

PWE Population-Weighted Exposure

RRTMG Rapid Radiative Transfer Model

$\mathrm{SO}_{2} \quad$ Sulfur Dioxide

TOA Top of the Atmosphere

UCX Unified Tropospheric-Stratospheric Chemistry Extension

UN United Nations

UNEP United Nations Environmental Program

USD United States Dollars

USEPA United States Environmental Protection Agency

VOCs Volatile Organic Compounds

WHO World Health Organisation 
Most of the materials in this thesis have been published on Journal of Environmental Science and Technology as Bockarie, A. S., Marais, E. A. and MacKenzie, A. R. (2020) 'Air Pollution and Climate Forcing of the Charcoal Industry in Africa', Environmental Science \& Technology. doi: 10.1021/acs.est.0c03754.

\subsection{Overview of Air Pollution and Climate Change}

There are increasing efforts locally and internationally to combat air pollution and climate change. At least USD 11 billion is spent annually in every region of the world to tackle climate change (Buchner et al., 2019) and USD 21 billion is spent annually on health care to tackle both indoor and ambient pollution globally (OECD, 2016). Air pollution (indoor and outdoor) has been attributed to 7 million premature deaths annually across the globe which makes it the fifth largest global health burden and the largest environmental health risk factor (HEI, 2019a). Ambient air pollution alone is attributed to 4.2 million premature deaths (60\% of total air pollution deaths). Long term changes in climate are driven by increasing atmospheric concentrations of long-lived greenhouse gases, resulting directly in global temperature and indirectly in precipitation and other meteorological changes (Olivier et al., 2020). Studies have shown that the Earth has undergone a rise in global temperature of $1^{\circ} \mathrm{C}$ since the pre-industrial era (IPCC, 2018). Current projections suggest that global temperatures will likely rise by $1.5^{\circ} \mathrm{C}$ between 2030 and 2052 and $2.9-3.4^{\circ} \mathrm{C}$ by 2100 (IPCC, 2018). Such an increase in temperature, and accompanying precipitation changes, may negatively impact global health and the economy due to the projected rise 
in natural disaster, food insecurity, and thermal discomfort for humans and animals (Watson et al., 2007; IPCC, 2018). Figure 1.1, shown below, is from Tol (2018) and shows the economic impact of climate change. Specifically, it shows how the welfare equivalent income per person changes with global temperature increase. Welfareequivalent income per person will decrease by about $1.3 \%$ with a global mean temperature of $2.5^{\circ} \mathrm{C}$ due to economic losses from agriculture, natural disasters, and disease outbreaks. Africa is dominated by low and middle-income countries and has the lowest share of global GDP (WB, 2018), so is likely to suffer the most (Barros et al., 2014).

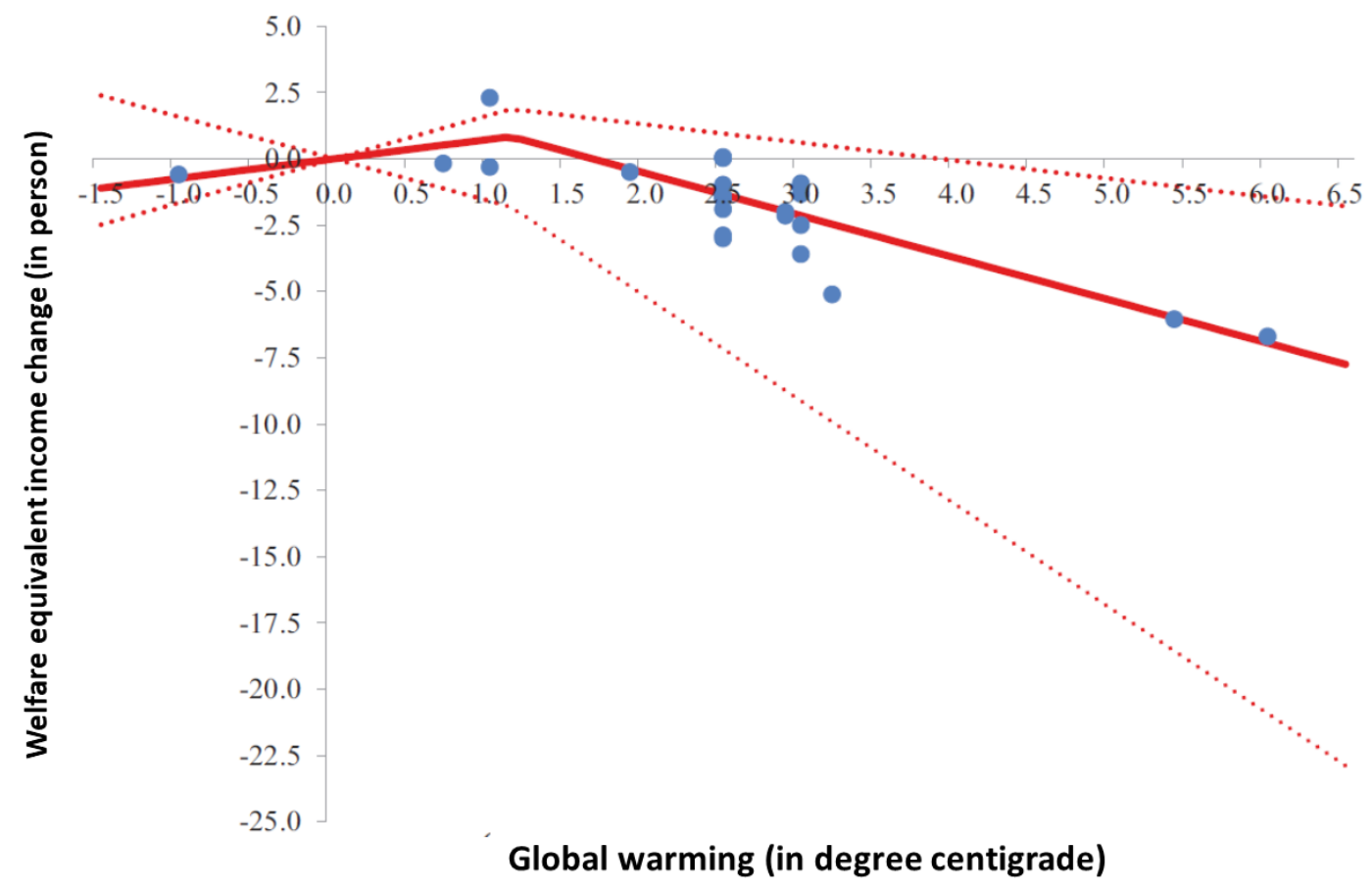

Figure 1.1 Impact of climate change on the economy. Panel shows the global total impact of climate change on welfare-equivalent income. The solid blue dots are estimates of welfare impact of climate change. The dotted red lines represent the $95 \%$ confidence 
interval and the solid red line represents the best-fit pairwise linear function. Source: Tol (2018).

Figure 1.2 shows premature deaths attributed to exposure to outdoor air pollution from $\mathrm{PM}_{2.5}$ and ozone in each country. The attributable death values are obtained from a combination of exposure, dose-response relationship linking pollutant and death derived from epidemiological studies, and baseline mortality. Figure 1.3 shows that most of the ambient pollution related deaths from $\mathrm{PM}_{2.5}$ and ozone are in Asia (where number of deaths can range from 10-100 persons per 100,000 population) and Africa (where number of deaths can range from $10-75$ persons per 100,000 population), although the elevated values in Africa are in countries where population density is low. The country with most deaths from $\mathrm{PM}_{2.5}$ and ozone is Egypt, where the number of deaths is above 100 persons per 100,000 population. This high deaths in Egypt are due to a combination of high mineral dust and biomass burning activities in the cities (Wheida et al., 2018), coupled with dense population (Roser et al., 2013) and large enhancements in pollution from European sources (Duncan et al., 2008). Following Egypt, there are also high death rates in middle-income countries across Asia and Central Europe including India, China, Bangladesh, and Pakistan. 


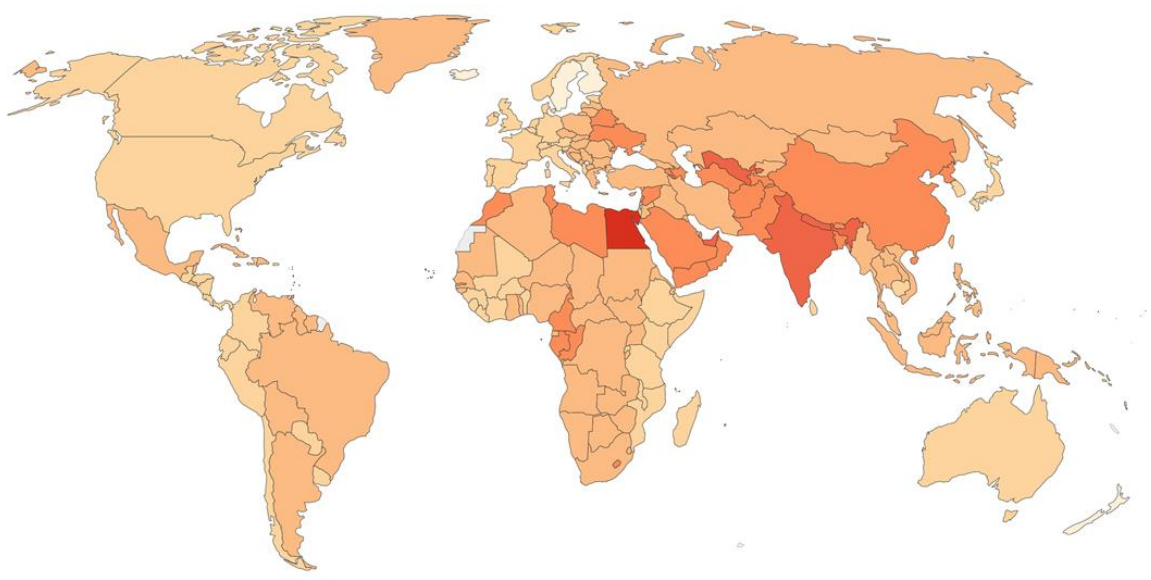

$\begin{array}{llllllll}\text { No data } & 0 & 10 & 25 & 50 & 75 & 100 & 150\end{array}$

Figure 1.2 Premature mortality from ambient air pollution. Map shows number of premature deaths attributed to exposure to ambient ozone and $\mathrm{PM}_{2.5}$ per 100,000 people. Source: Ritchie (2019)

Biomass burning is among the many sources that make a large contribution to of air pollutants, and atmospheric components that alter climate by absorbing or scattering incoming and outgoing radiation (Table 1.1). Biomass is any solid fuel derived from plant material and animal excrement for energy purposes (Vakkilainen, 2017). The share of biomass in the total fuel consumption in Africa is 54\% (UN, 2017a) and the dominant forms of biomass are fuelwood and charcoal. Fuelwood is fresh or air-dried wood, predominantly used in rural areas of Africa, whereas charcoal is predominantly used in urban areas (Janssen et al., 2012). Details on charcoal, its history, and the supply chain in Africa, are discussed in Chapter 2. 


\subsection{Climate and Air Quality Effects of Air Pollutants}

Both air pollution and climate change are caused by particles and trace gases in the Earth's atmosphere. Air pollution occurs when gases and particles are introduced into the environment at concentrations sufficient to have a measurable effect on humans, animal and building materials (Lois et al., 2003). Air pollution can be either ambient (outdoor) or indoor. Outdoor air pollution (which is the focus of this thesis) can originate from both natural and anthropogenic sources. While the natural sources play a substantial role to local air pollution in areas more prone to dust storms and forest fires (WHO, 2020), the contribution from anthropogenic activities far outweighs the natural sources. Anthropogenic sources that contribute to outdoor pollution include: residential cooking and heating, fuel combustion from motor vehicles, heat and power generation, industrial facilities and waste burning (WHO, 2020). Climate change is due to changes in the balance of the Earth's energy system (measured in $\mathrm{W} \mathrm{m}^{-2}$ ) due to some imposed

perturbation (Myhre et al., 2013). Such perturbations can be brought about by changes in the concentrations of species that absorb or scatter ingoing or outgoing radiation (e.g., $\mathrm{CO} 2, \mathrm{O} 3$, and aerosols), changes in solar irradiance incident upon the planet, or other changes that affect the radiative energy absorbed by the surface such as changes in the albedo of clouds or the ground surface (Betts et al., 2001). Table 1.1 shows global pollutants and trace gases and their relevance to either air pollution or climate change based on information in (Sher, 1998; World Health Organization, 2006; Von Schneidemesser et al., 2015). Also shown are their sources and effects. Some of the pollutants in Table 1.1 such as ozone $\left(\mathrm{O}_{3}\right)$, methane $\left(\mathrm{CH}_{4}\right)$ and aerosols, are short-lived climate forcers, as these exist in the Earth's atmosphere in order of weeks as is the case 
Table 1.1 Pollutants and gases in the atmosphere that are discussed in this thesis.

\begin{tabular}{|c|c|c|c|}
\hline Pollutant & Natural sources & Anthropogenic sources & Effects in PBL \& troposphere \\
\hline $\begin{array}{l}\text { Carbon } \\
\text { monoxide }\end{array}$ & $\begin{array}{l}\text { Forest fires. Atmospheric } \\
\text { oxidation of NMVOC and } \\
\text { methane }\end{array}$ & $\begin{array}{l}\text { Fossil fuel or biomass } \\
\text { combustion. Oxidation of } \\
\text { methane of NMVOCs }\end{array}$ & $\begin{array}{l}\text { Lower concentrations can lead to headache, fatigue, nausea and } \\
\text { vomiting. Higher concentration can lead to death. Contributes to } \\
\text { ozone formation and therefore contributes to positive radiative } \\
\text { forcing }\end{array}$ \\
\hline $\begin{array}{l}\text { Nitrogen } \\
\text { oxides }(\mathrm{NO}+ \\
\left.\mathrm{NO}_{2}\right)\end{array}$ & $\begin{array}{l}\text { Lightning and bacterial } \\
\text { activity in soils }\end{array}$ & $\begin{array}{l}\text { Combustion of fossil and } \\
\text { modern (biomass) fuels }\end{array}$ & $\begin{array}{l}\text { Eye, throat, and lung irritation }\left(\mathrm{NO}_{2}\right) \text {. Contributes to photochemical } \\
\text { smog and acid rain. } \mathrm{NO}_{\mathrm{x}} \text { has overall negative radiative forcing effect. }\end{array}$ \\
\hline Particulates & $\begin{array}{l}\text { Wildfires, volcanic eruptions, } \\
\text { sea spray, and wind erosion. } \\
\text { Formation of secondary } \\
\text { particulate in atmosphere. }\end{array}$ & $\begin{array}{l}\text { Fossil fuel burning, } \\
\text { industrial processes. } \\
\text { Formation of secondary } \\
\text { particulate in atmosphere. }\end{array}$ & $\begin{array}{l}\text { Can reduce visibility. Can contribute to respiratory infections, heart } \\
\text { disease, stroke, lung cancer, diabetes, and death. Has both warming } \\
\text { effect (e.g. BC and brown carbon) and cooling effect (e.g. organic } \\
\text { carbon, sulfates and nitrates). As cloud condensation nuclei (CCN), } \\
\text { particulates also have cooling effect. }\end{array}$ \\
\hline
\end{tabular}

\author{
Sulfur \\ dioxide $\left(\mathrm{SO}_{2}\right)$ emissions of dimethyl sulfide \\ (DMS)
}

Stratosphere. Photochemical

Ozone $\left(\mathrm{O}_{3}\right)$ reactions of $\mathrm{NO}_{\mathrm{x}}$ and

$\mathrm{CO} / \mathrm{VOCs}$
Combustion of sulfurcontaining fossil fuels.

Biomass burning (minor)
Oxidises to form sulfate which cools the atmosphere and has health effect similar to particulates. Can form acid rain which is harmful to plants and monuments.
Photochemical reactions of $\mathrm{NO}_{\mathrm{x}}$ and $\mathrm{CO} / \mathrm{VOCs}$
Harmful to the human respiratory system. Warms the atmosphere. Can impair photosynthesis and indirectly inhibits the uptake of $\mathrm{CO}_{2}$ by plants. 
Carbon

dioxide

$\left(\mathrm{CO}_{2}\right)$

Respiration, decay of organic material, and release from oceans

Non-methane

VOCs

Biological processes

(NMVOCs)

Methane

$\left(\mathrm{CH}_{4}\right)$
Microbial activity (rice), termites
Fossil fuel and wood combustion, cement manufacture, industry

Road transport, industry, solvents, biomass burning benzene or styrene). Has warming effect due to its contribution to ozone formation. Oxidises to form organic aerosol which cools the atmosphere and cause harm to the human respiratory system. Cause photochemical smog.

Microbial activity

(agriculture), oil/gas

industry

Warming (28 times $\mathrm{CO}_{2}$ ). 
for aerosols to about 10 years as is the case for $\mathrm{CH}_{4}$ (Pierrehumbert, 2014). Black carbon, methane, tropospheric ozone and hydrofluorocarbon are the most important short-lived climate forcers (pollutants) (IPCC, 2018). These contribute to 40-45\% of current global warming and could contribute up to half the warming from anthropogenic activities by 2050 if not reduced (IPCC, 2018). If reduced, the increase in temperature due to anthropogenic global warming could decrease between $1.5^{\circ} \mathrm{C}$ and $1.6^{\circ} \mathrm{C}$ by 2050 compared to $2{ }^{\circ} \mathrm{C}$ for business-as-usual (IPCC, 2018). Reduction of short-lived climate forcers will as well reduce the 3.3 million premature deaths which they cause annually from related outdoor activities (Lelieveld et al., 2015). This thesis will focus on the health and climate impact of aerosols and ozone from the burgeoning charcoal industry in Africa. These are two major short-lived climate forcers and also pose the greatest threat to public health (WHO, 2020). Figure 1.3 shows global population-weighted particulate matter $\left(\mathrm{PM}_{2.5}\right)$ and ozone for each country. Values of $\mathrm{PM}_{2.5}$ for ambient air only and were obtained by combining data from of air pollution monitoring stations, satellite observations and global chemical transport models, whilst values of ozone for ambient air only were obtained by combining data from monitoring stations and chemical transport models (Apte et al., 2015; Shaddick et al., 2018). Highest levels for $\mathrm{PM}_{2.5}$ (particles with aerodynamic diameter less than $2.5 \mu \mathrm{m}$ ) are in Asia at $58 \mu \mathrm{g} \mathrm{m}^{-3}$ followed by Africa at $48 \mu \mathrm{g} \mathrm{m}^{-3}$. The highest levels of ozone are in Asia at $61 \mathrm{ppb}(28 \%)$ followed by Europe at $54 \mathrm{ppb}(24 \%)$. As can be seen in Figure 1.3, the $\mathrm{PM}_{2.5}$ is well above the World Health Organisation (WHO) guideline of $10 \mu \mathrm{g} \mathrm{m}^{-3}$ annual mean for $\mathrm{PM}_{2.5}$. Persistent exposure above the WHO guideline levels have been associated with many severe health outcomes including high blood pressure, heart attack and stroke (WHO, 2006). 
The particles and gases which affect both are quality and climate are also referred to as trace constituents. They make up only $1 \%$ of the atmosphere by mass or volume and are mostly found in the troposphere which is the lowest layer of the atmosphere. The most abundant components of the atmosphere are nitrogen (78\% v/v) and Oxygen $(21 \%)$. The troposphere is the major reservoir through which compounds enter the Earth's atmosphere from their source locations and get dispersed and deposited at receptor locations. The troposphere is also the medium through which different species undergo physical and chemical change in the atmosphere (Seinfeld et al., 2006). The troposphere is never empty of trace constituents; gases and particulate matter from either natural or anthropogenic (human) source are always present in it (Hoesly et al., 2018). While some particles or gases present would be freshly emitted, others would have resided for a long time and might have even interacted with other atmospheric components. The troposphere is also where the planetary boundary layer (PBL) is present (Brancher et al., 2017). Details of the radiative forcing of climate, gas reactions in the atmosphere, PBL, atmospheric aerosols, lifetime of pollutants, and climate of Africa are discussed in the following sections. 


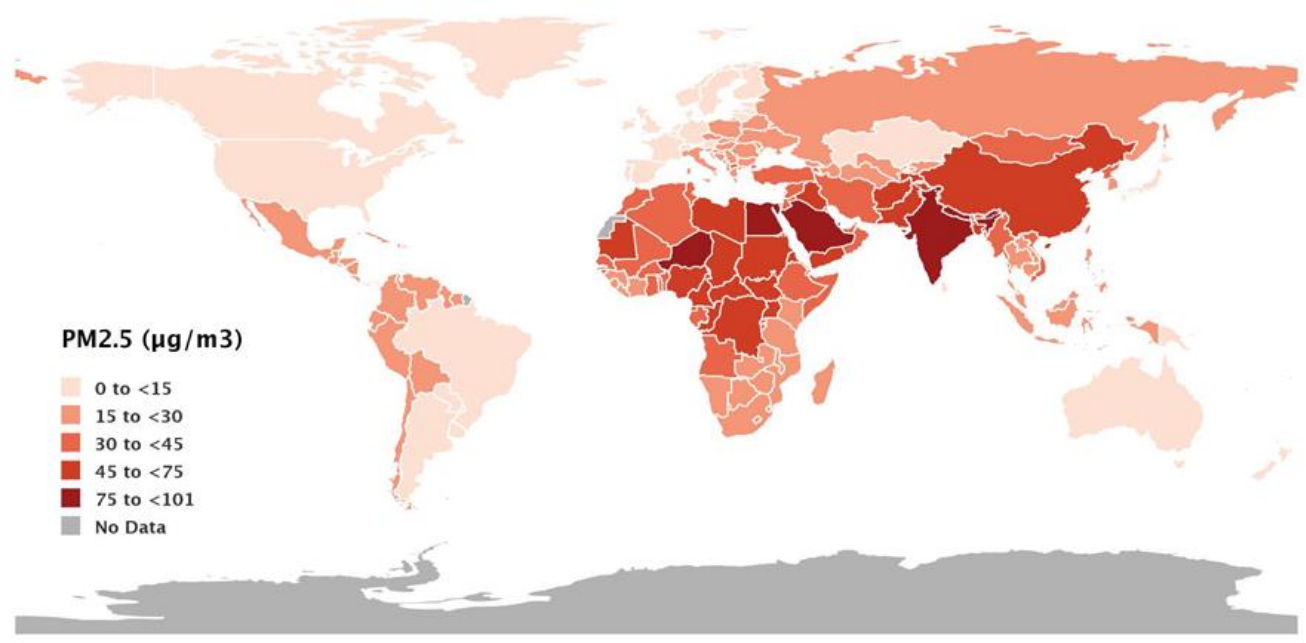

State of Global Air

Average Seasonal Population-Weighted Ozone Concentrations in 2017

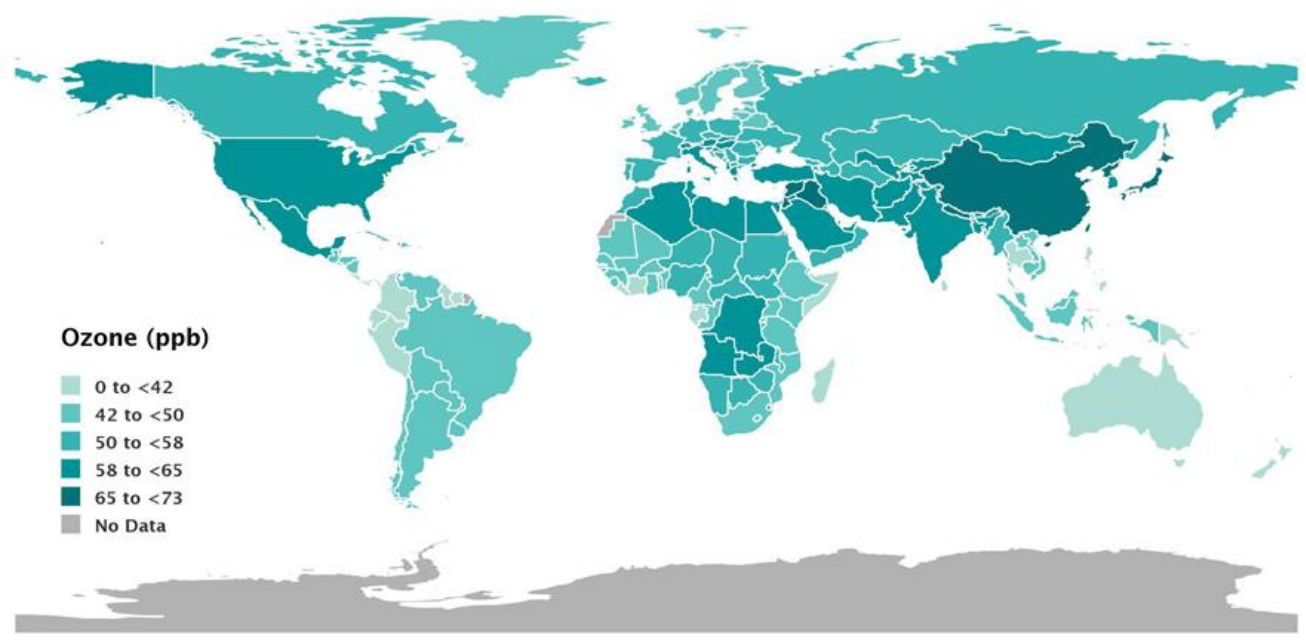

State of Global Air

Figure 1.3 Global population-weighted $\mathrm{PM}_{2.5}$ and ozone in 2017. Top panel shows ambient population-weighted $\mathrm{PM}_{2.5}$ while the bottom panel shows ambient seasonal ozone in countries and regions across the globe. Ozone was data was collected during summer when ozone production is maximum. Source: HEI (2019b). 


\subsubsection{Radiative forcing of short-lived climate forcers}

Radiative forcing as defined by the Intergovernmental Panel on Climate change (IPCC) is the net change in net downward radiative flux at the tropopause, after stratospheric temperatures have adjusted to radiative equilibrium, while state variables such as water vapour and cloud cover and tropospheric and surface temperature are being held fixed at the unperturbed values (Myhre et al., 2013). The net change in flux can be caused by natural environmental sources, such as volcanic emissions and desert dust or anthropogenic sources, such as widespread combustion of a range of fuels, including fossil fuels, wood, and charcoal. For each agent, the radiative forcing is calculated for the period between 1750 (pre-industrial) and present day. Figure 1.4 shows radiative forcing of climate between 1750 and 2011 obtained from the latest (fifth assessment) IPCC report (Myhre et al., 2013). Climate agents that contribute to warming of the Earth's surface and so exert a net "positive forcing" include carbon dioxide, halocarbons, methane, nitrous oxide, tropospheric ozone, stratospheric water vapour, black carbon, contrails (trails of vapour produced by airline exhaust), and solar irradiance. Those that exert a net "negative forcing" or cooling effect include stratospheric ozone, land use change, aerosols. The latter includes reflection of incident sunlight by aerosols and the effect of aerosols on cloud lifetime and microphysics.

Anthropogenic forcing far outweighs natural forcing and the impact of aerosols is overall negative (with large uncertainties in the estimates). This is insufficient to offset the warming effect of $\mathrm{CO}_{2}$ and the other well-mixed greenhouse gases, as cooling from aerosols is often local to the emission sources. Aerosols are also much shorter lived than 
well-mixed greenhouse gases. The net positive in radiative forcing due to anthropogenic activities since the industrial revolution is estimated to be $1.6 \mathrm{~W} \mathrm{~m}^{-2}$.

\section{Radiative forcing of climate change between 1750 and 2011}

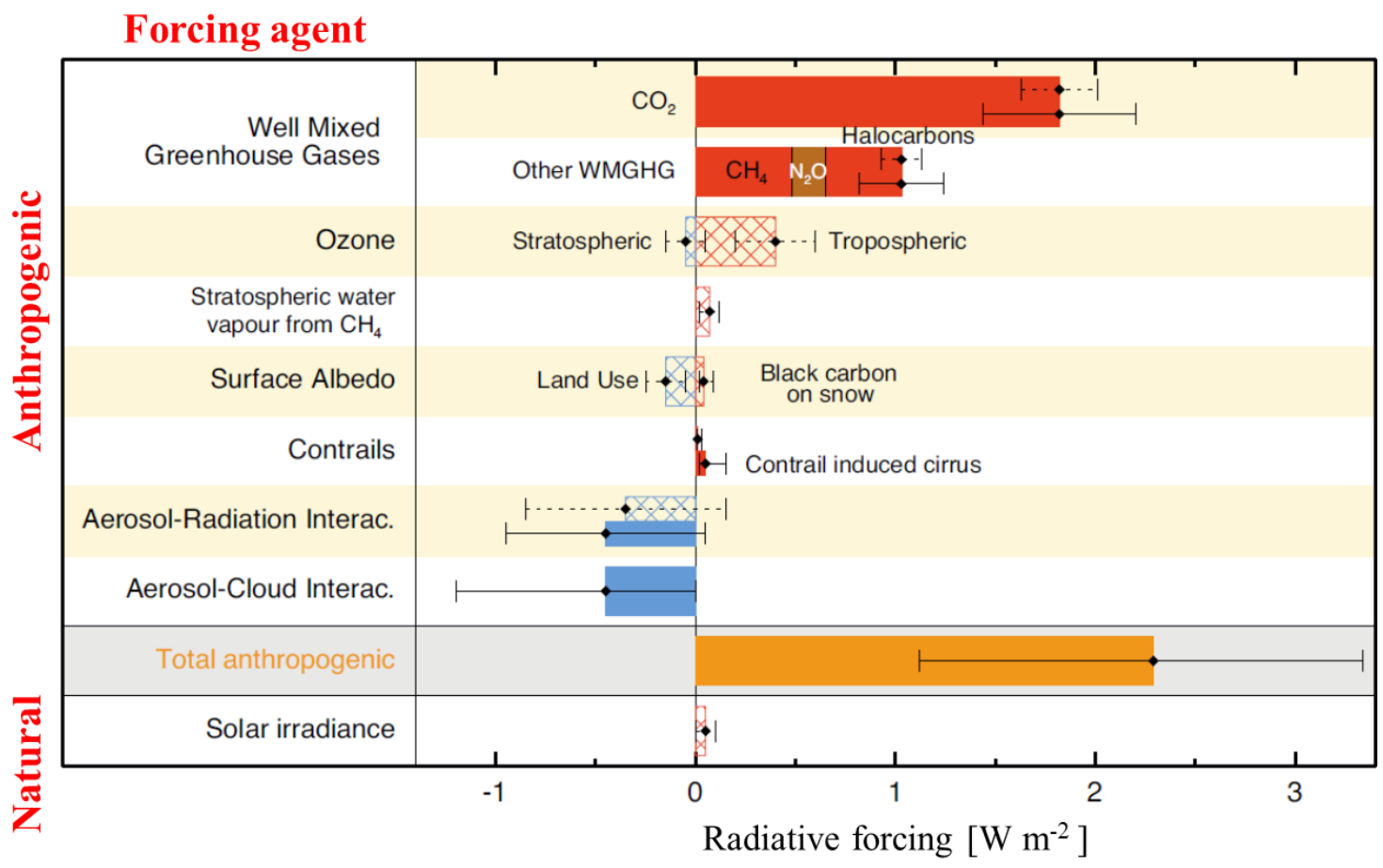

Figure 1.4 Radiative forcing effect of individual climate forcers. Panel shows bar charts for radiative forcing (hatched) and effective radiative forcing (solid) between 1750 and 2011. Source: Myhre et al. (2013)

\subsubsection{Chemistry of trace gases and aerosols in the atmosphere}

Reaction of gases in the atmosphere are largely driven by daytime photochemistry and meteorology. Initiation of the gas phase oxidation by reaction with a hydroxy radical $(\mathrm{OH})$, or via photolysis is the initial process through which most species evolve or are removed from the atmosphere (Jacob, 1999; Monks, 2005). OH is produced from the 
reaction of $\mathrm{O}\left({ }^{1} \mathrm{D}\right)$ atoms (formed from near-UV photolysis of ozone) with water vapour owing to the presence of high humidity and intense sunlight (Monks, 2005).

Chemical reactions in the troposphere heavily depends on $\mathrm{NO}_{\mathrm{x}}\left(\mathrm{NO}+\mathrm{NO}_{2}\right)($ Brown et al., 2007). During the day, $\mathrm{NO}_{\mathrm{x}}$ is emitted in the atmosphere mainly as nitric oxide (NO). The NO then become $\mathrm{NO}_{2}$ through oxidation. Oxidation of $\mathrm{NO}_{\mathrm{x}}$ in the atmosphere forms nitric acid $\left(\mathrm{HNO}_{3}\right)$, which condenses to form secondary inorganic aerosols (especially in the presence of ammonia) or wet and dry deposits. Sources of $\mathrm{NO}_{\mathrm{x}}$ are in Table 1.1. In Africa, $\mathrm{NO}_{\mathrm{x}}$ is mostly from biomass burning $\left(4.6 \mathrm{Tg} \mathrm{N} \mathrm{a}-1\right.$ or $50.3 \%$ of total $\mathrm{NO}_{\mathrm{x}}$ ) and biogenic sources $\left(2.4 \mathrm{Tg} \mathrm{N} \mathrm{a}^{-1}\right.$ or $26.3 \%$ ). Industrial sources contribute $1.4 \mathrm{Tg} \mathrm{N} \mathrm{a}^{-1}$ or 15\% (Aghedo et al., 2007). In Africa $\mathrm{NO}_{\mathrm{x}}$ emissions have a large influence on global atmospheric composition, due to efficient and deep convective in the tropics (Christian et $a l ., 2003)$. This includes influencing the variability of $\mathrm{OH}$, the tropospheric $\mathrm{O}_{3}$ budget in most of the $\mathrm{NO}_{\mathrm{x}}$-limited free troposphere, and also the formation of nitrate aerosols that makes a large contribution to $\mathrm{PM}_{2.5}$ (Miyazaki et al., 2012).

\subsubsection{Oxidation of volatile organic compounds (VOCs)}

Most volatile organic compounds include highly reactive species that, once emitted, are oxidized by $\mathrm{OH}$ during the day and by $\mathrm{NO}_{3}$ or ozone at night (Atkinson, 2000a; Pitts et $a l ., 2000)$. Oxidation of VOCs can be initiated by reaction with chloride $(\mathrm{Cl})$ atoms, mostly during the day over the marine environment (Ivatt, 2017).

Major classes of anthropogenic VOCs include alkanes, alkenes and aromatic compounds. Emissions of biogenic VOCs (BVOCs) such as isoprene, monoterpenes, sesquiterpenes 
and other oxygenated VOCs (Laothawornkitkul et al., 2009) are about an order of magnitude higher than emissions from anthropogenic sources (Guenther et al., 2012). In tropical Africa emissions from BVOCs are sustained year-round and make large local contributions to surface ozone and $\mathrm{PM}_{2.5}$ (Marais et al., 2012, 2014). Sources of NMVOCs in Africa include $7.9 \mathrm{Tg}$ or $3.9 \%$ of total NMVOCs from biomass burning and $189 \mathrm{Tg}$ or $93.2 \%$ from vegetation (Aghedo et al., 2007). The chemistry of $\mathrm{O}_{3}$ in the atmosphere is influenced by BVOCs in many ways and plays a dominant role in the chemistry of the lower troposphere and boundary layer of the atmosphere (Fuentes et al., 2000). Isoprene, for example, can act as direct sink for oxidants such as $\mathrm{NO}_{\mathrm{x}}$, thereby competing with $\mathrm{O}_{3}$, and can contribute to sequestration of $\mathrm{NO}_{2}$ and products of oxidation (Bates et al., 2019).

\subsubsection{Formation of tropospheric ozone $\left(\mathrm{O}_{3}\right)$}

Ozone $\left(\mathrm{O}_{3}\right)$ is a secondary pollutant that is formed in the atmosphere when $\mathrm{OH}$ reacts with either $\mathrm{CO}$, VOCs or $\mathrm{CH}_{4}$ in the presence of $\mathrm{NO}_{\mathrm{x}}\left(\mathrm{NO}_{2}+\mathrm{NO}\right)$ and sunlight. The chemistry leading to ozone is shown in the following reactions: (Monks et al., 2015).

$$
\begin{aligned}
& \mathrm{VOC}+\mathrm{OH} \stackrel{\mathrm{O}_{2}}{\rightarrow} \mathrm{RO}_{2}+\mathrm{H}_{2} \mathrm{O} \\
& \mathrm{CO}+\mathrm{OH} \stackrel{\mathrm{O}_{2}}{\rightarrow} \mathrm{HO}_{2}+\mathrm{CO}_{2} \\
& \mathrm{RO}_{2}+\mathrm{NO} \stackrel{\mathrm{O}_{2}}{\rightarrow} \text { secondary VOC }+\mathrm{HO}_{2}+\mathrm{NO}_{2} \\
& \mathrm{HO}_{2}+\mathrm{NO} \rightarrow \mathrm{OH}+\mathrm{NO}_{2} \\
& \mathrm{NO}_{2}+\mathrm{hv} \rightarrow \mathrm{NO}+\mathrm{O} \\
& \mathrm{O}+\mathrm{O}_{2}+\mathrm{M} \rightarrow \mathrm{O}_{3}+\mathrm{M} \\
& \mathrm{O}_{3}+\mathrm{h} v \rightarrow \mathrm{O}\left({ }^{1} \mathrm{D}\right)
\end{aligned}
$$


$\mathrm{O}\left({ }^{1} \mathrm{D}\right)+\mathrm{H}_{2} \mathrm{O} \rightarrow 2 \mathrm{OH}$

In the presence of nitrogen oxides, NMVOCs, $\mathrm{CO}$ and $\mathrm{CH}_{4}$ emissions contribute to the formation of tropospheric ozone. When NMVOCs, $\mathrm{CO}$ and $\mathrm{CH}_{4}$ are oxidised, predominantly by $\mathrm{OH}$, the peroxy radical $\left(\mathrm{RO}_{2}\right)$ if formed in the first oxidation step for VOCs and the hydroperoxyl radical $\left(\mathrm{HO}_{2}\right)$ is produced in the first oxidation step for CO. $\mathrm{RO}_{2}$ (where $\mathrm{R}$ represents an organic carbon chain, such as $-\mathrm{CH}_{3}$ for the methyl group) or $\mathrm{HO}_{2}$ then oxidizes $\mathrm{NO}$ to $\mathrm{NO}_{2}$ which is then photolyzed to form an oxygen atom $(\mathrm{O})$. The oxygen atom then reacts with diatomic oxygen $\left(\mathrm{O}_{2}\right)$ to form to ozone (Atkinson, 2000b). In this reaction, $\mathrm{OH}$ is recycled to sustain $\mathrm{VOC}$ oxidation.

The rate at which ozone is produced can be limited by either VOCs or $\mathrm{NO}_{\mathrm{x}}$. Ozone formation from VOCs and $\mathrm{NO}_{\mathrm{x}}$ is reliant upon the relative sources of $\mathrm{OH}$ and $\mathrm{NO}_{\mathrm{x}}$. When the rate at which $\mathrm{OH}$ is produced exceeds the rate at which $\mathrm{NO}_{\mathrm{x}}$ is emitted, indicating that the $\mathrm{NO}_{\mathrm{x}}$ is in short supply, the rate of ozone production becomes $\mathrm{NO}_{\mathrm{x}}$-limited. When this happens, the concentration of zone can be decreased by lowering emissions of $\mathrm{NO}_{\mathrm{x}}$, instead of lowering emissions of VOCs. When the rate of production of $\mathrm{OH}$ is less than the rate at which $\mathrm{NO}_{\mathrm{x}}$ is produced, ozone production becomes VOC-limited. At this point, lowering VOC emissions is most effective at decreasing the formation of ozone (Seinfeld et al., 2006). Figure 1.5 shows an isopleth plot of daily maximum ozone as a function of $\mathrm{NO}_{\mathrm{x}}$ and VOC concentration. The relationship between ozone and its precursors is complex, so the isopleth plot helps us identify the ozone formation regime and which precursor to target to effectively address ozone pollution (Sillman, 1999). The curved lines give the daily maximum concentration of ozone. Ozone is equally sensitive to $\mathrm{NO}_{\mathrm{x}}$ 
and VOC when the VOC: $\mathrm{NO}_{\mathrm{x}}$ ratio is $8: 1$. In locations of high pollution where $\mathrm{NO}_{\mathrm{x}}$ and VOCs are dominated by efficient combustion sources, the ratio of VOC: $\mathrm{NO}_{\mathrm{x}}$ is less than 8.1. Between the extremes of $\mathrm{NO}_{\mathrm{x}}$-limited and VOC-limited regimes, there is a point at which ozone becomes nearly equally sensitive to both. In this situation, ozone becomes insensitive towards any marginal changes on both $\mathrm{NO}_{\mathrm{x}}$ and VOC. In highly populated urban areas where biomass energy sources like charcoal are burned, ozone formation might tend toward being VOC-limited. In rural and downwind suburban areas where biomass sources like charcoal is mostly produced under very inefficient combustion conditions, ozone is expected to be $\mathrm{NO}_{\mathrm{x}}$-limited.

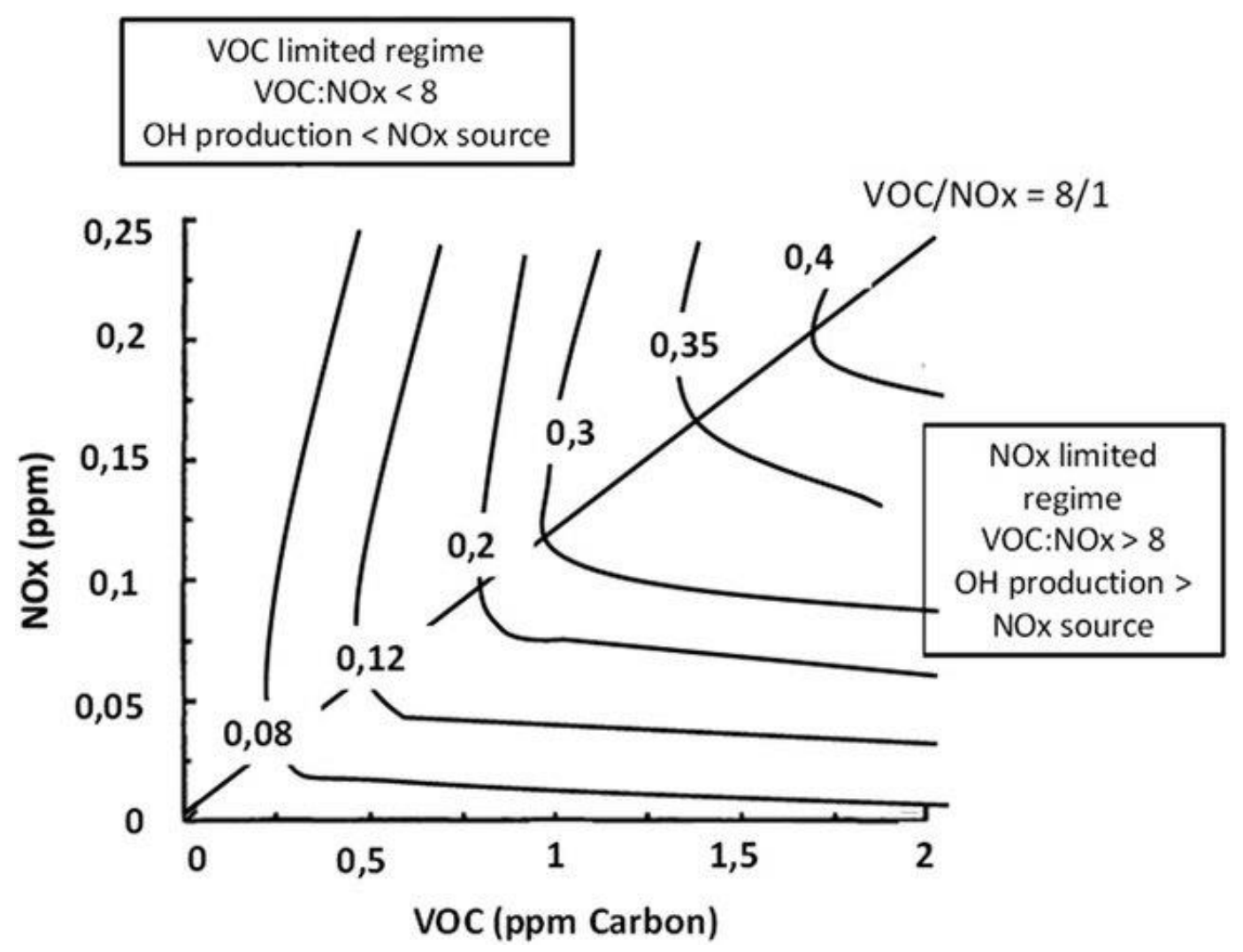

Figure 1.4 Effect of $\mathrm{NO}_{\mathrm{x}}$ and VOC concentrations on ozone abundance. The curved lines or isopleths give the concentration of daily maximum $\mathrm{O}_{3}$ [in ppmv] as a function of $\mathrm{NO}_{\mathrm{x}}$ 
and VOC concentrations. Equal sensitivity of $\mathrm{O}_{3}$ to VOCs and $\mathrm{NO}_{\mathrm{x}}$ is shown at the 8:1 line (diagonal line through the origin). Source: Melkonyan and Kuttler (2012)

\subsubsection{Atmospheric aerosol emission and formation in the atmosphere}

Atmospheric aerosols, also called particulate matter (PM), are fine solid or liquid-like particles suspended in the atmosphere (Tomasi et al., 2017). Primary aerosol sources can be natural such as sea salt, desert dust, volcanic eruptions or wildfires, or anthropogenic such as fossil fuels, industrial activity, and biomass burning. Secondary aerosols sources result from condensation of gases onto pre-existing particle surfaces or new particle formation through nucleation (Tomasi et al., 2017). Nucleation is when new particles with diameters below $2 \mathrm{~nm}$ form from clustering of vapour molecules (Kulmala et al., 2013). Primary aerosol components include carbonaceous aerosols emitted during incomplete combustion of biomass or fossil fuels and comprise various forms of carbon such as black carbon (BC) and organic carbon (OC). Secondary aerosol components include sulphate from oxidation of $\mathrm{SO}_{2}$, nitrate from oxidation $\mathrm{NO}_{\mathrm{x}}$, ammonium from partitioning of $\mathrm{NH}_{3}$, and secondary organic aerosols (SOA) from oxidation of NMVOCs (Tomasi et al., 2017). Classification of atmospheric aerosols comes from their aerodynamic diameter. $\mathrm{PM}_{2.5}$ is the mass concentration of aerosols with aerodynamic diameter $<2.5 \mu \mathrm{m}$ that are small enough to pass through the body's natural filtration system and into our lungs (Von Schneidemesser et al., 2015). Particles remain suspended in the air until they settle out (typical of large aerosols), dry deposit to surfaces, are washed out by rain, or contribute to cloud formation (Von Schneidemesser et al., 2015) . 


\subsubsection{The influence of meteorology on air pollutants and short-lived climate forcers}

Air pollutant emissions enter the general atmospheric circulation and exchange of species takes place through different vertical layers which are controlled by meteorological patterns that cause the transport and mixing of both trace gas and particulates (Chapman et al., 2009). Species concentrations are controlled by a number of factors including reactions with other substances such oxidation and photochemistry, emission rate from sources, and the planetary boundary layer (PBL). Air pollutants are emitted into the PBL where they are well mixed and can be transferred from the Earth's surface to the free troposphere. Vertical transport in the PBL is due to turbulence that plays a leading role in the transfer of momentum, moisture, heat and gases. Its height can range from 100-3000 $\mathrm{m}$ and varies with land cover, terrain, temperature, and other environmental factors (Luo et al., 2006). During the day, the surface temperature of the Earth increases as it absorbs solar radiation. This facilitates turbulent mixing. At night, when photochemical processes are dormant, inversions are created near the ground as the surface air cools. At this time the lower layer of the PBL is stable which prevents the ventilation of emissions (Seinfeld et al., 2006). With time, the boundary layer shrinks, and the pollutant emitted during this period achieve a relatively high concentration as they are trapped within a shallow boundary layer. After sunrise the following day, the surface heats up and pollutants are transported within the boundary layer with increasing turbulence.

There are also regional natural inversions in West Africa that are established in the dry season due to the cold dry Harmattan winds which occur between November and mid 
March (Schwanghart et al., 2008). This happens when cold dry Harmattan wind from the Sahara meets warm air over West Africa causing a rise of warm air above the cold air. The air in PBL become more stable leading to the build up of pollutant which gets dispersed by the monsoon winds in the wet season.

Pollutants emitted during charcoal production in Africa are susceptible to both shallow and deep boundary layer and regional inversion systems as the pyrolysis process lasts day and night for at least two weeks. Pollutants from charcoal use on the other hand are susceptible to deeper boundary layer condition since the use activity is mostly during the day when there is stronger surface heating.

\subsubsection{Weather patterns that influence pollutant transport in Africa}

At the macro scale, the climate in Africa is dominated by three major and interconnected features: tropical convection, monsoons, and the El Nino-Southern Oscillation (ENSO) of the Southern Pacific Ocean (Conway, 2009). The first and second are local and regional-scale processes that determine the seasonal patterns of rainfall and temperature. The third is remote in origin and decadal, but has strong influence on the patterns of temperature and rainfall in Africa (MacLeod et al., 2019).

Tropical convection results from intense solar heating near the equator which cause warm moist air to rise leading to heavy rainfall. As the air rises, it creates a zone of low pressure at the surface. This zone is called the Inter-tropical convergent zone (ITCZ). The rising air also distributes pollutants vertically. It diverges in the upper troposphere, moving 
north and south towards the edges of the subtropics sinking as it does so to produce warm, dry air between $20^{\circ}$ and $30^{\circ}$ north and south. From there it is then carried back toward the equator by the low-level trade winds. Figure 1.6 shows the position of the ITCZ north of the Sahel in July. Also evident are the monsoonal (southwesterly) winds travelling from the Gulf of Guinea over the West African coastline. In January, the ITCZ moves southward, tracking the sun, to about $20{ }^{\circ} \mathrm{S}$.

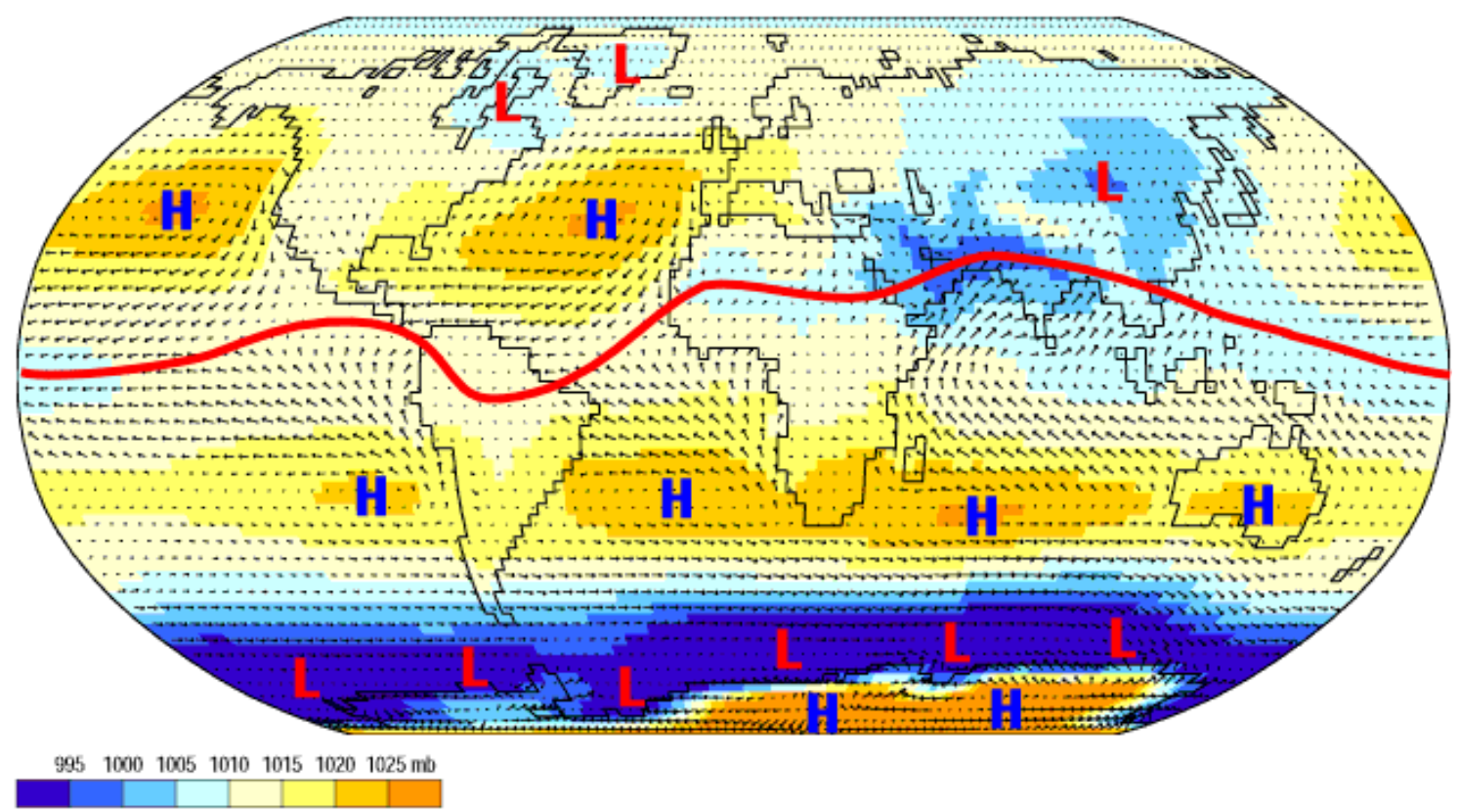

Figure 1.5 Position of the ITCZ and monsoon in July (red line). The other colours signify sea-level pressure. The arrows indicate direction and intensity of surface winds. Source: Pidwirny (2006)

Each year as the tilt of the globe becomes directed towards and away from the sun, the ITCZ moves north and south (Guertin et al., 2020). This leads to the emergence of four distinct climate zones in Africa (O'Hare et al., 2014): (1) tropical moist climates (15 - 25 
${ }^{\circ} \mathrm{N}$ ) with close to $2000 \mathrm{~mm}$ rain annually, which supports the equatorial rainforest, (2) tropical climate that alternates between short dry winters and wet summers (brought by the ITCZ), with annual rainfall total ranging from 1000 to $2000 \mathrm{~mm}$; (3) tropical semiarid climate, which has a long dry season towards the northernmost extent of the annual ITCZ excursion and annual rainfall of $300-800 \mathrm{~mm}$; and (4) arid climate $30-40^{\circ}$ north/south, with rainfall $<250 \mathrm{~mm} \mathrm{a}^{-1}$.

These zones are not distinct, but rather have overlapping boundaries which can vary from year to year with the latitudinal and longitudinal extent of the ITCZ. The rainfall in these zones wash out PM and, when absent, lead to build-up of air pollution. Monsoon winds in East, West, and Southern Africa transport large quantities of precipitation to the continent. These result from differential heating of land and sea. The intensity, location, and characteristics of these monsoonal systems are linked to tropical convection, the relatively shallow ITCZ, and jet streams aloft (O’Hare et al., 2014).

West Africa is of particular interest, due to rapid population growth, the distinct wet and dry seasons, and the profound influence on pollutant concentrations. The region is affected by southwesterly monsoon winds that undergo meridional oscillations. The monsoon system is complex, not well understood, and is associated with sea surface temperature and the location and intensity of the ITCZ and the African easterly jet (Giannini, 2010; Crespo et al., 2019). The monsoon winds are located over the ocean during the dry season (December to April) when warm Harmattan winds from the Sahara Desert establish an intense natural inversion across West Africa south of the Sahel that prevents ventilation of the region and causes build-up of pollution (Knippertz et al., 
2015). The monsoon then migrates northward and rainfall over the region occurs in two phases as can be seen in Figure 1.7 which shows how daily rainfall and sea surface temperature varies with the West African Monsoon. The winds migrate northwards to $4^{\circ}$ $\mathrm{N}$ in April-June for the first phase of the monsoon causing pollutants to disperse. In the second and most intense phase, the monsoon winds are located at their most northerly point (about $10^{\circ} \mathrm{N}$ ) in mid-July.

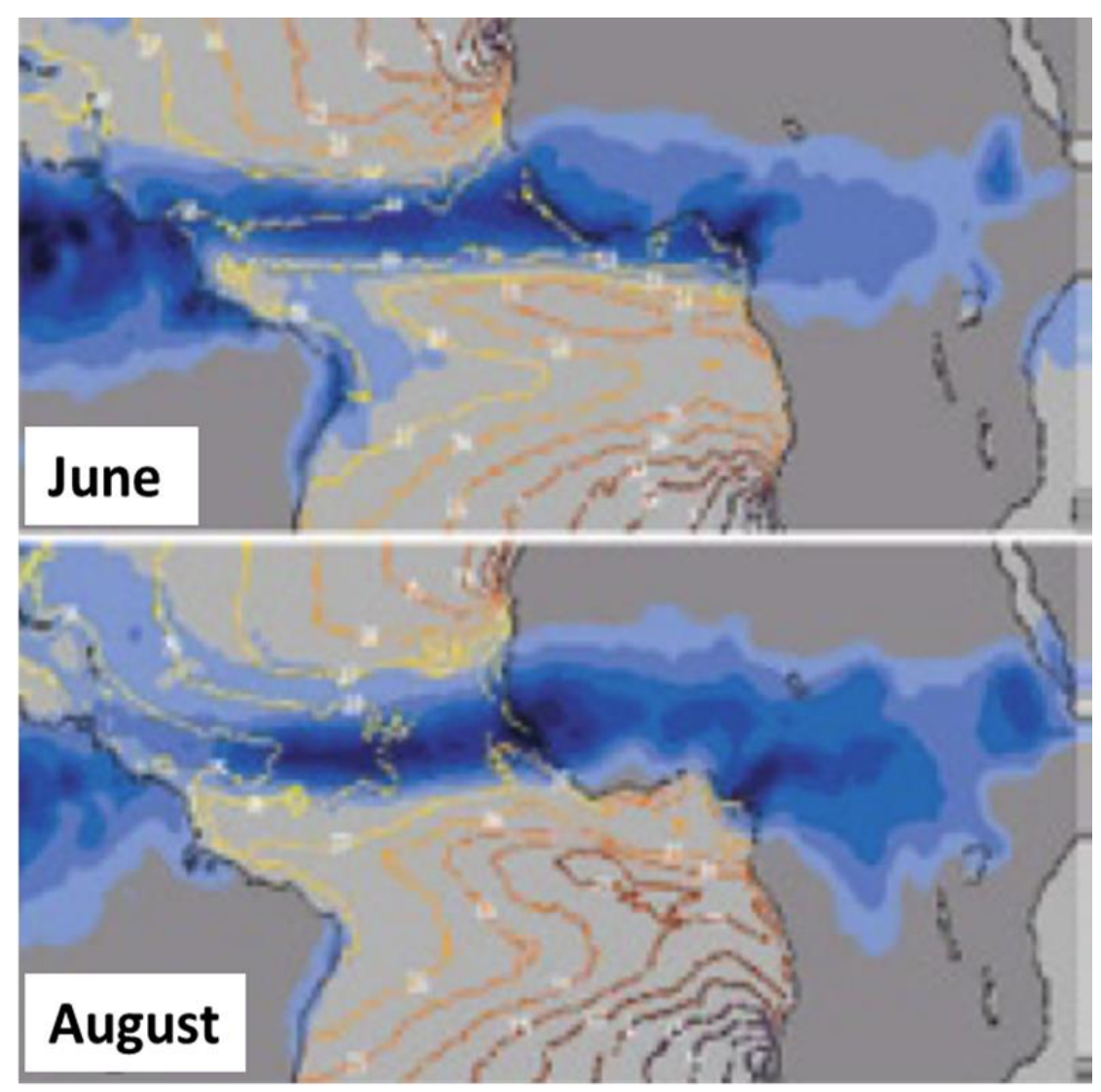

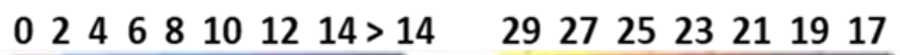

\section{Precipitation $\mathrm{mm} /$ day}

Sea surface

temperature

${ }^{\circ} \mathrm{C} /$ day 
Figure 1.6 The two phases of the West African Monsoon. The map shows variation in rainfall and temperature due to the West Africa monsoon. Source: Gu and Adler (2004).

The El Niño-Southern Oscillation (ENSO) is another important driver of climate variability in Africa. The ENSO originates in the remote Pacific Ocean and switches between two extreme phases over decadal timescales: the warm El Niño and cold La Niña phases. The Peru current, under 'normal circumstance', brings cool water to the Central Pacific. From there, increasing warm water is being moved towards the west from the high-pressure zone of the Central Pacific to the low-pressure zone in Indonesia. ENSO is commonly linked to drought and extreme rainfall in some parts of Africa (Gannon et al., 2018). During El Nino events, the White Nile and countries in East Africa including Tanzania and Kenya experience long rains from March to May, that makes these locations wetter than normal as can be seen in Figure 1.8 (Fer et al., 2017). During winter (December, January, and February), it gets drier than normal in South-Central Africa, mainly in Zambia, Botswana, Zimbabwe and Mozambique (Mason, 2001). During La Nina the opposite happens. In December, January and February, it gets drier than normal in East Africa and wetter than normal in Southern Africa. Warm and dry conditions could favour longer lifetime of pollutants in the atmosphere and reaction of ozone precursors while cool and wet conditions could promote scavenging of atmospheric particles and gases from the atmosphere. 

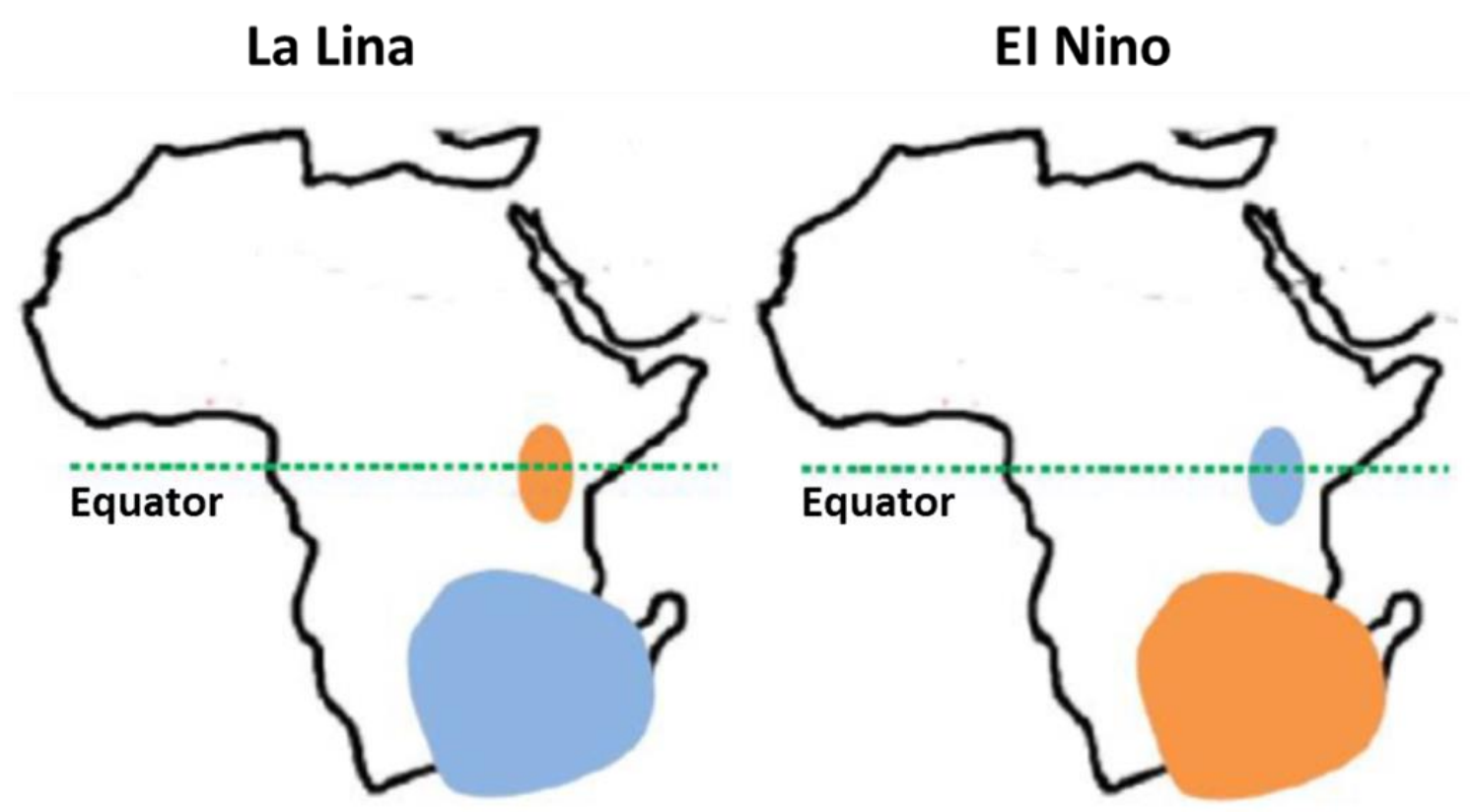

Figure 1.7 The schematic representation of La Nina (left) and El Nino (right) conditions over Africa. The light-blue areas indicate wet and cool conditions while the orange areas indicate warm and dry conditions. Dashed green lines represent the equator. Source: (Salau et al., 2016)

\subsubsection{Lifetime of pollutants in the atmosphere}

The lifetime of pollutants (the e-folding time) defined as the time taken for the pollutant concentration to fall to $1 / \mathrm{e}$ of its initial value (e is the base of the natural logarithms, 2.718) (Sokolik, 1998), is determined by the loss pathways that can be either chemical or physical. Chemical processes include oxidation or photolysis discussed above for NMVOCs, $\mathrm{CH}_{4}$, and CO. Physical processes include dry and wet deposition (Amodio et al., 2014). Dry deposition refers to the direct collection of particles or gases on the air 
Earth's surface or vegetation (Dolske et al., 1985). Wet deposition refers to the scavenging of particles and gases in the air by rain or clouds. Dry deposition can be accompanied by chemical processes such as oxidation reactions at the surface on which the pollutant is deposited (Tai et al., 2017). Wet deposition can be accompanied by various interactions such as nucleation, absorption, precipitation, reaction and solubility (Amodio et al., 2014).

Fine particles can be transported over long distances and are eventually removed predominantly by wet deposition for fine particles and gravitational settling for coarse particles. Intermediate-sized particles can coagulate to form larger particles and similarly undergo gravitational settling. Ozone removal from the atmosphere occurs as a result of $\mathrm{OH}$ reduction. $\mathrm{NO}_{\mathrm{x}}$ is eventually lost from the atmosphere via the formation of nitrates and ozone (Von Schneidemesser et al., 2015).

\subsubsection{Ambient air pollution in Africa and the effect on health and climate}

Premature deaths attributed to exposure to air pollution in Africa is greater than other major health risk factors like unsafe water and sanitation (Niang et al., 2014). Both human health and economic cost of air pollution in Africa are high and increasing. Deaths from ambient particulate matter in Africa increased by more than 30\% between 1990 and 2013, costing the African economy USD 215 billion annually in 2013 (Roy, 2016). Deaths from $\mathrm{PM}_{2.5}$ increased by $17.5 \%$ between 2013 and 2017 (HEI, 2019b). It is estimated that premature deaths due to exposure to air pollution from domestic fuel combustion increased by $18 \%$ between 1990 and 2013 costing the African economy by USD 232 
billion in 2013 (Roy, 2016). The most common sources of outdoor air pollution in Africa are open fires, and other anthropogenic sources related to fossil fuel combustion such industry, transport and energy. Natural contributions include bacteria in soils, vegetation emissions of BVOCs, and $\mathrm{NO}_{\mathrm{x}}$ from lightning (Aghedo et al., 2007; WHO, 2020). Open fires in Africa are the largest global source of aerosols (Marticorena et al., 2011) and air pollution formed from open fire emissions are the third largest contributor to premature deaths in Africa (Fecht, 2017). Africa is urbanising at 4\% $\mathrm{a}^{-1}$ (World Bank, 2018), which is a faster rate higher than on any other continent. Rapid urbanisation drives an increase in emissions from many sources, in particular biomass energy in Africa which makes about $50 \%$ of the total primary energy supply (UNEP, 2019). More than $80 \%$ of the population relying on it for economic, household and cooking purposes due to limited access to electricity or the sustained reliance on biomass (wood, charcoal) as a residential energy source (Bildirici et al., 2016; UNEP, 2019).

The median temperature increase in Africa in all regions and in all seasons lies between $3^{\circ} \mathrm{C}$ and $4^{\circ} \mathrm{C}, \sim 1.5$ times the global mean temperature increase (Christensen et al., 2007). Future projections indicate that extreme weather in Africa will become more severe. This includes more frequent floods, more severe droughts, higher sea levels, more storm surges, more intense cyclones (Niang et al., 2014). This will have a negatively affect agriculture, biodiversity and ecosystems management, population health and governance (Conway, 2009). Africa is least prepared and most vulnerable to these effects, in particular the poorest countries and communities (Magrath et al., 2006). 


\subsubsection{Assessing the impact of pollution sources on air quality and climate}

Monitoring of air quality in Africa is exceedingly sparse, due to absence in most countries of local air quality monitoring networks. Even when there are extensive air quality monitoring networks it is challenging to discern the contribution of individual sources to air pollution concentrations. Emission inventories developed and embedded in chemical transport models (CTMs) address this deficiency. Emission inventories are collations of the contributions which individual source categories make to total emission for one or more pollutants for a given period or geographic domain (Frey, 2007). These are routinely used for policy decision-making including emission mitigation strategies, analysis of emission trends, emission projections, health and environmental impact modelling, exposure and risk analysis, and data needs prioritisation (Frey, 2007). CTMs represent our best understanding of the sources and physical and chemical processing of atmospheric pollutants. These are routinely evaluated against observations to assess their skill at reproducing reality (Stroud et al., 2012; Moorthy et al., 2013). CTMs are versatile tools that be used to assess emission sources and, when coupled to a radiative transfer model, provide information about the radiative effect of the short-lived climate forcers aerosols and ozone (Heald et al., 2014). CTM estimates of air pollutant concentrations that impact human health are routinely used to assess the detrimental impacts of pollution sources to human health and the natural ecosystem (Dore et al., 2015).

There are global and regional inventories developed for Africa by various research groups some of which have been used to assess air quality and climate. The most widely used global emission inventories are the Emission Database for Global Atmospheric Research 
(EDGAR) (Janssens-Maenhout et al., 2019) and the Community Emission Database Systems (CEDS) (Hoesly et al., 2018). The EDGAR inventory is provided for a number of emission sectors following the IPCC as annual datasets either on a grid map or as country totals. One of the sectors specific to this research is Energy. The available monthly emissions are for 2010. Data for the EDGAR inventory are produced using the bottom-up approach and rely on energy statistics from the international Energy Agency (IEA) and agricultural information from Food and Agriculture Organization (FAO). One major advantage of EDGAR dataset for all years is that the same method is used to calculate emissions. This approach may however ignore more detailed country specific information that could improve emission estimates and their a spatial distribution (Janssens-Maenhout et al., 2015). CEDS is another widely used global inventory (Hoesly et al., 2018). One reason for the development is to avoid unrealistic gradients between geographical regions that might appear in hybrid inventories such as Hemispheric Transport of Air Pollution (HTAP_V2.2) as far as possible. Hybrid inventories are inventories which complement regional inventories with global datasets or use inventories prepared for important substances such as NMVOCs or $\mathrm{NH}_{3}$ from noncombustion sources or sectors such as vegetation or agriculture. Like EDGAR, CEDS is also based on energy statistics data from IEA. CEDS was developed to create a community-based data system where community-based emission data developers, national or regional, would be able to improve the quality of the database (Hoesly et al., 2018). CEDS emissions are gridded based on spatial proxies from EDGAR and VOC speciation (Huang et al., 2017). 
There have been a number of regional anthropogenic emissions inventories developed for Africa. The emissions from diffuse and inefficient combustion sources (DICE-Africa) has been developed by Marais and Wiedinmyer (2016) for 2006 and 2013 to fill gaps in anthropogenic emissions in global inventories to better represent these sources in CTMs. These include sources like motorbikes, backup generators, charcoal production and use, and kerosene use. It is currently implemented in the GEOS-Chem CTM. Liousse et al., (2014) developed a regional anthropogenic emission inventory for Africa motivated by the projected increase in cities and megacities in Africa. That inventory is for 2005 and 2030. Other inventories exist for Africa for specific pollution sources. These include the inventory of gas flaring and waste burning for 1990-2016 by Liousse et al. (2017), the inventory of $\mathrm{BC}$ and $\mathrm{OC}$ emissions from two-wheeled vehicles in West Africa for year 2002 by Assamoi and Liousse (2010), and the inventory of vehicle emissions by Mbandi et al. (2019). The latter is for Nairobi, Kenya only. In this work, the focus is on developing an inventory of air pollutant emissions specifically linked to activities associated with the charcoal industry in Africa. 


\section{LITERATURE REVIEW}

\subsection{An Introduction to Charcoal}

Charcoal use dates as far back as 32,000 years ago (30,000 BC) for cave painting. Its use as fuel started about 7000 years ago (5,500 BC) in Europe for smelting copper (Nhatkhoa, 2018), expanding to smelting of other metals like gold and iron for manufacturing gunpowder, glass and domestic fuel (Graves, 2012). By the $13^{\text {th }}$ century, the number of charcoal burners increased with development of gunpowder as well as armour and other weaponry. Due to the increased demand for wood as timber, there was general shortage of wood so that charcoal became prohibitively expensive and iron smelters used newly discovered alternatives like coke (partially burnt coal). The coal tar industry eventually replaced the charcoal burning industry, and by 1800, discovery of oil and natural gas replaced coal. Charcoal as residential energy quickly fell out of favour as a result (Shilling, 2016). Today, in Europe and North America, charcoal is widely used for recreational purposes (barbecuing). In Africa, it is increasingly replacing wood as a primary household energy source, predominantly used for cooking (Bailis et al., 2013; WWF, 2018).

Charcoal is a solid biomass energy source produced from the pyrolysis of wood. In the conversion of wood to charcoal, the energy density (amount of energy released per unit mass burnt) of the biomass increases from 17-24 to 27-33 $\mathrm{MJ} \mathrm{kg}^{-1}$ (FAO, 2015b; Talbot and Harwood, 2017). The higher energy density of charcoal compared to wood is because charcoal is mostly carbon (50-95\% compared to $46-49 \%$ for wood) and is typically drier 
than wood (Hibagene et al., 1994; Martin et al., 2011). Charcoal is not pure carbon nor a single compound. Its elemental composition is predominantly carbon (on average about $47.9 \%$ ), but with non-negligible amounts of hydrogen (5.8\%), oxygen (41.6\%), nitrogen (0.92\%), sulfur (0.09\%) and mineral ash (3.93\%) (Neves et al., 2011). The elemental composition will vary with wood type used to produce charcoal, combustion conditions, and the amount of fixed carbon in the fuelwood. (FAO, 1987; Steve, 2014).

The carbonisation process takes place in kilns. These include kilns made out of soil (earthmound), brick, metal, concrete and retort kilns. (Habitat, 1991; Steve, 2014). Combustion efficiencies (mass of charcoal produced per kg of dry wood burned) of kilns range from 9\% for earth-mound kilns to 35\% for retort kilns (Schure et al., 2019). The combustion efficiency and the quality of charcoal produced are determined by the type of kiln, the moisture content of the wood, the density and diameter of the wood, tree species used, skill of the producer, and the climate condition (KFS, 2013; GIZ, 2014). Charcoal production releases smoke (trace gases and particles), water (liquid and steam) and tar as by-products (Fagbemi et al., 2001; Neves et al., 2011). Tar is a viscous liquid which is mostly left to drain on the ground and not used after.

\subsection{Charcoal production in Africa}

Charcoal provides energy for urban households in Africa and a livelihood for rural inhabitants who are largely involved in its production (Vollmer et al., 2017). Africa produces more than $60 \%$ of global charcoal, almost all of which is used on the continent primarily for cooking by urban and peri-urban households (GIZ, 2014; FAO, 2016). 
Figure 2.1 shows charcoal production in Africa in 2017 as well as the respective countries and subregions. Data are from UN energy statistics database (UN, 2017b). It can be seen from Figure 2.1 that charcoal is produced in almost every country in Africa with highest production in Kenya, Nigeria and the Democratic Republic of the Congo. This is likely happening because these countries have among the largest city population in Africa. For example, Lagos, Nigeria and Kinshasa, Congo, are cities in Africa with the first and second largest populations (Hoornweg et al., 2017). Other possible reason is lack of access to electricity or other viable off-grid energy sources. There is also more production in East Africa than the other subregions.

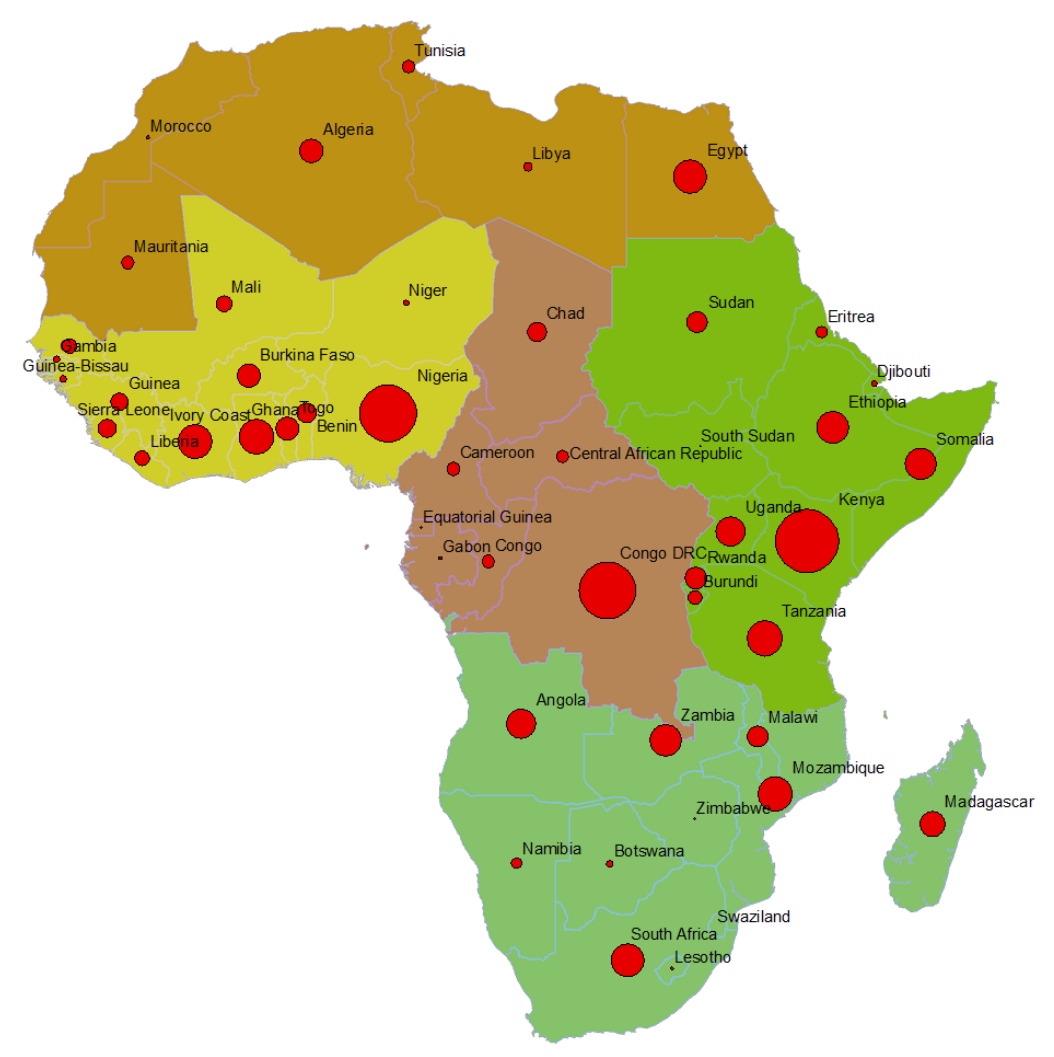

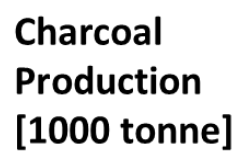

[1000 tonne]

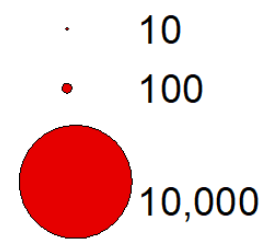

Region

Central Africa

Eastern Africa Northern Africa

Southern Africa

Western Africa

Figure 2.1 Charcoal production in Africa in 2017. Countries are coloured by subregions as defined by the key on the right of the map. The size of the red circles indicate the 
amount of charcoal produced in each country from the UN energy statistics database (UN, 2017b). The total for the continent in 2017 is $48.4 \mathrm{Tg}$.

Demand for charcoal will increase dramatically, given that Africa's urban population is projected to treble between 2015 and 2050 (UN, 2015) due to population growth and increased rural-urban migration. This will be particularly severe in the key charcoal producing countries Nigeria, Egypt, and Congo DRC (FAO, 2016). At the same time, the availability of woody biomass is declining due to extensive net deforestation, mostly from irreversible land-use change to agriculture (Hansen et al., 2013). Charcoal is also putting strain on forests, in particular in locations where charcoal production is high, but woody vegetation is sparse. These include countries in the arid and the semi-arid regions where it is believed that fuelwood is a major contributing factor of deforestation (Gorse et al., 1987; Coulter, 1995; Benjaminsen, 1997). In the Sudanian and Sahelian areas, wood has been identified as a critical and scarce resource and (WB, 1996; Sanchez et al., 1997) have found that it carrying capacity has already been exceeded.

Charcoal has aided the transition from dirtier burning wood, as charcoal is preferred by urban dwellers for cooking because it is cleaner, lighter, and has higher energy content (Akpalu et al., 2011). There are alternative energy sources that are cleaner than charcoal. These include liquified petroleum gas (LPG) and electricity, though the latter depends on the energy that the electricity if sourced from. Urban populations are resistant to these cleaner energy sources, as charcoal is still more affordable, reliable and readily available (Sawe, 2014) 


\subsection{The Charcoal Supply Chain in Africa}

The charcoal supply chain in Africa involves sourcing wood from suitable woody vegetation from forest, woodland, shrubland or savanna landscapes, slow-burning the wood for a few weeks in kilns in rural areas a few kilometres from major roadways, transport of charcoal to cities, and its eventual use in urban households. The people involved at each stage in the process are wood collectors, charcoal producers, truck drivers, consumers and owners of resources like land, trucks and distribution centres.

Wood used for charcoal production in Africa is sourced from rainforest, woodland, shrubland, and savanna vegetation (Msuya, 2011; Agyeman et al., 2012; Kiruki et al., 2017). Factors such as land ownership, climatic conditions, local demand, infrastructure, landuse rights and available workforce can determine how readily available a landscape is for harvesting wood. The majority of wood gathered for charcoal production in Africa is from unpatrolled natural forests and woodlands (Gazull et al., 2015). Acacia species are the most widely harvested tree species for producing charcoal (Njenga et al., 2013), due to their high energy density (Mugo et al., 2007). Trees used to produce charcoal either undergo selective felling as applied in West Africa or complete removal (clear-felling) as applied in East and Southern Africa (Chidumayo et al., 2013). The wood is gathered into piles locally and then covered with earth and green leaves to form a kiln for the charcoal production process.

The most common type of kiln in Sub-Saharan Africa is the earth-mound kiln. An example of an earth-mound kiln is shown in Figure 2.2. In some cases, earth-mound kilns 
also include a chimney that is used to direct the escape of smoke (Megevand et al., 2013). Kambewa et al., (2007) report from field observations that most charcoal is produced in the rainy season, as charcoal producers capitalise on higher charcoal prices in this season when other fuel sources are unreliable. It can be seen from Figure 2.2 that there is visible smoke from the pyrolysis process which indicates the production of light-scattering aerosols. Procuring wood for charcoal has the potential to reduce the land carbon sink, alter surface albedo, and may also alter the types of BVOCs emitted by vegetation (Laothawornkitkul et al., 2009).

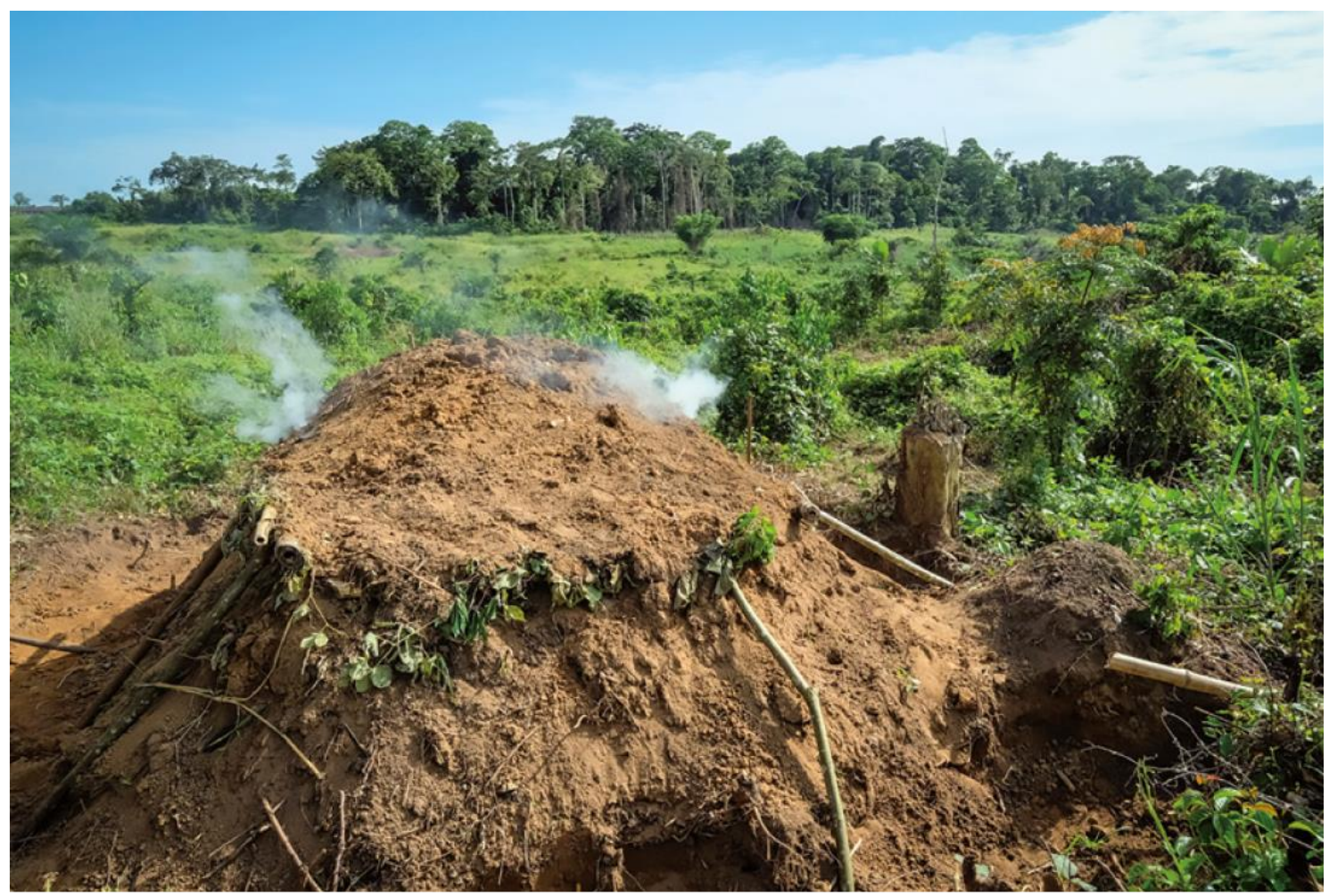

Figure 2.2 Earth-mound kiln commonly used to produce charcoal in Africa. Source: Schure et al. (2019). 
The charcoal production process involves converting wood to charcoal in a limited supply of air. This promotes carbonization of wood to form carbon-rich charcoal. In the first phase which occurs at a temperature below $170^{\circ} \mathrm{C}$, the wood dries. In the second phase, chemical breakdown of the wood is initiated and carbonisation starts. This phase occurs between $170-270{ }^{\circ} \mathrm{C}$. Here organic acids, water vapour, $\mathrm{CO}$ and $\mathrm{CO}_{2}$ are emitted and tar is formed. In the third phase, external breakdown (breakdown of the ligno-cellulosic skeleton) takes place at temperatures between $270-350^{\circ} \mathrm{C}$. Here wood continues to undergo chemical breakdown leading to evolution of gases, particles and tar at a higher rate than the previous phase. Chemical breakdown of wood ends with the final stage when temperatures rise above $350{ }^{\circ} \mathrm{C}$. At this stage, relative amount of $\mathrm{CO}$ and $\mathrm{CO}_{2}$ to $\mathrm{H}_{2}$ and light hydrocarbons decrease as the temperature increases. $\mathrm{H}_{2}$ is a small fraction of the total mass and can react with $\mathrm{OH}$ in the troposphere to form water and atomic hydrogen (Schmidt, 1974). The chemical breakdown process ceases at temperatures between 450 $550{ }^{\circ} \mathrm{C}$, as above $550{ }^{\circ} \mathrm{C}$ charcoal combustions occurs which decreases the yield. The operating carbonisation temperatures determine the yield of combustible gases. Evolved gases analysed from carbonisation process show the following composition (by volume): (CO: $25 \% ; \mathrm{CO}_{2}: 15 \% ; \mathrm{O}_{2}: 5 \% ; \mathrm{CH}_{4}: 4.5 \% ; \mathrm{H}_{2}: 2 \% ; \mathrm{C}_{2} \mathrm{H}_{6}: 1 \% ; \mathrm{N}_{2}: 47.5 \%$ ) (Gomaa et $a l .$, 2000). Earth-mound kilns have the lowest combustion efficiencies (9-30\%) than any other kiln type, and so would include the release of relatively large quantities of $\mathrm{CO}, \mathrm{CH}_{4}$, organic compounds and other pollutants that are signatures of partially combusted fuel (Yevich et al., 2003; FAO, 2017). The production process takes between 2-4 weeks to complete (Demirbas, 2009). The charcoal is left to cool for 2-5 days (UN, 2014) before it is packed into bags for transport to the consumers. 
The most common means of transportation of charcoal to cities in Africa is with diesel trucks (Malimbwi et al., 2004; Alem et al., 2010). An example of one heavily loaded with charcoal is shown in Figure 2.3. These trucks are mostly very old (Malimbwi et al., 2008) and about $80 \%$ are second hand (Kablan, 2010). According to the Ministry of Transport of Ivory Coast (Ministry of Transport, 2012) these vehicles are more than 20 years old and as such are highly polluting due to inefficient combustion and absence of updated emission mitigation technology (Boughedaoui et al., 2009). Charcoal transport vehicles also include mini-buses, private and public cars, tankers, motorbikes, and bicyles (Kilahama, 2008). Trucks emit particles (BC and OC) and gases such $\mathrm{CO}, \mathrm{NO}_{\mathrm{x}}, \mathrm{SO}_{2}$ and NMVOCs. In the city, the charcoal is either bought directly from trucks or distributed to wholesale points by trucks, bicycles or minibuses.

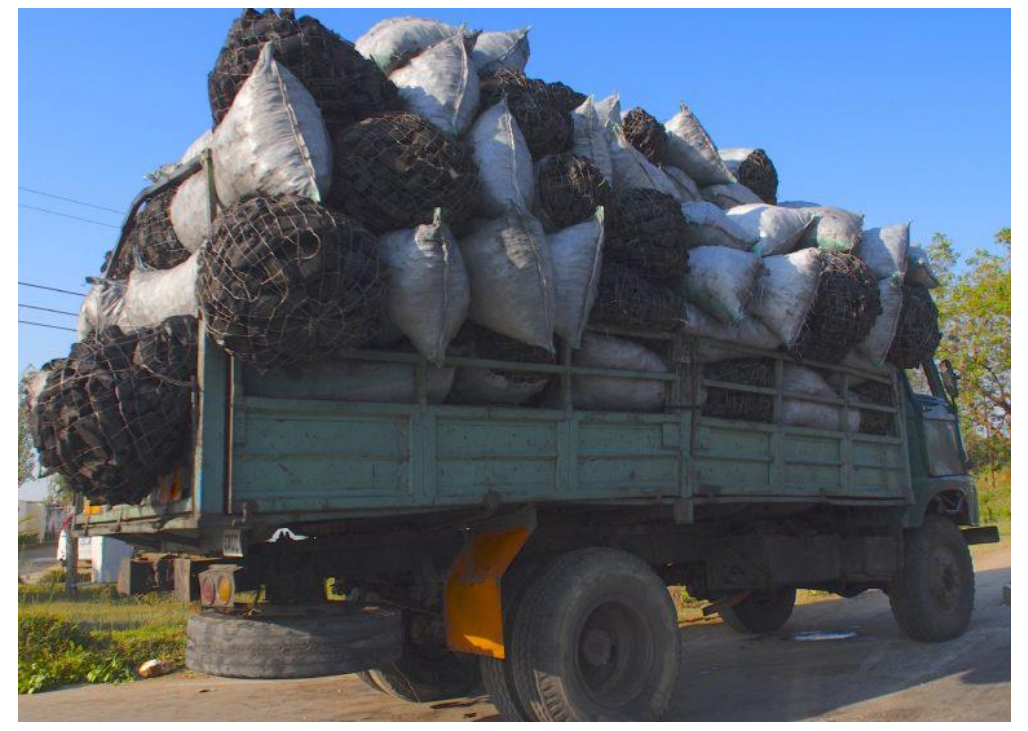

Figure 2.3 Transportation of charcoal to cities in Africa. Image shows a diesel truck transporting charcoal to cities in Zambia. Note the potholed, unmetalled road and that some of the charcoal is in net bags. Source: Pearson (2020). 
In cities, charcoal is mainly used for cooking (Schure et al., 2013) and mostly consumed by the local population (Shively et al., 2010). Current studies reveal that more than $90 \%$ of urban dwellers use charcoal in their homes in Africa (World Bank, 2011; Zulu et al., 2013). The higher income earners use it with a mix of other energy sources like LPG and kerosene (Chiteculo et al., 2018a). Kerosene, however, is falling out of favour in Africa. Kerosene usage declined at a rate of $0.2 \% \mathrm{a}^{-1}$ from 2006 to 2013 (Marais et al., 2016). Suburban dwellers in slum areas cannot afford cleaner energy alternatives and therefore use a mix of charcoal and firewood (Mulenga et al., 2019). Most charcoal use in slums includes the use of plastic to initiate and sustain combustion of charcoal (Chavula, 2019). When burned, plastics can contribute to emissions of hydrochloric acid ( $\mathrm{HCl})$ (Stockwell et al. 2016) which impacts abundance of tropospheric ozone and OH (Sherwen et al. 2017; Wang et al. 2019), but can also rapidly partition into the aerosol phase if ammonium is present (Pio et al., 1987) or dry deposit efficiently onto surfaces (Fowler et al., 2009).

At these end-use locations, the importance of charcoal quality becomes less, reason being, the various tree species harvested to produce charcoal are put through a single pyrolysis process and the charcoal lumps produced are put in to bags from their production sites indiscriminately (Nabukalu et al., 2019). The most common cookstove used to burn charcoal in Africa is the traditional cookstove (Arthur et al., 2010) generally made of metal with a grating at the base as shown in Figure 2.4. The traditional cookstoves are less efficient than the improved cookstoves which can lead more fuel use and longer cooking time (Still et al., 2015; Mitchell et al., 2020). A traditional cookstove has higher emissions CO, NMVOCs, and OA compared to an improved cookstove (Akagi et al. 2011), though the improved cookstoves are more efficient, and so release relatively large 
quantities of $\mathrm{NO}_{\mathrm{x}}$ and $\mathrm{BC}$. Although the improved cookstove improves the combustion efficiency of the charcoal, they are relatively expensive and unaffordable to the poorer urban dwellers (Mamuye et al., 2018).

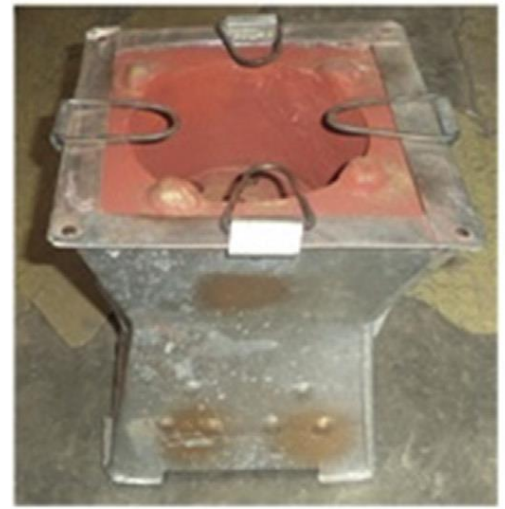

a

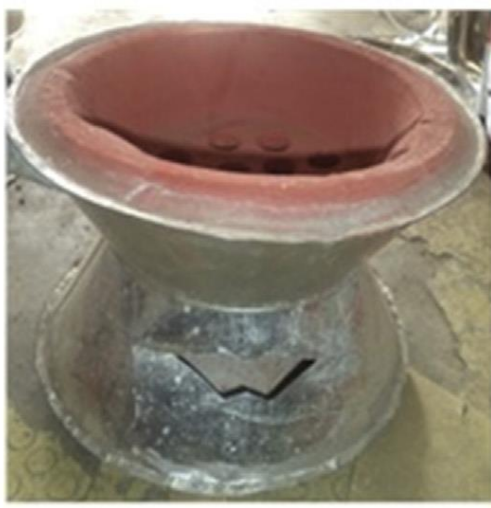

b

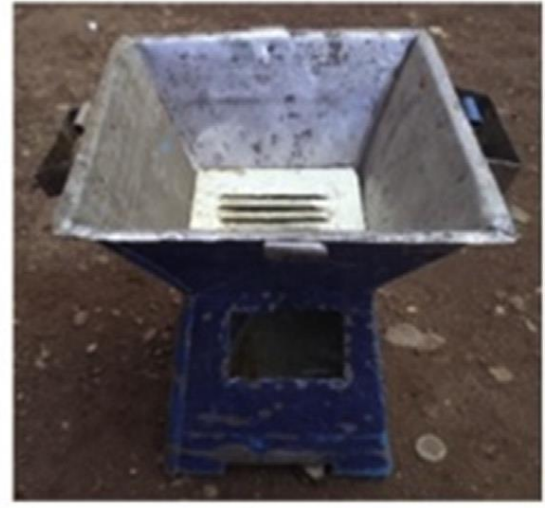

C

Figure 2.4 Charcoal cookstoves used in Africa. Image compares improved charcoal cookstoves (a and b) to a traditional charcoal cookstove (c). Source: Mamuye et al. (2018)

\subsection{Aerosols and Trace Gases from the Charcoal Supply Chain}

Trace gases and aerosols are emitted throughout the charcoal supply chain. Pollutants emitted include $\mathrm{BC}, \mathrm{OC}, \mathrm{CO}, \mathrm{CH}_{4}, \mathrm{NO}_{\mathrm{x}}, \mathrm{SO}_{2}, \mathrm{NMVOCs}$, and $\mathrm{HCl}$. The combustion efficiency of charcoal determines the amount and mix of pollutants it emits. Complete combustion of charcoal in the presence of air $\left(21 \% \mathrm{O}_{2}\right)$ would yield $\mathrm{CO}_{2}, \mathrm{NO}_{\mathrm{x}}$, and $\mathrm{H}_{2} \mathrm{O}$. As combustion efficiency decreases, the relative amount of $\mathrm{CO}, \mathrm{CH}_{4}, \mathrm{OA}$, and NMVOCs increases. $\mathrm{CO}, \mathrm{CH}_{4}$, and NMVOCs in the present of $\mathrm{NO}_{\mathrm{x}}$ and sunlight form ozone which is harmful to plant and human health and can contribute to global warming. Pollutants such as $\mathrm{OA}$ contribution to $\mathrm{PM}_{2.5}$ directly and $\mathrm{NO}_{\mathrm{x}}, \mathrm{SO}_{2}$, and NMVOCs indirectly by undergoing oxidation or nucleation to from $\mathrm{PM}_{2.5}$ which is harmful to health and can 
either reflect or scatter outgoing or incoming radiation depending on the light absorbing or scattering properties of the aerosols. The following discusses the charcoal supply chain pollutant emissions and their effects on health and climate.

Black carbon (BC) is a component of PM. In the charcoal supply chain, it is emitted mostly during charcoal burning as defined by its emission factor of $1 \mathrm{~g} \mathrm{~kg}^{-1}$ as opposed to charcoal making which has an emission factor of $0.02 \mathrm{~g} \mathrm{~kg}^{-1}$ (Akagi et al., 2011). BC is resistant to chemical transformation (Forbes et al., 2006; Petzold et al., 2013). As a component of fine PM, BC potentially has an adverse effect on human health (Janssen et al., 2011; Hamatui et al., 2016). It can aggravate existing illnesses and increase the morbidity and hospital admissions as well as mortality from cardiovascular and respiratory diseases and from lung cancer (Fullerton et al., 2008). Recent studies have revealed that $\mathrm{BC}$ has a greater impact on health than $\mathrm{PM}_{2.5}$ as a whole (Grahame et al., 2014; Tobias et al., 2014). A study conducted by Janssen et al. (2011) revealed that a 1 $\mu \mathrm{g} \mathrm{m}^{-3}$ decrease in BC increases life expectancy by 4-9 times that of reducing $1 \mu \mathrm{g} \mathrm{m}^{-3}$ of $\mathrm{PM}_{2.5}$. BC can indirectly reduce crop yield by reducing availability of sunlight (Chameides et al., 1999).

BC can efficiently absorb solar radiation which makes it an important light absorbing aerosol. Its exact climate forcing is under debate, but it is known to be the strongest forcing agent driving global warming after $\mathrm{CO}_{2}$ (Myhre et al., 2013). BC may also have an indirect effect on climate by interacting with clouds to change cloud cover, emissivity, cloud albedo, and the height at which clouds form (Cherian et al., 2017). Fresh BC emissions are generally hydrophobic. As these age, these mix with water-soluble 
compounds and transition from hydrophobic to hydrophilic (Andreae et al., 2008), are able to act as efficient cloud condensation nuclei (CCN) to promote cloud formation. This changes the number concentration of liquid cloud droplets (Gunthe et al., 2011; Lawson et al., 2015; Andreae and Gelencsér, 2006; McMeeking et al., 2011). BC can also mix with reflecting particles and in so doing increases the absorption of solar radiation (Cappa et al., 2012; You et al., 2016).

Organic carbon (OC), also called organic aerosol (OA), is a significant fraction of PM throughout the world and so affect human health (Hamatui et al., 2016). Its fraction of the total PM depends on location. In the charcoal supply chain, more OC is emitted during charcoal production than during charcoal use (Pfotenhauer et al., 2019). In addition to the directly emitted OC also referred to as primary organic aerosol (POA), secondary organic aerosol (SOA) can also form condensation, nucleation or reactive uptake of oxidation products of gas-phase non-methane volatile organic compounds (NMVOCs) (Ahern et al., 2019). The effect of OC on climate varies from cooling to warming and depends on the optical properties of the aerosol (Jinhuan et al., 2000). OC that absorbs light is referred to as brown carbon and typically absorbs in the shorter wavelengths (Zhang et al., 2019). Light absorption of individual OC particles is weather than that of $\mathrm{BC}$, but the overall abundance of brown carbon may increase its impact from a warming perspective (Kirchstetter et al., 2004; Andreae et al., 2006).

Carbon monoxide (CO) is directly emitted mostly during charcoal production, but can also form when $\mathrm{CH}_{4}$ and NMVOCs are oxidised in the atmosphere (Matsumura et al., 1994; Grant et al., 2010). Lower concentrations of CO can have adverse effect on humans 
like fatigue, headache, and vomiting. At concentrations $>1000 \mathrm{ppmv}, \mathrm{CO}$ can be lethal (Godish, 1997). CO indirectly contributes to warming of the atmosphere through its role in ozone production but also through increasing methane lifetime by acting as a sink for $\mathrm{OH}$. It has been estimated that a uniform increase in $\mathrm{CO}$ from $25 \mathrm{ppbv}$ to $100 \mathrm{ppbv}$ leads a clear sky radiative forcing of $0.024 \mathrm{~W} \mathrm{~m}^{-2}$ (Sinha et al., 1996).

Methane $\left(\mathrm{CH}_{4}\right)$ is the most important greenhouse gas after carbon dioxide $\left(\mathrm{CO}_{2}\right)$. It is a powerful infrared absorber, 28 times more efficient per mass as a greenhouse gas than $\mathrm{CO}_{2}$ (Hofmann et al., 2006; Jackson et al., 2019). It persists in the atmosphere for 9-11 years (Holmes et al., 2013; Myhre et al., 2013). CH4 alters the oxidative capacity of the atmosphere by reacting with hydroxyl radical $(\mathrm{OH})$ and forming tropospheric ozone.

$\mathrm{NO}_{\mathrm{x}}\left(\mathrm{NO}+\mathrm{NO}_{2}\right)$ emission factors from the charcoal supply chain are highest from its use and transport (Akagi et al., 2011; Zavala et al., 2017), predominantly (90\%) emitted as NO (Arashidani et al., 1996). $\mathrm{NO}_{\mathrm{x}}$ has both direct and indirect effects on health. Exposure to $\mathrm{NO}_{2}$ can have adverse health effects such as airway inflammation and respiratory issues like asthma (Delfino et al., 2006; Ezratty et al., 2014). $\mathrm{NO}_{\mathrm{x}}$ can also be oxidised to nitrate to contribute to $\mathrm{PM}_{2.5}$ (Godish, 1997). $\mathrm{NO}_{\mathrm{x}}$ can also have adverse effects on ecosystems by offsetting the natural balance of nitrogen leading to eutrophication of lakes and other water bodies (Richter, 2009). $\mathrm{NO}_{\mathrm{x}}$ also indirectly contributes to warming of the atmosphere through the production of ozone, but also cooling by producing $\mathrm{OH}$ that in turn reduces $\mathrm{CH}_{4}$ abundance. Due to differences in lifetime of $\mathrm{CH}_{4}$ and ozone, the perturbation of $\mathrm{NO}_{x}$ on $\mathrm{CH}_{4}$ and cooling effect of $\mathrm{NO}_{x}$ acts on a global scale for about a decade while the ozone forcing and warming effect of $\mathrm{NO}_{\mathrm{x}}$ is regional and occurs in a 
time scale of weeks (Fuglestvedt et al., 1999; Stevenson et al., 2013). In the atmosphere $\mathrm{NO}_{\mathrm{x}}$ can take hours to days to be removed.

Non-methane volatile organic compound (NMVOCs) are organic compounds with varying chemical composition. NMVOCs affect health directly and some, like benzene and formaldehyde, are toxic (Laurent et al., 2014). NMVOCs also have an indirect effect on health by forming ozone (Atkinson, 2000b) and secondary organic aerosols (SOAs) (Atkinson, 2000b; Yee et al., 2013). Some prominent reactive NMVOCs emitted in the charcoal supply chain are formic acid, formaldehyde, acetic acid, furan, phenol, acetol, methanol, ethane and acetylene (Von Schneidemesser et al., 2015). NMVOCs contributes to positive radiative forcing by forming ozone (warming), increasing the lifetime of $\mathrm{CH}_{4}$ (warming) (Shindell et al., 2012), forming OA (both warming and cooling have been reported) (Lin et al., 2014). The net effect is cooling (Fry et al., 2014)

Sulfur dioxide $\left(\mathrm{SO}_{2}\right)$ emissions from the charcoal supply chain mainly come from transportation of charcoal to cities. $\mathrm{SO}_{2}$ has lifetime of few days and can be oxidised into sulfuric acid (Kulmala, 2003). The reaction sequence is as follows (Chandler et al., 1988) (Finlayson-Pitts et al., 2000):

$$
\begin{aligned}
& \mathrm{SO}_{2}(\text { gas }) \stackrel{\mathrm{H}_{2} \mathrm{O}}{\leftrightharpoons} \mathrm{SO}_{2}(\mathrm{aq}) \\
& \mathrm{SO}_{2}(\mathrm{aq}) \stackrel{\mathrm{H}_{2} \mathrm{O}}{\leftrightharpoons} \mathrm{HSO}_{3}^{-}+\mathrm{H}^{+} \\
& \mathrm{HSO}_{3}^{-}+\mathrm{H}_{2} \mathrm{O}_{2} \leftrightharpoons \mathrm{SO}_{4}^{2-}+\mathrm{H}^{+}+\mathrm{H}_{2} \mathrm{O}
\end{aligned}
$$


The aqueous $\mathrm{SO}_{2}$ reacts with water to form bisulfite $\left(\mathrm{HSO}_{3}^{-}\right)$, and then the $\mathrm{HSO}_{3}^{-}$reacts with hydrogen peroxide $\left(\mathrm{H}_{2} \mathrm{O}_{2}\right)$ to form sulfate $\left(\mathrm{SO}_{4}^{2-}\right)$ and hydrogen $\left(\mathrm{H}^{+}\right)$ions which react to from sulfuric acid. The gas-phase sulfuric acid can be transported over long distances and, when at very high concentrations $>2.0$ ppm (Casiday et al., 1998), can be deposited as acid rain leading to destruction of plants, aquatic ecosystems, and the built environment (Godish, 1997; Seinfeld et al., 2006). $\mathrm{SO}_{2}$ influences the radiative budget through its oxidation to form sulfate particles (Weber et al., 1996) which scatter solar radiation and so cool the atmosphere. The effect is regional rather than global, as sulfate particles are relatively short-lived (weeks) (Myhre et al., 2013) compared to $\mathrm{CH}_{4}(\sim 10$ years) (Forster et al., 2010; Sonnemann et al., 2014). Sulfate is also a key component of fine PM that is harmful to health (Reiss et al., 2007).

\subsection{Environmental Impacts of Charcoal Production}

If the charcoal supply chain is well managed it has the potential to become a renewable energy fuel source (Schlesinger, 2018). Accomplishing renewable energy status for charcoal requires protecting harvested areas cultivated for charcoal production and preventing bush fires and overgrazing (Doggart et al., 2017). The disposal of spent charcoal on agricultural soils can also improve the organic content and fertility of soils (Glaser et al., 2002; Blango et al., 2019).

The process of production could have potential impacts if not well managed. For example, clear or selective cutting of forest trees to produce charcoal could lead to deforestation or forest degradation (Chidumayo et al., 2013). Degradation is the less obvious change in 
woody canopy cover and deforestation is temporary or permanent removal of forest cover (Grainger, 1999). There have been reports highlighting concern about deforestation and forest degradation in almost all countries where charcoal is produced (Kilahama, 2008; Hofstad et al., 2009; Megevand et al., 2013; Sedano et al., 2016). Annual deforestation rates associated with charcoal production in Africa in 2009 are estimated at $29,760 \mathrm{~km}^{2}$ in Africa; much worse than values estimated for Oceania $\left(5.40 \mathrm{~km}^{2}\right)$, Central America $\left(390 \mathrm{~km}^{2}\right)$, South America $\left(2,400 \mathrm{~km}^{2}\right)$, and Asia $\left(5,100 \mathrm{~km}^{2}\right)$, i.e., Africa is responsible for close to $80 \%$ of charcoal-based deforestation in the tropics (Chidumayo et al., 2013).

Whether wood harvest leads to permanent deforestation or temporary forest degradation, harvest for charcoal production will inevitably impact forest catchment hydrology, soil and ecosystem services at least temporarily (Chidumayo et al., 2013). Forest clearing to produce charcoal could lead to an increase in runoff from watershed thereby reducing the capacity of the forest to regulate stream flow by intercepting rainfall and absorbing water into the underlying soil (Pereira, 1991). Charcoal production can also impact the soil underneath kilns by reducing its bulk density, altering its albedo, and increasing its porosity and surface temperature (Ayodele et al., 2009). Charcoal production could potentially reduce the availability of other goods and services that forests provide. These include wood product such as timber and biofuel (firewood and charcoal), and non-wood products such as honey, bushmeat, medicines, tubers, fruits and edible insects (FAO, 2010).

Both the potentially negative and positive impact mentioned above requires sustainable management of forest to be addressed but uncontrolled forest clearing and unregulated 
charcoal production activities especially in Africa could reduce the ability for forests to regenerate and recover degraded forests. More intriguing is the recovery period which takes longer and can range from 8-23 years (Chidumayo et al., 2013).

\subsection{Modelling the Effects of Emissions on Air Quality and Climate}

GEOS-Chem is a global three-dimensional model of atmospheric chemistry driven by assimilated meteorology from the NASA Global Modelling Assimilation Office (GMAO). It is used worldwide as a versatile tool for application to a wide range of atmospheric composition research topics. An overview of GEOS-Chem and its meteorology product is provided below, including descriptions of the treatment of transport, deposition, chemistry, radiation, and emissions.

There are two meteorological products at GMAO, namely, GEOS-Forward Processing product (GEO-FP) and the Modern-Era Retrospective Analysis for Research and Applications (MERRA-2). In this thesis, the MERRA-2 product is used. MERRA-2 provides a continuous and consistent archive of meteorology from 1979 to present. The horizontal (longitude, latitude) resolution of MERRA-2 is $0.5^{\circ} \times 0.625^{\circ}$ and the vertical extent is from the Earth's surface to $0.01 \mathrm{hPa}$ spanning 72 vertical levels. MERRA-2 is degraded to the model horizontal $\left(2^{\circ} \times 2.5^{\circ}\right)$ and vertical (47 layers) resolution for simulations on a global grid.

GEOS-Chem uses the Eulerian form of the continuity equation to quantify the concentration of species from emissions, transport, chemistry and deposition. This 
calculates the concentration of species in a fixed reference frame. The general form of the Eulerian continuity equation is as follows (Jacob, 2019):

$\frac{\partial n}{\partial t}=-\nabla \cdot(n \boldsymbol{U})+P-L$

Where $\frac{\partial n}{\partial t}$ is the change in concentration, $n$, of a species (atmospheric constituent) with time $t, \nabla .(n \boldsymbol{U})$ is the transport term (flux divergence), $P$ denoted sources (production) from emissions and chemistry, and L denotes sinks (losses) from chemistry and deposition. Integration of equation (2.4) yields the concentration, $n$, of the species of interest in space and time.

The emissions of GEOS-Chem are all configured to the model spatial and time resolution at run-time using the Harvard-NASA Emission Component (HEMCO) module (Keller et al., 2014). There are optional inventories, but the following are the default inventories relevant for this research. The default anthropogenic emission used in HEMCO which includes biomass burning, is the community emission database systems (CEDS) (Hoesly et al., 2018). The emissions from diffuse and inefficient combustion sources (DICE) is an anthropogenic inventory specific to Africa that is also present in HEMCO (Marais et $a l ., 2016)$. It provides more detail emission sources that supersedes the global inventories. The default emission from open fires for individual years which includes wood burning, are from the Global Fire Emission Database (GFED4) inventory (Giglio et al., 2013). GFED4 and CEDS were preferred for this work because they are comprehensive and cover longer periods. 
Natural emissions in GEOS-Chem include biogenic NMVOCs from the Model of Emissions of Gases and Aerosols in Nature (MEGAN2.1) (Guenther et al. 2012) and soil $\mathrm{NO}_{\mathrm{x}}$ as described in Hudman et al. (2012). Emissions are regridded and scaling factors applied using the NASA-Harvard Emission Components (HEMCO) emissions processing package (Keller et al., 2014).

In GEOS-Chem, the standard simulation includes coupled aerosol-oxidant chemistry in the troposphere and stratosphere. The chemical solver is the Kinetic PreProcessor KPP. KPP is a software that automatically generates F90 code that solves the chemistry (defined by and input file) in a box model (Damian et al., 2002).

GEOS-Chem includes detailed $\mathrm{HO}_{\mathrm{x}}-\mathrm{NO}_{\mathrm{x}}$-VOC-ozone-halogen-aerosol chemistry of the troposphere and loss processes (wet and dry deposition) to represent formation and loss of ozone and individual components of $\mathrm{PM}_{2.5}$ : sulphate, nitrate, ammonium (Park et al., 2004; Zhang et al., 2012), OA (Heald et al., 2006), BC (Wang et al., 2014), dust (Philip et al., 2017), and sea salt (Jaeglé et al., 2011). Surface $\mathrm{PM}_{2.5}$ concentrations are calculated in the model at $35 \%$ relative humidity which makes it mostly dry. (http://wiki.seas.harvard.edu/geos-chem/index.php/Particulate_matter_in_GEOS-

Chem). This involves summing the mass concentrations of sulfate, nitrate, ammonium, $\mathrm{BC}, \mathrm{OA}$, accumulation mode sea salt, and mineral dust with effective radii $<2.5 \mu \mathrm{m}$. The dust contribution to $\mathrm{PM}_{2.5}$ includes all dust mass in the first four size bins (dry geometric radii up to and including $1.5 \mu \mathrm{m}$ ) and $38 \%$ of the mass in the fifth size bin (dry geometric radius of $2.5 \mu \mathrm{m})$. Hygroscopic growth factors are applied to sulfate, nitrate, and ammonium (each 1.33), sea salt (1.86), and hydrophilic OA (1.16) to determine the mass 
contribution of aerosol water. The gas-phase chemistry kinetics generally follows recommendations of the Journal of Physical Chemistry/International Union of Pure and Applied Chemistry (JPC/IUPAC) which are regularly updated. Heterogeneous chemistry in the model includes reactive uptake of $\mathrm{NO}_{2}, \mathrm{NO}_{3}, \mathrm{~N}_{2} \mathrm{O}_{5}$ and $\mathrm{HO}_{2}$ to aerosols. Sulfatenitrate-ammonium aerosol thermodynamics is determined with the thermodynamic module of ISORROPIA (Nenes et al., 1998). Formation of secondary organic aerosol (SOA) is determined with the simple, irreversible direct yield scheme of Kim et al., (2015). GEOS-Chem also couples tropospheric chemistry to detailed stratospheric chemistry through the unified tropospheric-stratospheric chemistry extension (UCX) described in Eastham et al., (2014).

GEOS-Chem is coupled to the rapid radiative transfer module (RRTMG) to calculate the radiative forcing from changes in atmospheric composition (Heald et al., 2013). RRTMG is a swift radiative transfer code that calculates shortwave and longwave fluxes of the atmosphere using the correlated-k method (Lacis et al., 1991). The correlated kdistribution method is widely employed in radiative transfer schemes of atmospheric chemistry transport models and general circulation models. In the method, the spectra are divided into a number of bands and in so doing the computational efficiency of the radiative transfer code is increased relative to a model that is at high spectral resolution. The rates of heating and fluxes are calculated for each of these bands. (Hogan, 2010). 


\subsection{Concluding Remarks and Research Gaps}

Past research on understanding the adverse effects of charcoal on the environment have focused largely on the impact on forests/vegetation (Chidumayo et al., 2013) and longlived greenhouse gases (Bailis et al., 2004; Sjølie, 2012), with relatively few studies examining and quantifying the impact of air pollutant emissions on air quality and nearterm climate. The regional emission inventories that are available for Africa have used relatively crude mapping approaches. These have typically involved using population distribution data and so misrepresent the location of the actual emissions (Liousse et al., 2014; Marais et al., 2016). These inventories also used a constant emission rate throughout the year, rather than considering the seasonal and diurnal variability of these pollution sources. Better representation of the spatial and temporal variability of these pollution sources would provide more reliable assessment of their effects to also develop robust policies. Also absent in current inventories that include charcoal emissions are emissions attributable to truck transport from this specific sector and also prevalence of plastic burning to initiate combustion.

\subsection{Aims and Objectives of this Work}

The aim of this research is to investigate the impact of the charcoal industry in Africa on primarily air quality and climate, but also forest degradation and loss. This is achieved through the following objectives: 
1. Quantify and determine the drivers of the long-term trend (2000-2014) in charcoal production and use in Africa to predict charcoal production, use and forest loss in the future (2030)

2. Determine current (2014) and future (2030) emissions from the charcoal supply chain in Africa by developing a spatially resolved inventory of emissions from charcoal production, use and transport for 2014 and 2030

3. Assess the current (2014) and future (2030) impact of the charcoal industry in Africa on air quality and climate by embedding the inventory developed in this work in the GEOS-Chem chemical transport model coupled to a radiative transfer model 


\subsection{Overview}

This chapter covers the methodology of this research. The steps involved in the achievement of each objective of my research are explained. The chapter consists of four parts: methods to assess current and future charcoal production and use trends in Africa, methods for inventory development to estimate current and future emissions from the charcoal supply chain in Africa, methods to map charcoal activity locations, and methods to integrate the inventory into simulations of the GEOS-Chem model.

\subsection{Trend Analysis in Charcoal Production and Use in $\mathbf{2 0 1 4}$}

To understand charcoal production and use trend in Africa and its sub-regions from 20002014, Mann-Kendall with Theil-Sen's Slope analysis was conducted from which the change over the 14-year period was calculated. Mann-Kendall with Theil-Sen's Slope analysis is a non-parametric test used to study trends on time series data in diverse fields of study such as energy (Zhou et al., 2018), hydrology (Onyutha et al., 2016), air pollution (Emami et al., 2018), transportation (Garbarova et al., 2015) and health (Gwatkin, 2017). Non-parametric tests (test conducted when data does not follow normal distribution) are more often used to spot trends than parametric ones due to their stability for data with specific distribution of properties like skewed distribution or presence of outliers (Onyutha et al., 2016). In Mann-Kendall analysis, data are evaluated as an ordered time series. Each data value is compared to all subsequent data values. An assumed value, 0 , 
meaning no trend, is assigned to the initial value of the Mann-Kendall statistic, S. If the value of subsequent data is lower than a value from an earlier period, $\mathrm{S}$ is decreased by 1. Likewise, if a data value at a later time period is higher than from an earlier period, $S$ is incremented by 1 . The net total of all reductions and increments yields the final value of S (USACE, 2005). The Theil-Sen's Slope estimator is obtained by calculating the slope of all pairs of ordered (ordinal) time points and then finding the median of all slopes previously calculated (Glen, 2020). Mann-Kendall gives the significance of trends, while Theil-Sen's Slope gives the magnitude of trends.

The following formula was used to calculate the percent change in charcoal production from 2000 to 2014:

$$
\text { Percent change }=(\text { Theil-Sen's Slope } * \text { Period } / \text { Mean }) * 100 \ldots \ldots \ldots \ldots
$$

Charcoal production (Table A3.1) and use (Table A3.2) statistics for each country in Africa were obtained from the United Nations energy statistics database (UN, 2017b). The charcoal data used for this work is the 2017 United Nations Energy Statistics Database (UNSD) data. The database is curated by the UN Statistics Division using statistics collected with annual questionnaires of contemporary and revised historical data from individual countries (UN, 2019). The 2017 UNSD data used for this work was downloaded on 15 August 2017 and the most recent complete year was 2014. There is about a three-year time lag between the date of the most recently reported data (2014) and the publication date (2017). Similarly, the DICE-Africa data for 2013 was accessed from the same UN Energy database in 2015 (Marais et al., 2016). Figure 3.1 is an example plot 
for Kenya, Ghana and Somalia, showing difference in the 2017 UNSD data and 2020 UNSD data for charcoal production presented on $\log 10$ scale. We can see from Figure 3.1 that whilst the 2020 UNSD charcoal production data looks linear, there is a jump in the UNSD 2017 data which could introduce more uncertainty in trend analysis and extrapolation. We address this by identifying and removing spurious data from the 2017 UNSD data.
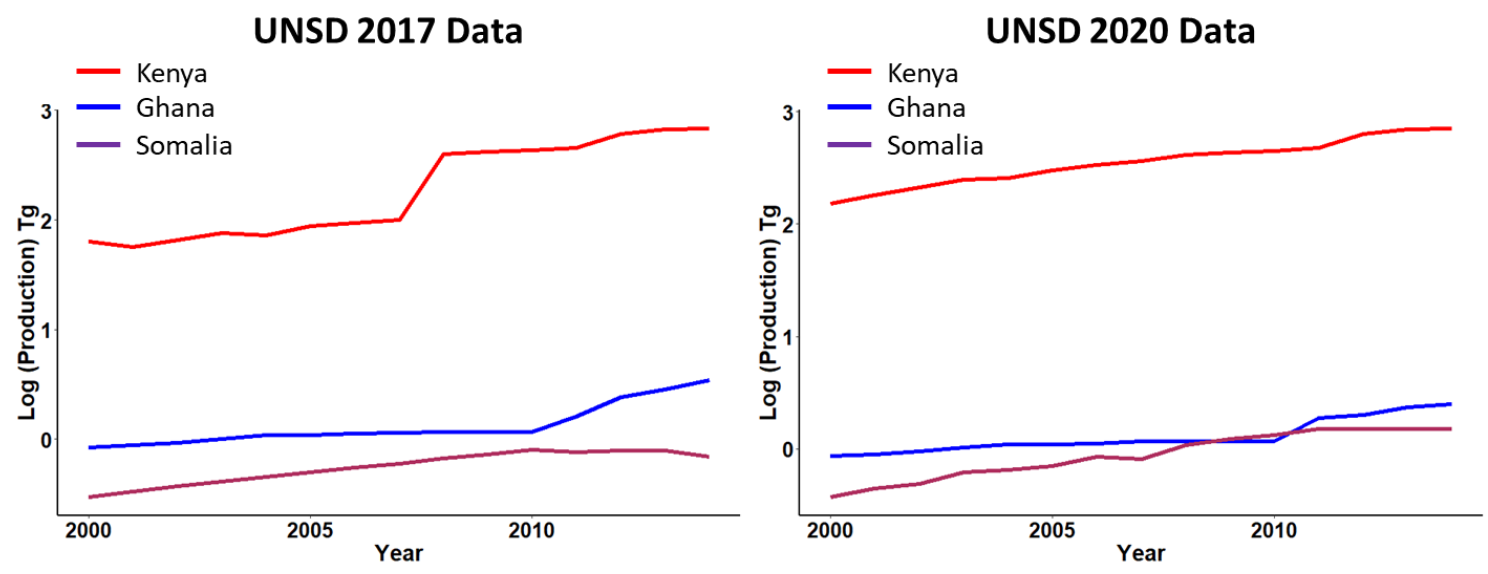

Figure 3.1 Historically revised UN energy statistics data for charcoal production in Kenya, Ghana and Somalia. Left panel (a), shows 2017 UNSD charcoal production data whilst the right panel (b), shows the 2020 UNSD charcoal production data. Panels (a) and (b) are on $\log 10$ scale for charcoal production.

Table 3.1 shows the results obtained from the regional trend analysis conducted for this work using Mann-Kendall with Theil-Sen's slope method. It shows the significance of the trend indicated by the p-value and the slope in charcoal production and use in the subregions of Africa. 
Table 3.1 Trend analysis using Mann-Kendall with Theil-Sen's slope method. Table shows slope and p-values for 14-year (2000-2014) trend analysis on charcoal production and use $\left(\mathrm{Tg} \mathrm{a}^{-1}\right)$ in Africa and its subregions.

\begin{tabular}{|c|c|c|c|c|c|c|c|c|}
\hline \multicolumn{5}{|c|}{ Production } & \multicolumn{4}{|c|}{ Use } \\
\hline \multicolumn{5}{|c|}{ Theil-Sen's Slope } & \multicolumn{4}{|c|}{ Theil-Sen's Slope } \\
\hline Region & Median & Lower Bound & Upper Bound & p-value & Median & Lower Bound & Upper Bound & p-value \\
\hline East Africa & 0.90 & 0.43 & 1.14 & $<0.001$ & 0.91 & 0.41 & 1.10 & $<0.001$ \\
\hline West Africa & 0.37 & 0.34 & 0.41 & $<0.001$ & 0.37 & 0.33 & 0.41 & $<0.001$ \\
\hline Southern Africa & 0.21 & 0.18 & 0.23 & $<0.001$ & 0.22 & 0.19 & 0.23 & $<0.001$ \\
\hline Central Africa & 0.10 & 0.04 & 0.22 & 0.05 & 0.10 & 0.04 & 0.22 & 0.05 \\
\hline North Africa & 0.03 & 0.03 & 0.03 & $<0.001$ & 0.02 & 0.02 & 0.02 & $<0.001$ \\
\hline Africa & 1.68 & 1.21 & 2.09 & $<0.001$ & 1.67 & 1.17 & 2.09 & $<0.001$ \\
\hline
\end{tabular}




\subsection{Estimating Forest Degradation from Charcoal Production}

Forest Degradation $\left(\mathrm{F}_{\mathrm{d}}\right)$ from charcoal production for each country is estimated as a product of wood burned (in tonnes) to produce charcoal in 2014 and the above-ground biomass (AGB) density (tonnes of wood per hectare of forest) given by:

$\mathrm{F}_{\mathrm{d}}=\frac{\text { Wood burned }}{\mathrm{AGB}}$

The amount of wood burned was estimated as the ratio of charcoal produced to kiln efficiency (wood-charcoal-conversation rate). For this research, a kiln efficiency range of 9-30\% was used, as this is representative of the range reported for earth-mound kilns (Yevich et al., 2003). The mean AGB for each country was retrieved from a global biomass grid produced by Hengeveld et al. (2015) at a horizontal resolution of $1^{\circ} \mathrm{x} 1^{\circ}$ with values ranging from 0 to 265 tonne $\mathrm{ha}^{-1}$. The gridded data was produced from a compilation of forest area and growing stock from the FAO international assessment, Forest Europe and the United Nations Economic Commission for Europe (UNECE). An estimate is also obtained for 2030 using projected charcoal produced in 2030 and assuming the AGB density remains the same in 2014 and 2030. That is, no account is taken of the ' $\mathrm{CO}_{2}$ fertilisation effect' of increasing atmospheric $\mathrm{CO}_{2}$ concentrations giving rise to increased biomass (Zhu et al., 2016), or to loss of forest due to land-use change (Houghton et al., 2017). The amount of wood burned for each country and the area of forest loss in 2014 and 2030 can be found in Table A3.4. 


\subsection{Estimating Emissions from the Charcoal Industry in Africa}

Annual emissions of trace gases $\left(\mathrm{CO}, \mathrm{NO}, \mathrm{SO}_{2}, \mathrm{NMVOCs}\right.$ and $\left.\mathrm{HCl}\right)$ and primary particles (BC and $\mathrm{OA}$ ) from charcoal production, use (including plastic burning), and transport are estimated for 2014 in Africa using a standard approach (IPCC, 2006):

$\mathrm{E}_{i}=\mathrm{A}_{j} \times \mathrm{EF}_{i, j}$

$\mathrm{E}_{i}$ is the emission of pollutant $i$ in grams; $\mathrm{A}_{j}$ is the country-level amount of fuel, $j$, burned (in $\mathrm{kg} \mathrm{a}^{-1}$ ); and $\mathrm{EF}_{i, j}$ is the emission factor of pollutant $i$ in g pollutant per $\mathrm{kg}$ fuel $j$ burned. The amount of charcoal produced and used in 2014 is from the UN energy statistics database (UN, 2017b).

Most plastic use is in slums on the periphery of cities (Gathui et al., 2010). There is no activity data on the amount of plastic burned for charcoal use, so a value for each country was estimated as the product of the relative proportion of the urban population living in slums ranging from none in Algeria to $>90 \%$ in South Sudan in 2014 (World Bank, 2016), the quantity of charcoal consumed, and my own speculative guess of the amount of plastic used per $\mathrm{kg}$ charcoal consumed $\left(4 \mathrm{~g} \mathrm{~kg}^{-1}\right)$. The $4 \mathrm{~g} \mathrm{~kg}^{-1}$ was determined as the minimum of the ratio of the average mass of a plastic shopping bag (8g) (Cadman et al., 2005) to daily charcoal usage for a 4-person household (2.0-2.6 kg) (Jagger et al., 2018). In this work, it is assumed that a slum household typically cooks one large meal a day and therefore would use the equivalent mass of one shopping plastic bag per meal 
The diesel use by trucks to transport charcoal to urban centres was determined as the product of the number of trucks required to transport the charcoal, the distance these travel (detailed below), and diesel fuel efficiency $\left(0.25 \mathrm{~kg} \mathrm{~km}^{-1}\right)$ representative of inefficient and unregulated vehicles (Huo et al., 2012). The number of trucks in each country is estimated assuming each truck is heavy duty and transports the recommended maximum payload of 16 tonnes of charcoal. The average distance travelled by the majority of trucks to urban centres is estimated relative to the urban population using scaling factors guided by findings in Philip and Munslow (1984) for Maputo in Mozambique. A fixed travelling distance was used from the city centre of $2 \mathrm{~km}$ for small cities ( $\leq 1000$ people), a scale factor of $0.025 \mathrm{~km}$ per 1000 people to determine the distance travelled to medium-sized cities $(1000<$ inhabitants $\leq 2$ million), and a fixed distance from the city centre of $50 \mathrm{~km}$ for large cities (> 2 million people). The urban population was obtained by sampling population density from the Gridded Population of the World (GPW) version 4.10 dataset (CIESIN, 2017) within the urban extent of the city. The city extent was identified as OpenStreetMap residential road networks, a category in the data (GeoFABRIK, 2017), with road density $\geq 0.4$ miles ha ${ }^{-1}$. Table 3.2 shows activity data for charcoal production, transport and use in 2014. Charcoal use is distributed to sums and central busines district. This was done as an approach to including plastic emission in the charcoal inventory. We recognise this is a very crude approach based on extrapolation from a single study, but it gives some indication of the likely magnitude of plastic emissions from charcoal use. This crude approach has however enabled us to account for plastic emission from charcoal use in Africa for the first time. 
Table 3.2 Activity data for charcoal production, use and transport in Africa in 2014.

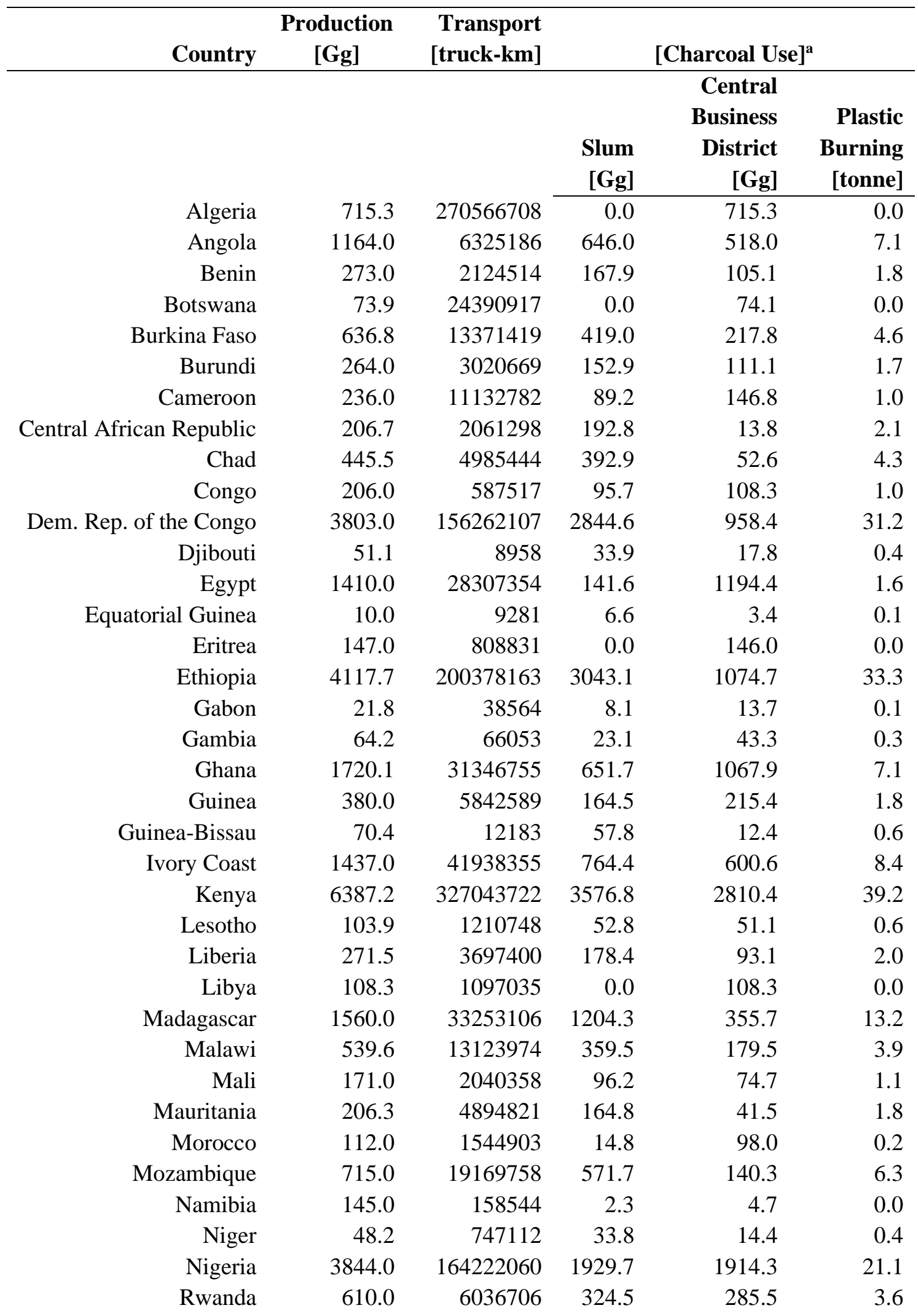




\begin{tabular}{rrrrrr} 
Sao Tome and Principe & 9.2 & 20121 & 8.0 & 1.2 & 0.1 \\
Senegal & 497.0 & 8608232 & 195.8 & 301.2 & 2.1 \\
Sierra Leone & 421.0 & 2333195 & 318.3 & 102.7 & 3.5 \\
Somalia & 1136.1 & 7871948 & 625.7 & 224.4 & 6.9 \\
South Africa & 714.6 & 187819027 & 178.5 & 597.5 & 2.0 \\
South Sudan & 11.0 & 133091 & 10.5 & 0.5 & 0.1 \\
Sudan & 1596.0 & 85727315 & 1461.9 & 134.1 & 16.0 \\
Swaziland & 47.4 & 462756 & 0.0 & 44.2 & 0.0 \\
Tanzania & 1937.0 & 192381208 & 982.1 & 954.9 & 10.8 \\
Togo & 670.0 & 9636212 & 343.0 & 327.0 & 3.8 \\
Tunisia & 208.0 & 2294477 & 16.7 & 191.7 & 0.2 \\
Uganda & 1037.4 & 45734849 & 555.1 & 480.6 & 6.1 \\
Zambia & 1083.0 & 33711259 & 584.8 & 498.2 & 6.4 \\
Zimbabwe & 9.0 & 265764 & 2.3 & 6.7 & 0.0 \\
\hline
\end{tabular}

${ }^{a}$ Charcoal use distributed to slums and the city centre though gridding. Plastic burning is limited to slums. Activity for transport is derived from activity data for charcoal use, urban population, and weight of charcoal bag (see text for details).

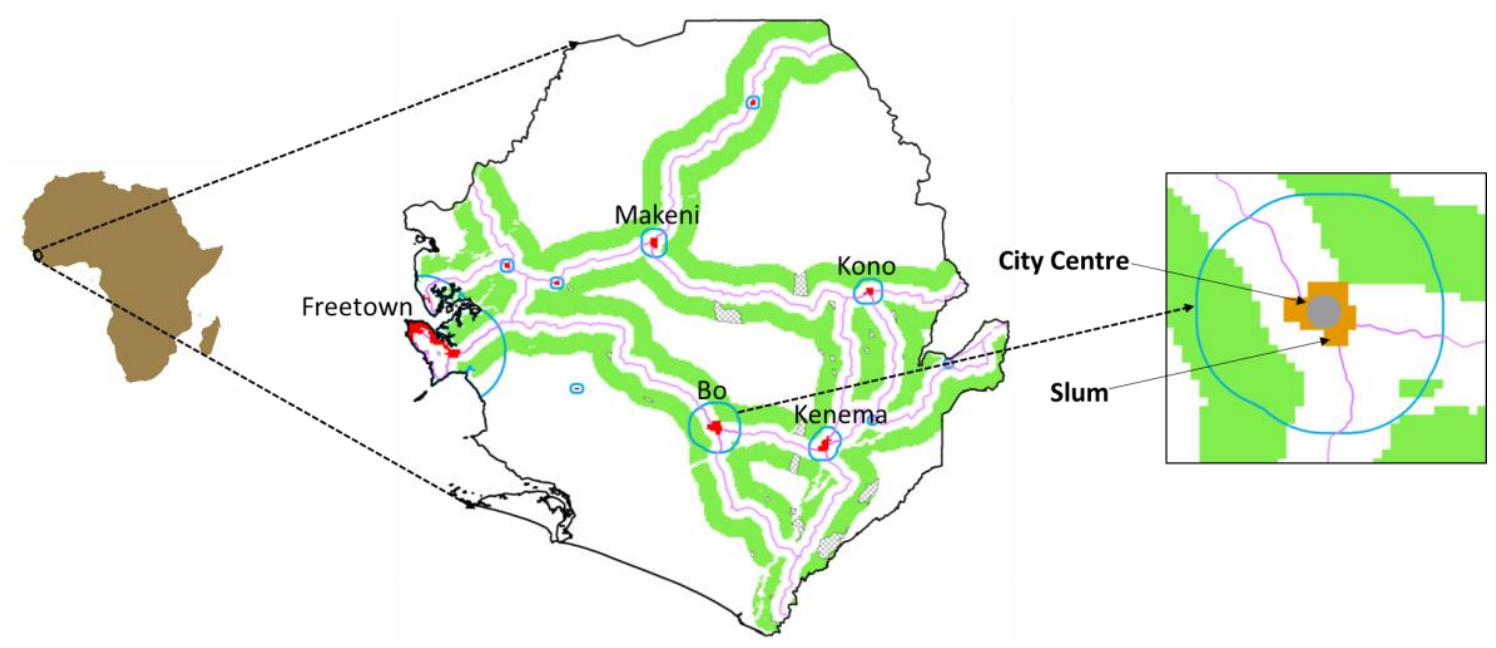

Figure 3.2 Geospatial mapping of charcoal supply chain activities for Sierra Leone. Centre map shows charcoal production zones (green), charcoal use (red), and the extent of routes with the greatest density of trucks (blue). Hatchings are protected areas (see text 
for details) that are excluded from charcoal production. The Map on the right shows the distinction between the city centre (grey) and slums (brown).

Figure 3.2 illustrates the approach taken to map charcoal supply chain activities for Sierra Leone in West Africa. In 2014 in Sierra Leone charcoal production and use were equal, each $0.42 \mathrm{Tg}$. OpenStreetMap primary roads (GeoFABRIK, 2017), the UN Food and Agriculture Organization (FAO) land cover type (FAO, 2015), and protected area data (UNEP-WCMC, 2016) were used to identify viable production zones in each country in Africa. These are typically concentrated 5-15 km from roadways, out of sight but with easy access to transport routes (Malimbwi et al., 2009). This approach is to avoid detection by authorities (UN, 2010), in particular in countries where charcoal production is banned. Viable production zones are those coincident with FAO vegetation types that would be harvested to produce charcoal (forest, woodland, shrubland or savannah vegetation) (green zones in Figure 3.2), and not designated as protected areas (hatchings in Figure 3.2). Plastic burning is mapped to urban populations living at distance $\geq 2 \mathrm{~km}$ from the centre of the city, based on the spatial extent of slums from the central business district (CBD) of Nairobi, Kenya (Bird et al., 2017). This likely overestimates the spatial extent of slums, as Kibera is one of the largest slum in Africa (Bird et al., 2017). We subdivide cities into slums and central business districts to spatially allocate plastic emissions of $\mathrm{HCl}$, as the use of plastic is concentrated in low-cost and informal settlements. This then accounts for the distribution of informal settlements within cities, as is the case for many cities in Africa (World Bank, 2016; Visagie et al., 2020). This spatial allocation is limited to plastic emissions of $\mathrm{HCl}$ only, which are relatively minor in comparison to the other activities. 
Table 3.3 summarizes the EFs that were applied to the gridded data. Values are from Akagi et al. (2011) for charcoal production and use. Transport EFs are from measurements of trucks under driving conditions in Mexico City (Zavala et al., 2017), which was assumed to be more consistent with conditions in Africa than emission factors compiled by European Monitoring and Evaluation Programme (EMEP) (EEA, 2019) or the United States Environmental Protection Agency (USEPA) (USEPA, 2009) The most significant pollutant from plastic burning is $\mathrm{HCl}$, which forms from combustion of chlorinated plastics. These plastics, while regulated in Europe and the US, are not in African countries (Alam et al. 2018). Values for $\mathrm{HCl}$ are from plastic burning measurements made during the NAMaSTE campaign in Nepal (Jayarathne et al., 2018). The conditions under which the emissions factors in Table 3.3 are obtained can be highly variable, as indicated by the ranges in measurements reported in Table 3.3: up to $100 \%$ of the mean value for $\mathrm{BC}, \mathrm{OA}$, and $\mathrm{NO}$ for charcoal production. Recent measurement campaigns in West Africa included measurements of emissions of $\mathrm{BC}$ and $\mathrm{OC}$ from charcoal use (Keita et al., 2019; Pfotenhauer et al. (2019)), production (Keita et al., 2019), and heavy-duty diesel vehicles (HHDVs) (Keita et al., 2019). Pfotenhauer et al. (2019) also measured CO EFs from charcoal use. Values in Table 3.3 fall within or close to the range of EFs measured in those studies for charcoal use (BC: $<0.15-0.95 \mathrm{~g} \mathrm{~kg}^{-1}$; OC: 0.48 $6.4 \mathrm{~g} \mathrm{~kg}^{-1}$; CO: 113-276 $\left.\mathrm{g} \mathrm{kg}^{-1}\right)$, and OC from HHDVs (1.15-3.93 $\left.\mathrm{g} \mathrm{kg}^{-1}\right)$. Whereas, values used here are at least 3-times lower than $\mathrm{OC}$ and $\mathrm{BC}$ EFs for charcoal production (OC: 2.92-4.94 $\mathrm{g} \mathrm{kg}^{-1}$; BC: 0.06-0.38 $\left.\mathrm{g} \mathrm{kg}^{-1}\right)$ and BC EFs from HHDVs (1.15-3.25 $\left.\mathrm{g} \mathrm{kg}^{-1}\right)$.

The spatially allocated activity factors in Figure 3.2 were regridded to a uniform latitudelongitude grid at $0.1^{\circ} \mathrm{x} 0.1^{\circ}$ and the emission factors detailed in Table 3.3 were applied to these to obtain mapped emissions of pollutants to use in GEOS-Chem. 


\subsection{Gridding of emissions}

The emission locations for charcoal production, use and transport were respectively intersected with a $0.1^{\circ} \times 0.1^{\circ}$ grid created over Africa and then the area (for charcoal production and use) or length (for charcoal transport) of feature that falls within each grid calculated. The national amount of fuel burned is then allocated to the individual grids according to the area or length in the corresponding grid pixel of each country as described by Veldeman et al., (2016). The amount of fuel burned in the p pixel $\left(\mathrm{F}_{\mathrm{p}}\right)$ was calculated using the following equation:

$F_{p}=\sum_{k=1}^{k=N} \frac{T_{p, k}}{T_{k}} \cdot F_{k}$

Where $T_{p}$ is area in the pixel $p, T_{k}$ is the total area of country $k$, and $F_{k}$ is the total fuel burned in country k. N indicates the number of countries. Finally, emission factors were applied to produce $0.1^{\circ} \times 0.1^{\circ}$ spatial resolution of all aerosols and trace gases. The gridded emissions were then used as input to GEOS-Chem. 
Table 3.3 Emission factors during charcoal production, use and transport

\begin{tabular}{|c|c|c|c|c|c|c|c|c|c|}
\hline \multirow[t]{2}{*}{ Activity } & \multirow[t]{2}{*}{ Reference } & \multicolumn{8}{|c|}{ Emission Factor $\left[\mathrm{g} \mathrm{kg}^{-1}\right]^{\mathrm{a}}$} \\
\hline & & BC & OC & $\mathrm{CO}$ & NO & $\mathrm{SO}_{2}$ & $\mathrm{CH}_{4}$ & NMVOC & $\mathrm{HCl}$ \\
\hline \multirow[t]{2}{*}{ Production $^{\mathrm{b}}$} & Used here & $0.02(0.02)$ & $0.74(0.72)$ & $255(52)$ & $0.22(0.22)$ & - & $39.69(11.4)$ & $161(115)$ & - \\
\hline & Keita et al. (2018) & - & $3.93(1.01)$ & & & & & & \\
\hline \multirow[t]{3}{*}{$\mathrm{Use}^{\mathrm{b}}$} & Used here & 1 & 1.3 & $189(36)$ & $1.41(150)$ & - & $5.29(2.42)$ & 5.56 & - \\
\hline & Pfotenhauer et al. (2019) & - & 6.4 & 276 & - & - & - & - & - \\
\hline & Keita et al. (2018) & - & $1.78(2.80)$ & & & & & & \\
\hline \multirow[t]{2}{*}{ Transport } & Used here & $0.14(0.1)^{\mathrm{c}}$ & $2.07(0.2)^{\mathrm{c}}$ & $23.1(3)^{\mathrm{c}}$ & $28.9(4)^{\mathrm{c}}$ & $0.35(0.1)^{\mathrm{c}}$ & $0.40^{\mathrm{d}}$ & $2.80^{\mathrm{d}}$ & - \\
\hline & Keita et al. (2018) & - & $2.50(1.43)$ & & & & & & \\
\hline $\begin{array}{l}\text { Plastic } \\
\text { burning }\end{array}$ & Used here & - & - & & 2.36 & - & 2.04 & - & 77.9 \\
\hline
\end{tabular}




\subsection{Estimating future (2030) charcoal production and emissions from the charcoal supply chain}

Prior to estimating future charcoal production, an assessment was done to check the forest availability for charcoal production beyond 2014. For this work, the forest availability for future charcoal production was estimated as the difference between total above ground biomass (AGB) (in tonnes $\mathrm{a}^{-1}$ ) and the biomass wood used to produce charcoal (in tonnes $\left.\mathrm{a}^{-1}\right)$. The total AGB gridded at horizontal resolution of $1^{\circ} \times 1^{\circ}$, was obtained from Hengeveld et al., (2015). Wood burned to produce charcoal was obtained by applying kiln efficiency to the gridded country level charcoal production which was created in section 3.4.3 (to grid emissions). The wood burned (at $0.1^{\circ} \times 0.1^{\circ}$ ) was given the same resolution as the AGB after which the forest availability was determined. For this work, a kiln efficiency of $30 \%$ was used.

The charcoal production and use data employed in this work to predict future charcoal production (and use) for each country were examined. Suspicious data which led to a step change in charcoal production (and use) were identified and excluded. The suspicious data identified were the 2000-2007 data for Kenya (step change factor 325), the 20002006 data for Central African Republic (factor 8), and the 2000-2003 data for Eritrea, although, this is smaller step change (factor $\sim 1.3$ ). So, for this work, future charcoal production was estimated based on 2000-2014 data for other countries and the 2008-2014 data for Kenya, 2007-2014 data for Central African Republic and the 2004-2014 data for Eritrea, respectively. 
The likely emissions from the charcoal industry in Africa in 2030 was determined by regressing charcoal production for each country against urban population (Table A3.3), as, consistency was found with Arnold et al. (2006), that urban population explains more than $70 \%$ of the trend in charcoal production $\left(\mathrm{R}^{2}>0.7\right)$ for countries that account for $84 \%$ of charcoal production in 2014. A relationship between urban population and charcoal production was obtained that varies from $-1.3 \mathrm{~kg}$ charcoal (urban person) ${ }^{-1} \mathrm{a}^{-1}$ for Zimbabwe to $449 \mathrm{~kg}$ charcoal (urban person) ${ }^{-1} \mathrm{a}^{-1}$ for Swaziland. These were applied to total predicted 2030 urban population in each country from the UN (UN, 2015) to estimate the increase in charcoal activity and emissions from 2014 to 2030 . The negative charcoal production reported for Zimbabwe could be due to increasing charcoal imports cropped from the banning of charcoal production in the country due to excessive forest loss (Ngezi, 2019). Figure A3.2 shows the relative error (uncertainty) associated with the regression used to predict future charcoal production for each country. We can see from Figure A3.2 that the uncertainty varies from 0.006 for Chad to 1.4 for Zimbabwe. Figure 3.3 shows regression plots of charcoal production versus urban population for two countries (Sierra Leone and Nigeria) with consistent charcoal production and use from 2000-2014. The plot is extrapolated to 2030 using World Bank urban population for 2030. We can see from Figure 3.3 that there is a significant relationship between charcoal production and urban population for both Sierra Leone and Nigeria. There is however larger uncertainty in extrapolation for Nigeria (38.6\%) than Sierra Leone (3.2\%). 
Sierra Leone

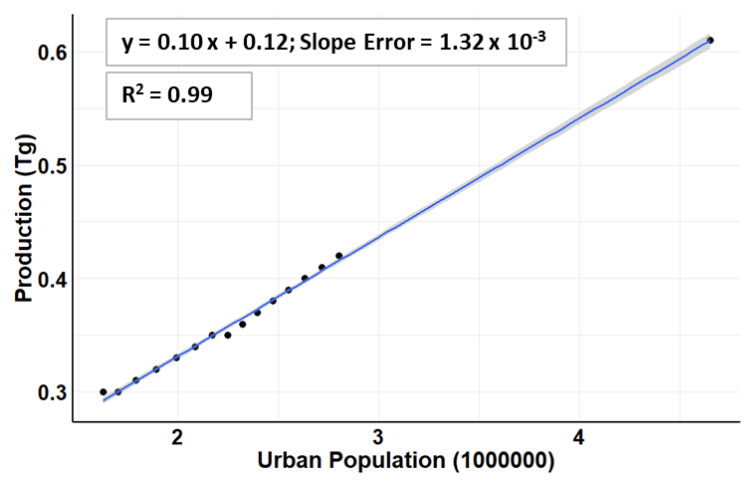

Nigeria

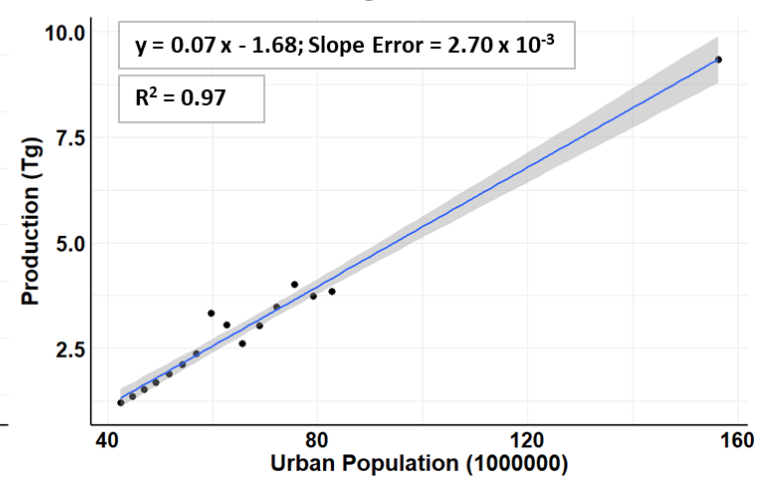

Figure 3.3 Regression plots for charcoal production $\left(\mathrm{Tg} \mathrm{a}^{-1}\right)$ and urban population for Sierra Leone (left) and Nigeria (right). Plot is extrapolated to 2030. The shaded grey area is the region of uncertainty in the extrapolation at $95 \%$ confidence interval.

\subsection{Assessing Air Quality and Climate Impact of The Charcoal Industry in Africa}

In this study, a 3D global chemical transport model was used to assess air quality and climate from the charcoal industry in Africa. Remote sensing, whether from satellite, aerial or ground-based makes it possible to investigate a wide domain of parameters associated with the chemistry of the atmosphere, like total ozone column or trace gas concentrations. However, observations are always limited by the visibility window of the instrument used. In bid to portray a 3D chemistry of the atmosphere at a given location, so called 3D chemical transport models are used. Values in models not known are to a possible extent replaced with current measurements or estimates based on previous forecasts. This creates a realistic representation of the atmosphere to the best extent. The choice of model employed for a study usually depends on the area of interest (scale of 
study) for which an investigation needs to be done (e.g. city, national, regional, or global). Global models are generally coarser in resolution than city, or national levels, so they are much more appropriate for regional or global assessments. For this work, GOES-Chem software was employed since the scale of study was regional for air quality assessment and global for the climate forcing assessment.

GEOS-Chem version 12.0.0 (https://zenodo.org/record/1343547) coupled to the rapid radiative transfer model (RRTMG) (Heald et al., 2014) was used to determine the contribution of the charcoal supply chain in Africa to local concentrations of tropospheric ozone and $\mathrm{PM}_{2.5}$ and the global direct radiative effect of ozone and aerosols. RRTMG is radiative transfer code that calculate both shortwave and longwave fluxes (Lacis et al., 1991). Within GEOS-Chem, RRTMG calculates instantaneous total flux and the difference in flux associated with specific species (ozone, methane, sulphate, nitrate, ammonium, BC, OA, sea salt or dust) every 3 hour. The atmospheric chemistry and radiative effects are calculated as the difference in model results with and without our inventory. GEOS-Chem is driven with the NASA Global Modelling and Assimilation Office (GMAO) MERRA-2 reanalysis meteorology that is gridded from its native horizontal resolution $\left(0.5^{\circ} \times 0.625^{\circ}\right.$; latitude $\times$ longitude $)(\sim 50-60 \mathrm{~km})$ to the global $2^{\circ} \times$ $2.5^{\circ}$ grid $(\sim 200-250 \mathrm{~km})$.

Total NMVOCs emissions (Table 3.3) were partitioned into individual chemical components based on source profiles from Akagi et al. (2011) for charcoal and production and use and from (Zavala et al., 2017) for trucks. In this research, individual NMVOC species partitioned for charcoal production and use are: ethylene, ethane, methanol, 
formaldehyde, acetic acid, and formic acid. Individual NMVOC species partitioned for charcoal transport are: acetaldehyde, benzene and toluene.

Representative temporal scaling factors were also calculated to represent seasonal variability in charcoal production and transport and diurnal variability in charcoal use in GEOS-Chem. Kambewa et al. (2007) report from field observations that most charcoal is produced in the rainy season. Other fuel sources are unreliable, so charcoal producers capitalise on higher charcoal prices in this season. In this work, the majority (60\%) of charcoal production is assumed during the wet season whilst $40 \%$ is assumed during the dry season. The 60:40 split is an approach to represent seasonal variability in charcoal production and transport in GEOS-Chem model simulation used for this work. The $60 \%$ assumed for the rains is conservative, based on observation by Chiteculo et al. (2018b) which suggests higher production during the rains. Table 3.4 shows the period of rainy season and dry season in each regions in Africa subdivided by broadly distinct wet and dry seasons (Buckle, 1996; Zijlma, 2019). It is however good to note that the wet and dry seasonal periods are not fixed, they can vary over time (Nicholson et al., 2018). The rainy season in Central Africa persists throughout the year. Table 3.5 shows the seasonal scaling factors for each month that applied regionally to charcoal production emissions and Figure 3.4 visualizes these for January and July. The scaling factors in Table 3.5 were obtained as a ratio of the percent of charcoal produced per annum and the number of months of rain or dry. The diurnal scaling applied assumes that all charcoal use, primarily for cooking, is evenly distributed from $06 \mathrm{~h} 00$ to $20 \mathrm{~h} 00$ local time. The 14 -hour cooking duration is capture variations in cooking time among households. 
Table 3.4 Regional timing of the wet and dry seasons in Africa.

\begin{tabular}{lll}
\hline Region & \multicolumn{2}{c}{ Season ${ }^{\text {a }}$} \\
\hline West Africa & Novem season & Wet season \\
\cline { 2 - 3 } East Africa & July - September & May - October \\
Central Africa & Not Applicable & January - December \\
North Africa & April - October & November - March \\
Southern Africa & April - October & November - March \\
\hline a Includes months when the region transitions from the wet to the dry season for the
\end{tabular}

Table 3.5 Regional seasonal scaling factors applied to charcoal production emissions

\begin{tabular}{rrrrrr}
\hline Month & \multicolumn{4}{c}{ Scale factor by region a $^{\text {a }}$} \\
\hline & $\begin{array}{r}\text { West } \\
\text { Africa }\end{array}$ & $\begin{array}{r}\text { East } \\
\text { Africa }\end{array}$ & $\begin{array}{r}\text { Southern } \\
\text { Africa }\end{array}$ & $\begin{array}{r}\text { North } \\
\text { Africa }\end{array}$ & $\begin{array}{r}\text { Central } \\
\text { Africa }\end{array}$ \\
\hline January & 0.8 & 0.8 & 1.4 & 1.4 & 1 \\
February & 0.8 & 0.8 & 1.4 & 1.4 & 1 \\
March & 0.8 & 0.8 & 1.4 & 1.4 & 1 \\
April & 0.8 & 0.8 & 0.7 & 0.7 & 1 \\
May & 1.2 & 0.8 & 0.7 & 0.7 & 1 \\
June & 1.2 & 0.8 & 0.7 & 0.7 & 1 \\
July & 1.2 & 1.6 & 0.7 & 0.7 & 1 \\
August & 1.2 & 1.6 & 0.7 & 0.7 & 1 \\
September & 1.2 & 1.6 & 0.7 & 0.7 & 1 \\
October & 1.2 & 0.8 & 0.7 & 0.7 & 1 \\
November & 0.8 & 0.8 & 1.4 & 1.4 & 1 \\
December & 0.8 & 0.8 & 1.4 & 1.4 & 1 \\
\hline
\end{tabular}

${ }^{a}$ Blue colour indicates rainy season, red colour indicates dry season 

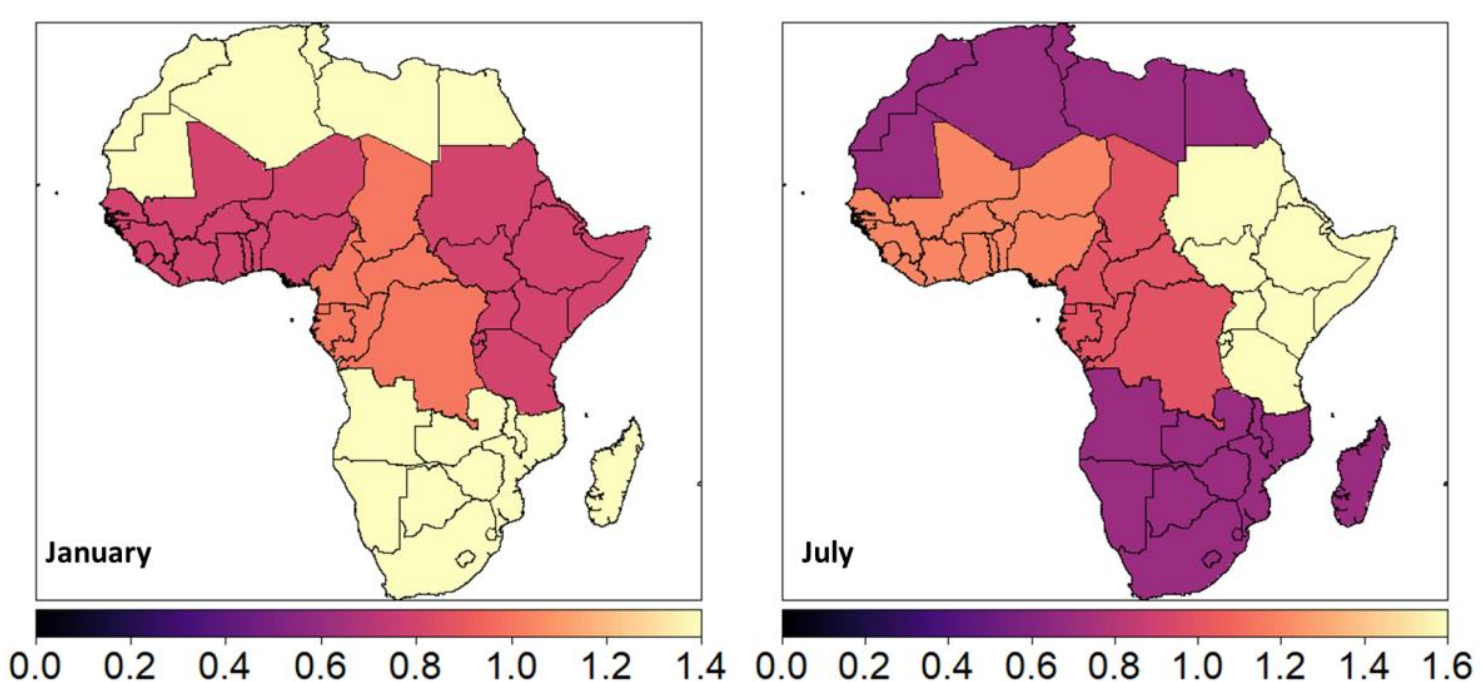

Figure 3.4 Seasonal scaling for charcoal production in Africa in January (left) and July (right).

The GEOS-Chem model has already been shown in previous work to reproduce annual mean $\mathrm{PM}_{2.5}$ across Africa by comparing modelled $\mathrm{PM}_{2.5}$ to that derived with satellite observations of aerosol optical depth (AOD) and measured in situ at limited surface network sites in South Africa (Marais et al., 2019). In all model simulations in this work, meteorology is for 2014 to isolate the effects of emissions only. The model was sampled in 2014 following two months of spin-up for chemical initialization. 


\subsection{Current and Future Population-Weighted $\mathbf{P M}_{2.5}$ from the Charcoal Supply Chain in Africa}

Population-weighted exposure to ambient $\mathrm{PM}_{2.5}$ pollution is the average exposure level of a nations population to concentration of suspended $\mathrm{PM}_{2.5}$ (World Bank, 2020). It is calculated by weighting mean annual concentration of $\mathrm{PM}_{2.5}$ by population in an area. Population-weighted annual average concentration are better estimates of population exposure. Reason being, they give proportionately more weights to the air pollution experienced where most people live.

The population-weighted $\mathrm{PM}_{2.5}$ exposure (PWE) from the charcoal supply chain is obtained for Africa using the following equation (Chen et al., 2018).

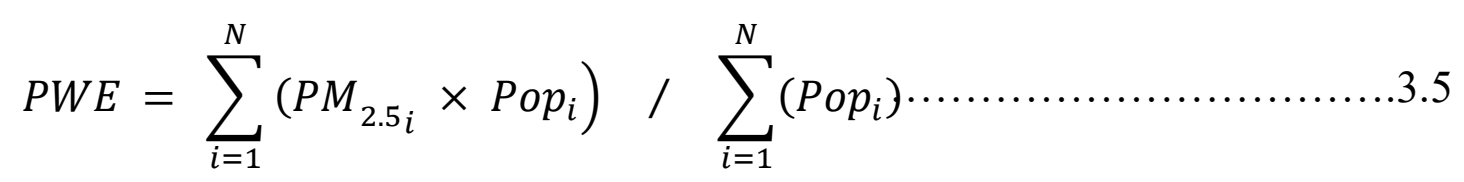

Where $P M_{2.5 i}$ is the $\mathrm{PM}_{2.5}$ enhancement from the charcoal supply chain within the $i$-th grid, $\mathrm{Pop}_{i}$ is the population in the $i$-th grid. $\mathrm{N}$ is the total number of grids within a country boundary.

The $\mathrm{PM}_{2.5}$ enhancement was obtained as the difference in GEOS-Chem model simulations with and without emissions from the charcoal supply chain. Estimates of $\mathrm{PM}_{2.5}$ were obtained for 2014 and 2030 using the model configuration described in Section 3.7 to obtain PWE for both years. The gridded population density data is from 
the CIESIN (2017) for 2014 and 2030 provided at a horizontal resolution of $1 \mathrm{~km} \mathrm{x} 1 \mathrm{~km}$ and was regridded to the GEOS-Chem grid. 


\section{CURRENT (2014) AND FUTURE (2030) CHARCOAL PRODUCTION AND USE IN AFRICA}

\subsection{Overview}

This chapter presents trends (current and future) in charcoal production and use in Africa and its subregions (East, West, Central, and Southern Africa). A 14-year regional trend (2000-2014) in charcoal production and use in Africa and its subregions is obtained to forecast future (2030) charcoal industry emissions. Forest degradation or loss from charcoal production is also estimated to understand how future production will affect the Africa forest cover by 2030.

\subsection{Past (200-2014) Trends in Charcoal Production and Use in Africa}

Table 4.1 shows 14-year (2000-2014) trend in charcoal production and use in Africa and its subregions as defined in Section 2.3. As can be seen in Table 4.1, the annual increase in charcoal production and use is highest in East Africa $\left(10.7 \% \mathrm{a}^{-1}\right)$ and West Africa, $\left(5.9 \% \mathrm{a}^{-1}\right)$. Almost all the charcoal produced is used locally as there is only $\sim 1 \%$ difference between charcoal production and use (Shively et al., 2010; UN, 2017b). 
Table 4.1 Charcoal production and use in Africa. 14-year (2000-2014) trend in charcoal production and use in Africa and its subregions.

\begin{tabular}{rcr}
\hline Region & Production & Use \\
& \multicolumn{2}{c}{ Annual Increase [\%] } \\
North Africa & $1.8(0.1)$ & $1.4(0.1)$ \\
\cline { 2 - 3 } East Africa & $10.7(4.2)$ & $10.7(4.2)$ \\
Central Africa & $4.4(4.7)$ & $4.4(4.7)$ \\
West Africa & $5.9(0.6)$ & $5.8(0.6)$ \\
Southern Africa & $5.7(0.7)$ & $5.9(0.7)$ \\
Africa & $7.7(2.1)$ & $7.7(2.1)$ \\
\hline${ }^{a}$ Average annual increase in charcoal production and use. Numbers in parenthesis are \\
standard deviations in trend. Data source: United Nations energy statistics database (UN, \\
2017b).
\end{tabular}

Higher productions in East and West Africa is due to their higher urban population densities relative to their neighbours. Countries with the highest rates of increase in charcoal production are Nigeria $\left(9.5 \% \mathrm{a}^{-1}\right)$ and Cameroon $\left(7.4 \% \mathrm{a}^{-1}\right)$. The few countries with low charcoal production in Africa either have electricity access for $>90 \%$ of the population (in the case of Gabon) or are countries that may not report reliable data (Zimbabwe, South Sudan). 


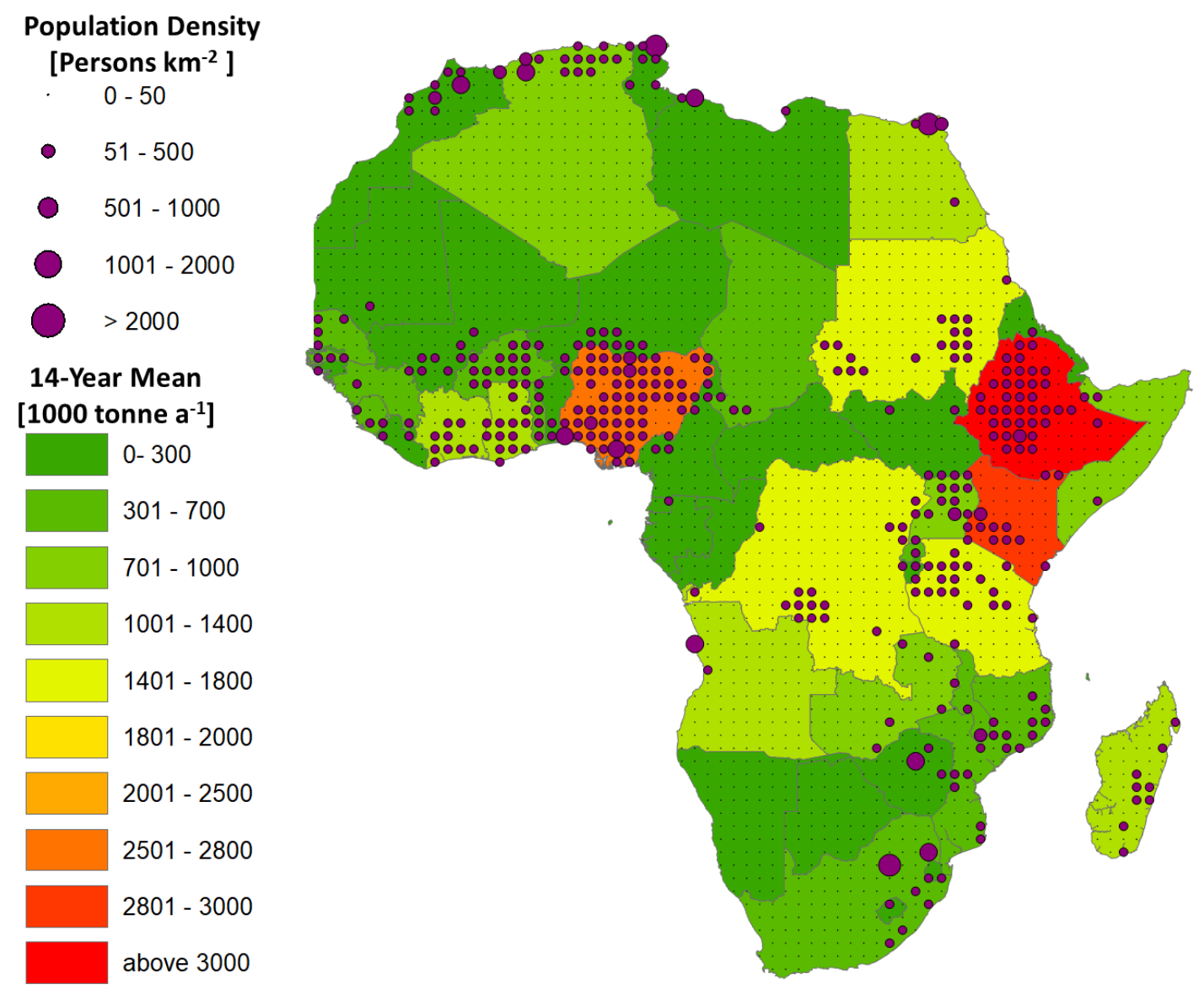

Figure 4.1 Charcoal production in Africa. Countries are coloured by 14-year mean charcoal production values for 2000 to 2014 . The size of the maroon circles are population densities for large urban centres. Data for charcoal production and use are from the UN (UN, 2017b) and for population density are from CIESIN (CIESIN, 2017).

Figure 4.2 shows the significant increase $(\mathrm{p}<0.001)$ in charcoal production and use in Africa and its subregions from 2000 to 2014. There is a significant increase in charcoal production and use in Africa and its subregions. The average annual increment in charcoal production and use in Africa is $7.7 \pm 2.1 \%$. This is twice as fast as the annual increase in LPG use (Rockall, 2016) and almost twice the annual increase of commercial fuelwood 
use (Marais et al., 2016) in Africa. The regional average annual increment ranges from $1.8 \pm 0.1 \%$ in North Africa to $10.7 \pm 4.2 \%$ in East Africa. This slower rate of increase in North Africa is likely due to the high rate of LPG use there of $55 \mathrm{~kg}_{\text {person }}{ }^{-1} \mathrm{a}^{-1}$ compared to $23 \mathrm{~kg}_{\text {person }}{ }^{-1} \mathrm{a}^{-1}$ for Sub-Saharan Africa (Rockall, 2016).
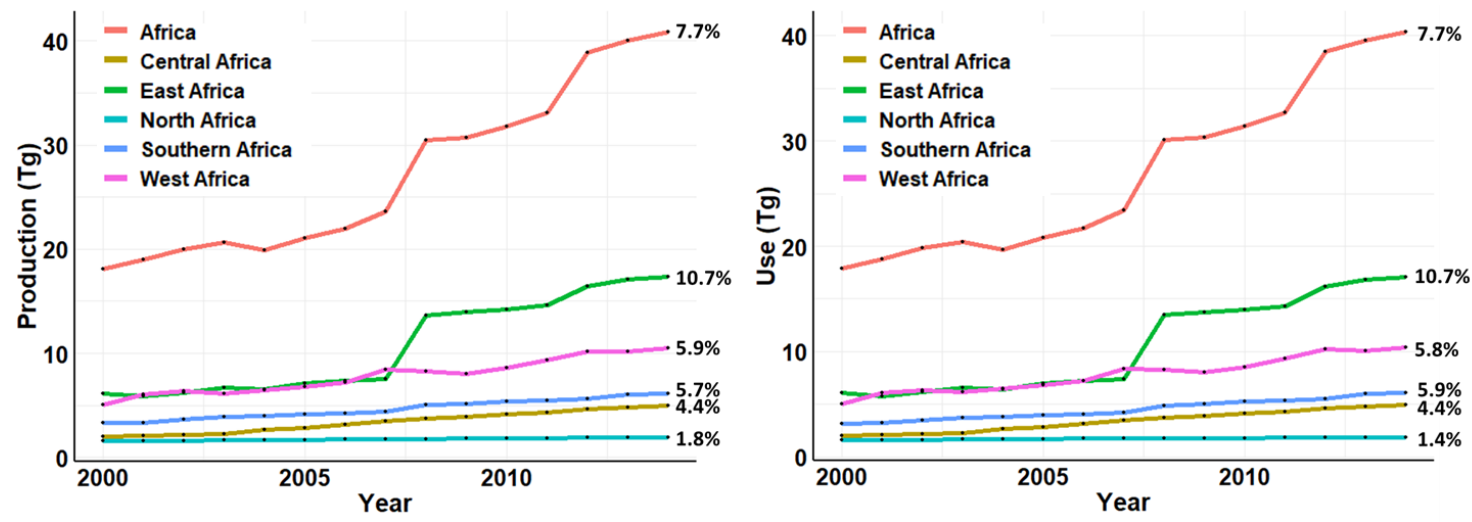

Figure 4.2 Time series of charcoal production and use in Africa for 2000 to 2014. Units are in $\mathrm{Tg} \mathrm{a}^{-1}$. Values inset give average annual increases in charcoal production (left) and use (right).

The average annual increase in Africa and East Africa is largely influenced by the step change in charcoal production for Kenya from 2007 to 2008 as reported in the UNSD 2017 data. If for instance the annual change is assessed for East Africa after removing the years affected by the spurious Kenya data (i.e. 2000-2007), the average annual increase in charcoal production for East Africa will reduce by a factor of $\sim 1.9$ as can be seen in Figure 4.3 which shows timeseries of charcoal production in Africa and East Africa with and without the period affected by the spurious Kenya data respectively. We can see from Figure 4.3 that with the 2008-2014 East Africa data, the average annual increase in 
charcoal production in East Africa will drop to 5.5\%. Similarly, if the trend is assessed for Africa based on data from 2008-2014, the average annual increase will drop from $7.7 \%$ to $6.8 \%$.
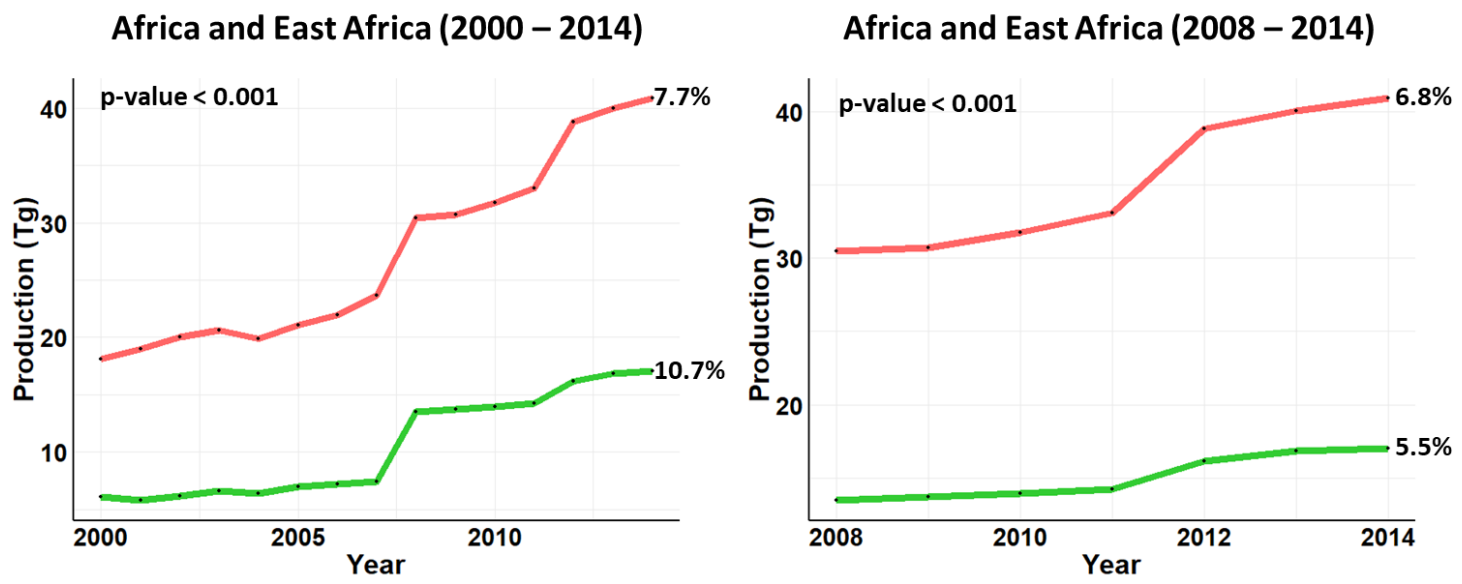

Figure 4.3 Time series of charcoal production in Africa and East Africa from 2000-2014 (left) and from 2008-2014 (right) using UNSD 2017 data respectively. Units are in $\mathrm{Tg} \mathrm{a}^{-1}$. Values inset gives the $\mathrm{p}$-value and average annual increases.

East Africa also exports the largest fraction of exported charcoal (50\%) from Africa (Figure A4.1). The export rise in Somalia is from the trade of charcoal for weapons with Gulf states to arm and fund Al Shabaab rebels (UN, 2012; Keatinge, 2014). Satellite images confirm that before 2007 hardly any charcoal was produced in Somalia (Vrieling, 2015). Average annual rates of change in charcoal production and use for the other regions range from $1.8 \pm 0.1 \%$ in North Africa to $5.9 \pm 0.6 \%$ in West Africa. 


\subsection{Future (2030) Charcoal Production and Use in Africa}

Forest available for charcoal production beyond 2014 was determined using total AGB and wood burned as detailed in Section 3.4. Figure 4.4 shows biomass availability for charcoal production in Africa for 2014 obtained as the difference between total forest biomass (tonnes $\mathrm{a}^{-1}$ ) and wood biomass (tonnes) used to produce charcoal in Africa in 2014. This rough calculation suggests that available forest biomass is sufficient for harvesting wood for charcoal production in almost all parts of Africa. The areas negative values where forest biomass is insufficient for charcoal production in 2014 are mostly along the Sahara Desert where biomass density is low. These negative areas also correspond to the red pixels in Figure 4.4 (b). Anyway, this approach assumes that the harvesting of biomass is spatially consistent throughout the country. For countries along the Sahara Desert, harvesting would occur in more densely vegetated locations along the Mediterranean coast in North Africa and along the Sahel in West Africa.
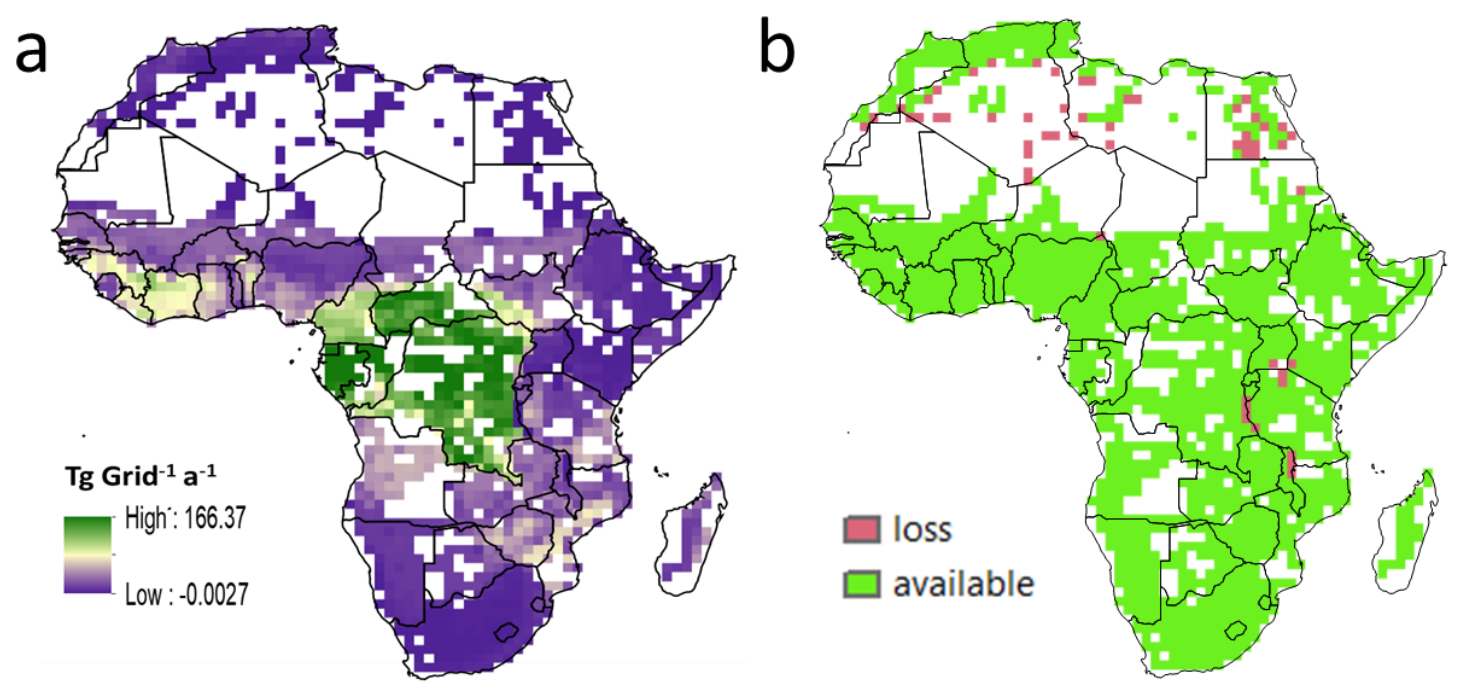
Figure 4.4 Biomass availability for charcoal production in Africa in tonnes grid ${ }^{-1} \mathrm{a}^{-1}$. Difference between total forest biomass and wood biomass harvested for charcoal production in 2014 (left panel), and available (green) and depleted (red) grids due to tree harvesting for charcoal production (right panel).

The rest of vegetated Africa (97\% green pixels) has sufficient biomass available for more than one year's charcoal production, which indicates, forest cover is available for charcoal production in almost every country in Africa by this simplistic measure. The sustainability of this available biomass for charcoal is however largely dependent on the relative rates of charcoal production and forest re-growth. The rate of charcoal production is dominated by the rate of urbanisation. The rate of forest re-growth is dominated by net primary productivity (NPP; Pan et al., 2011) but must also take account of competing forest needs such as timber (Burgess,1993), temporary losses due to open fires (JuárezOrozco et al., 2017), and permanent loss due to land-use change, principally for agriculture (Ordway et al., 2017).

We aggregate country level charcoal production and use in Africa at regional and continental scales to project charcoal production and use in 2030 using linear regression of charcoal production against urban population. Figure 4.5 shows charcoal production and use in Africa and its subregions projected to 2030. Charcoal production and use almost double from $41.7 \mathrm{Tg}$ in 2014 to $74.3 \mathrm{Tg}$ in 2030 . This is about 2 times the charcoal production (46.4 Tg) predicted by Broadhead et al., (2001) for 2030 for a doubling in charcoal production relative to 1970 . 


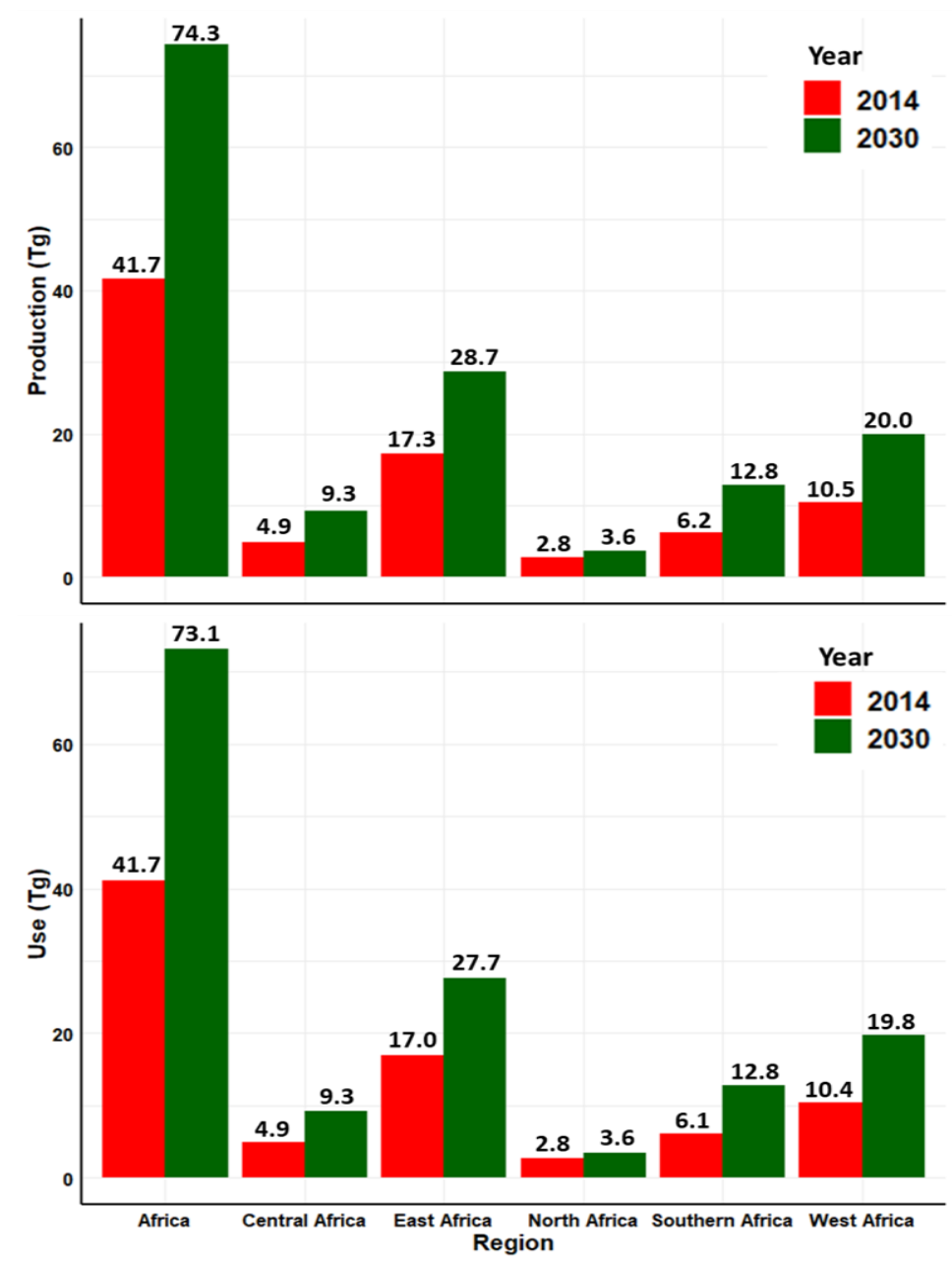

Figure 4.5 Current and future charcoal production and use in Africa. Plot shows charcoal production (top) and use (bottom) for 2014 to 2030 . Units are $\mathrm{Tg} \mathrm{a}^{-1}$.

The Global Environmental Fund (GEF, 2013) similarly predicted that charcoal production in Africa will double by 2030 due to urban demand. The largest regional increase in charcoal production and use is in Southern Africa (110\%) and East Africa (60\% for production, $70 \%$ for use).

The projections in Figure 4.5 assume that current driving factors such as urbanisation, population growth and poor electricity access coupled with high tariffs (Mwitwa and 
Makano, 2012; Leo C. Zulu and Richardson, 2013) are unchanged. Studies have shown that even with increased electricity access charcoal production has continued to increase (Davis, 1998). Even households with relatively high income use a mix of electricity and charcoal (Yonemitsu et al., 2014; Mulenga et al., 2019). Increased charcoal production and use, due to this projected future demand, may have adverse socio-economic, environmental and health effects in Africa.

\subsection{Implications for Forest Degradation in 2030}

Unsustainable harvesting of wood that may result from the projected doubling in charcoal production from 2014 to 2030 may degrade local forests leading to damage of wildlife habitat, deforestation and poor functioning of watersheds (Heltberg, 2001; Chidumayo et al., 2013). Forest degradation in 2030 was estimated based on projected wood demand to produce charcoal following the same method as before. Figure 4.6 shows forest degradation for 2030 relative to 2014. In 2030, the extrapolation suggests that 247-826 Tg of wood (for a kiln efficiency of 9-30\%) will be used to produce charcoal in Africa, $38 \%$ of which is required in East Africa. The extrapolation further suggests that 4.5-15 million hectares of forest will be degraded to produce charcoal in 2030. This is between 0.7-2.3\% of projected forest area (646 million ha) estimated by D'Annunzio et al., (2015) for Africa in 2030. Majority (38\% ) of the forest degradation will take place in East Africa whilst 34\% loss will take place in West Africa. D'Annunzio et al., (2015) also predicted that the greatest forest degradation will be in East Africa. 


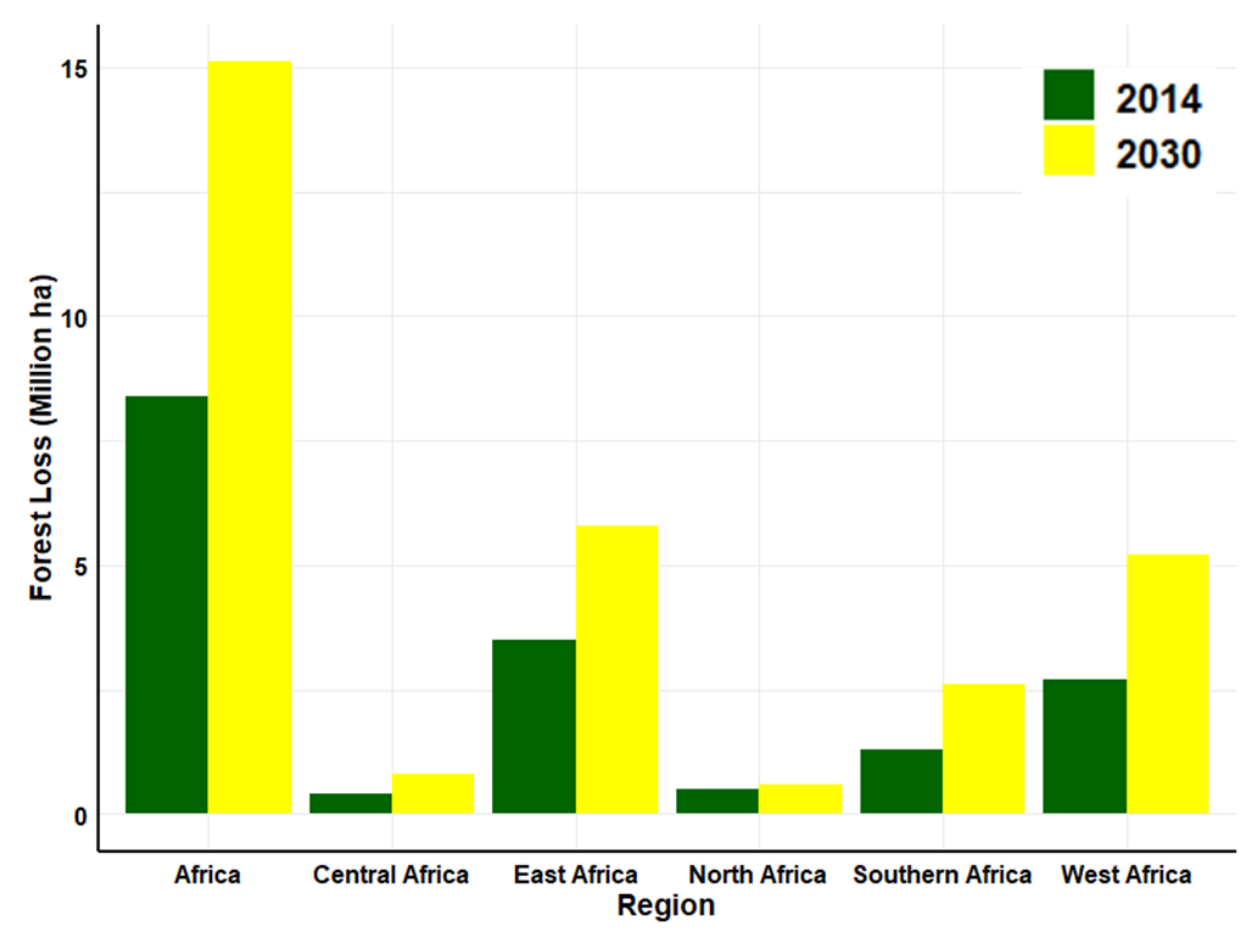

Figure 4.6 Forest degradation from charcoal production in Africa. The yellow bars show forest degradation in 2030. The green bars show forest degradation in 2014. Values are for kiln efficiency at 9\%. Unit is million hectare per year (Million ha $\mathrm{a}^{-1}$ ).

Between 2014 (based year) and 2030, 2-6 million hectares of forest will be degraded to produce charcoal in Africa. Projected forest loss of 2.3 million hectares from all sources in Africa was estimated by D'Annunzio et al., (2015) for the period 2015-2030, which falls well within this range. However, the figure D'Annunzio et al., (2015) reported is likely conservative since only 22 countries in Africa reported their forest degradation in the study they conducted. The review by Cais et al. (2011) reports a range of 0.37 to 0.81 tonnes of carbon per hectare per year for carbon uptake by savannah vegetation in Africa that would include the dominant vegetation types harvested for charcoal production. Therefore, removal of 4.5-15 million ha of the forest will reduce the Earth's capacity to sequester between 1.7-12.2 million tonnes of carbon from the atmosphere over Africa in 
2030, thereby reducing the potential for global warming and the effects. Reduced forest cover could also lead to scarcity in charcoal supply to cities which could lead to an inflation of market price for charcoal, loss of business for the rural communities in Africa, and re-adoption of dirtier burning fuels like wood. Biodiversity loss and shortage of ecosystem services such as bushmeat and herbal medicine (Chidumayo et al., 2013) are also potential threats that could increase with the projected forest removal by 2030 .

Since charcoal production is associated with forest removal which has related consequences for ecosystem services, there is need for intervention to reduce charcoal export and use especially by households in East and West Africa that accounts for $72 \%$ of forest loss in 2030, in order to reduce the impact on forest loss from charcoal production in Africa. This would require increases in the income levels of households to afford energy alternatives like LPG and biogas, but also by increasing access to reliable electricity that is generated from renewable energy sources. LPG has the potential to reduce household charcoal use by more than $50 \%$ (Yonas et al., 2015) and biogas from animal and agricultural products has the potential to cut deforestation by $4-26 \%$ in 2030 (Subedi et al., 2014). Another potential intermediary option is to increase the efficiency of conversion of wood to charcoal by adopting more efficient techniques or using more efficient kilns.

\subsection{Summary}

Urbanisation and urban population increase can influence deforestation and forest degradation from charcoal production for household use and can place constrain on future 
charcoal availability. In this work, a 14-year long trend (2000-2014) in charcoal production using Mann-Kendall with Theil-Sen's Slope was calculated. Regression analysis of charcoal production against urban population was used to predict future trends in charcoal production and use in 2030 and determine forest loss. There is a strong positive increase in charcoal production and use ( $\mathrm{p}$-value $<0.001, \mathrm{R}>0.90)$ for the period investigated that is driven by urbanization. In Africa, the average annual increase in charcoal production and use is $\sim 7 \%$. In the subregions, the average annual increase varies from $1.7 \%$ in North Africa to $10.5 \%$ in East Africa. If such a trend continues, by 2030 , charcoal production and use will almost double relative to 2014, from $41.7 \mathrm{Tg}$ in 2014 to 74.3 Tg in 2030. This could lead to forest degradation of 4.3-14.5 million hectares at a kiln efficiency of 9-30\%. Such loss will have negative implications on health, food security, climate, and infrastructure in Africa. LPG and electricity, are prohibitively expensive and unreliable, sustaining the current widespread adoption and use of charcoal. Prohibitively expensive in this work refers to total cost, which comprises both the startup cost and running cost. The cost also fluctuates, which makes the running/maintenance costs also unpredictable. Governments could implement policies such as, protecting harvested areas from cultivation, fire, and intensive grazing, thus enabling natural regeneration. This will reduce forest loss and ensure future charcoal supply in the coming decades. Governments could also provide viable alternatives to charcoal like LPG. This is challenging, but achievable with the correct implementation. 


\section{PRESENT-DAY (2014) AND FUTURE (2030) \\ EMISSIONS FROM THE CHARCOAL INDUSTRY IN}

\section{AFRICA}

\subsection{Overview}

This chapter presents the results and interpretation of emissions from the charcoal supply chain in Africa in 2014 and 2030. Emissions are estimated as the product of activity data and emission factor. Here the spatial distribution of the emissions and contribution of each charcoal activity to pollutant emissions are given.

\subsection{Current (2014) Charcoal Industry Emissions}

In this research, country level charcoal produced, used and transported in 2014 are gridded to a $0.1^{\circ}$ x $0.1^{\circ}$ grid and then emission factors (Table 3.3) applied to estimate the emissions from each activity in 2014. Pollutants considered are black carbon (BC), organic aerosol $(\mathrm{OA})$, carbon monoxide $(\mathrm{CO})$, methane $\left(\mathrm{CH}_{4}\right)$, nitrogen oxide $\left(\mathrm{NO}_{\mathrm{x}}\right)$, sulfur dioxide $\left(\mathrm{SO}_{2}\right)$ hydrogen chloride $(\mathrm{HCl})$ and NMVOCs, speciated into ethylene, ethane, methanol, formaldehyde, acetic acid, and formic acid for charcoal production and use, and acetaldehyde, benzene and toluene, for charcoal transport.

The amount of wood pyrolysed to produce charcoal in 2014, assuming a conversion efficiency of 9-30\% (Yevich et al., 2003; FAO, 2017) is 140-460 Tg. This represents 6$22 \%$ of annual open fire dry matter burned from the GFEDv4.1 biomass burning 
inventory for Africa (Randerson et al., 2017) Based on the emission estimates of our study, the importance of charcoal relative to open fires may be increasing rapidly. In West Africa, for example, we estimate that 35-120 Tg fuelwood was used to produce charcoal in 2014. This is 2-6 times the $21 \mathrm{Tg}$ obtained by Lacaux et al. (1994) for West Africa in 1992 for a conversion efficiency of $28 \%$. The amount of charcoal produced (Figure 1) and used in 2014 is 1.4 times more than that in the regional DICE-Africa inventory for 2013 (29.8 Tg from production; $27.7 \mathrm{Tg}$ from use) (Marais et al., 2016) even though DICE-Africa activity data is from the same database and most charcoal production and EFs for DICE-Africa are similar to those used here (Table 5.1). Larger production and use in our inventory is due to a combination of annual growth from 2013 to 2014, availability of data for more countries (49 countries) than was available for DICE-Africa (43), and a $32 \%$ increase in the revised UN database charcoal production and use statistics used in this study. The latter we estimate by comparing data for the same countries for 2013 used in DICE-Africa and the UN data we use. Fuel usage for transporting charcoal of $0.07 \mathrm{Tg}$ represents just $0.2 \%$ of all motor gasoline used for transport in Africa in 2014 (UN, 2017b).

Figures 5.1 and Figure 5.2 show the spatial distribution of OC and NMVOCs emissions from charcoal production, use and transport in Africa in 2014. We use the OC distribution to present our results, since we find that all other pollutants show similar spatial distribution, apart from $\mathrm{HCl}$ (emitted in slums only) and $\mathrm{SO}_{2}$ (from transport only). Emissions from all activities peak in East and West Africa (as is expected from Figure 4.1). Intense production in rural areas is concentrated along major road networks, and 
consumption and transport peak in urban centres where population is high and truck traffic is concentrated (Figure 3.2).

\section{Organic Aerosol Emissions [tonnes $a^{-1}$ ]}
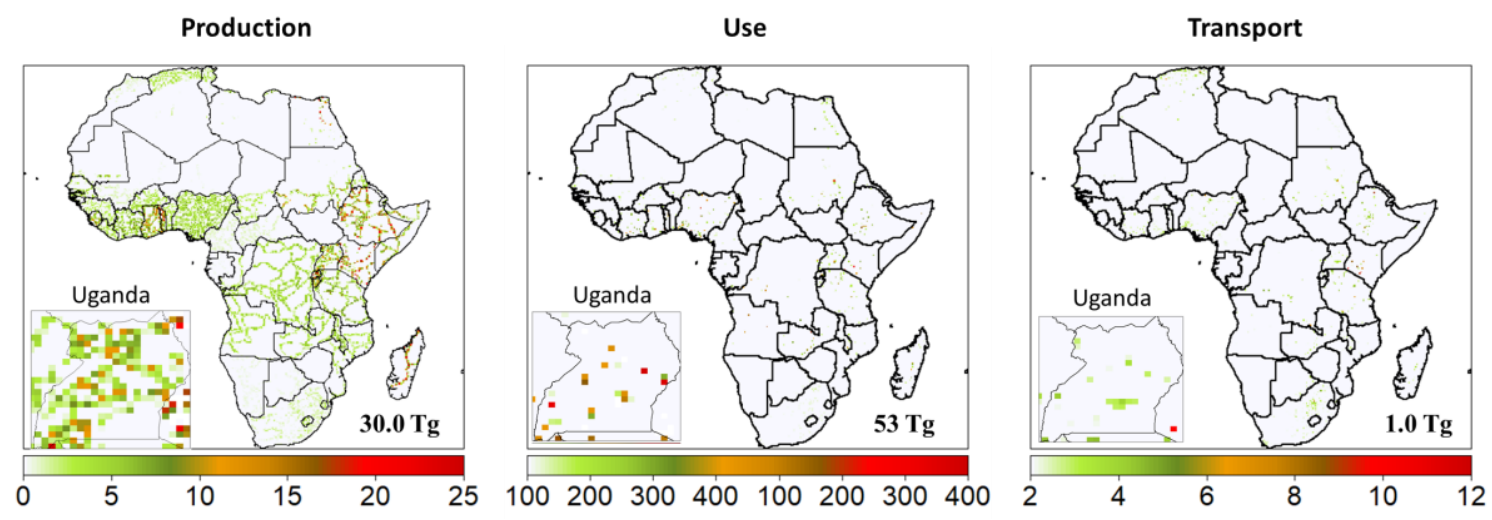

Figure 5.1 Emissions of OC from the charcoal industry in Africa in 2014. Emissions are of OC on a $0.1^{0}$ x $0.1^{0}$ grid from charcoal production (left), use (centre) and transport (right). Values inset are emission totals for 2014. Inset map is Uganda.

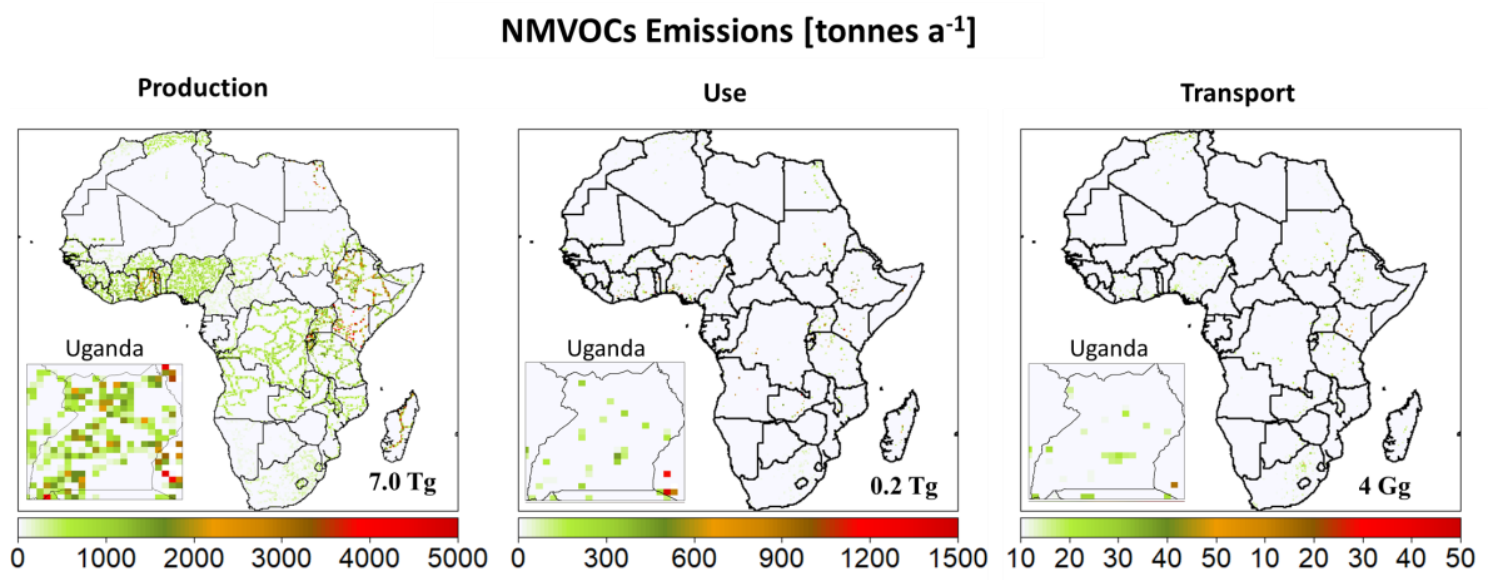

Figure 5.2 Same as above, but for NMVOCs. 
Figure 5.3 shows total emissions of each pollutant and the relative contribution of the different activities to the total in 2014. The majority of $\mathrm{NO}_{\mathrm{x}}$ and $\mathrm{BC}$ emissions are from use in urban centres $\left(76.1 \%\right.$ for $\mathrm{NO}_{\mathrm{x}} ; 97.8 \%$ for $\left.\mathrm{BC}\right)$, due to higher combustion efficiencies compared to charcoal production. The NMVOC-to- $\mathrm{NO}_{\mathrm{x}}$ emission ratios are much higher for production (700:1) than use (4:1), so we would expect ozone formation to be more sensitive to $\mathrm{NO}_{\mathrm{x}}$ emissions in charcoal production zones than in urban areas (Sillman, 1999). This effect will be diluted at the coarse resolution of the model used here $(200-250 \mathrm{~km})$.

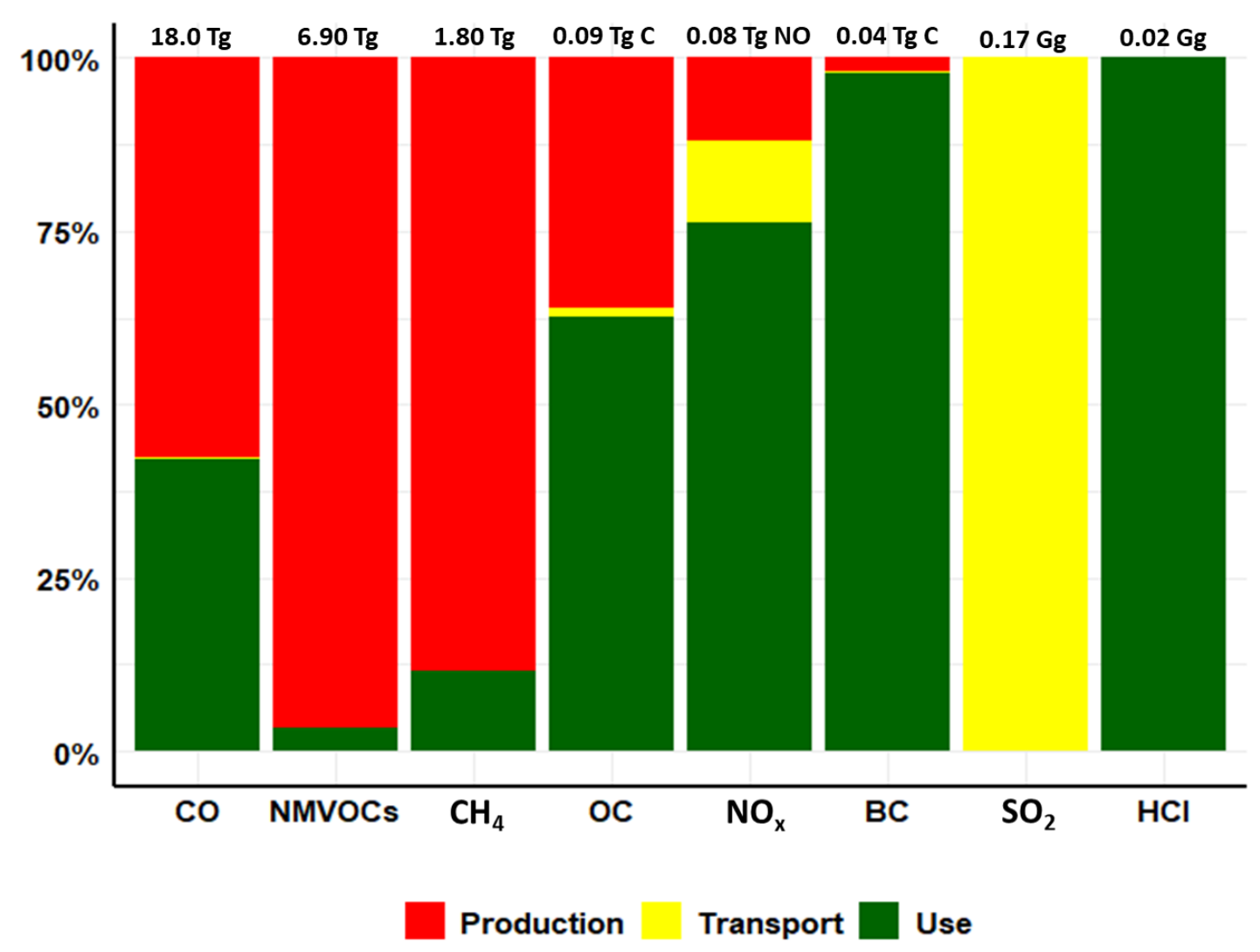

Figure 5.3 Contribution of charcoal activities to emitted charcoal pollutants in 2014 .

Total emissions are given for each pollutant. Colours distinguish emissions for charcoal production (red), use (green), and transport (yellow). 
Charcoal production should make the largest contribution to OC emissions, as charcoal production is a more inefficient process than charcoal use, but we obtain the opposite in our inventory: $36.1 \%$ from production; $62.7 \%$ from use. The BC and OC EFs for charcoal use that we use from Akagi et al. (2011) are originally from Bond et al. (2004), with reported uncertainties of $110 \%$ for $\mathrm{BC}$ and $91 \%$ for OC. The mean of the OC EFs for charcoal production from the recent field measurements obtained by Keita et al. (2018) of $3.93 \mathrm{~g} \mathrm{~kg}^{-1}$ are 5-times higher than $0.74 \mathrm{~g} \mathrm{~kg}^{-1}$ used in this work (Table 3.2). If instead we used the Keita et al. (2018) EFs, the relative contribution of OC would be $69.2 \%$ production, $30.4 \%$ use.

In cities, emissions are higher in slums than the city centre, reflecting greater population density and dependence on charcoal for energy generation in slums. $\mathrm{HCl}$ is exclusively from plastic burning in our inventory. There are also $\mathrm{HCl}$ emissions from burning fuelwood and charcoal, but these are much lower than burning plastic (Jayarathne et al. 2018). The total plastic burned in 2014 to initiate combustion, obtained as the product of the rate of usage $\left(4 \mathrm{~g} \mathrm{~kg}^{-1}\right)$ and the mass of charcoal used in slums (Figure 3.2), is 260 tonnes. Values for individual countries are in Figure A5.3. Plastic burning also releases $\mathrm{OA}, \mathrm{BC}$ and $\mathrm{CO}$. Total emissions of these from burning 260 tonnes of plastic is 2.2 tonnes BC, 8.8 tonnes OC, and 22 tonnes CO using reported EFs of BC (Jayarathne et al., 2018), OC (Jayarathne et al., 2018) and CO (Stockwell et al., 2016). These are at least 3 orders of magnitude less than charcoal industry emission totals (Figure 5.3). All the $\mathrm{SO}_{2}$ is from transport, as there are no detectable emissions of $\mathrm{SO}_{2}$ from charcoal production and use (Pennise et al. 2001; Akagi, Yokelson, C. Wiedinmyer, et al. 2011). With the exception of $\mathrm{NO}_{\mathrm{x}}$ and $\mathrm{SO}_{2}$ emissions, transport contributes $<2 \%$ to total emissions. A similar small 
$(0.15 \%)$ contribution of transport to emissions of $\mathrm{CO}_{2}$ from the charcoal supply chain was estimated by Ekeh et al. (2014) for Kampala, the capital city of Uganda.

Emissions from this work are higher than those in DICE-Africa (Marais and Wiedinmyer, 2016) for charcoal use due to differences in activity factors already discussed, but much lower than DICE-Africa for charcoal production. That inventory used the same Akagi et al. (2011) emission factors, but applied these as fuelwood burned instead of charcoal burned and assumed a $20 \%$ combustion efficiency that resulted in a 5-fold overestimate in emissions. After correcting for this error, we find that the $\mathrm{BC}, \mathrm{OC}, \mathrm{CO}, \mathrm{NMVOCs}$ and $\mathrm{CH}_{4}$ emissions from this work are higher than DICE-Africa charcoal production and use emissions by $30-80 \%$. Table 5.1 shows a comparison of charcoal production and use emissions from this work and that from DICE-Africa. We can see from Table 5.1 that emissions from this study are higher than for DICE-Africa. This is due to the higher charcoal production in Africa in 2014 than in 2013. Also, more countries were considered for this study (49) than for DICE-Africa (43).

Table 5.1 Comparison of emissions from this study and DICE-Africa ${ }^{a, b}$

\begin{tabular}{|c|c|c|c|c|}
\hline \multirow{2}{*}{ Emitted Species } & \multicolumn{2}{|c|}{ Charcoal Production } & \multicolumn{2}{c|}{ Charcoal Use } \\
\cline { 2 - 5 } & DICE-Africa $^{\mathrm{c}}$ & This study & DICE-Africa & This study \\
\hline $\mathrm{CO}[\mathrm{Tg}]$ & 6.1 & 10 & 5.2 & 7.9 \\
\hline $\mathrm{NMVOCs}[\mathrm{Tg}]$ & 3.6 & 6.7 & 0.15 & 0.30 \\
\hline $\mathrm{CH}_{4}[\mathrm{Tg}]$ & - & 1.7 & - & 0.23 \\
\hline $\mathrm{OC}[\mathrm{Gg} \mathrm{C}]$ & 18 & 32 & 36 & 57 \\
\hline $\mathrm{NO}_{\mathrm{x}}[\mathrm{Gg} \mathrm{NO}]$ & 5.3 & 21 & 39 & 61 \\
\hline $\mathrm{BC}[\mathrm{Gg}]$ & 0.48 & 0.80 & 28 & 39 \\
\hline
\end{tabular}


a Annual emissions for 2013 from DICE-Africa (Marais et al., 2016) and 2014 from this study. The table only compares emissions for species provided in at least one of the inventories.

${ }^{\mathrm{b}}$ Dashes indicate no reported emissions.

${ }^{c}$ Values here differ from those in DICE-Africa, as DICE-Africa values in this work are reduced by a factor of 5 to correct for miscalculation of charcoal production emissions .

Table 5.2 shows a comparison table of the total emissions from this work and other emission sources in Africa. We can see from Table 5.2 that CO and NMVOC emissions from this work are higher than emissions from the formal industry, traffic and open waste burning, respectively. Open waste burning emissions for $\mathrm{BC}, \mathrm{OC}, \mathrm{CO}$ and $\mathrm{NOx}$ are however larger than from charcoal industry emissions. $\mathrm{OC}$ and $\mathrm{BC}$ from this work are half those emissions from formal industry. Charcoal emissions are in general less than residential use of wood, but charcoal use is increasing at a faster rate than wood use (Marais et al., 2016), so charcoal emissions may soon surpass those from residential fuelwood.

Table 5.2 A comparison of the emissions from this work and other sources in Africa.

\begin{tabular}{|c|c|c|c|c|c|c|c|}
\hline \multirow[t]{2}{*}{ Source } & \multicolumn{7}{|c|}{ Unit $\left[\operatorname{Tg~a~}^{-1}\right]^{a}$} \\
\hline & BC & OC & $\mathrm{CO}$ & $\mathbf{N O}_{\mathbf{x}}$ & $\mathrm{SO}_{2}$ & $\mathrm{CH}_{4}$ & NMVOCs \\
\hline Charcoal Industry (This work) & 0.04 & 0.09 & 18.41 & 0.08 & 0.00 & 1.87 & 6.94 \\
\hline Charcoal Industry (DICE) ${ }^{\mathrm{b}}$ & 0.03 & 0.05 & 11.30 & 0.04 & 0.00 & 1.09 & 3.75 \\
\hline Wood burning (DICE) $)^{\mathrm{b}}$ & 0.30 & 1.13 & 30.00 & 0.13 & 0.19 & 4.70 & 7.00 \\
\hline Open Biomass Burning & $2.30^{\mathrm{c}}$ & $17.00^{\mathrm{c}}$ & $106.20^{\mathrm{d}}$ & $6.29^{\mathrm{d}}$ & $0.78^{\mathrm{d}}$ & $3.49^{\mathrm{d}}$ & $5.86^{\mathrm{d}}$ \\
\hline Formal Industry & 0.08 & 0.18 & 1.19 & 1.20 & 1.09 & 2.30 & 0.18 \\
\hline Traffic ${ }^{\mathrm{e}}$ & 0.15 & 0.29 & 15.40 & 1.83 & 0.12 & - & 3.20 \\
\hline Open Waste Burning ${ }^{\mathrm{e}}$ & 0.47 & 1.08 & 6.42 & 0.56 & 0.08 & - & 3.45 \\
\hline Ongrid Energy Generation ${ }^{\mathrm{e}}$ & 0.01 & 0.01 & 0.37 & 1.90 & 1.75 & - & 0.02 \\
\hline
\end{tabular}


${ }^{\mathrm{a}}$ Emissions are in $\mathrm{Tg} \mathrm{a}^{-1} .{ }^{\mathrm{b}}$ Marais and Wiedinmyer, (2016), ${ }^{\mathrm{c}}$ Liousse et al. (2010), ${ }^{\mathrm{d}}$ Giglio et al. (2013), ${ }^{\text {e }}$ Keita et al. (2020), dashes indicates no reported emissions.

Assessment of uncertainties in emission factors have been indirectly done for this work by comparing different estimates of emission factors from different studies. Uncertainties in emission factors used for this research (Table 3.3) determined as the range in reported estimates, are as large as $\pm 100 \%$ for black carbon to as little as $\pm 10 \%$ for organic carbon from truck transport. This misrepresents the true range in uncertainties associated with emission factors, as the wide range of conditions (kiln efficiencies, cookstoves, truck quality and fuel) have been measured. In many cases there is only one measurement available, such as for the range of possible NMVOCs emitted during charcoal production and use.

Uncertainties in emission inventory from this work result from limited availability of activity data, assumptions about activities in the absence of data (specifically trucks and plastic burning), limited information about EFs representative of conditions in Africa, and extrapolation of information from a few reports or local case studies to the whole continent. Even so, emissions estimates from the inventory developed for this work suggest that the charcoal industry makes a substantial contribution to biomass emissions in Africa. Our estimate of $\mathrm{CH}_{4}$ emissions from the charcoal supply chain, mostly from production (Figure 5.3), is $40 \%$ of $\mathrm{CH}_{4}$ emissions from open fires in Africa from the global GFEDv4.1 inventory in 2014 (Randerson et al., 2017). Rapid urbanisation is driving an increase in charcoal production of $\sim 7 \% \mathrm{a}^{-1}$ across Africa (Section 4.2). Burned area from open fires in countries in West Africa decreased by $0.7-2.0 \% \mathrm{a}^{-1}$ from 2001 to 
2012 due to cropland expansion alone (Andela et al., 2014). At these rates, $\mathrm{CH}_{4}$ from the charcoal industry in West Africa may surpass that from open fires as early as 2025. This has implications for estimating the regional budget of methane emissions to better regulate this source as part of the United Nations Framework Convention on Climate Change (UNFCCC) Paris Agreement.

\subsection{Future (2030) Emissions from the Charcoal Industry}

Regression analysis of charcoal production and use against urban population (the dominant driver) were conducted to predict charcoal production and use in 2030 from which scaling factors (charcoal production, use ratio in 2030 and 2014) were calculated and applied to predict emissions for respective charcoal pollutants in 2030.

Figure 5.4 shows the 2014-to-2030 charcoal production scaling factors mapped to all countries across Africa and gridded at the same spatial resolution $\left(0.1^{0} \times 0.1^{0}\right)$ as the charcoal production, use and transport emissions for this work (Figure 5.1). These scaling factors were produced to scale the 2014 emissions in the inventory developed for this work to 2030, to enable the modelling of future air quality. The scaling factors range from 0.7 in Zimbabwe to 2.7 in Eritrea due to varying difference in charcoal production and use projection to 2030 using urban population as predictor. The increase in charcoal supply chain activities from 2014 to 2030 in each country ranges from $20 \%$ to $130 \%$. Only in Zimbabwe does production and use decrease (by 30\%). Total biomass (wood and other dry matter) required to produce charcoal in 2030 is $300-1000 \mathrm{Tg}$, depending on combustion efficiency. Our business-as-usual approach assumes no significant change in 
EFs, in combustion efficiencies of charcoal production and consumption, and in the relative proportion of charcoal exported. One might expect widespread adoption of cleaner alternatives and other initiatives to slow growth in charcoal use. This is not apparent in past behaviour. Imposed bans in countries with intensive charcoal production, such as Somalia and Kenya, have been ineffectual (Wanjiru et al., 2016). Historical growth in charcoal production and use has occurred alongside increased adoption of cleaner energy. The use of LPG and electric stoves as primary cooking devices rose by $3.5 \% \mathrm{a}^{-1}$ (LPG) and 4.3\% $\mathrm{a}^{-1}$ (electric stoves) from 2000 to 2010 (World Bank, 2014). Dominant factors that mitigate much faster adoption of cleaner alternatives to reduce reliance on charcoal include low willingness to pay, low grid connectivity, unreliable electricity supply, and irregular household income(IEA, 2019). The transition to clean fuels may also be disrupted by the economic recession anticipated as a result of the covid19 pandemic (IEA, 2020; Mbandi, 2020).

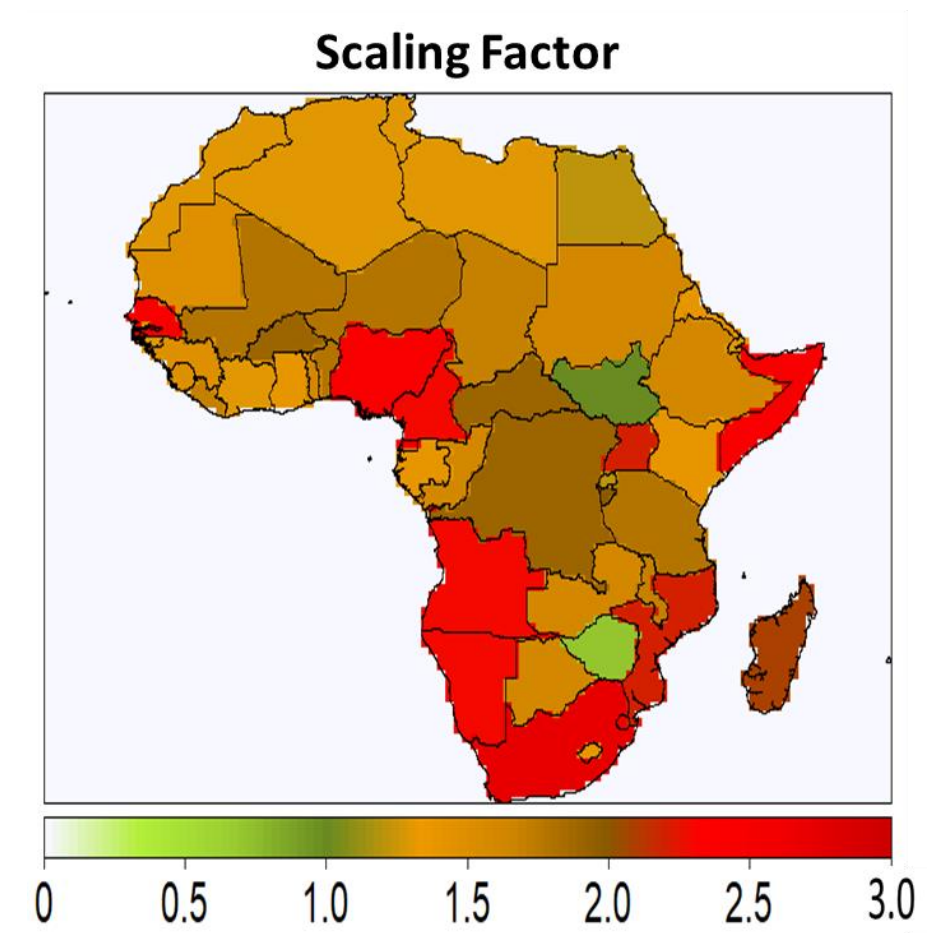


Figure 5.4 Ratios of 2030-to-2014 charcoal production and use for each African country. These are the scale factors used to project charcoal production, use, and transport emissions to 2030. The scale factors are gridded at a horizontal resolution of $0.1^{0} \times 0.1^{0}$.

\subsection{Summary}

Charcoal production and use, including the burning of plastic to initiate charcoal combustion, release trace gases and particulate matter with the potential to impact air quality and climate. Here, we develop an inventory of emissions of reactive trace gases and aerosols from charcoal production, use, and transport in Africa in 2014 and 2030. We combine open access datasets of land cover, population density, road network and United Nations energy statistics data for African countries to map charcoal production to production zones 5-10 $\mathrm{km}$ from major roadways, transport by unregulated trucks to urban centres, and use in urban households. We estimate that 130-462 $\mathrm{Tg}$ of dry fuelwood is required to produce charcoal in 2014 . This is $15-53 \%$ of annual biomass burned from intense seasonal open fires in Africa. Emissions from charcoal are highest in the Eastern and Western regions of Africa in rural areas where most of the charcoal is produced and in densely populated urban areas where charcoal is consumed. Total annual emissions are $18 \mathrm{Tg} \mathrm{CO}, 6.9 \mathrm{Tg}$ NMVOCs, $1.8 \mathrm{Tg} \mathrm{CH}_{4}, 85 \mathrm{Gg} \mathrm{C}$ as OC, $76 \mathrm{Gg} \mathrm{NO}, 42 \mathrm{Gg} \mathrm{BC}, 0.2 \mathrm{Gg}$ $\mathrm{SO}_{2}$, and $0.02 \mathrm{Gg} \mathrm{HCl}$. Emissions will almost double from 2014 to 2030. The inventory developed here has the versatility to be used in regional and global models to achieve a better understanding of influence of emissions from the charcoal industry in Africa on atmospheric chemistry, air quality and climate. 


\section{AIR POLLUTION AND CLIMATE FORCING OF THE CHARCOAL INDUSTRY IN AFRICA NOW AND IN THE FUTURE}

\subsection{Overview}

This chapter presents the impact of the charcoal supply chain in Africa on local surface concentrations of the air pollutants ozone and $\mathrm{PM}_{2.5}$. Also presented is the radiative forcing aerosol and ozone due to the charcoal supply chain emissions in Africa. This was done by developing a gridded inventory of emissions from charcoal production, use and transport for Africa now (2014) and in the future (2030) and embedding the inventory in the global GEOS-Chem chemical transport model coupled to a radiative transfer model.

\subsection{Air Quality Impacts of Charcoal Emissions in Africa}

Figure 6.1 shows GEOS-Chem present-day (2014) annual mean surface (lowest model layer) concentrations of $\mathrm{PM}_{2.5}$ and ozone from all sources. $\mathrm{PM}_{2.5}$ is mostly from windblown Sahara Desert dust. Other sources include coal burning in South Africa and biomass burning north and south of the tropics. Elevated ozone concentrations in North Africa are influenced by emissions in Europe (Duncan et al. 2008), and those in southern Africa by emissions from industry and power generation in South Africa (Tyson et al. 1996; Leah Laban et al. 2018). Seasonal sources that influence ozone over Africa are open fires and natural emissions from biogenic BVOCs and lightning (Bouarar et al., 2011). 

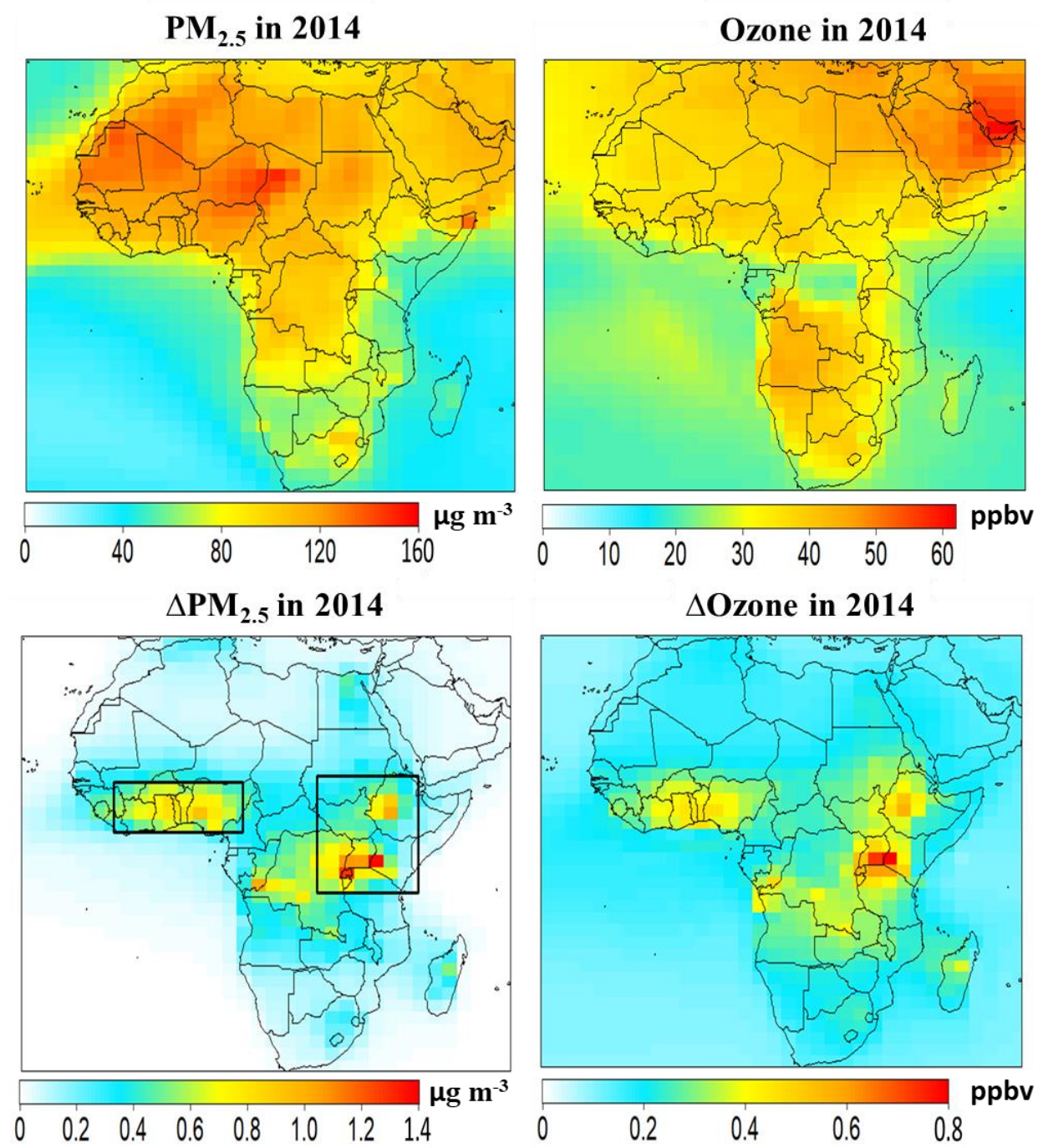

Figure 6.1 The effect of the charcoal supply chain on surface $\mathrm{PM}_{2.5}$ and ozone in 2014 . Panels show the spatial distribution of GEOS-Chem annual mean surface $\mathrm{PM}_{2.5}$ (left) and ozone (right) from all sources (top) and from the charcoal supply chain only (bottom) (see text for details). Black boxes are domains used to generate data shown in Figure 6.2.

Figure 6.1 also includes the enhancement in annual mean surface $\mathrm{PM}_{2.5}$ and ozone in 2014 due to the charcoal supply chain, obtained as the difference in GEOS-Chem simulations with and without the charcoal industry emissions. $\mathrm{PM}_{2.5}$ is comprised of $\mathrm{BC}, \mathrm{OA}$, sulfate, nitrate and ammonium. It is clear from the emission factors (Table 3.2) that OC will make 
the largest contribution to the change in $\mathrm{PM}_{2.5}$ as the response of $\mathrm{PM}_{2.5}$ to primary emissions of OC is linear (Thunis et al., 2015; Liu et al., 2016). The annual mean surface $\mathrm{PM}_{2.5}$ and ozone in are highest in East and West Africa and closely follow supply chain emissions (Figure 5.1). The peak enhancement of $1.3 \mu \mathrm{g} \mathrm{m}^{-3} \mathrm{PM}_{2.5}$ occurs at the border between Kenya and Uganda and very small when compared to peak $\mathrm{PM}_{2.5}$ from biomass burning $\left(64 \mu \mathrm{g} \mathrm{m}^{-3}\right)$ and anthropogenic $\left(77 \mu \mathrm{g} \mathrm{m}^{-3}\right)$ sources in Africa (Bauer et al., 2019). The $\mathrm{PM}_{2.5}$ enhancement seems small but can have a significant health impact by causing premature mortality as can be seen in concentration-response curve produced by Vodonos et al. (2018). The peak $\mathrm{PM}_{2.5}$ from this work is likely conservative, as we use OC EFs that are 5-times lower than recent field measurements Keita et al. (2018). The size of the $\mathrm{PM}_{2.5}$ enhancement over Kenya and Uganda propagates up to $\sim 2 \mathrm{~km}$ altitude in the model. In southern and East Africa annual mean $\mathrm{PM}_{2.5}$ is $<40 \mu \mathrm{g} \mathrm{m}^{-3}$, so a unit change in $\mathrm{PM}_{2.5}$ would increase the risk of premature mortality by $0.8 \%$, according to the relationship between $\mathrm{PM}_{2.5}$ and premature mortality from the meta-regression analysis of Vodonos et al. (2018). That relationship was derived without cohorts from African countries. A weaker health response is expected for North Africa where annual mean $\mathrm{PM}_{2.5}$ far exceeds $40 \mu \mathrm{g} \mathrm{m}^{-3}$ due to persistence of windblown dust from the Sahara Desert. The surface ozone enhancement due to the charcoal supply chain is small, peaking at just $0.7 \mathrm{ppbv}$ in the region of the densely populated cities Nairobi and Kampala in East Africa. The contribution of open fire emissions to surface ozone in Africa in the dry burning season is much larger (10-50 ppbv) (Aghedo et al. 2007).

Figure 6.2 shows the seasonality of the enhancement in surface $\mathrm{PM}_{2.5}$ and ozone from charcoal where these peak in East and West Africa (black boxes in Figure 6.1). $\mathrm{PM}_{2.5}$ 
seasonality is stronger in West than East Africa and is opposite to the seasonality that we impose in the charcoal production emissions (60\% in the wet season; Figure 3.2). This difference in the seasonality of the $\mathrm{PM}_{2.5}$ concentrations compared to the seasonality of the emissions because of efficient dispersal of air pollution by the south-westerlies of the West African Monsoon in June-August. Spatial displacement of $\mathrm{PM}_{2.5}$ to the northeast in the wet season in West Africa supports this (Figure 6.3). In December-February, $\mathrm{PM}_{2.5}$ accumulates in West Africa due to very stagnant conditions resulting from a natural inversion across West Africa established by southerly shift of the warm Harmattan winds (Marais et al. 2014).

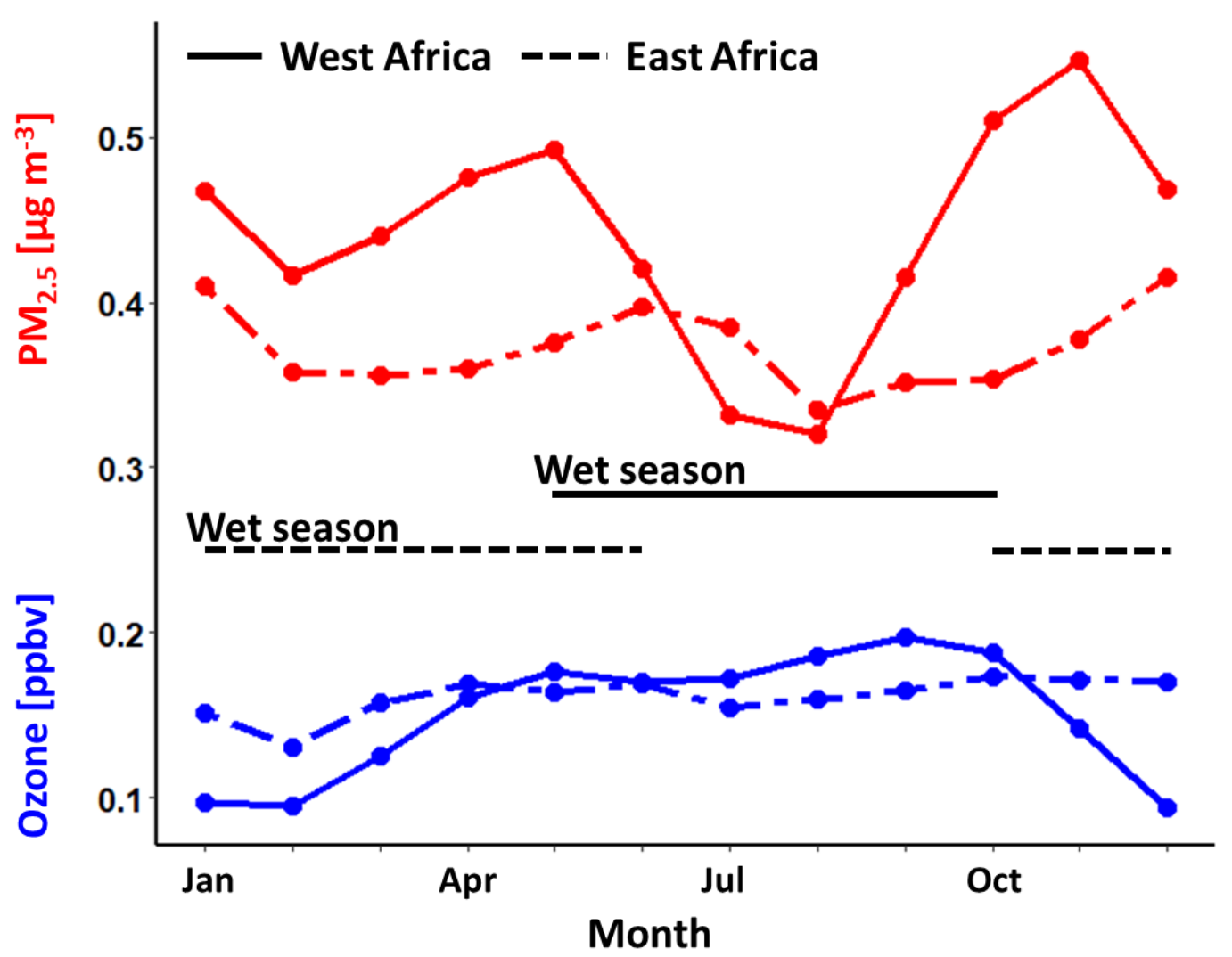

Figure 6.2 Seasonality of $\mathrm{PM}_{2.5}$ and ozone enhancement from charcoal emissions in Africa in 2014. Points are monthly means obtained as the difference in GEOS-Chem 
$\mathrm{PM}_{2.5}$ (red) and ozone (blue) with and without our inventory over West Africa (solid line) and East Africa (dashed line). Domains sampled are indicated in Figure 6.1. Black lines show the duration of the wet season for West Africa (solid line) and East Africa (dashed line).

Ozone seasonality is also most pronounced in West than East Africa and is enhanced in all months except the dry season. The dry season in Africa includes emissions of $\mathrm{NO}_{\mathrm{x}}$ from intense and widespread biomass burning, whereas outside the biomass burning season $\mathrm{NO}_{\mathrm{x}}$ emissions are relatively low. This leads to sensitivity of ozone formation to $\mathrm{NO}_{\mathrm{x}}$ in West Africa outside the dry season (Saunois et al. 2009) and the seasonal pattern shown in Figure 6.2. Most charcoal $\mathrm{NO}_{\mathrm{x}}$ emissions come from charcoal use (Figure 5.2) that has imposed diurnal variability in the model, but no seasonality.
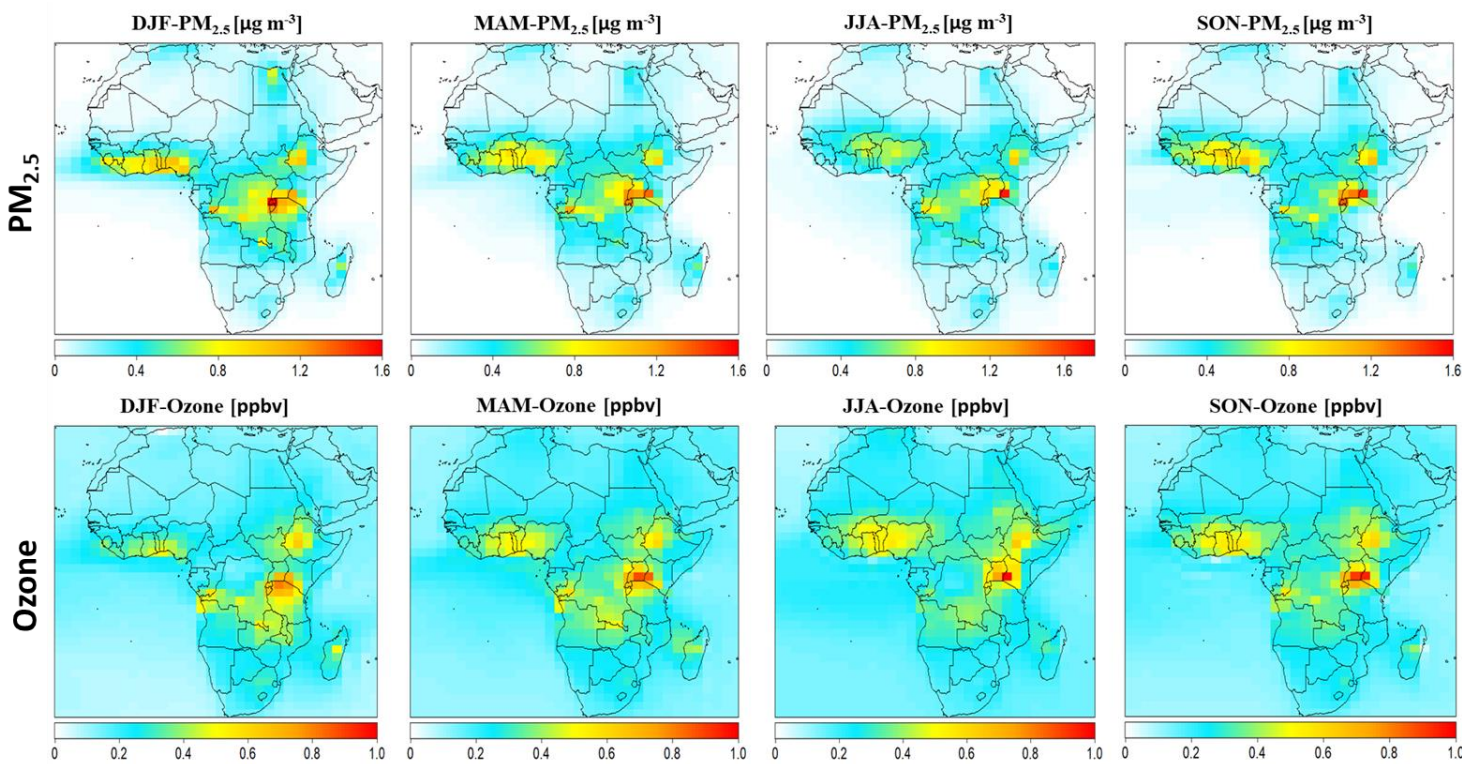
Figure 6.3 Seasonality of $\mathrm{PM}_{2.5}$ and ozone enhancements from the charcoal industry in Africa. Values are seasonal surface $\mathrm{PM}_{2.5}$ (top panel) and surface ozone (bottom) enhancements obtained as the difference in simulations with and without the charcoal industry inventory.

Figure 6.4 shows annual mean enhancements in $\mathrm{PM}_{2.5}$ and ozone in 2030, obtained from GEOS-Chem simulations with and without charcoal emissions in 2030 using the same meteorology and all other emissions (that for 2014) in both simulations. The enhancements in $\mathrm{PM}_{2.5}$ and ozone in 2030 shows similar spatial patterns to that in 2014 (Figure 6.1). The enhancements are highest in East and West Africa and match closely the spatial distribution of future emissions. Annual mean $\mathrm{PM}_{2.5}$ and ozone enhancement over Africa in 2030 are $0.12 \mu \mathrm{g} \mathrm{m}^{-3}$ and $0.08 \mathrm{ppbv}$ respectively. This is a factor of 1.4 more for $\mathrm{PM}_{2.5}$ and 1.8 more for ozone than is obtained in 2014. Peak values of $1.7 \mu \mathrm{g} \mathrm{m}^{-}$ ${ }^{3}$ and $1.1 \mathrm{ppbv}$ are in the region of the cities along the borders between Kenya and Uganda. The enhancement estimated for future (2030) concentrations are least in North Africa where present-day electricity access is highest (97\%) on the continent (Pappis et al., 2019). Alongside charcoal, other emission sources such as electricity, industry and natural gas have been also projected to double in Africa by 2030, charcoal use however, is growing at a rate $\left(7.7 \% \mathrm{a}^{-1}\right)$ faster than electricity $\left(5.3 \% \mathrm{a}^{-1}\right)$, industry $\left(5.6 \% \mathrm{a}^{-1}\right)$ and natural gas $\left(5.6 \% \mathrm{a}^{-1}\right)$ (Ouedraogo, 2017; Marais et al., 2019). Emissions from open biomass burning, transport, oil and coal will increase by $10 \%, 32 \%, 73 \%$ and $92 \%$ respectively (Ouedraogo, 2017). This suggests, an increase in energy demand from these sources would have an implication for an increase in $\mathrm{PM}_{2.5}$ and ozone which will lead to more pollution in Africa. 

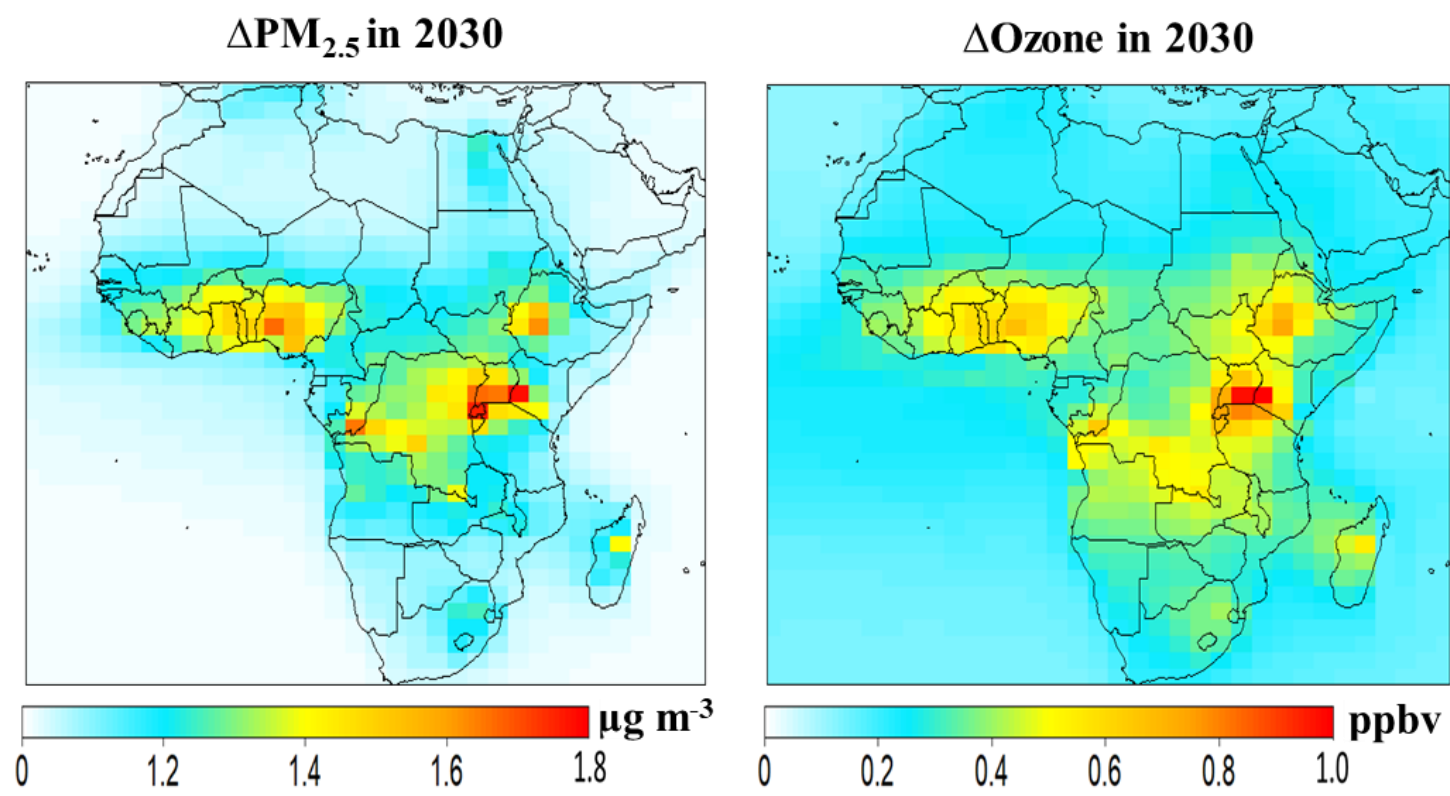

Figure 6.4 The effect of the charcoal supply chain on surface $\mathrm{PM}_{2.5}$ and ozone in 2030. Panels show the spatial distribution of GEOS-Chem annual mean surface $\mathrm{PM}_{2.5}$ (left) and ozone (right) from the charcoal supply chain.

Population-weighted $\mathrm{PM}_{2.5}$ provides a measure of the $\mathrm{PM}_{2.5}$ concentrations that people in Africa will be directly exposed to. These are calculated from the surface $\mathrm{PM}_{2.5}$ obtained from the GEOS-Chem simulations with and without the charcoal emissions and gridded population data. The results are shown in Figure 6.5 for the 2014 and 2030 simulations. More people are exposed to $\mathrm{PM}_{2.5}$ in East and West Africa. Annual mean populationweighted $\mathrm{PM}_{2.5}$ in Africa in 2014 is $0.34 \mu \mathrm{g} \mathrm{m}^{-3}$. This is $17 \%$ of population-weighted annual ambient $\mathrm{PM}_{2.5}$ from solid fuel use for household cooking in Sub-Sahara Africa (Chafe et al., 2015). The African population increases from 1.2 billion people in 2014 to 1.7 billion people in 2030 (Roser, 2013) and population-weighted $\mathrm{PM}_{2.5}$ increases to 0.51 $\mu \mathrm{g} \mathrm{m}^{-3}$ due to the combined increase in $\mathrm{PM}_{2.5}$ and urban population. 
2014

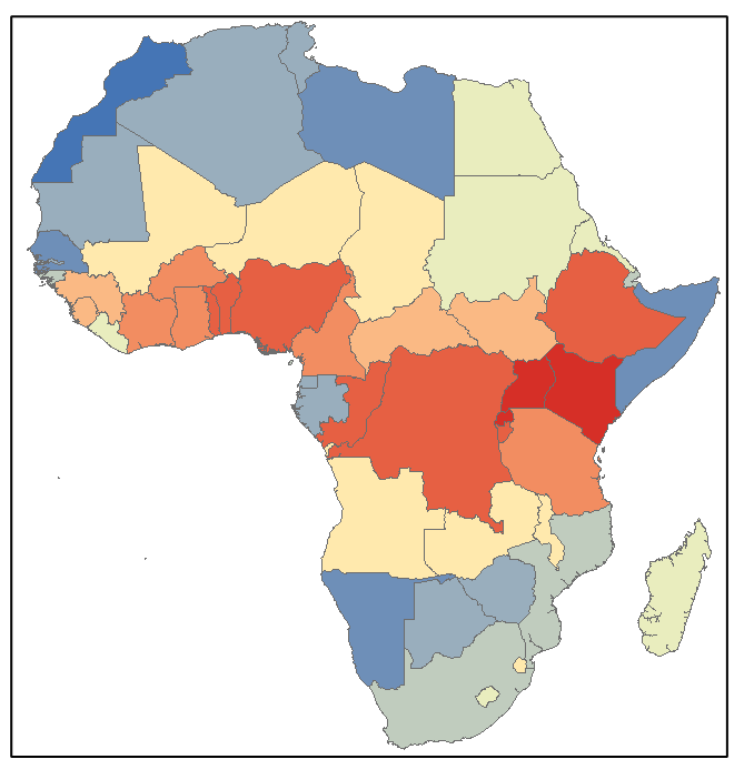

2030

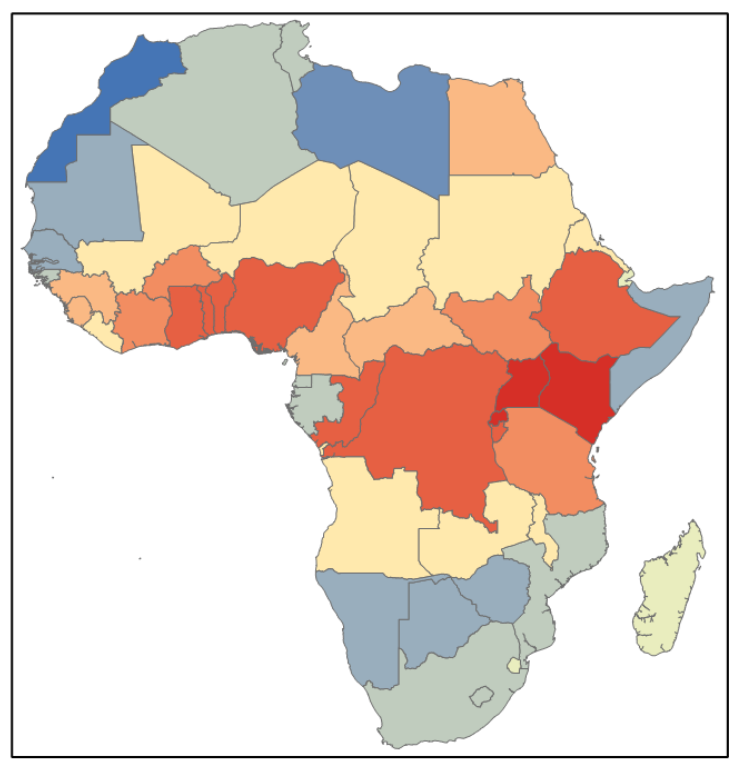

Population-weighted $\mathrm{PM}_{2.5}\left[\mathrm{ug} \mathrm{m}^{-3}\right]$

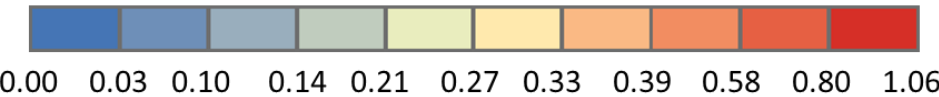

Figure 6.5 Population-weighted charcoal industry $\mathrm{PM}_{2.5}$ in Africa. Maps show population-weighted $\mathrm{PM}_{2.5}$ obtained for $\mathrm{PM}_{2.5}$ from charcoal industry emissions in Africa in 2014 (left) and 2030 (right). Unit is $\mu \mathrm{g} \mathrm{m}^{-3}$.

The population-weighted estimate is even much more (22\%) when only East and West Africa domains (bottom left of Figure 6.1) with elevated $\mathrm{PM}_{2.5}$ from the charcoal industry and rapid population growth and urbanisation are sampled. If this work had used the updated OC emission factors, the population-weighted exposure values would be higher and suggests a large and rapidly increasing contribution of charcoal to populationweighted exposure in these regions. 


\subsection{Climate Impacts from Charcoal Emissions in Africa}

Figure 6.6 shows present-day (2014) all-sky (clear and cloudy pixels) top-of-theatmosphere (TOA) direct radiative forcing due to aerosols and ozone from the charcoal supply chain in Africa. These are obtained as the difference in the GEOS-Chem-RRTMG calculated radiative effects with and without our inventory. The all-sky TOA direct aerosol forcing is localised over the continent due to the short lifetime of aerosols of days to weeks. The radiative effect is negative, mostly due to negative OA radiative forcing. The positive contribution from $\mathrm{BC}$ is small, peaking at just $3 \mathrm{~mW} \mathrm{~m} \mathrm{~m}^{-2}$. The average aerosol radiative forcing for the continent is $-30 \mathrm{~mW} \mathrm{~m}^{-2}$; much more than the response of $-4.1 \mathrm{~mW} \mathrm{~m}^{-2}$ from a $10 \%$ reduction in early 1990s open fire emissions in Africa obtained with a CTM and an offline radiative transfer model (Naik et al. 2007). The 10\% emissions reduction in that study is equivalent in magnitude to our $\mathrm{CO}$ emissions for 2014, but is more than our $\mathrm{BC}, \mathrm{OC}$, and $\mathrm{NO}_{\mathrm{x}}$, and less than our NMVOCs. The higher $\mathrm{BC}$ emissions in that scenario may have been more effective at offsetting cooling from $\mathrm{OA}$ than is the case with $\mathrm{BC}$ emissions from charcoal.
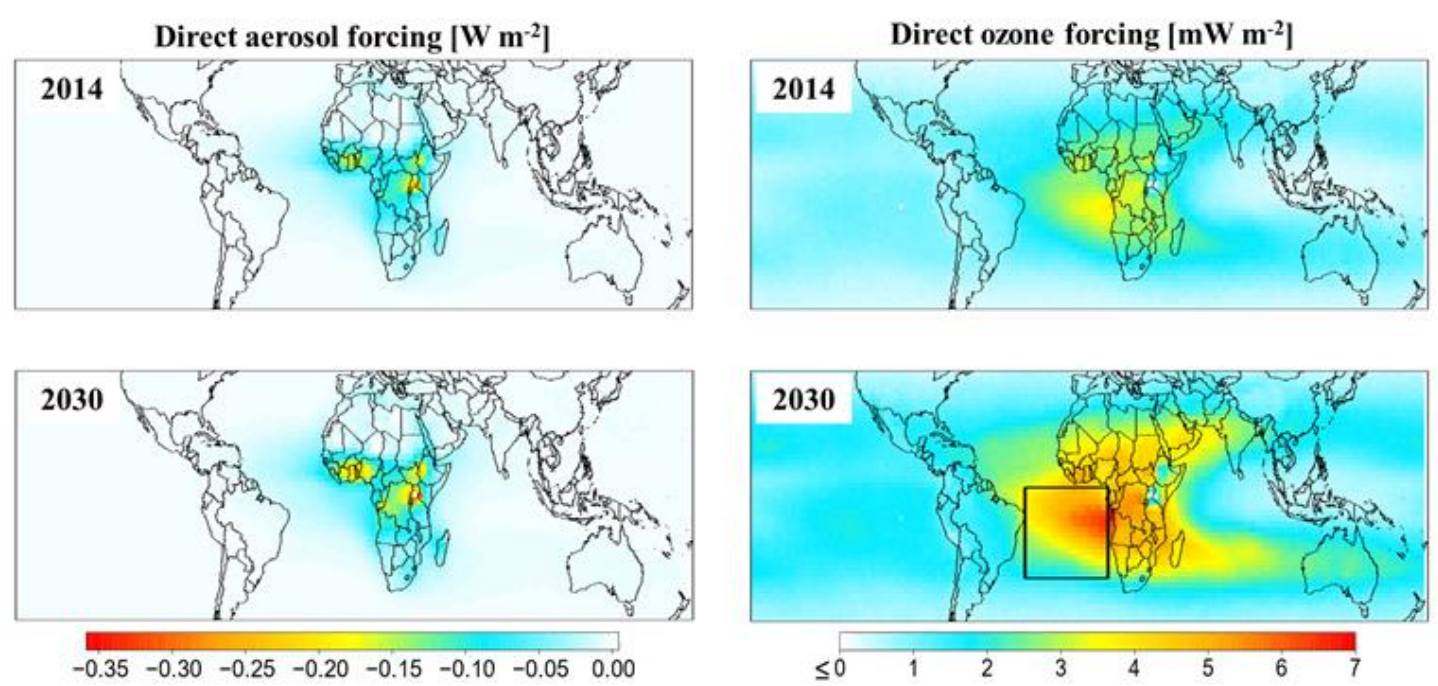
Figure 6.6 Direct radiative forcing in the tropics and subtropics due to the charcoal supply chain in Africa now and in the future. Model simulated annual mean all-sky topof-the-atmosphere direct aerosol shortwave (left) and ozone longwave and shortwave (right) forcing for 2014 (top) and 2030 (bottom) from GEOS-Chem coupled to RRTMG (see text for details). The box in the bottom right panel shows peaks peak ozone radiative forcing over the Atlantic Ocean.

The all-sky TOA direct ozone radiative forcing in Figure 6.6 extends across the tropics and subtropics and is mostly positive. This is because ozone is formed between 100-1000 $\mathrm{km}$ from its source emissions and absorbs longwave and shortwave radiation emitted from the earth's surface resulting in positive forcing (warming). There are some locations with negative forcing in East Africa. These occur over cities in Kenya (Nairobi), Uganda (Kampala), and Ethiopia (Addis Ababa) that show large local enhancements in $\mathrm{PM}_{2.5}$ from charcoal emissions (Figure 6.1). The negative ozone forcing results from reduced availability of light due to absorption by strong absorbers like BC emitted during urban charcoal use (Figures 5.3 and 6.1). Positive ozone radiative forcing peaks at $4.2 \mathrm{~mW} \mathrm{~m}^{-2}$ over the mid-Atlantic in 2014. The average ozone radiative forcing over the Atlantic Ocean (box in Figure 6.6) is $2.2 \mathrm{~mW} \mathrm{~m}^{-2}$. The ozone radiative forcing estimated by Naik et al. (2007) for the continent from a $10 \%$ reduction in 1990 s open fire emissions is -4.6 $\mathrm{mW} \mathrm{m} \mathrm{m}^{-2}$; more than double the response $\left(+1.9 \mathrm{~mW} \mathrm{~m}^{-2}\right)$ from an increase in ozone precursor emissions from the charcoal supply chain in 2014.

Figure 6.7 shows the vertical distribution of modelled ozone for 2014 north and south of the Equator. 
Longitude-pressure plot of ozone (pptv) due to 2014 charcoal emissions
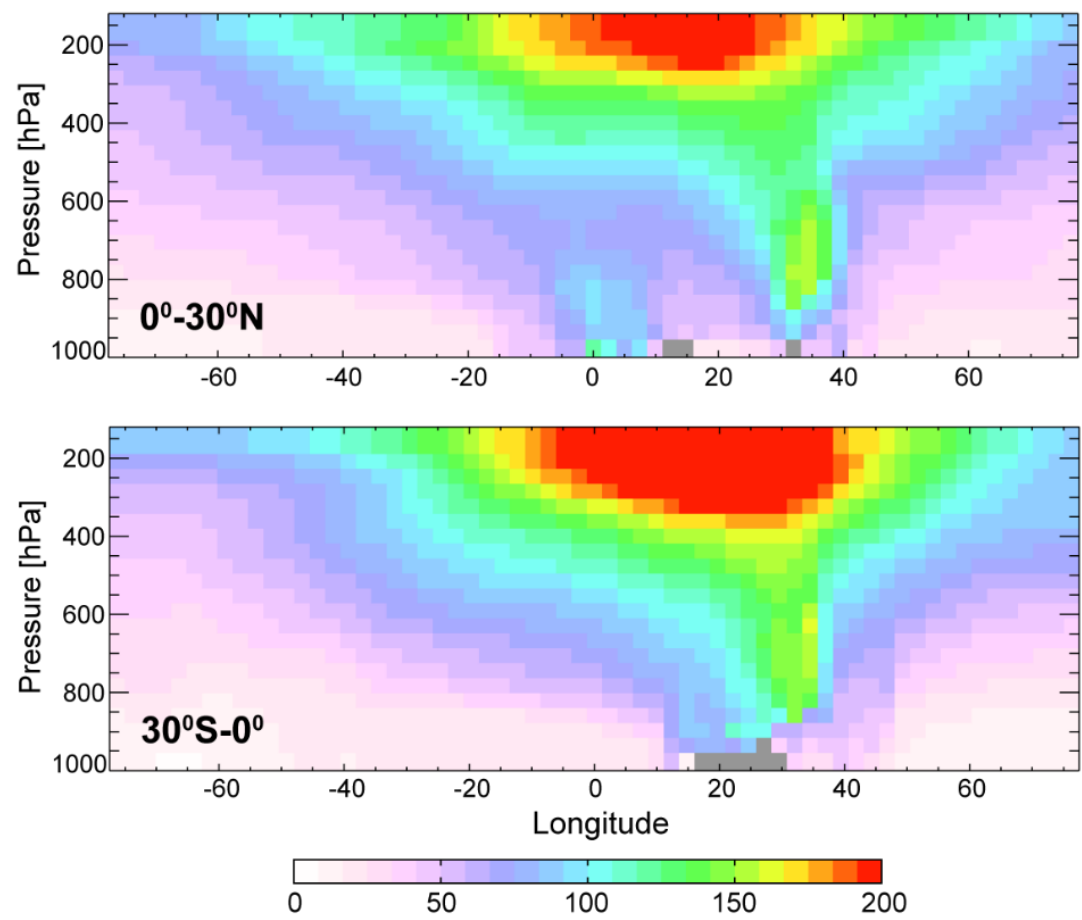

Figure 6.7 Vertical distribution of tropospheric ozone attributed to the charcoal supply chain in Africa in 2014. Longitude-pressure plot of GEOS-Chem ozone enhancements in the northern (top) and southern (bottom) hemispheres averaged into $50 \mathrm{hPa}$ bins. The top of the troposphere is diagnosed with tropopause height from the MERRA-2 meteorology. Grey indicates topography.

The ozone enhancements associated with the positive TOA direct ozone radiative forcing in Figure 6.6 occur aloft and predominantly in the upper troposphere (above $350 \mathrm{hPa}$; > $8 \mathrm{~km}$ ). This is associated with increased ozone radiative forcing efficiency (the radiative forcing induced by a unit change in ozone) aloft in the tropics (Mickley et al., 1999) and an increase in ozone production efficiency (ozone produced per molecule of $\mathrm{NO}_{\mathrm{x}}$ lost to 
temporary reservoirs or permanent sinks) with altitude due to the longer lifetime of $\mathrm{NO}_{\mathrm{x}}$ in the troposphere (Jaeglé et al., 1998; Dahlmann et al., 2011) and transport.

Figure 6.6 also includes future (2030) annual mean all-sky TOA direct aerosol and ozone radiative forcing from the charcoal supply chain in Africa. The mean all-sky TOA aerosol direct forcing over Africa in 2030 is $-40 \mathrm{~mW} \mathrm{~m}^{-2} ; 1.3$ times the aerosol direct forcing in 2014. The peak all-sky TOA ozone direct radiative forcing is $6.3 \mathrm{~mW} \mathrm{~m}^{-2}$ over the midAtlantic Ocean. The mean over Sub-Saharan Africa in 2030 is $3.4 \mathrm{~mW} \mathrm{~m}^{-2}$. This is almost double that for Sub-Saharan Africa in $2014\left(1.9 \mathrm{~mW} \mathrm{~m}^{-2}\right)$ and can be compared to $10 \mathrm{~mW}$ $\mathrm{m}^{-2}$ and $15 \mathrm{~mW} \mathrm{~m} \mathrm{~m}^{-2}$ direct ozone radiative forcing for all household biofuel use and open burning of biomass, respectively, in Sub-Saharan Africa for 2030 relative to 1995 obtained with a general circulation model using a middle-of-the-road future scenario to calculate 2030 emissions (Unger et al. 2008).

\subsection{Summary}

Biomass burning, natural emissions (from vegetation and soil), lightning (for $\mathrm{NO}_{\mathrm{x}}$ ), and anthropogenic sources (fossil fuel for energy transport, energy, industry and domestic use) are four major sources of emissions of air pollutants and short-lived climate forcers in Africa that are currently contributing to air pollution and climate change. In this work, it was found that emissions from the charcoal contribute to peak concentrations in $\mathrm{PM}_{2.5}$ of $1.3 \mu \mathrm{g} \mathrm{m}^{-3}$ and in ozone of $0.7 \mathrm{ppbv}$ in 2014 and cooling due to aerosols (-100 to -300 $\mathrm{mW} \mathrm{m} \mathrm{m}^{-2}$ ) is concentrated over dense cities, whereas warming due to ozone is widespread, peaking at $4.2 \mathrm{~mW} \mathrm{~m}^{-2}$ over the Atlantic Ocean. By 2030 urban population in Africa will 
increase charcoal production by a factor of 1.7. This will lead to an increase in mean allsky TOA forcing of $-5 \mathrm{~mW} \mathrm{~m} \mathrm{~m}^{-2}$ for aerosols and $0.7 \mathrm{~mW} \mathrm{~m}$ for ozone. Annual mean population-weighted $\mathrm{PM}_{2.5}$ in Africa in 2014 is $0.34 \mu \mathrm{g} \mathrm{m}^{-3}$. This will increase by a factor of 1.5 in 2030. 


\section{CONCLUSIONS AND RECOMMENDATIONS}

\subsection{Overview}

The burgeoning charcoal industry in Africa provides energy to more than $80 \%$ of households across the continent. Increase in household income and urban population in Africa are sustaining growth in this industry. In this work, Mann-Kendall with ThielSen's Slope analysis was used to determine past trends (2000-2014) in charcoal production and use in Africa and its subregions. Regression analysis was applied to charcoal production statistics and charcoal of charcoal production (and use) against urban population has been also conducted to estimate future charcoal production and use in Africa and its subregions and the amount of forest degradation charcoal production might cause. Reported activity data and emission factors were used to develop an inventory of emissions from charcoal supply chain activities (production, transport, and use) in Africa in 2014. These were projected to 2030 using urban population growth rates, informed by the previous trend analysis. The inventory was applied to the GEOS-Chem coupled to a rapid radiative transfer model to assess the contribution of the 2014 and 2030 charcoal industry to surface $\mathrm{PM}_{2.5}$ and surface ozone and direct radiative forcing due to aerosols and tropospheric ozone. Meteorology from the model was held fixed at 2014 to isolate the effect of changes in emissions on air quality and radiative forcing. 


\subsection{Conclusions}

Between 2000 and 2014 average annual increase in charcoal production in Africa was $7.7 \pm 2.1 \%$. The increase was largely driven by urbanization. Charcoal production in Africa will continue to increase from 2014 to 2030 , driven predominantly by rapid urbanization. If charcoal production continues to be unregulated, as is anticipated (Chidumayo and Gumbo, 2013) charcoal production will almost double on the continent from $41 \mathrm{Tg}$ in 2014 to $74 \mathrm{Tg}$ in 2030 . This will lead to degradation of forest cover of 4.5-15 million hectares in 2030. East Africa makes the largest contribution to this increase (38\%) due to highest production of charcoal in the region. Our results suggest that biomass required for charcoal production will continue to be available for charcoal production in most of Africa, except areas close the Sahara Desert that have low forest cover and relatively high harvesting rates.

A detailed inventory of geospatial emissions from the charcoal supply chain was developed using existing country-level statistics on charcoal production and use to determine the regional and global significance of pollution from this industry. Charcoal production was mapped to production zones in rural areas located close to major roadways, charcoal use was mapped to urban populations, and transport to routes with the greatest density of these extending from the city centre. Use of plastic to initiate combustion, estimated to be 260 tonnes, was restricted to low-income homes on the periphery of city centres. Total emissions of pollutants from the supply chain were: 42 Gg BC, $85 \mathrm{Gg}$ OC, $18 \mathrm{Tg} \mathrm{CO}, 76 \mathrm{Gg} \mathrm{NO}_{\times}, 0.8 \mathrm{Gg} \mathrm{SO}_{2}, 1.9 \mathrm{Gg} \mathrm{CH}_{4}, 10 \mathrm{Tg}$ NMVOCs, and $0.02 \mathrm{Gg} \mathrm{HCl}$. The $\mathrm{CH}_{4}$ emissions from the charcoal supply chain mostly (88\%) come 
from charcoal production and are $40 \%$ of $\mathrm{CH}_{4}$ from open fire emissions. These may be equivalent to open fire $\mathrm{CH}_{4}$ emissions by 2025 . $\mathrm{CO}$ is $87 \%$ of $\mathrm{CO}$ from open fire biomass burning emissions in Africa. Pollutant emissions are predictably emitted from different charcoal activities based on combustion efficiency, except for OC. Charcoal production is very inefficient and so accounts for most $\mathrm{CH}_{4}(1.6 \mathrm{Tg}$ or $88.3 \%), \mathrm{CO}(10.6 \mathrm{Tg}$ or 57.7 $\%)$, and NMVOCs (6.7 Tg or 96.7\%) emissions. Charcoal use is a more efficient process and so accounts for most $\mathrm{BC}(33 \mathrm{Gg}$ or $97.8 \%)$, OC (53 Gg or $62.7 \%)$, and $\mathrm{NO}_{\mathrm{x}}(58 \mathrm{Gg}$ or $76 \%$ ) emissions. OC comes mostly from charcoal use. This will be corrected in future with new measurements of emission factors from charcoal production and use (Keita $e t$ al., 2018) that would lead to 2:1 production-to-use OC emission ratios. $\mathrm{HCl}$ from burning plastic during charcoal use, estimated to be $0.02 \mathrm{Gg}$, is just $0.3 \%$ of global anthropogenic $\mathrm{HCl}$ emissions. Charcoal transport contributed $9 \mathrm{Gg}(11.8 \%)$ towards $\mathrm{NO}_{\mathrm{x}}$ and emitted all the $\mathrm{SO}_{2}(0.17 \mathrm{Gg})$. If current rates of use continue without viable energy alternatives, these emissions are likely to double by 2030 driven by urbanization, though the COVID19 pandemic may temporarily slow rates of population growth due its role in reduction of life expectancy as revealed in study conducted by Marois et al. (2020). According the ozone isopleth in section 1, future ozone production in Africa may increase or decrease depending on the location of emission. In the cities, emission of $\mathrm{NO}_{\mathrm{x}}$ from charcoal use and transport would increase, promoting ozone production in cities that are relatively $\mathrm{NO}_{\mathrm{x}}$-limited compared to cities in the United Kingdom. In rural areas, inefficient charcoal production will continue to contribute large quantities of NMVOCs, methane and CO that will likely sustain $\mathrm{NO}_{\mathrm{x}}$-limited conditions there and ongoing sensitivity of ozone formation to $\mathrm{NO}_{\mathrm{x}}$ in rural areas. 
Present day contribution of the charcoal industry to annual surface $\mathrm{PM}_{2.5}$ and ozone in Africa peaks at of $1.3 \mathrm{ug} \mathrm{m}^{-3}$ for $\mathrm{PM}_{2.5}$ and $0.7 \mathrm{ppbv}$ for ozone. The $\mathrm{PM}_{2.5}$ spreads vertically up to $\sim 2 \mathrm{~km}$ and horizontally to city centres where the emissions are heavily concentrated. Annual mean population-weighted exposure to surface ambient $\mathrm{PM}_{2.5}$ in Africa is $0.34 \mu \mathrm{g} \mathrm{m}^{-3}$. This will increase by $50 \%$ in 2030 . Tropospheric aerosols from the charcoal industry has a net cooling effect of $-4 \mathrm{~mW} \mathrm{~m}^{-2}$. The warming effect of tropospheric ozone in the long- and short-wave is $0.4 \mathrm{~m} \mathrm{~W} \mathrm{~m}^{-2}$. Air pollution and climate forcing by $\mathrm{PM}_{2.5}$ and ozone is projected increase almost two-fold in 2030 with a doubling in emissions. This should incentivise the development of effective policies that could include emission controls on all steps in the supply chain and the provision of alternative sources of energy that are both reliable and cost effective.

\subsection{Future work}

The work was carried out using a model simulated at relatively coarser spatial resolution $\left(2^{\circ} \times 2.5^{\circ}\right)$ to determine the combined effects of charcoal industry emissions on surface concentrations of air pollutants and global climate. This was useful for identifying regional hotspots in East Africa and West Africa to target future high-resolution simulations that better resolve spatial heterogeneities like political boundaries and ruralurban divide and population distribution. This will be necessary to conduct detailed health studies to determine the adverse health outcomes associated with exposure to air pollution. In doing this, however, there are likely to be limitations on the granularity of information on baseline mortality and other relevant health statistics. 
This work also only focuses on outdoor air pollution. Premature deaths due to exposure to indoor air pollution in Africa is estimated to be 404,400 in 2017 (HEI, 2019b). Children and women are particularly vulnerable to the adverse effects of indoor air pollution (Bailis et al., 2005; Rehfuess et al., 2006; Benaissa et al., 2014). Some urban households in Africa use charcoal cookstove indoors whilst others use it outdoor. Both indoor and outdoor use of charcoal cookstoves leads to increase in particulate matter area concentration levels and hence smoke exposure (Dasgupta et al., 2006; Bensch et al., 2015). Cookstove use indoor to prepare meals has higher impact potentials. If meals are prepared outdoor, natural ventilation can reduce levels of concentrations substantially, thereby reducing risk of exposure (Grabow et al., 2013; Rosa et al., 2014). Charcoal, however, is cleaner, it produces less smoke than wood (Pfotenhauer et al., 2019) and therefore has more health benefits as has been investigated by Woolley et al. (2020) and Taylor and Nakai (2012). A study focusing on indoor air pollution would require detailed information or appropriate generalizations about the characteristics of homes (such as ventilation and shading), other emissions in the home, and the complex physical and chemical processing of these emissions (Abbatt et al., 2020).

Another future application of the inventory developed in this work could be to test the efficacy of emission mitigation scenarios, such as the use of more efficient kilns and cookstoves (Kituyi, 2000) or the use of a mix of energy sources in the home. Both the effects on air pollution and climate could be tested with a model that forecasts meteorology and either is coupled to a radiative transfer model it can be used as input to offline radiative transfer code. 


\section{REFERENCES}

Abbatt, J. P. D. et al. (2020) 'The atmospheric chemistry of indoor environments', Environmental Science: Processes \& Impacts, 22(1), pp. 25-48. doi: 10.1039/C9EM00386J.

Aghedo, A. M. et al. (2007) 'The influence of African air pollution on regional and global tropospheric ozone', Atmospheric Chemistry and Physics, 7(5), pp. 1193-1212. doi: 10.5194/acp-7-1193-2007.

Agyeman, K. O. et al. (2012) 'Commercial Charcoal Production and Sustainable Community Development of the Upper West Region, Ghana', Journal of Sustainable Development, 5(4). doi: 10.5539/jsd.v5n4p149.

Ahern, A. T. et al. (2019) 'Production of Secondary Organic Aerosol During Aging of Biomass Burning Smoke From Fresh Fuels and Its Relationship to VOC Precursors', Journal of Geophysical Research: Atmospheres. doi: 10.1029/2018JD029068.

Akagi, S. K. et al. (2011) 'Emission factors for open and domestic biomass burning for use in atmospheric models', Atmospheric Chemistry and Physics, 11(9), pp. 4039-4072. doi: 10.5194/acp-11-4039-2011.

Akpalu, W. et al. (2011) 'Demand for cooking fuels in a developing country: To what extent do taste and preferences matter?', Energy Policy, 39(10), pp. 6525-6531. doi: 10.1016/J.ENPOL.2011.07.054.

Alam, O. et al. (2018) 'Characteristics of plastic bags and their potential environmental hazards', Resources, Conservation and Recycling, 132, pp. 121-129. doi:

10.1016/j.resconrec.2018.01.037.

Alem, S. et al. (2010) 'Wood charcoal supply to Addis Ababa city and its effect on the environment', Energy and Environment, 21(6), pp. 601-609. doi: 10.1260/0958- 
305X.21.6.601.

Amodio, M. et al. (2014) 'Atmospheric Deposition: Sampling Procedures, Analytical Methods, and Main Recent Findings from the Scientific Literature', Advances in Meteorology. Edited by C. Borrego, 2014, p. 161730. doi: 10.1155/2014/161730. Andela, N. et al. (2014) 'Recent trends in African fires driven by cropland expansion and El Niño to la Niña transition', Nature Climate Change, 4(9), pp. 791-795. doi: 10.1038/nclimate2313.

Andreae, M. O. et al. (2006) 'Black carbon or brown carbon? the nature of lightabsorbing carbonaceous aerosols', Atmospheric Chemistry and Physics. doi: 10.5194/acp-6-3131-2006.

Andreae, M. O. et al. (2008) 'Aerosol-cloud-precipitation interactions. Part 1. The nature and sources of cloud-active aerosols', Earth-Science Reviews, 6, pp. 3131-3148. doi: 10.1016/j.earscirev.2008.03.001.

Apte, J. S. et al. (2015) 'Addressing Global Mortality from Ambient PM2.5', Environmental Science and Technology, 49(13), pp. 8057-8066. doi: 10.1021/acs.est.5b01236.

Arashidani, K. et al. (1996) 'Indoor pollution from heating', Industrial Health, 34, pp. 205-215. doi: 10.2486/indhealth.34.205.

Arthur, M. de F. S. R. et al. (2010) 'On the adoption of electricity as a domestic source by Mozambican households', Energy Policy. doi: 10.1016/j.enpol.2010.07.054.

Assamoi, E.-M. et al. (2010) 'A new inventory for two-wheel vehicle emissions in West Africa for 2002', Atmospheric Environment, 44(32), pp. 3985-3996. doi: https://doi.org/10.1016/j.atmosenv.2010.06.048. Atkinson, R. (2000a) 'Atmospheric chemistry of VOCs and NO(x)', Atmospheric 
Environment, 34, pp. 2063-2101. doi: 10.1016/S1352-2310(99)00460-4.

Atkinson, R. (2000b) 'Atmospheric chemistry of VOCs and NO(x)', Atmospheric Environment. doi: 10.1016/S1352-2310(99)00460-4.

Ayodele, A. et al. (2009) 'Numerical analysis of the impact of charcoal production on soil hydrological behavior, runoff response and erosion susceptibility', Revista Brasileira de Ciência do Solo, 33(1), pp. 137-146. doi: 10.1590/S010006832009000100015.

Bailis, R. et al. (2004) 'Impacts of Greenhouse Gas and Particulate Emissions from Woodfuel Production and End-Use in Sub-Saharan Africa', Unknown, 1, p. 1. Bailis, R. et al. (2013) 'Innovation in charcoal production: A comparative life-cycle assessment of two kiln technologies in Brazil', Energy for Sustainable Development, 17(2), pp. 189-200. doi: https://doi.org/10.1016/j.esd.2012.10.008.

Bailis, R. et al. (2005) 'Mortality and Greenhouse Gas Impacts of Biomass and Petroleum Energy Futures in Africa', Science, 308(5718), pp. 98-103. doi: 10.1126/science. 1106881 .

Barros, V. R. et al. (2014) Climate change 2014 impacts, adaptation, and vulnerability Part B: Regional aspects: Working group ii contribution to the fifth assessment report of the intergovernmental panel on climate change, Climate Change 2014: Impacts, Adaptation and Vulnerability: Part B: Regional Aspects: Working Group II Contribution to the Fifth Assessment Report of the Intergovernmental Panel on Climate Change. doi: 10.1017/CBO9781107415386.

Bates, K. H. et al. (2019) 'A new model mechanism for atmospheric oxidation of isoprene: global effects on oxidants, nitrogen oxides, organic products, and secondary organic aerosol', Atmospheric Chemistry and Physics, 19(14), pp. 9613-9640. doi: 
10.5194/acp-19-9613-2019.

Bauer, S. E. et al. (2019) 'Desert Dust, Industrialization, and Agricultural Fires: Health Impacts of Outdoor Air Pollution in Africa', Journal of Geophysical Research:

Atmospheres, 124, pp. 4104-4120. doi: 10.1029/2018JD029336.

Benaissa, F. et al. (2014) 'Assessment of Air Pollution Impacts on Population Health in Bejaia City, Northern Algeria', Iranian journal of public health, 43(9), pp. 1221-1228. Available at: https://pubmed.ncbi.nlm.nih.gov/26175976.

Benjaminsen, T. A. (1997) 'Is there a fuelwood crisis in rural Mali?', GeoJournal, 43(2), pp. 163-174. doi: 10.1023/A:1006875711435.

Bensch, G. et al. (2015) 'Why do households forego high returns from technology adoption? Evidence from improved cooking stoves in Burkina Faso', Journal of Economic Behavior \& Organization, 116, pp. 187-205. doi:

https://doi.org/10.1016/j.jebo.2015.04.023.

Betts, R. et al. (2001) 'Chapter 6: Radiative Forcing of Climate Change', in Climate change 2001: The scientific basis, pp. 349-416.

Bildirici, M. et al. (2016) 'Woody Biomass Energy Consumption and Economic Growth in Sub-Saharan Africa', Procedia Economics and Finance, 38, pp. 287-293. doi: https://doi.org/10.1016/S2212-5671(16)30202-7.

Bird, J. et al. (2017) 'Life in a slum: Understanding living conditions in Nairobi's slums across time and space', Oxford Review of Economic Policy, 33(3), pp. 496-520. doi: 10.1093/oxrep/grx036.

Blango, M. M. et al. (2019) 'Effect of soil and water management practices on crop productivity in tropical inland valley swamps', Agricultural Water Management, 222, pp. 82-91. doi: https://doi.org/10.1016/j.agwat.2019.05.036. 
Bond, T. C. et al. (2004) 'A technology-based global inventory of black and organic carbon emissions from combustion', Journal of Geophysical Research: Atmospheres, 109(14), pp. 1-43. doi: 10.1029/2003JD003697.

Bouarar, I. et al. (2011) 'Emission sources contributing to tropospheric ozone over Equatorial Africa during the summer monsoon', Atmospheric Chemistry and Physics, 11, pp. 13395-13419. doi: 10.5194/acp-11-13395-2011.

Boughedaoui, M. et al. (2009) Mesure des émissions de VUL avec un système embarqué à Blida, in Environnement et Transports dans des contextes différents. Available at: https://hal.archives-ouvertes.fr/hal-01253510/ (Accessed: 26 March 2018).

Brancher, M. et al. (2017) 'A review of odour impact criteria in selected countries around the world', Chemosphere, 168, pp. 1531-1570. doi: https://doi.org/10.1016/j.chemosphere.2016.11.160.

Broadhead, J. et al. (2001) Past trends and future prospects forthe utilisation of wood for energy. GFPOS/WP/05,. Rome. Available at: http://www.fao.org/tempref/docrep/fao/005/y4450e/y4450e07.pdf.

Brown, S. S. et al. (2007) 'High resolution vertical distributions of NO3 and N $2 \mathrm{O} 5$ through the nocturnal boundary layer', Atmospheric Chemistry and Physics, 7, pp. 139149. doi: 10.5194/acp-7-139-2007.

Buchner, B. et al. (2019) Global Landscape of Climate Finance. London. Available at: https://climatepolicyinitiative.org/publication/\%0Aglobal-climate-finance-2019/. Buckle, C. (1996) Weather and Climate in Africa. illustrate. Longman. Burgess, J. C. (1993) ‘Timber Production, Timber Trade and Tropical Deforestation', Ambio, 22(2/3), pp. 136-143. Available at: http://www.jstor.org/stable/4314058. Cadman, J. et al. (2005) Proposed Plastic Bag Levy - Extended Impact Assessment 
Final Report. Edinburgh: Scottish Executive. Available at:

https://www2.gov.scot/resource/doc/57346/0016899.pdf.

Cappa, C. D. et al. (2012) 'Radiative absorption enhancements due to the mixing state of atmospheric black carbon', Science. doi: 10.1126/science.1223447.

Casiday, R. et al. (1998) Acid Rain. Inorganic Reactions Experiment. Available at: http://www.chemistry.wustl.edu/ edudev/LabTutorials/Water/FreshWater/acidrain.html (Accessed: 28 July 2020).

Chafe, Z. A. et al. (2015) 'Household cooking with solid fuels contributes to ambient PM2.5air pollution and the burden of disease', Environmental Health Perspectives, 122(12), pp. 1314-20. doi: 10.1289/ehp.1206340.

Chameides, W. L. et al. (1999) 'Case study of the effects of atmospheric aerosols and regional haze on agriculture: An opportunity to enhance crop yields in China through emission controls?', Proceedings of the National Academy of Sciences of the United States of America. doi: 10.1073/pnas.96.24.13626.

Chandler, A. S. et al. (1988) 'Measurements of $\mathrm{H} 2 \mathrm{O} 2$ and SO2 in clouds and estimates of their reaction rate', Nature, 336, p. 8. doi: 10.1038/336562a0.

Chapman, E. G. et al. (2009) 'Coupling aerosol-cloud-radiative processes in the WRFChem model: Investigating the radiative impact of elevated point sources', Atmospheric Chemistry and Physics, 9, pp. 945-964. doi: 10.5194/acp-9-945-2009.

Chavula, J. (2019) Burning issues about plastic pollution. Available at: https://medium.com/thebeammagazine/burning-issues-about-plastic-pollutiona4f4d1264f3d (Accessed: 4 June 2019).

Chen, B. et al. (2018) 'Real-Time Estimation of Population Exposure to PM(2.5) Using Mobile- and Station-Based Big Data', International journal of environmental research 
and public health, 15(4), p. 573. doi: 10.3390/ijerph15040573.

Cherian, R. et al. (2017) 'Black carbon indirect radiative effects in a climate model', Tellus, Series B: Chemical and Physical Meteorology, 69(1), p. 1369342. doi: 10.1080/16000889.2017.1369342.

Chidumayo, E. N. et al. (2013) 'The environmental impacts of charcoal production in tropical ecosystems of the world: A synthesis', Energy for Sustainable Development, 17(2), pp. 86-94. doi: https://doi.org/10.1016/j.esd.2012.07.004.

Chiteculo, V. et al. (2018a) 'Value Chain of Charcoal Production and Implications for Forest Degradation: Case Study of Bié Province, Angola', Environments. doi: 10.3390/environments5110113.

Chiteculo, V. et al. (2018b) 'Value Chain of Charcoal Production and Implications for Forest Degradation: Case Study of Bié Province, Angola', Environments. doi: 10.3390/environments5110113.

Christensen, J. H. et al. (2007) Regional Climate Projections. In: Climate Change 2007: The Physical Science Basis. Contribution of Working Group I to the Fourth Assessment Report of the Intergovernmental Panel on Climate Change, Cambridge University Press. doi: 10.1080/07341510601092191.

Christian, H. J. et al. (2003) 'Global frequency and distribution of lightning as observed from space by the Optical Transient Detector', Journal of Geophysical Research: Atmospheres, 108(D1), p. ACL 4-1-ACL 4-15. doi: 10.1029/2002JD002347. Ciais, P. et al. (2011) 'The carbon balance of Africa: synthesis of recent research studies', Philosophical transactions. Series A, Mathematical, physical, and engineering sciences, 369(1943), pp. 2038-2057. doi: 10.1098/rsta.2010.0328.

CIESIN (2017) Gridded Population of the World, Version 4 (GPWv4): Population 
Density, Revision 10. Palisades, NY: NASA Socioeconomic Data and Applications Center (SEDAC). Available at: https://doi.org/10.7927/H4DZ068D (Accessed: 12 November 2018).

Conway, G. (2009) The science of climate change in Africa:impacts and adaptation. No 1. London. Available at: https://www.mamopanel.org/media/uploads/files/SCIENCE_OF_CLIMATE_CHANGE _IN_AFRICA-_IMPACTS_AND_ADAPTION_2009.pdf.

Coulter, J. K. (1995) 'Reversing the Spiral: The Population, Agriculture, and Environment Nexus in Sub-Saharan Africa. (Directions in Development.) By K. M. Cleaver and G. A. Schreiber. Washington DC: The World Bank† (1994), pp. 293, $£ 17.05$, US\$18.95. ISBN 0-8213-2760-0.', Experimental Agriculture. 2008/10/03, 31(4), p. 513. doi: DOI: 10.1017/S0014479700026570.

Crespo, L. R. et al. (2019) 'The role of sea surface temperature in the atmospheric seasonal cycle of the equatorial Atlantic', Climate Dynamics, 52(9), pp. 5927-5946. doi: 10.1007/s00382-018-4489-4.

d'Annunzio, R. et al. (2015) 'Projecting global forest area towards 2030', Forest Ecology and Management, 352, pp. 124-133. doi: 10.1016/j.foreco.2015.03.014. Dahlmann, K. et al. (2011) 'Quantifying the contributions of individual $\mathrm{NO}_{\mathrm{x}}$ sources to the trend in ozone radiative forcing', Atmospheric Environment, 45(17), pp. 2860-2868. doi: 10.1016/j.atmosenv.2011.02.071.

Damian, V. et al. (2002) 'The kinetic preprocessor KPP - A software environment for solving chemical kinetics', Computers and Chemical Engineering, 26, pp. 1567-1579. doi: 10.1016/S0098-1354(02)00128-X.

Dasgupta, S. et al. (2006) 'Who suffers from indoor air pollution? Evidence from 
Bangladesh', Health Policy and Planning, 21(6), pp. 444-458. doi:

10.1093/heapol/czl027.

Davis, M. (1998) 'Rural household energy consumption: The effects of access to electricity - Evidence from South Africa', Energy Policy, 26(3), pp. 207-217. doi: 10.1016/S0301-4215(97)00100-6.

Delfino, R. J. et al. (2006) 'Personal and ambient air pollution is associated with increased exhaled nitric oxide in children with asthma', Environmental Health Perspectives. doi: 10.1289/ehp.9141.

Demirbas, A. (2009) 'Sustainable charcoal production and charcoal briquetting', Energy Sources, Part A: Recovery, Utilization and Environmental Effects. doi:

10.1080/15567030802094060.

Doggart, N. et al. (2017) 'The marginalization of sustainable charcoal production in the policies of a modernizing African Nation', Frontiers in Environmental Science, 5, p. 27. doi: 10.3389/fenvs.2017.00027.

Dolske, D. A. et al. (1985) 'A field intercomparison of methods for the measurement of particle and gas dry deposition', Journal of Geophysical Research: Atmospheres, 90(D1), pp. 2076-2084. doi: 10.1029/JD090iD01p02076.

Dore, A. J. et al. (2015) 'Evaluation of the performance of different atmospheric chemical transport models and inter-comparison of nitrogen and sulphur deposition estimates for the UK', Atmospheric Environment, 119, pp. 131-143. doi: 10.1016/j.atmosenv.2015.08.008.

Duncan, B. N. et al. (2008) 'The influence of European pollution on ozone in the Near East and northern Africa', Atmospheric Chemistry and Physics, 8(8), pp. 2267-2283. doi: 10.5194/acp-8-2267-2008. 
Eastham, S. D. et al. (2014) 'Development and evaluation of the unified troposphericstratospheric chemistry extension (UCX) for the global chemistry-transport model GEOS-Chem', Atmospheric Environment, 89, pp. 52-63. doi: 10.1016/j.atmosenv.2014.02.001. EEA (2019) EMEP/EEA air pollutant emission inventory guidebook 2019. Technical guidance to prepare national emission inventories. Luxembourg. doi: doi:10.2800/293657.

Ekeh, O. et al. (2014) 'Quantifying greenhouse gases from the production, transportation and utilization of charcoal in developing countries: a case study of Kampala, Uganda', The International Journal of Life Cycle Assessment, 19(9), pp. 1643-1652. doi: 10.1007/s11367-014-0765-7.

Emami, F. et al. (2018) 'Air pollution at Rochester, NY: Long-term trends and multivariate analysis of upwind SO2 source impacts', Science of The Total Environment, 612, pp. 1506-1515. doi: https://doi.org/10.1016/j.scitotenv.2017.09.026. Ezratty, V. et al. (2014) 'Repeated nitrogen dioxide exposures and eosinophilic airway inflammation in asthmatics: A randomized crossover study', Environmental Health Perspectives, 122, p. 8. doi: 10.1289/ehp.1307240.

Fagbemi, L. et al. (2001) 'Pyrolysis products from different biomasses: application to the thermal cracking of tar', Applied Energy, 69(4), pp. 293-306. doi: https://doi.org/10.1016/S0306-2619(01)00013-7. FAO (1987) Simple Technologies for charcoal making. 41.

FAO (2010) Criteria and indicators for sustainable woodfuels, FAO Forestry Paper. Rome:

FAO (2015) FAO GEONETWORK. Rome, Italy: FAO. Available at: 
http://www.fao.org/geonetwork/srv/en/main.home?uuid=063720fb-79b5-44e5-832b1c03f6b845ac (Accessed: 14 May 2018).

FAO (2016) FAOSTAT (dataset). Available at: http://faostat3.fao.org/\%0Afaostatgateway/go/to/browse/F/FO/E (Accessed: 20 June 2018).

FAO (2017) The charcoal transition: greening the charcoal value chain to mitigate climate change and improve local livelihoods. Rome.

Fecht, S. (2017) Air Pollution May Kill More Africans Than HIV/AIDS. Available at: https://blogs.ei.columbia.edu/2017/12/18/air-pollution-may-kill-africans-hiv-aids/ (Accessed: 7 July 2020).

Fer, I. et al. (2017) 'The influence of El Niño-Southern Oscillation regimes on eastern African vegetation and its future implications under the RCP8.5 warming scenario', Biogeosciences, 14(18), pp. 4355-4374. doi: 10.5194/bg-14-4355-2017.

Finlayson-Pitts, B. J. et al. (2000) Chemistry of the Upperand Lower Atmosphere: Theory, Experiments, and Applications. San Diego, CA, USA: Academic Press. Forbes, M. S. et al. (2006) 'Formation, transformation and transport of black carbon (charcoal) in terrestrial and aquatic ecosystems', Science of the Total Environment, 360, pp. 190-206. doi: 10.1016/j.scitotenv.2006.06.007.

Forster, P. et al. (2010) Changes in Atmospheric Constituents and in Radiative Forcing Coordinating, Climate Change 2007: The Physical Science Basis. Contribution of Working Group I to the Fourth Assessment Report of the Intergovernmental Panel on Climate Change.

Fowler, D. et al. (2009) 'Atmospheric composition change: Ecosystems-Atmosphere interactions', Atmospheric Environment, 43(33), pp. 5193-5267. doi: https://doi.org/10.1016/j.atmosenv.2009.07.068. 
Frey, C. H. (2007) 'Quantification of Uncertainty in Emissions Factors and Inventories', in 16th Annual International Emission Inventory Conference Emission Inventories: 'Integration, Analysis and Communications'. Raleigh, NC.

Fry, M. M. et al. (2014) 'Air quality and radiative forcing impacts of anthropogenic volatile organic compound emissions from ten world regions', Atmospheric Chemistry and Physics, 14(2), pp. 523-535. doi: 10.5194/acp-14-523-2014.

Fuentes, J. D. et al. (2000) 'Biogenic Hydrocarbons in the Atmospheric Boundary Layer: A Review', Bulletin of the American Meteorological Society, 81(7), pp. 15371576. doi: 10.1175/1520-0477(2000)081<1537:BHITAB>2.3.CO;2.

Fuglestvedt, J. S. et al. (1999) 'Climatic forcing of nitrogen oxides through changes in tropospheric ozone and methane; global 3D model studies', Atmospheric Environment. doi: 10.1016/S1352-2310(98)00217-9.

Fullerton, D. G. et al. (2008) 'Indoor air pollution from biomass fuel smoke is a major health concern in the developing world', Transactions of the Royal Society of Tropical Medicine and Hygiene, 102, pp. 843-851. doi: 10.1016/j.trstmh.2008.05.028.

Gannon, K. E. et al. (2018) 'Business experience of floods and drought-related water and electricity supply disruption in three cities in sub-Saharan Africa during the 2015/2016 El Niño', Global Sustainability. 2018/12/04, 1, p. e14. doi: DOI: 10.1017/sus.2018.14.

Garbarova, M. et al. (2015) 'The Trend Analysis of Transport Development in Slovak Republic', Procedia Economics and Finance, 26, pp. 584-591. doi: https://doi.org/10.1016/S2212-5671(15)00958-2.

Gathui, T. wa et al. (2010) Bioenergy and Poverty in Kenya: Attitudes, Actors and Activities. Kenya. Available at: http://www.pisces.or.ke/pubs/index.html; Commercial 
reproduction prohibited; OSTI as DE21328683.

Gazull, L. et al. (2015) 'Woodfuel in a global change context', Wiley Interdisciplinary Reviews: Energy and Environment, pp. 156-170. doi: 10.1002/wene.115.

GEF (2013) Africa will import - not export - wood. Chevy Chase, MD, USA.

GeoFABRIK (2017) OpenStreetMap for Africa. Available at:

http://download.geofabrik.de/africa.html (Accessed: 10 June 2018).

Giannini, A. (2010) The Influence of Sea Surface Temperatures on African Climate.

Palisades NY. Available at:

https://www.ecmwf.int/sites/default/files/elibrary/2012/9554-influence-sea-surfacetemperatures-african-climate.pdf.

Giglio, L. et al. (2013) 'Analysis of daily, monthly, and annual burned area using the fourth-generation global fire emissions database (GFED4)', Journal of Geophysical Research: Biogeosciences, 118(1), pp. 317-328. doi: 10.1002/jgrg.20042.

GIZ (2014) Multiple-household fuel use: a balanced choice between fuelwood, charcoal and LPG. Eschborn, Germany.

Glaser, B. et al. (2002) 'Ameliorating physical and chemical properties of highly weathered soils in the tropics with charcoal - A review', Biology and Fertility of Soils, 41, pp. 50-58. doi: 10.1007/s00374-002-0466-4.

Glen, S. (2020) 'Sen's Slope / Theil-Sen estimator'. From StatisticsHowTo.com:

Elementary Statistics for the rest of us! Available at:

https://www.statisticshowto.com/sens-slope-theil-sen-estimator/ (Accessed: 4 May 2020).

Godish, T. (1997) Air Quality, Third Edition, Air Quality, Third Edition. doi: 10.1201/noe1566702317. 
Gomaa, H. et al. (2000) A Simple Charcoal Kiln for Hardwoods or Other Dense Biomass (Quick, Efficient, Eco- nomic with Low Environmental Impact. Cairo. Available at: http://virtualacademia.com/pdf/clea167_174.pdf. Gorse, J. E. et al. (1987) Desertification in the Sahelian and Sudanian zones of West Africa. 61. Washington DC. Available at: Desertification in the Sahelian and Sudanian zones of West Africa.

Grabow, K. et al. (2013) 'Test Kitchen studies of indoor air pollution from biomass cookstoves', Energy for Sustainable Development, 17(5), pp. 458-462. doi: https://doi.org/10.1016/j.esd.2013.05.003.

Grahame, T. J. et al. (2014) 'Public health and components of particulate matter: The changing assessment of black carbon', Journal of the Air and Waste Management Association, 64(6), pp. 620-660. doi: 10.1080/10962247.2014.912692.

Grainger, A. (1999) 'Constraints on modelling the deforestation and degradation of tropical open woodlands', Global Ecology and Biogeography, 8(3-4), pp. 179-190. doi: 10.1046/j.1466-822X.1999.00135.x.

Grant, A. et al. (2010) 'Modelling the oxidation of seventeen volatile organic compounds to track yields of $\mathrm{CO}$ and CO2', Atmospheric Environment, 44(31), pp. 3797-3804. doi: 10.1016/j.atmosenv.2010.06.049.

Graves, B. (2012) THE STORY OF CHARCOAL. Available at: https://pyrites.org/publications_files/Charcoal Making.pdf (Accessed: 25 June 2020). Gu, G. et al. (2004) 'Seasonal evolution and variability associated with the West African monsoon system', Journal of Climate, 17, pp. 3364-3377. doi: 10.1175/15200442(2004)017<3364:SEAVAW>2.0.CO;2.

Guenther, A. B. et al. (2012) 'The model of emissions of gases and aerosols from nature 
version 2.1 (MEGAN2.1): An extended and updated framework for modeling biogenic emissions', Geoscientific Model Development, 5(6), pp. 1471-1492. doi: 10.5194/gmd5-1471-2012.

Guertin, L. et al. (2020) EARTH 105: Environments of Africa. Available at: https://courseware.e-education.psu.edu/courses/earth105new/content/lesson07/03.html (Accessed: 22 July 2020).

Gunthe, S. S. et al. (2011) 'Cloud condensation nuclei (CCN) from fresh and aged air pollution in the megacity region of Beijing', Atmospheric Chemistry and Physics. doi: 10.5194/acp-11-11023-2011.

Gwatkin, D. R. (2017) 'Trends in health inequalities in developing countries', The Lancet Global Health, 5(4), pp. e371-e372. doi: https://doi.org/10.1016/S2214109X(17)30080-3.

Habitat (1991) Energy for Low-income Settlements.

Hamatui, N. et al. (2016) 'Respiratory health effects of occupational exposure to charcoal dust in Namibia', International Journal of Occupational and Environmental Health, 22, pp. 240-248. doi: 10.1080/10773525.2016.1214795.

Hansen, M. C. et al. (2013) 'High-resolution global maps of 21st-century forest cover change', Science. doi: 10.1126/science.1244693.

Heald, C. L. et al. (2006) 'Concentrations and sources of organic carbon aerosols in the free troposphere over North America', Journal of Geophysical Research: Atmospheres, 111(D23), p. n/a-n/a. doi: 10.1029/2006jd007705.

Heald, C. L. et al. (2013) 'Beyond direct radiative forcing: the case for characterizing the direct radiative effect of aerosols', Atmospheric Chemistry and Physics Discussions, 14, pp. 5513-5527. doi: 10.5194/acpd-13-32925-2013. 
Heald, C. L. et al. (2014) 'Contrasting the direct radiative effect and direct radiative forcing of aerosols', Atmospheric Chemistry and Physics, 14(11), pp. 5513-5527. doi: 10.5194/acp-14-5513-2014.

HEI (2019a) State of Global Air 2019. Boston, MA. Available at: https://www.stateofglobalair.org/sites/default/files/soga_2019_report.pdf. HEI (2019b) State of Global Air 2019. Available at: https://www.stateofglobalair.org/data/\#/health/map (Accessed: 15 June 2020). Heltberg, R. (2001) 'Determinants and impact of local institutions for common resource management', Environment and Development Economics, 6, pp. 183-208. doi: 10.1017/S1355770X01000110.

Hengeveld, G. . et al. (2015) Global 1-degree Maps of Forest Area, Carbon Stocks, and Biomass, 1950-2010. doi: http://dx.doi.org/10.3334/ORNLDAAC/1296.

Hibagene, S. H. et al. (1994) MANUAL FOR CHARCOAL PRODUCTION IN EARTH KILNS IN ZAMBIA. Lusaka, Zambia.

Hoesly, R. M. et al. (2018) 'Historical (1750-2014) anthropogenic emissions of reactive gases and aerosols from the Community Emissions Data System (CEDS)', Geoscientific Model Development, 11(1), pp. 369-408. doi: 10.5194/gmd-11-369-2018.

Hofmann, D. J. et al. (2006) 'The role of carbon dioxide in climate forcing from 1979 to 2004: Introduction of the Annual Greenhouse Gas Index', in Tellus, Series B: Chemical and Physical Meteorology. doi: 10.1111/j.1600-0889.2006.00201.x.

Hofstad, O. et al. (2009) 'How can emissions from woodfuel be reduced?', in In Angelsen, A. et al. (eds) Realising REDD+.

Hogan, R. J. (2010) 'The Full-Spectrum Correlated-k Method for Longwave Atmospheric Radiative Transfer Using an Effective Planck Function', Journal of the 
Atmospheric Sciences, 67(6), pp. 2086-2100. doi: 10.1175/2010JAS3202.1.

Holmes, C. D. et al. (2013) 'Future methane, hydroxyl, and their uncertainties: Key climate and emission parameters for future predictions', Atmospheric Chemistry and Physics, 13(1), pp. 285-302. doi: 10.5194/acp-13-285-2013.

Hoornweg, D. et al. (2017) 'Population predictions for the world's largest cities in the 21 st century', Environment and Urbanization, 29, pp. 195-216. doi:

10.1177/0956247816663557.

Houghton, R. A. et al. (2017) 'Global and regional fluxes of carbon from land use and land cover change 1850-2015', Global Biogeochemical Cycles, 31(3), pp. 456-472. doi: 10.1002/2016GB005546.

Huang, G. et al. (2017) 'Speciation of anthropogenic emissions of non-methane volatile organic compounds: a global gridded data set for 1970--2012', Atmospheric Chemistry and Physics, 17(12), pp. 7683-7701. doi: 10.5194/acp-17-7683-2017.

Hudman, R. C. et al. (2012) 'Steps towards a mechanistic model of global soil nitric oxide emissions: Implementation and space based-constraints', Atmospheric Chemistry and Physics, 12(6), pp. 7779-7795. doi: 10.5194/acp-12-7779-2012.

Huo, H. et al. (2012) 'On-board measurements of emissions from diesel trucks in five cities in China', Atmospheric Environment, 54, pp. 159-167. doi:

10.1016/j.atmosenv.2012.01.068.

IEA (2019) Africa Energy Outlook 2019. Paris. Available at:

https://www.iea.org/reports/africa-energy-outlook-2019 (Accessed: 5 June 2020).

IEA (2020) Africa and Covid-19: Economic recovery and electricity access go hand in hand. Paris. Available at: https://www.iea.org/commentaries/africa-and-covid-19economic-recovery-and-electricity-access-go-hand-in-hand (Accessed: 5 June 2020). 
IPCC (2006) 'Guidelines for National Greenhouse Gas Inventories.', Agriculture, Forestry and other land use, pp. 4.1-4.83. doi: 10.1016/j.phrs.2011.03.002.

IPCC (2018) Global warming of $1.5^{\circ} \mathrm{C}$, Ipcc - Sr15. Available at:

https://www.ipcc.ch/site/assets/uploads/sites/2/2019/06/SR15_Full_Report_Low_Res.p

df.

Ivatt, P. (2017) Modelling of atmospheric chlorine and its effecton volatile organic compounds. University of York. Available at:

https://core.ac.uk/download/pdf/96890445.pdf.

Jackson, R. B. et al. (2019) 'Methane removal and atmospheric restoration', Nature Sustainability, 2, pp. 436-438. doi: 10.1038/s41893-019-0299-х.

Jacob, D. J. (1999) '11. Oxidizing Power of the Troposphere', in Introduction to Atmospheric Chemistry. doi: 10.1515/9781400841547-012.

Jacob, D. J. (2019) ‘The Continuity Equation', in Introduction to Atmospheric

Chemistry. doi: 10.1515/9781400841547-006.

Jaeglé, L. et al. (1998) 'Sources and chemistry of $\mathrm{NO}_{\mathrm{x}}$ in the upper troposphere over the United States', Geophysical Research Letters, 25, pp. 1705-1708. doi:

10.1029/97GL03591.

Jaeglé, L. et al. (2011) 'Global distribution of sea salt aerosols: New constraints from in situ and remote sensing observations', Atmospheric Chemistry and Physics, 11, pp. 3137-3157. doi: 10.5194/acp-11-3137-2011.

Jagger, P. et al. (2018) 'Implementation and scale-up of a biomass pellet and improved cookstove enterprise in Rwanda', Energy for Sustainable Development, 46, pp. 32-41. doi: https://doi.org/10.1016/j.esd.2018.06.005.

Janssen, N. A. H. et al. (2011) 'Black carbon as an additional indicator of the adverse 
health effects of airborne particles compared with pm10 and pm2.5', Environmental Health Perspectives. doi: 10.1289/ehp.1003369.

Janssen, R. et al. (2012) Bioenergy for sustainable development in Africa, Bioenergy for sustainable development in Africa. doi: 10.1007/978-94-007-2181-4.

Janssens-Maenhout, G. et al. (2015) 'HTAP-v2.2: A mosaic of regional and global emission grid maps for 2008 and 2010 to study hemispheric transport of air pollution', Atmospheric Chemistry and Physics. doi: 10.5194/acp-15-11411-2015.

Janssens-Maenhout, G. et al. (2019) 'EDGAR v4.3.2 Global Atlas of the three major Greenhouse Gas Emissions for the period 1970\&amp;ndash;2012', Earth System Science Data Discussions. doi: 10.5194/essd-2018-164.

Jayarathne, T. et al. (2018) 'Nepal Ambient Monitoring and Source Testing Experiment (NAMaSTE): Emissions of particulate matter from wood-and dung-fueled cooking fires, garbage and crop residue burning, brick kilns, and other sources', Atmospheric Chemistry and Physics, 18(3), pp. 2259-2286. doi: 10.5194/acp-18-2259-2018.

Jinhuan, Q. et al. (2000) 'Variation characteristics of atmospheric aerosol optical depths and visibility in North China during 1980-1994', Atmospheric Environment, 34(4), pp. 603-609. doi: 10.1016/S1352-2310(99)00173-9.

Juárez-Orozco, S. M. et al. (2017) 'Causes and Effects of Forest Fires in Tropical Rainforests: A Bibliometric Approach', Tropical Conservation Science, 10, pp. 1-14. doi: $10.1177 / 1940082917737207$.

Kablan, N. H. J. (2010) 'L'invasion des véhicules d'occasion en transit par le port d'Abidjan: le dynamisme ambivalent d'une activité en plein essor', Les Cahiers d?Outre-Mer, 63(251), pp. 365-390. doi: 10.4000/com.6044, 2010. Kambewa, P. et al. (2007) Charcoal The Reality: A case study of charcoal consumption, 
trade and production in Malawi, Small and Medium Forestry Enterprise. Available at: http://pubs.iied.org/pdfs/13544IIED.pdf.

Keatinge, T. (2014) THE ROLE OF FINANCE IN DEFEATING AL-SHABAAB.

Available at: https://rusi.org/sites/default/files/201412_whr_2-14_keatinge_web_0.pdf. Keita, S. et al. (2018) 'Particle and VOC emission factor measurements for anthropogenic sources in West Africa', Atmospheric Chemistry and Physics, 18(10), pp. 7691-7708. doi: 10.5194/acp-18-7691-2018.

Keita, S. et al. (2020) 'African Anthropogenic Emissions Inventories for gases and particles from 1990 to 2015', Earth Syst. Sci. Data, p. submitted. doi: https://doi.org/10.24380/ks45-9147.

Keller, C. A. et al. (2014) 'HEMCO v1.0: A versatile, ESMF-compliant component for calculating emissions in atmospheric models', Geoscientific Model Development, 7(4), pp. 1409-1417. doi: 10.5194/gmd-7-1409-2014.

KFS (2013) Analysis of the charcoal value chain in Kenya. A report by Camco Advisory Services (Kenya) Limited for the Kenya Forest Service (KFS). Nairobi, Kenya.

Available at: http://www.kenyaforestservice.org/documents/redd/Charcoal Value Chain Analysis.pdf.

Kilahama, F. (2008) 'Impact of increased charcoal consumption to forests and woodlands in Tanzania', TAF Charcoal. Available at: http://www.tfcg.org/pdf/Charcoal\&Forests Kilahama.pdf.

Kim, P. S. et al. (2015) 'Sources, seasonality, and trends of southeast US aerosol: An integrated analysis of surface, aircraft, and satellite observations with the GEOS-Chem chemical transport model', Atmospheric Chemistry and Physics, 15, pp. 10411-10433. doi: 10.5194/acp-15-10411-2015. 
Kirchstetter, T. W. et al. (2004) 'Evidence that the spectral dependence of light absorption by aerosols is affected by organic carbon', Journal of Geophysical Research: Atmospheres, 109(D21). doi: 10.1029/2004JD004999.

Kiruki, H. M. et al. (2017) 'Land Cover Change and Woodland Degradation in a Charcoal Producing Semi-Arid Area in Kenya', Land Degradation and Development, 28(2), pp. 472-481. doi: 10.1002/ldr.2545.

Kituyi, E. (2000) Towards Sustainable Charcoal Production and Use: a Systems Approach, Economic Report on Africa.

Knippertz, P. et al. (2015) 'The possible role of local air pollution in climate change in West Africa', Nature Climate Change, 5(9), pp. 815-822. doi: 10.1038/nclimate2727. Kulmala, M. (2003) 'How Particles Nucleate and Grow', Science. doi: 10.1126/science. 1090848 .

Kulmala, M. et al. (2013) 'Direct observations of atmospheric aerosol nucleation', Science, 339, p. 943. doi: 10.1126/science.1227385.

Lacaux, J. P. et al. (1994) 'Traditional charcoal making: an important source of atmospheric pollution in the African Tropics', Atmospheric Research, 35(1), pp. 71-76. doi: 10.1016/0169-8095(94)90073-6.

Lacis, A. A. et al. (1991) 'A description of the correlated $\mathrm{k}$ distribution method for modeling nongray gaseous absorption, thermal emission, and multiple scattering in vertically inhomogeneous atmospheres', Journal of Geophysical Research:

Atmospheres, 96(D5), pp. 9027-9063. doi: 10.1029/90JD01945.

Laothawornkitkul, J. et al. (2009) 'Biogenic volatile organic compounds in the Earth system', New Phytologist, 183(1), pp. 27-51. doi: 10.1111/j.1469-8137.2009.02859.x. Laurent, A. et al. (2014) 'Impacts of NMVOC emissions on human health in European 
countries for 2000-2010: Use of sector-specific substance profiles', Atmospheric Environment. doi: 10.1016/j.atmosenv.2013.11.060.

Lawson, S. J. et al. (2015) 'Biomass burning emissions of trace gases and particles in marine air at Cape Grim, Tasmania', Atmospheric Chemistry and Physics. doi: 10.5194/acp-15-13393-2015.

Leah Laban, T. et al. (2018) 'Seasonal influences on surface ozone variability in continental South Africa and implications for air quality', Atmospheric Chemistry and Physics, 18(20), pp. 15491-15514. doi: 10.5194/acp-18-15491-2018.

Lelieveld, J. et al. (2015) 'The contribution of outdoor air pollution sources to premature mortality on a global scale', Nature, 525(7569), pp. 367-371. doi: 10.1038/nature15371.

Lin, G. et al. (2014) 'Radiative forcing of organic aerosol in the atmosphere and on snow: Effects of SOA and brown carbon', Journal of Geophysical Research: Atmospheres, 119(12), pp. 7453-7476. doi: 10.1002/2013JD021186.

Liousse, C. et al. (2010) 'Updated African biomass burning emission inventories in the framework of the AMMA-IDAF program, with an evaluation of combustion aerosols', Atmospheric Chemistry and Physics, 10(19), pp. 9631-9646. doi: 10.5194/acp-10-96312010.

Liousse, C. et al. (2014) 'Explosive growth in African combustion emissions from 2005 to 2030', Environmental Research Letters, 9(3), p. 35003. doi: 10.1088/17489326/9/3/035003.

Liousse, C. et al. (2017) 'African Anthropogenic Emissions Inventories for gases and particles from 1990 to 2016', in.

Liu, J. et al. (2016) 'Air pollutant emissions from Chinese households: A major and 
underappreciated ambient pollution source', Proceedings of the National Academy of Sciences, 113(28), pp. 7756 LP - 7761. doi: 10.1073/pnas.1604537113.

Lois, E. et al. (2003) 'Fuels', in Meyers, R. A. B. T.-E. of P. S. and T. (Third E. (ed.). New York: Academic Press, pp. 275-314. doi: https://doi.org/10.1016/B0-12-227410$5 / 00268-4$

Luo, Y. et al. (2006) Soil Respiration and the Environment, Soil Respiration and the Environment. doi: 10.1016/B978-0-12-088782-8.X5000-1.

MacLeod, D. et al. (2019) 'The Moderate Impact of the 2015 El Niño over East Africa and Its Representation in Seasonal Reforecasts', Journal of Climate, 32(22), pp. 79898001. doi: 10.1175/JCLI-D-19-0201.1.

Magrath, J. et al. (2006) 'Africa: Up in Smoke?: Second Report from the Working Group on Climate Change and Development', The Economics Foundation. London. Malimbwi, R. . et al. (2004) 'Charcoal supply in Dar es Salaam City, Tanzania', The Tanzania Journal of Forestry and Nature Conservation, 17(2), pp. 197-210.

Malimbwi, R. E. et al. (2008) Woodlands and the charcoal trade: the case of Dar es Salaam City. 98-114. Tanzania.

Malimbwi, R. et al. (2009) 'The analysis of sustainable charcoal production systems in Tanzania', FAO: Criteria and indicators for sustainable woodfuels, pp. 229-261. Available at: http://www.fao.org/docrep/012/i1321e/i1321e00.pdf. Mamuye, F. et al. (2018) 'Emissions and fuel use performance of two improved stoves and determinants of their adoption in Dodola, southeastern Ethiopia', Sustainable Environment Research, 28(1), pp. 32-38. doi: 10.1016/j.serj.2017.09.003. Marais, E. A. et al. (2012) 'Isoprene emissions in Africa inferred from OMI observations of formaldehyde columns', Atmospheric Chemistry and Physics, 12(14), 
pp. 6219-6235. doi: 10.5194/acp-12-6219-2012.

Marais, E. A. et al. (2014) 'Anthropogenic emissions in Nigeria and implications for atmospheric ozone pollution: A view from space', Atmospheric Environment. doi: 10.1016/j.atmosenv.2014.09.055.

Marais, E. A. et al. (2019) 'Air quality and health impact of future fossil fuel use for electricity generation and transport in Africa.', Environmental science \& technology, 53(22), pp. 13524-13534. doi: 10.1021/acs.est.9b04958.

Marais, E. A. et al. (2016) 'Air Quality Impact of Diffuse and Inefficient Combustion Emissions in Africa (DICE-Africa)', Environmental Science and Technology, 50(19), pp. 10739-10745. doi: 10.1021/acs.est.6b02602.

Marois, G. et al. (2020) 'Assessing the potential impact of COVID-19 on life expectancy', PLoS ONE, 15(5). doi: 10.1371/journal.pone.0238678.

Marticorena, B. et al. (2011) 'Tropospheric aerosols over West Africa: highlights from the AMMA international program', Atmospheric Science Letters, 12(1), pp. 19-23. doi: 10.1002/asl.322.

Martin, A. R. et al. (2011) 'A reassessment of carbon content in tropical trees', PLoS ONE, 6(8), p. e23533. doi: 10.1371/journal.pone.0023533.

Mason, S. J. (2001) 'El Niño, climate change, and Southern African climate', Environmetrics, 12(4), pp. 327-345. doi: 10.1002/env.476.

Matsumura, Y. et al. (1994) 'Partial Oxidation of Methane to Carbon-Monoxide and Hydrogen with Molecular-Oxygen and Nitrous-Oxide over Hydroxyapatite Catalysts', Journal of Catalysis, 148(1), pp. 323-333. doi: https://doi.org/10.1006/jcat.1994.1213. Mbandi, A. (2020) 'Air Pollution in Africa in the time of COVID-19: the air we breathe indoors and outdoors', Clean Air Journal, 30(1 SE-Commentary), pp. 1-3. doi: 
10.17159/caj/2020/30/1.8227.

Mbandi, A. M. et al. (2019) 'Estimating on-road vehicle fuel economy in Africa: A case study based on an urban transport survey in Nairobi, Kenya', Energies, 12(6), p. 1177. doi: 10.3390/en12061177.

McMeeking, G. R. et al. (2011) 'Influences on the fraction of hydrophobic and hydrophilic black carbon in the atmosphere', Atmospheric Chemistry and Physics. doi: 10.5194/acp-11-5099-2011.

Megevand, C. et al. (2013) Deforestation Trends in the Congo Basin, Deforestation Trends in the Congo Basin. doi: 10.1596/978-0-8213-9742-8.

Melkonyan, A. et al. (2012) 'Long-term analysis of NO, NO2 and O3 concentrations in North Rhine-Westphalia, Germany', Atmospheric Environment, 60, pp. 316-326. doi: https://doi.org/10.1016/j.atmosenv.2012.06.048.

Mickley, L. J. et al. (1999) 'Radiative forcing from tropospheric ozone calculated with a unified chemistry-climate model', Journal of Geophysical Research: Atmospheres, 104(D23), pp. 30153-30172. doi: 10.1029/1999JD900439.

Ministry of Transport (2012) Ministry of Transport: Ministère des Transports Republique de Côte d'Ivoire. Available at:

http://www.transports.gouv.ci/projetsuite.php?rd=2 (Accessed: 26 March 2018). Mitchell, E. J. S. et al. (2020) 'Pollutant Emissions from Improved Cookstoves of the Type Used in Sub-Saharan Africa', Combustion Science and Technology, 192(8), pp. 1582-1602. doi: 10.1080/00102202.2019.1614922.

Miyazaki, K. et al. (2012) 'Global NO\$_\{x\}\$ emission estimates derived from an assimilation of OMI tropospheric NO\$_\{2\}\$ columns', Atmospheric Chemistry and Physics, 12(5), pp. 2263-2288. doi: 10.5194/acp-12-2263-2012. 
Monks, P. S. (2005) 'NucleobasesGas-phase radical chemistry in the troposphere', Chemical Society Reviews. doi: 10.1039/b307982c.

Monks, P. S. et al. (2015) 'Tropospheric ozone and its precursors from the urban to the global scale from air quality to short-lived climate forcer', Atmospheric Chemistry and Physics, 14, p. 32709. doi: 10.5194/acp-15-8889-2015.

Moorthy, K. K. et al. (2013) 'Performance evaluation of chemistry transport models over India', Atmospheric Environment, 71, pp. 210-225. doi:

https://doi.org/10.1016/j.atmosenv.2013.01.056.

Msuya, N. (2011) 'Environmental Burden of Charcoal Production and Use in Dar es Salaam, Tanzania', Journal of Environmental Protection, 02(10), pp. 1364-1369. doi: 10.4236/jep.2011.210158.

Mugo, F. et al. (2007) An assessment of the energy saving potential and heat loss pattern in fireless cooking for selected commonly foods in Kenya. 2.

Mulenga, B. P. et al. (2019) 'Electricity access and charcoal consumption among urban households in Zambia', Development Southern Africa, 36(5), pp. 585-599. doi: 10.1080/0376835X.2018.1517036.

Myhre, G. et al. (2013) Anthropogenic and natural radiative forcing, Climate Change 2013 the Physical Science Basis: Working Group I Contribution to the Fifth Assessment Report of the Intergovernmental Panel on Climate Change. doi:

10.1017/CBO9781107415324.018.

Nabukalu, C. et al. (2019) 'Charcoal as an Energy Resource: Global Trade, Production and Socioeconomic Practices Observed in Uganda', Resources. doi:

10.3390/resources8040183.

Naik, V. et al. (2007) 'On the sensitivity of radiative forcing from biomass burning 
aerosols and ozone to emission location', Geophysical Research Letters, 34, p. L03818. doi: 10.1029/2006GL028149.

Nenes, A. et al. (1998) 'ISORROPIA: A new thermodynamic equilibrium model for multiphase multicomponent inorganic aerosols', Aquatic Geochemistry, 7, pp. 46394659. doi: 10.1023/A:1009604003981.

Neves, D. et al. (2011) 'Characterization and prediction of biomass pyrolysis products', Progress in Energy and Combustion Science, 37(5), pp. 611-630. doi: https://doi.org/10.1016/j.pecs.2011.01.001.

Ngezi, M. (2019) Zimbabwe turns to charcoal for cooking as power outages bite. Available at: https://www.france24.com/en/20191126-zimbabwe-turns-to-charcoal-forcooking-as-power-outages-bite (Accessed: 26 October 2020).

Nhatkhoa (2018) The History of Charcoal - Since 30,000 BC. Available at: http://charcoalkiln.com/history-charcoal-30000-bc/ (Accessed: 7 February 2018). Niang, I. et al. (2014) Chapter 22 - Africa, Change 2014: Impacts, Adaptation, and Vulnerability. Part B: Regional Aspects. Contribution of Working Group II to the Fifth Assessment Report of the Intergovernmental Panel on Climate Change. doi: 10.1017/CBO9781107415386.002.

Nicholson, S. E. et al. (2018) 'Rainfall over the African continent from the 19th through the 21 st century', Global and Planetary Change, 165, pp. 114-127. doi: https://doi.org/10.1016/j.gloplacha.2017.12.014.

Njenga, M. et al. (2013) 'Charcoal production and strategies to enhance its sustainability in Kenya', Development in Practice, 23(3), pp. 359-371. doi: $10.1080 / 09614524.2013 .780529$.

O'Hare, G. et al. (2014) Weather, climate and climate change: Human perspectives, 
Weather, Climate and Climate Change: Human Perspectives. doi: $10.4324 / 9781315847757$.

OECD (2016) The Economic Consequences of Outdoor Air Pollution. doi: https://doi.org/https://doi.org/10.1787/9789264257474-en.

Olivier, J. G. J. et al. (2020) Trends in Global CO2 and Total Greenhouse Gas Emissions: Report 2019, PBL Netherlands Environmental Assessment Agency. Hague. Available at: https://www.pbl.nl/sites/default/files/downloads/pbl-2020-trends-inglobal-co2-and-total-greenhouse-gas-emissions-2019-report_4068.pdf.

Onyutha, C. et al. (2016) 'Analyses of rainfall trends in the Nile River Basin', Journal of Hydro-environment Research, 13, pp. 36-51. doi:

https://doi.org/10.1016/j.jher.2015.09.002.

Ordway, E. M. et al. (2017) 'Deforestation risk due to commodity crop expansion in sub-Saharan Africa', Environmental Research Letters, 12(4), p. 44015. doi: 10.1088/1748-9326/aa6509.

Ouedraogo, N. S. (2017) 'Africa energy future: Alternative scenarios and their implications for sustainable development strategies', Energy Policy, 106, pp. 457-471. doi: https://doi.org/10.1016/j.enpol.2017.03.021.

Pan, Y. et al. (2011) 'A Large and Persistent Carbon Sink in the World, Äôs Forests 10.1126/science.1201609', Science, 333(6045), pp. 988-993. Available at: http://www.sciencemag.org/content/333/6045/988.abstract.

Pappis, I. et al. (2019) Energy projections for African countries. Luxembour. doi: doi:10.2760/678700.

Park, R. J. et al. (2004) 'Natural and transboundary pollution influences on sulfatenitrate-ammonium aerosols in the United States: Implications for policy', Journal of 
Geophysical Research D: Atmospheres, 109(15). doi: 10.1029/2003JD00473.

Pearson, K. (2020) My Oh So Amazing Week in Zambia | Lifeline Energy. Available at: https://www.lifelineenergy.org/my-amazing-week-in-zambia/ (Accessed: 11 June 2020).

Pennise, D. M. et al. (2001) 'Emissions of greenhouse gases and other airborne pollutants from charcoal making in Kenya and Brazil', Journal of Geophysical Research Atmospheres, 106(D20), pp. 24143-24155. doi: 10.1029/2000JD000041. Pereira, H. C. (1991) Hydrology of moist tropical forests and effects of conversion: A state of knowledge review, Journal of Hydrology. Amsterdam, Netherlands. doi: 10.1016/0022-1694(91)90061-1.

Petzold, A. et al. (2013) 'Recommendations for reporting black carbon measurements', Atmospheric Chemistry and Physics. doi: 10.5194/acp-13-8365-2013.

Pfotenhauer, D. J. et al. (2019) 'Updated Emission Factors from Diffuse Combustion Sources in Sub-Saharan Africa and Their Effect on Regional Emission Estimates', Environmental Science and Technology, 53, pp. 6392-6401. doi: 10.1021/acs.est.8b06155. Philip, O. et al. (eds) (1984) Energy and Development in Southern Africa. Stockholm: Beijer Institute, Royal Swedish Academy of Sciences. Available at: https://books.google.co.uk/books?id=tJuuhUzwr0C\&pg=PA146\&lpg=PA146\&dq=charcoal+production+2+to+50+km+from+urban+ centers\&source $=$ bl\&ots $=8 w$ Hqb9JwGK\&sig $=$ ACfU3U1x9vfvsIq67cCV9nRuJcMz_zS X9Q\&hl=en\&sa=X\&ved=2ahUKEwiTiauXs4blAhXKgVwKHTwJBAgQ6AEwBXoE CAkQAQ\#v=onepa.

Philip, S. et al. (2017) 'Anthropogenic fugitive, combustion and industrial dust is a 
significant, underrepresented fine particulate matter source in global atmospheric models', Environmental Research Letters, 12(4), p. 044018. doi: 10.1088/17489326/aa65a4.

Pidwirny, M. (2006) 'Global Scale Circulation of the Atmosphere'. Fundamentals of Physical Geography, 2nd Edition. Available at:

http://www.physicalgeography.net/fundamentals/7p.html (Accessed: 7 July 2020). Pierrehumbert, R. T. (2014) 'Short-Lived Climate Pollution', Annual Review of Earth and Planetary Sciences, 42(1), pp. 341-379. doi: 10.1146/annurev-earth-060313054843.

Pio, C. A. et al. (1987) 'Vapour pressure of ammonium chloride aerosol: Effect of temperature and humidity', Atmospheric Environment (1967), 21(12), pp. 2711-2715. doi: https://doi.org/10.1016/0004-6981(87)90203-4.

Pitts, F. et al. (2000) 'Global Tropospheric Chemistry and Climate Change', in Chemistry of the Upper and Lower Atmosphere. doi: 10.1016/b978-012257060$5 / 50016-2$

Randerson, J. T. et al. (2017) Global Fire Emissions Database, Version 4.1 (GFEDv4), ORNL DAAC. ORNL Distributed Active Archive Center. doi:

\subsection{4/ORNLDAAC/1293.}

Rehfuess, E. et al. (2006) 'Fuel for life : household energy and health'. Geneva PP Geneva: World Health Organization. Available at:

https://apps.who.int/iris/handle/10665/43421.

Reiss, R. et al. (2007) 'Evidence of Health Impacts of Sulfate-and Nitrate-Containing Particles in Ambient Air', Inhalation Toxicology, 19, pp. 419-449.

Richter, A. (2009) 'THE EUROPEAN PHYSICAL JOURNAL CONFERENCES 
Nitrogen oxides in the troposphere-What have we learned from satellite measurements?', Eur. Phys. J. Conferences. doi: 10.1140/epjconf/e2009-00916-9. Ritchie, H. (2019) Outdoor Air Pollution. Available at: https://ourworldindata.org/outdoor-air-pollution\#citation (Accessed: 6 July 2020). Rockall, J. (2016) The role of LPG in supporting African Development. Durban. Available at: https://www.igu.org/sites/default/files/The role of LPG in supporting African Development_WLPGA_James Rockall.pdf.

Rosa, G. et al. (2014) 'Assessing the impact of water filters and improved cook stoves on drinking water quality and household air pollution: A randomised controlled trial in Rwanda', PLoS ONE. doi: 10.1371/journal.pone.0091011.

Roser, M. (2013) Future Population Growth. Available at: https://ourworldindata.org/future-population-growth (Accessed: 30 July 2020). Roser, M. et al. (2013) World Population Growth. Available at: https://ourworldindata.org/world-population-growth (Accessed: 17 December 2020). Roy, R. (2016) The cost of air pollution in Africa. 333. Paris. Available at: http://dx.doi.org/10.1787/5jlqzq77x6f8-en.

Salau, O. R. et al. (2016) 'Effects of changes in ENSO on seasonal mean temperature and rainfall in Nigeria', Climate, 4, p. art. no. 5. doi: 10.3390/cli4010005. Sanchez, P. A. et al. (1997) 'Soil fertility replenishment in Africa: an investment in natural resource capital', Replenishing soil fertility in Africa, 51, pp. 1-46.

Saunois, M. et al. (2009) 'Factors controlling the distribution of ozone in theWest African lower troposphere during the AMMA (African Monsoon Multidisciplinary Analysis) wet season campaign', Atmospheric Chemistry and Physics, 9, pp. 61356155. doi: 10.5194/acp-9-6135-2009. 
Sawe, E. N. (2014) 'Sustainable charcoal and firewood production and use in Africa', in Bioenergy for sustainable development in Africa, pp. 75-80. doi: 10.1007/978-94-0072181-4-7.

Schlesinger, W. H. (2018) ‘Are wood pellets a green fuel?’, Science, 359(6382), pp. 1328 LP - 1329. doi: 10.1126/science.aat2305.

Schmidt, U. (1974) 'Molecular hydrogen in the atmosphere', Tellus, 26(1-2), pp. 78-90. doi: 10.1111/j.2153-3490.1974.tb01954.x.

Von Schneidemesser, E. et al. (2015) 'Chemistry and the Linkages between Air Quality and Climate Change', Chemical Reviews, 115(10), pp. 3856-3897. doi: 10.1021/acs.chemrev.5b00089.

Schure, J. et al. (2013) 'Formalisation of charcoal value chains and livelihood outcomes in Central- and West Africa', Energy for Sustainable Development. doi: 10.1016/j.esd.2012.07.002.

Schure, J. et al. (2019) 'Efficiency of charcoal production in sub-Saharan Africa: Solutions beyond the kiln', Bois et Forets des Tropiques, 347, pp. 57-70. doi: 10.19182/bft2019.340.a31691.

Schwanghart, W. et al. (2008) 'Meteorological causes of Harmattan dust in West Africa', Geomorphology, 95(3), pp. 412-428. doi: https://doi.org/10.1016/j.geomorph.2007.07.002. Sedano, F. et al. (2016) 'The impact of charcoal production on forest degradation: a case study in Tete, Mozambique', Environmental Research Letters, 11(9), p. 94020. doi: 10.1088/1748-9326/11/9/094020.

Seinfeld, J. H. et al. (2006) Atmospheric Chemistry and Physics, Atmospheric Chemistry and Physics. doi: 10.5194/acp-5-139-2005. 
Shaddick, G. et al. (2018) 'Data integration model for air quality: a hierarchical approach to the global estimation of exposures to ambient air pollution', Journal of the Royal Statistical Society: Series C (Applied Statistics), 67(1), pp. 231-253. doi: https://doi.org/10.1111/rssc.12227.

Sher, E. (1998) Handbook of Air Pollution From Internal Combustion Engines, Handbook of Air Pollution From Internal Combustion Engines. doi: 10.1016/b978-012-639855-7.x5038-8.

Sherwen, T. et al. (2017) 'Halogen chemistry reduces tropospheric $\mathrm{O}_{3}$ radiative forcing', Atmospheric Chemistry and Physics, 17, pp. 1557-1569. doi: 10.5194/acp-17$1557-2017$.

Shilling, A. G. (2016) Age of Deleveraging: Investment Strategies for a Decade of Slow Growth and Deflation, Updated Edition. Audible Studios.

Shindell, D. et al. (2012) 'Simultaneously mitigating near-term climate change and improving human health and food security', Science. doi: 10.1126/science.1210026. Shively, G. et al. (2010) 'Profits and margins along Uganda's charcoal value chain', International Forestry Review. doi: 10.1505/ifor.12.3.270.

Sillman, S. (1999) 'The relation between ozone, $\mathrm{NO}(\mathrm{x})$ and hydrocarbons in urban and polluted rural environments', Atmospheric Environment, 33, pp. 1821-1845. doi: 10.1016/S1352-2310(98)00345-8.

Sinha, A. et al. (1996) 'A Comparison of Climate Forcings Due to Chlorofluorocarbons and Carbon Monoxide', Geophysical Research Letters, 23(1), pp. 65-68. doi: 10.1029/95GL03593.

Sjølie, H. K. (2012) 'Reducing greenhouse gas emissions from households and industry by the use of charcoal from sawmill residues in Tanzania', Journal of Cleaner 
Production, 27, pp. 109-117. doi: 10.1016/j.jclepro.2012.01.008.

Sokolik, I. N. (1998) Lifetimes of air pollutants. Available at:

http://irina.eas.gatech.edu/ATOC3500_Fall1998/Lecture20.pdf (Accessed: 11 October 2020).

Sonnemann, G. R. et al. (2014) 'Global annual methane emission rate derived from its current atmospheric mixing ratio and estimated lifetime', Annales Geophysicae, 32(3), pp. 277-283. doi: 10.5194/angeo-32-277-2014.

Steve, S. (2014) Multiple-Household Fuel Use-a balanced choice between firewood, charcoal and LPG. Available at: http://www.ecoconsult.com/fileadmin/user_upload/pdf/Multiple-Household_Fuel_Use.pdf. Stevenson, D. S. et al. (2013) 'Tropospheric ozone changes, radiative forcing and attribution to emissions in the Atmospheric Chemistry and Climate Model Intercomparison Project (ACCMIP)', Atmospheric Chemistry and Physics. doi: 10.5194/acp-13-3063-2013.

Still, D. et al. (2015) 'Results of Laboratory Testing of 15 Cookstove Designs in Accordance with the ISO/IWA Tiers of Performance', EcoHealth, 12(1), pp. 12-24. doi: 10.1007/s10393-014-0955-6.

Stockwell, C. E. et al. (2016) 'Nepal Ambient Monitoring and Source Testing Experiment (NAMaSTE): Emissions of trace gases and light-absorbing carbon from wood and dung cooking fires, garbage and crop residue burning, brick kilns, and other sources', Atmospheric Chemistry and Physics, 16(17), pp. 11043-11081. doi: 10.5194/acp-16-11043-2016.

Stroud, C. A. et al. (2012) 'Evaluation of chemical transport model predictions of primary organic aerosol for air masses classified by particle component-based factor 
analysis', Atmospheric Chemistry and Physics, 12(18), pp. 8297-8321. doi: 10.5194/acp-12-8297-2012.

Subedi, M. et al. (2014) 'Can biogas digesters help to reduce deforestation in Africa?', Biomass and Bioenergy, 70, pp. 87-98. doi: 10.1016/j.biombioe.2014.02.029.

Sun, S. et al. (2016) 'Vehicle emission trends and spatial distribution in Shandong province, China, from 2000 to 2014', Atmospheric Environment. doi:

10.1016/j.atmosenv.2016.09.065.

Tai, A. Y.-C. et al. (2017) 'Atmospheric deposition of particles at a sensitive alpine lake: Size-segregated daily and annual fluxes from passive sampling techniques', Science of The Total Environment, 579, pp. 1736-1744. doi: https://doi.org/10.1016/j.scitotenv.2016.11.117.

Talbot, C. et al. (2017) Chemistry for the IB Diploma Study and Revision Guide. Hodder Education Group.

Taylor, E. T. et al. (2012) 'Prevalence of acute respiratory infections in women and children in western sierra leone due to smoke from wood and charcoal stoves', International Journal of Environmental Research and Public Health, 9, pp. 2252-65. doi: 10.3390/ijerph9062252.

Thunis, P. et al. (2015) 'Quantification of non-linearities as a function of time averaging in regional air quality modeling applications', Atmospheric Environment, 103, pp. $263-$ 275. doi: https://doi.org/10.1016/j.atmosenv.2014.12.057.

Tobias, A. et al. (2014) 'Effects of black carbon on respiratory health in the city of Barcelona', European Respiratory Journal. Conference: European Respiratory Society Annual Congress.

Tol, R. S. J. (2018) 'The Economic Impacts of Climate Change', Review of 
Environmental Economics and Policy, 12(1), pp. 4-25. doi: 10.1093/reep/rex027. Tomasi, C. et al. (2017) 'Primary and Secondary Sources of Atmospheric Aerosol', Atmospheric Aerosols. (Wiley Online Books), pp. 1-86. doi: doi:10.1002/9783527336449.ch1.

Tyson, P. D. et al. (1996) 'Large-scale recirculation of air over Southern Africa', Journal of Applied Meteorology, 35(12), pp. 2218-2236. doi: 10.1175/15200450(1996)035<2218:LSROAO>2.0.CO;2.

UN (2012) Report of the Monitoring Group on Somalia and Eritrea pursuant to Security Council resolution 2060. Somalia. Available at: https://reliefweb.int/sites/reliefweb.int/files/resources/N1336185.pdf. UN (2014) NAMA STUDY FOR A SUSTAINABLE CHARCOAL VALUE CHAIN IN GHANA. New York.

UN (2015) Population 2030: Demographic challenges and opportunities for sustainable development planning. doi: (ST/ESA/SER.A/389).

UN (2017a) Atlas of Africa Energy Resources, United Nations Environment Programme. Nairobi, Kenya.

UN (2017b) Energy Statistics Database| United Nations Statistics Division. Available at: http://data.un.org/Data.aspx?d=EDATA\&f=cmID\%3ACH\#EDATA (Accessed: 15 August 2017).

UN (2019) Guidelines for the 2017 United Nations Statistics Division. ANNUAL QUESTIONNAIREON ENERGY STATISTICS. Available at: https://unstats.un.org/unsd/energy/Energy-Questionnaire-Guidelines.pdf (Accessed: 4 June 2019).

UNEP-WCMC (2016) World Database on Protected Areas. Available at: 
https://www.protectedplanet.net/ (Accessed: 25 January 2018).

UNEP (2019) Review of Woodfuel Biomass Production and Utilization in Africa: A Desk Study. Nairobi, Kenya.

Unger, N. et al. (2008) 'Air pollution radiative forcing from specific emissions sectors at 2030', Journal of Geophysical Research Atmospheres, 113(2), p. D02306. doi: 10.1029/2007JD008683.

USACE (2005) MANN-KENDALL ANALYSIS. California. Available at: https://www.statisticshowto.com/wp-content/uploads/2016/08/Mann-Kendall-Analysis1.pdf.

USEPA (2009) Compilation of Air Pollutant Emissions Factors. Volume 1: Stationary Point and Area Sources, AP 42, Compilation of Air Pollutant Emissions Factors. Durham. Available at: https://www3.epa.gov/ttn/chief/ap42/oldeditions/1st_edition/ap42_phs_1968.pdf. Vakkilainen, E. K. (2017) '2 - Solid Biofuels and Combustion', in Vakkilainen, E. K. B. T.-S. G. from B. (ed.). Butterworth-Heinemann, pp. 18-56. doi: https://doi.org/10.1016/B978-0-12-804389-9.00002-2. Visagie, J. et al. (2020) 'Getting urban density to work in informal settlements in Africa', Environment and Urbanization, 32(2), pp. 351-370. doi: $10.1177 / 0956247820907808$.

Vodonos, A. et al. (2018) 'The concentration-response between long-term $\mathrm{PM}_{2.5}$ exposure and mortality; A meta-regression approach', Environmental Research, 166, pp. 677-689. doi: 10.1016/j.envres.2018.06.021.

Vollmer, F. et al. (2017) 'Charcoal income as a means to a valuable end: Scope and limitations of income from rural charcoal production to alleviate acute multidimensional 
poverty in Mabalane district, southern Mozambique', World Development Perspectives, 7-8, pp. 43-60. doi: 10.1016/j.wdp.2017.11.005.

Vrieling, A. (2015) Charcoal production by Al-Shabaab increases in survey area (2015, February 10). Available at: https://phys.org/news/2015-02-charcoal-production-alshabaab-surveyarea.\%0Ahtml (Accessed: 22 February 2018).

Wang, Q. et al. (2014) 'Global budget and radiative forcing of black carbon aerosol: Constraints from pole-to-pole (HIPPO) observations across the Pacific', Journal of Geophysical Research, 119(1), pp. 195-206. doi: 10.1002/2013JD020824.

Wang, X. et al. (2019) 'The role of chlorine in global tropospheric chemistry', Atmospheric Chemistry and Physics, 19(6), pp. 3981-4003. doi: 10.5194/acp-19-39812019.

Wanjiru, H. et al. (2016) How Kenya can transform the charcoal sector and create new opportunities for lowcarbon rural development. Stockholm. Available at: https://www.jstor.org/stable/resrep02811 (Accessed: 5 June 2020).

Watson, J. T. et al. (2007) 'Epidemics after natural disasters', Emerging Infectious Diseases, 13, pp. 1-5. doi: 10.3201/eid1301.060779.

WB (1996) Towards environmentally sustainable development in Sub-Saharan Africa (English). Washington, D.C. Available at: http://documents.worldbank.org/curated/en/926871468194651590/Towardsenvironmentally-sustainable-development-in-Sub-Saharan-Africa. WB (2018) GDP ranking 2018. Available at: https://datacatalog.worldbank.org/dataset/gdp-ranking (Accessed: 21 May 2020). Weber, R. J. et al. (1996) 'Measured atmospheric new particle formation rates: Implications for nucleation mechanisms', Chemical Engineering Communications. doi: 


\section{$10.1080 / 00986449608936541$.}

Wheida, A. et al. (2018) 'Tackling the mortality from long-term exposure to outdoor air pollution in megacities: Lessons from the Greater Cairo case study', Environmental Research, 160, pp. 223-231. doi: https://doi.org/10.1016/j.envres.2017.09.028. WHO (2006) WHO Air quality guidelines for particulate matter, ozone, nitrogen dioxide and sulfur dioxide: global update 2005: summary of risk assessment. WHO/SDE/PHE/OEH/06.02. Geneva.

WHO (2020) Ambient air pollution: Pollutants. Available at: https://www.who.int/airpollution/ambient/pollutants/en/ (Accessed: 6 July 2020). Woolley, K. E. et al. (2020) 'Investigating the association between wood and charcoal domestic cooking, respiratory symptoms and acute respiratory infections among children aged under 5 years in uganda: A cross-sectional analysis of the 2016 demographic and health survey', International Journal of Environmental Research and Public Health, 17, p. 3974. doi: 10.3390/ijerph17113974.

World Bank (2011) Wood-Based Biomass Energy Development for Sub-Saharan Africa, Wood-Based Biomass Energy Development for Sub-Saharan Africa. doi: $10.1596 / 26149$.

World Bank (2014) Clean and improved cooking in sub-Saharan Africa. Second edition. Washington, DC. Available at: http://documents.worldbank.org/curated/en/164241468178757464/pdf/98664REVISED-WP-P146621-PUBLIC-Box393185B.pdf (Accessed: 5 June 2020). World Bank (2016) Population living in slums (\% of urban population). Available at: https://data.worldbank.org/indicator/EN.POP.SLUM.UR.ZS (Accessed: 15 December 2018). 
World Bank (2018) Urban population. Available at:

https://data.worldbank.org/indicator/SP.URB.TOTL (Accessed: 5 July 2018).

World Health Organization (2006) Air Quality Guidelines. Global update 2005, World

Health Organization. doi: 10.1007/BF02986808.

WWF (2018) The dirty business of barbecue charcoal. Berlin. Available at:

https://mobil.wwf.de/fileadmin/fm-wwf/Publikationen-

PDF/WWF_Market_analysis_barbecue_charcoal_2018.pdf.

Yee, L. D. et al. (2013) 'Secondary organic aerosol formation from biomass burning intermediates: Phenol and methoxyphenols', Atmospheric Chemistry and Physics, 13, pp. 8019-8043. doi: 10.5194/acp-13-8019-2013.

Yevich, R. et al. (2003) 'An assessment of biofuel use and burning of agricultural waste in the developing world', Global Biogeochemical Cycles, 17, p. 1095. doi:

10.1029/2002gb001952.

Yonas, A. et al. (2015) 'Liquidity Constraint, LPG Stoves and Charcoal

Consumption:Evidence from a Randomised Controlled Trial'. Available at:

https://assets.publishing.service.gov.uk/media/57a08991e5274a27b2000147/89225_fina

1_report_ARBB2015-V5.pdf.

Yonemitsu, A. et al. (2014) 'Household Fuel Consumption Based on Multiple Fuel Use

Strategies: A Case Study in Kibera Slums', APCBEE Procedia, 10, pp. 331 - 340. doi:

10.1016/j.apcbee.2014.10.062.

You, R. et al. (2016) 'Measured Wavelength-Dependent Absorption Enhancement of Internally Mixed Black Carbon with Absorbing and Nonabsorbing Materials', Environmental Science and Technology. doi: 10.1021/acs.est.6b01473.

Zavala, M. et al. (2017) 'Emission factors of black carbon and co-pollutants from diesel 
vehicles in Mexico City', Atmospheric Chemistry and Physics, 17(24), pp. 1529315305. doi: 10.5194/acp-17-15293-2017.

Zhang, A. et al. (2019) 'Modeling global radiative effect of brown carbon: A larger heating source in the tropical free troposphere than black carbon', Atmospheric Chemistry and Physics Discussions. doi: 10.5194/acp-2019-594.

Zhang, L. et al. (2012) 'Nitrogen deposition to the United States: Distribution, sources, and processes', Atmospheric Chemistry and Physics, 12(10), pp. 4539-4554. doi: 10.5194/acp-12-4539-2012.

Zhou, Z. et al. (2018) 'Innovative trend analysis of solar radiation in China during 1962-2015', Renewable Energy, 119, pp. 675-689. doi:

https://doi.org/10.1016/j.renene.2017.12.052.

Zhu, Z. et al. (2016) 'Greening of the Earth and its drivers', Nature Climate Change, 6, pp. 791-795. doi: 10.1038/nclimate3004.

Zijlma, A. (2019) A Brief Overview of Africa's Dry and Rainy Seasons. Available at: https://www.tripsavvy.com/africas-dry-and-rainy-seasons-1453967 (Accessed: 12 January 2019).

Zulu, L. C. et al. (2013) 'Charcoal, livelihoods, and poverty reduction: Evidence from sub-Saharan Africa', Energy for Sustainable Development, 17(2), pp. 127-137. doi: https://doi.org/10.1016/j.esd.2012.07.007. 


\section{APPENDICES}

Table A3.1 Annual charcoal production in Africa from 2000 to 2014. Units are 1000 tonnes. Data source: United Nations energy statistics database (UN, 2017b).

\begin{tabular}{|c|c|c|c|c|c|c|c|c|c|c|c|c|c|c|c|}
\hline \multirow[t]{2}{*}{ Country } & \multicolumn{15}{|c|}{ Charcoal Production [1000 tonne] } \\
\hline & 2000 & 2001 & 2002 & 2003 & 2004 & 2005 & 2006 & 2007 & 2008 & 2009 & 2010 & 2011 & 2012 & 2013 & 2014 \\
\hline Algeria & 547 & 561 & 575 & 589 & 604 & 619 & 631 & 644 & 656 & 669 & 682 & 692 & 701 & 711 & 720 \\
\hline Angola & 851 & 876 & 901 & 928 & 956 & 984 & 1012 & 1040 & 1108 & 1145 & 1183 & 1221 & 1120 & 1142 & 1164 \\
\hline Benin & 183 & 181 & 188 & 191 & 197 & 204 & 212 & 220 & 228 & 236 & 245 & 252 & 259 & 266 & 273 \\
\hline Botswana & 59 & 60 & 62 & 63 & 65 & 67 & 68 & 69 & 70 & 71 & 72 & 73 & 73 & 74 & 74 \\
\hline Burkina Faso & 112 & 457 & 469 & 482 & 496 & 510 & 524 & 539 & 554 & 570 & 586 & 603 & 620 & 637 & 637 \\
\hline Burundi & 60 & 60 & 60 & 60 & 60 & 60 & 60 & 60 & 60 & 60 & 60 & 60 & 60 & 269 & 264 \\
\hline Ivory Coast & 826 & 1337 & 1387 & 923 & 958 & 995 & 1033 & 1079 & 1138 & 1192 & 1226 & 1267 & 1308 & 1402 & 1437 \\
\hline Cameroon & 99 & 101 & 103 & 105 & 105 & 105 & 207 & 201 & 205 & 214 & 214 & 219 & 225 & 230 & 236 \\
\hline Central African Republic & 21 & 21 & 21 & 21 & 21 & 21 & 21 & 182 & 186 & 186 & 192 & 196 & 199 & 203 & 207 \\
\hline Chad & 311 & 319 & 328 & 337 & 346 & 355 & 364 & 373.3 & 383 & 393 & 403 & 413 & 424 & 434 & 446 \\
\hline Congo & 137 & 142 & 148 & 154 & 159 & 165 & 177 & 167 & 172 & 180 & 185 & 209 & 196 & 200 & 206 \\
\hline Dem. Rep. of the Congo & 1431 & 1482 & 1535 & 1589 & 594 & 615 & 637 & 658 & 681 & 704 & 728 & 753 & 3550 & 3677 & 3803 \\
\hline Djibouti & 39 & 40 & 41 & 42 & 43 & 43 & 44 & 45.2 & 46 & 47 & 48 & 49 & 50 & 50 & 51 \\
\hline Egypt & 1201 & 1216 & 1232 & 1249 & 1265 & 1282 & 1297 & 1312 & 1328 & 1344 & 1360 & 1372 & 1385 & 1397 & 1410 \\
\hline Equatorial Guinea & 7 & 7 & 7 & 7 & 8 & 8 & 8 & 8 & 9 & 9 & 9 & 9 & 10 & 10 & 10 \\
\hline Eritrea & 76 & 80 & 82 & 85 & 111 & 114 & 117 & 121 & 125 & 128 & 135 & 138 & 141 & 144 & 147 \\
\hline Ethiopia & 2908 & 2984 & 3061 & 3140 & 3221 & 3304 & 3386 & 3470 & 3556 & 3644 & 3734 & 3827 & 3921 & 4018 & 4118 \\
\hline Gabon & 15 & 16 & 16 & 17 & 17 & 18 & 18 & 19 & 19 & 20 & 20 & 21 & 21 & 21 & 22 \\
\hline
\end{tabular}




\begin{tabular}{|c|c|c|c|c|c|c|c|c|c|c|c|c|c|c|c|}
\hline Gambia & 47 & 48 & 49 & 50 & 51 & 53 & 54 & 55.1 & 56 & 58 & 59 & 60 & 62 & 63 & 64 \\
\hline Ghana & 935 & 954 & 978 & 1007 & 1042 & 1044 & 1052 & 1066.2 & 1071 & 1072 & 1073 & 1234 & 1474 & 1578 & 1720 \\
\hline Guinea & 277 & 283 & 290 & 297 & 304 & 311 & 318 & 325.6 & 333 & 341 & 348 & 356 & 364 & 372 & 380 \\
\hline Guinea-Bissau & 51 & 53 & 54 & 55 & 56 & 57 & 59 & 59.854 & 61 & 63 & 64 & 66 & 67 & 69 & 70 \\
\hline Kenya & 640 & 16 & 17 & 17 & 18 & 18 & 18 & 17.7 & 5860 & 5906 & 5891 & 6044 & 6227 & 6395 & 6387 \\
\hline Lesotho & 78 & 80 & 82 & 84 & 85 & 87 & 89 & 90.9 & 93 & 95 & 97 & 98 & 100 & 102 & 104 \\
\hline Liberia & 153 & 160 & 167 & 175 & 183 & 192 & 243 & 208 & 217 & 225 & 235 & 243 & 252 & 262 & 272 \\
\hline Libya & 89 & 90 & 92 & 94 & 95 & 97 & 98 & 99.682 & 101 & 103 & 104 & 105 & 107 & 108 & 109 \\
\hline Madagascar & 645 & 589 & 795 & 833 & 872 & 910 & 950 & 989 & 1029 & 1068 & 1195 & 1195 & 1186 & 1560 & 1560 \\
\hline Malawi & 392 & 400 & 409 & 418 & 426 & 436 & 446 & 456.6 & 467 & 478 & 490 & 502 & 514 & 527 & 540 \\
\hline Mali & 96 & 100 & 103 & 106 & 110 & 113 & 117 & 121 & 125 & 129 & 133 & 141 & 141 & 172 & 171 \\
\hline Mauritania & 131 & 136 & 141 & 146 & 152 & 158 & 163 & 168 & 174 & 180 & 186 & 191 & 196 & 201 & 206 \\
\hline Morocco & 90 & 92 & 94 & 95 & 97 & 99 & 100 & 101.8 & 103 & 105 & 107 & 108 & 109 & 111 & 112 \\
\hline Mozambique & 373 & 383 & 391 & 398 & 406 & 414 & 423 & 431 & 439 & 447 & 455 & 464 & 695 & 692 & 715 \\
\hline Namibia & 72 & 72 & 70 & 73 & 102 & 102 & 104 & 115 & 145 & 145 & 151 & 142 & 144 & 135 & 145 \\
\hline Niger & 28 & 29 & 30 & 31 & 32 & 33 & 34 & 35.21 & 38 & 39 & 40 & 42 & 45 & 47 & 48 \\
\hline Nigeria & 1218 & 1361 & 1521 & 1698 & 1897 & 2120 & 2367 & 3333 & 3054 & 2619 & 3029 & 3483 & 4005 & 3743 & 3844 \\
\hline Rwanda & 48 & 48 & 48 & 48 & 48 & 406 & 427 & 452 & 478 & 506 & 535 & 558 & 575 & 606 & 610 \\
\hline ao Tome and Principe & 7 & 7 & 8 & 8 & 8 & 8 & 8 & 8.4 & 9 & 9 & 9 & 9 & 9 & 9 & 9 \\
\hline Senegal & 329 & 335 & 338 & 336 & 334 & 342 & 342 & 490 & 502 & 562 & 546 & 561 & 576 & 482 & 497 \\
\hline Sierra Leone & 297 & 304 & 312 & 320 & 328 & 336 & 345 & 354 & 363 & 373 & 382 & 392 & 401 & 411 & 421 \\
\hline Somalia & 651 & 702 & 732 & 807 & 831 & 863 & 933 & 912.7 & 1027 & 1089 & 1132 & 1187 & 1187 & 1187 & 1136 \\
\hline South Africa & 41 & 41 & 41 & 201 & 127 & 189 & 189 & 188.9 & 702 & 703 & 705 & 708 & 710 & 712 & 715 \\
\hline South Sudan & 11 & 11 & 11 & 11 & 11 & 11 & 11 & 11 & 11 & 11 & 11 & 11 & 11 & 11 & 11 \\
\hline Sudan & & & & & & & & & & & & & 1523 & 1550 & 1596 \\
\hline Swaziland & 30 & 31 & 32 & 34 & 35 & 36 & 38 & 38.8 & 40 & 41 & 43 & 44 & 45 & 46 & 47 \\
\hline Tanzania & 950 & 1153 & 1400 & 1700 & 1380 & 1449 & 1506 & 1522 & 1597 & 1645 & 1695 & 1747 & 1801 & 1856 & 1937 \\
\hline Togo & 449 & 460 & 471 & 482 & 494 & 509 & 518 & 530 & 543 & 584 & 601 & 618 & 635 & 652 & 670 \\
\hline Tunisia & 159 & 163 & 166 & 170 & 175 & 176 & 178 & 180 & 182 & 186 & 191 & 195 & 199 & 204 & 208 \\
\hline
\end{tabular}




\begin{tabular}{|c|c|c|c|c|c|c|c|c|c|c|c|c|c|c|c|}
\hline Uganda & 713 & 732 & 752 & 772 & 792 & 814 & 836 & 859 & 882 & 907 & 931 & 931 & 931 & 1000 & 1037 \\
\hline Zambia & 793 & 808 & 823 & 837 & 875 & 896 & 902 & 922 & 943 & 965 & 987 & 1010 & 1034 & 1058 & 1083 \\
\hline Zimbabwe & 11 & 9 & 9 & 9 & 9 & 9 & 14 & 13 & 12 & 9 & 9 & 9 & 9 & 9 & 9 \\
\hline
\end{tabular}

Table A3.2 Annual charcoal use in Africa from 2000 to 2014. Units are 1000 tonnes. Data source: United Nations energy statistics database (UN, 2017b).

\begin{tabular}{|c|c|c|c|c|c|c|c|c|c|c|c|c|c|c|c|}
\hline \multirow[t]{2}{*}{ Country } & \multicolumn{15}{|c|}{ Charcoal Use [1000 tonnes] } \\
\hline & 2000 & 2001 & 2002 & 2003 & 2004 & 2005 & 2006 & 2007 & 2008 & 2009 & 2010 & 2011 & 2012 & 2013 & 2014 \\
\hline Algeria & 547 & 561 & 575 & 589 & 604 & 619 & 631 & 644 & 656 & 669 & 682 & 692 & 701 & 711 & 720 \\
\hline Angola & 851 & 876 & 901 & 928 & 956 & 984 & 1012 & 1040 & 1108 & 1145 & 1183 & 1221 & 1120 & 1142 & 1164 \\
\hline Benin & 184 & 181 & 188 & 191 & 197 & 204 & 212 & 220 & 228 & 236 & 245 & 252 & 259 & 266 & 273 \\
\hline Botswana & 59 & 61 & 62 & 64 & 65 & 67 & 68 & 69 & 70 & 71 & 72 & 73 & 74 & 74 & 74 \\
\hline Burkina Faso & 112 & 457 & 469 & 482 & 496 & 510 & 524 & 539 & 554 & 570 & 586 & 603 & 620 & 625 & 637 \\
\hline Burundi & 60 & 60 & 60 & 60 & 60 & 60 & 60 & 60 & 60 & 60 & 60 & 60 & 60 & 269 & 264 \\
\hline Ivory Coast & 826 & 1337 & 1387 & 923 & 958 & 995 & 1033 & 1074 & 1138 & 1192 & 1226 & 1267 & 1308 & 1332 & 1365 \\
\hline Cameroon & 99 & 101 & 103 & 105 & 105 & 105 & 206 & 200 & 205 & 214 & 214 & 219 & 225 & 230 & 236 \\
\hline Central African Rep & 21 & 21 & 21 & 21 & 21 & 21 & 21 & 182 & 186 & 186 & 192 & 196 & 199 & 203 & 207 \\
\hline Chad & 311 & 319 & 328 & 337 & 346 & 355 & 364 & 373 & 383 & 393 & 403 & 413 & 424 & 434 & 446 \\
\hline Congo & 137 & 142 & 148 & 154 & 159 & 165 & 177 & 167 & 172 & 180 & 185 & 209 & 196 & 200 & 204 \\
\hline Dem. Rep. of the Congo & 1431 & 1482 & 1535 & 1589 & 594 & 615 & 637 & 658 & 681 & 704 & 728 & 753 & 3550 & 3677 & 3803 \\
\hline Djibouti & 39 & 40 & 41 & 42 & 43 & 43 & 44 & 45 & 46 & 47 & 48 & 49 & 50 & 50 & 52 \\
\hline Egypt & 1196 & 1212 & 1228 & 1242 & 1255 & 1264 & 1290 & 1303 & 1298 & 1318 & 1334 & 1364 & 1369 & 1336 & 1336 \\
\hline Equatorial Guinea & 7 & 7 & 7 & 7 & 8 & 8 & 8 & 8 & 9 & 9 & 9 & 9 & 10 & 10 & 10 \\
\hline
\end{tabular}




\begin{tabular}{|c|c|c|c|c|c|c|c|c|c|c|c|c|c|c|c|}
\hline Eritrea & 78 & 80 & 83 & 85 & 111 & 114 & 117 & 121 & 124 & 128 & 134 & 137 & 140 & 143 & 146 \\
\hline Ethiopia & 2908 & 2984 & 3061 & 3140 & 3221 & 3304 & 3386 & 3470 & 3556 & 3644 & 3734 & 3827 & 3921 & 4018 & 4118 \\
\hline Gabon & 15 & 16 & 16 & 17 & 17 & 18 & 18 & 19 & 19 & 20 & 20 & 21 & 21 & 21 & 22 \\
\hline Gambia & 47 & 48 & 49 & 50 & 51 & 53 & 54 & 55 & 56 & 58 & 59 & 60 & 63 & 66 & 66 \\
\hline Ghana & 932 & 951 & 974 & 1002 & 1038 & 1038 & 1049 & 1063 & 1068 & 1067 & 1071 & 1233 & 1472 & 1577 & 1720 \\
\hline Guinea & 277 & 280 & 290 & 297 & 304 & 311 & 318 & 326 & 333 & 341 & 348 & 356 & 364 & 372 & 380 \\
\hline Guinea-Bissau & 51 & 53 & 54 & 55 & 56 & 57 & 58 & 60 & 61 & 63 & 64 & 66 & 67 & 69 & 70 \\
\hline Kenya & 640 & 16 & 17 & 17 & 18 & 18 & 18 & 18 & 5860 & 5906 & 5891 & 6044 & 6227 & 6395 & 6387 \\
\hline Lesotho & 78 & 80 & 82 & 84 & 85 & 87 & 89 & 90 & 92 & 95 & 97 & 98 & 100 & 102 & 104 \\
\hline Liberia & 153 & 160 & 167 & 175 & 183 & 192 & 243 & 208 & 217 & 225 & 235 & 243 & 252 & 262 & 272 \\
\hline Libya & 89 & 90 & 92 & 94 & 95 & 97 & 98 & 100 & 101 & 103 & 104 & 105 & 107 & 108 & 109 \\
\hline Madagascar & 545 & 557 & 766 & 805 & 843 & 881 & 921 & 960 & 1028 & 1068 & 1195 & 1195 & 1186 & 1560 & 1560 \\
\hline Malawi & 392 & 400 & 409 & 418 & 426 & 436 & 446 & 457 & 467 & 478 & 490 & 502 & 514 & 527 & 539 \\
\hline Mali & 96 & 100 & 103 & 106 & 110 & 113 & 117 & 121 & 125 & 129 & 133 & 141 & 141 & 172 & 171 \\
\hline Mauritania & 131 & 136 & 141 & 146 & 152 & 158 & 163 & 168 & 174 & 180 & 186 & 191 & 196 & 201 & 206 \\
\hline Morocco & 90 & 92 & 94 & 95 & 97 & 99 & 100 & 102 & 103 & 105 & 107 & 108 & 110 & 111 & 113 \\
\hline Mozambique & 373 & 383 & 391 & 398 & 406 & 414 & 423 & 431 & 439 & 447 & 455 & 464 & 695 & 692 & 712 \\
\hline Namibia & 4 & 4 & 3 & 4 & 5 & 5 & 5 & 6 & 7 & 7 & 8 & 7 & 7 & 7 & 7 \\
\hline Niger & 28 & 29 & 30 & 31 & 32 & 33 & 34 & 35 & 38 & 39 & 40 & 42 & 45 & 47 & 48 \\
\hline Nigeria & 1218 & 1361 & 1521 & 1698 & 1897 & 2120 & 2367 & 3333 & 3054 & 2619 & 3029 & 3483 & 4005 & 3743 & 3844 \\
\hline Rwanda & 48 & 48 & 48 & 48 & 48 & 406 & 427 & 452 & 478 & 506 & 535 & 558 & 575 & 606 & 610 \\
\hline Sao Tome and Principe & 7 & 7 & 8 & 8 & 8 & 8 & 8 & 8 & 9 & 9 & 9 & 9 & 9 & 9 & 9 \\
\hline Senegal & 329 & 335 & 338 & 336 & 334 & 342 & 342 & 490 & 502 & 562 & 546 & 561 & 576 & 482 & 497 \\
\hline Sierra Leone & 297 & 304 & 312 & 320 & 328 & 336 & 345 & 354 & 363 & 373 & 382 & 392 & 401 & 411 & 421 \\
\hline Somalia & 591 & 618 & 646 & 675 & 706 & 737 & 769 & 803 & 838 & 874 & 911 & 890 & 901 & 901 & 850 \\
\hline South Africa & 4 & 12 & 18 & 183 & 100 & 154 & 165 & 188 & 693 & 681 & 737 & 757 & 755 & 767 & 776 \\
\hline South Sudan & 10 & 10 & 10 & 10 & 10 & 10 & 10 & 10 & 10 & 10 & 10 & 10 & 10 & 11 & 11 \\
\hline Sudan & & & & & & & & & & & & & 1523 & 1550 & 1596 \\
\hline Swaziland & 30 & 31 & 32 & 34 & 35 & 36 & 38 & 39 & 40 & 41 & 42 & 38 & 40 & 43 & 44 \\
\hline
\end{tabular}




\begin{tabular}{|c|c|c|c|c|c|c|c|c|c|c|c|c|c|c|c|}
\hline Tanzania & 950 & 1153 & 1400 & 1700 & 1380 & 1449 & 1506 & 1522 & 1597 & 1645 & 1695 & 1747 & 1801 & 1856 & 1937 \\
\hline Togo & 449 & 460 & 471 & 482 & 494 & 509 & 518 & 530 & 543 & 584 & 601 & 618 & 635 & 652 & 670 \\
\hline Tunisia & 196 & 173 & 181 & 189 & 197 & 206 & 215 & 180 & 182 & 186 & 190 & 195 & 199 & 204 & 208 \\
\hline Uganda & 713 & 732 & 752 & 772 & 792 & 814 & 836 & 859 & 882 & 907 & 931 & 931 & 931 & 1000 & 1036 \\
\hline Zambia & 793 & 808 & 823 & 837 & 875 & 896 & 902 & 922 & 943 & 965 & 987 & 1010 & 1034 & 1058 & 1083 \\
\hline Zimbabwe & 11 & 9 & 9 & 9 & 9 & 9 & 14 & 13 & 12 & 9 & 9 & 9 & 9 & 9 & 9 \\
\hline
\end{tabular}

Table A3.3 Urban population in Africa from 2000 to 2014. Data source: World Bank, (2018)

\begin{tabular}{|c|c|c|c|c|c|c|c|c|c|c|c|c|c|c|c|}
\hline \multirow[t]{2}{*}{ Country } & \multicolumn{15}{|c|}{ Urban Population [10000 people] } \\
\hline & 2000 & 2001 & 2002 & 2003 & 2004 & 2005 & 2006 & 2007 & 2008 & 2009 & 2010 & 2011 & 2012 & 2013 & 2014 \\
\hline Algeria & 1868 & 1918 & 1968 & 2018 & 2070 & 2125 & 2182 & 2241 & 2304 & 2370 & 2439 & 2511 & 2587 & 2665 & 2743 \\
\hline Angola & 533 & 563 & 596 & 631 & 668 & 707 & 749 & 792 & 838 & 886 & 937 & 991 & 1046 & 1105 & 1165 \\
\hline Benin & 263 & 274 & 284 & 296 & 307 & 319 & 331 & 344 & 357 & 371 & 385 & 400 & 415 & 431 & 448 \\
\hline Botswana & 92 & 95 & 97 & 99 & 100 & 102 & 104 & 106 & 109 & 111 & 113 & 116 & 118 & 121 & 124 \\
\hline Burkina Faso & 207 & 221 & 237 & 253 & 270 & 289 & 309 & 330 & 352 & 376 & 401 & 426 & 453 & 481 & 510 \\
\hline Burundi & 53 & 55 & 59 & 62 & 66 & 70 & 74 & 78 & 83 & 88 & 93 & 99 & 104 & 110 & 116 \\
\hline Cameroon & 696 & 723 & 752 & 782 & 813 & 846 & 880 & 915 & 952 & 990 & 1029 & 1069 & 1111 & 1153 & 1197 \\
\hline Cape Verde & 23 & 24 & 25 & 26 & 27 & 27 & 28 & 29 & 30 & 30 & 31 & 32 & 33 & 33 & 34 \\
\hline Central African Rep & 141 & 145 & 148 & 151 & 154 & 157 & 160 & 164 & 167 & 170 & 173 & 175 & 176 & 178 & 180 \\
\hline Chad & 181 & 188 & 195 & 203 & 211 & 219 & 228 & 236 & 244 & 252 & 261 & 271 & 281 & 292 & 303 \\
\hline Comoros & 15 & 16 & 16 & 16 & 17 & 17 & 17 & 18 & 18 & 19 & 19 & 20 & 20 & 21 & 21 \\
\hline Congo & 189 & 196 & 203 & 210 & 218 & 227 & 236 & 246 & 257 & 267 & 277 & 287 & 297 & 307 & 316 \\
\hline Dem. Rep. of the Congo & 1653 & 1722 & 1797 & 1877 & 1962 & 2052 & 2146 & 2246 & 2351 & 2461 & 2577 & 2698 & 2825 & 2957 & 3095 \\
\hline Djibouti & 55 & 56 & 57 & 58 & 59 & 60 & 61 & 62 & 63 & 64 & 66 & 67 & 68 & 69 & 70 \\
\hline Egypt & 2992 & 3052 & 3113 & 3176 & 3240 & 3304 & 3367 & 3426 & 3486 & 3549 & 3618 & 3694 & 3776 & 3864 & 3954 \\
\hline
\end{tabular}




\begin{tabular}{|c|c|c|c|c|c|c|c|c|c|c|c|c|c|c|c|}
\hline Equatorial Guinea & 24 & 25 & 26 & 27 & 28 & 29 & 31 & 32 & 34 & 36 & 37 & 39 & 41 & 43 & 45 \\
\hline Eritrea & 60 & 62 & 65 & 68 & 72 & 75 & 78 & 81 & 84 & 87 & 90 & 94 & 97 & 100 & 104 \\
\hline Ethiopia & 981 & 1022 & 1066 & 1111 & 1157 & 1205 & 1254 & 1305 & 1373 & 1444 & 1519 & 1597 & 1679 & 1764 & 1853 \\
\hline Gabon & 99 & 102 & 106 & 109 & 113 & 117 & 121 & 126 & 130 & 135 & 141 & 146 & 152 & 157 & 163 \\
\hline Gambia & 59 & 62 & 65 & 69 & 72 & 76 & 79 & 83 & 87 & 91 & 95 & 100 & 104 & 109 & 113 \\
\hline Ghana & 832 & 866 & 902 & 940 & 979 & 1019 & 1061 & 1105 & 1150 & 1196 & 1243 & 1291 & 1340 & 1389 & 1440 \\
\hline Guinea & 273 & 281 & 290 & 298 & 308 & 318 & 328 & 339 & 351 & 363 & 376 & 390 & 403 & 418 & 433 \\
\hline Guinea-Bissau & 46 & 48 & 50 & 52 & 54 & 56 & 59 & 62 & 64 & 67 & 70 & 74 & 77 & 80 & 84 \\
\hline Ivory Coast & 727 & 753 & 779 & 805 & 831 & 859 & 888 & 921 & 956 & 993 & 1031 & 1072 & 1115 & 1159 & 1205 \\
\hline Kenya & 626 & 654 & 684 & 715 & 747 & 781 & 817 & 854 & 893 & 933 & 975 & 1018 & 1064 & 1111 & 1160 \\
\hline Lesotho & 37 & 38 & 39 & 41 & 42 & 43 & 45 & 46 & 48 & 49 & 51 & 52 & 54 & 56 & 57 \\
\hline Liberia & 128 & 134 & 138 & 141 & 145 & 150 & 157 & 164 & 172 & 181 & 189 & 196 & 203 & 210 & 216 \\
\hline Libya & 409 & 416 & 423 & 430 & 438 & 445 & 453 & 461 & 468 & 474 & 479 & 482 & 483 & 484 & 486 \\
\hline Madagascar & 428 & 445 & 464 & 483 & 502 & 528 & 556 & 584 & 613 & 644 & 675 & 708 & 742 & 777 & 813 \\
\hline Malawi & 166 & 172 & 178 & 184 & 190 & 196 & 203 & 211 & 219 & 227 & 236 & 245 & 254 & 264 & 275 \\
\hline Mali & 311 & 328 & 347 & 367 & 388 & 410 & 434 & 460 & 486 & 514 & 543 & 572 & 602 & 632 & 664 \\
\hline Mauritania & 133 & 140 & 146 & 153 & 159 & 166 & 173 & 181 & 188 & 196 & 205 & 213 & 222 & 231 & 241 \\
\hline Mauritius & 51 & 51 & 51 & 51 & 51 & 51 & 51 & 51 & 51 & 51 & 51 & 51 & 50 & 50 & 50 \\
\hline Morocco & 1539 & 1566 & 1593 & 1621 & 1649 & 1683 & 1718 & 1753 & 1790 & 1829 & 1870 & 1912 & 1957 & 2002 & 2049 \\
\hline Mozambique & 526 & 544 & 564 & 584 & 606 & 628 & 650 & 674 & 698 & 723 & 750 & 778 & 807 & 837 & 869 \\
\hline Namibia & 61 & 64 & 66 & 69 & 72 & 74 & 77 & 80 & 83 & 87 & 90 & 94 & 99 & 103 & 108 \\
\hline Niger & 184 & 192 & 200 & 208 & 218 & 228 & 238 & 250 & 262 & 275 & 288 & 303 & 319 & 336 & 354 \\
\hline Nigeria & 4263 & 4475 & 4697 & 4930 & 5174 & 5429 & 5696 & 5977 & 6270 & 6576 & 6895 & 7226 & 7568 & 7920 & 8283 \\
\hline Rwanda & 120 & 132 & 143 & 153 & 162 & 173 & 186 & 199 & 214 & 229 & 245 & 262 & 279 & 297 & 316 \\
\hline io Tome and Principe & 7 & 8 & 8 & 8 & 9 & 9 & 9 & 10 & 10 & 10 & 11 & 11 & 12 & 12 & 12 \\
\hline Senegal & 399 & 410 & 422 & 435 & 449 & 463 & 477 & 493 & 509 & 527 & 545 & 565 & 586 & 608 & 631 \\
\hline Seychelles & 4 & 4 & 4 & 4 & 4 & 4 & 4 & 4 & 5 & 5 & 5 & 5 & 5 & 5 & 5 \\
\hline Sierra Leone & 163 & 170 & 179 & 189 & 199 & 208 & 217 & 225 & 232 & 239 & 247 & 255 & 263 & 272 & 280 \\
\hline Somalia & 300 & 312 & 325 & 338 & 352 & 366 & 381 & 397 & 414 & 431 & 449 & 468 & 487 & 507 & 528 \\
\hline
\end{tabular}




\begin{tabular}{|c|c|c|c|c|c|c|c|c|c|c|c|c|c|c|c|}
\hline South Africa & 2554 & 2600 & 2655 & 2713 & 2773 & 2834 & 2898 & 2963 & 3031 & 3100 & 3172 & 3246 & 3322 & 3401 & 3482 \\
\hline South Sudan & 111 & 116 & 121 & 127 & 133 & 139 & 146 & 154 & 163 & 171 & 180 & 188 & 197 & 206 & 214 \\
\hline Sudan & 886 & 910 & 935 & 961 & 987 & 1013 & 1037 & 1061 & 1085 & 1110 & 1137 & 1167 & 1199 & 1233 & 1269 \\
\hline Swaziland & 24 & 24 & 24 & 24 & 24 & 24 & 25 & 25 & 25 & 25 & 26 & 26 & 27 & 27 & 28 \\
\hline Tanzania & 762 & 796 & 832 & 877 & 927 & 979 & 1035 & 1095 & 1159 & 1226 & 1296 & 1370 & 1448 & 1529 & 1614 \\
\hline Togo & 164 & 171 & 178 & 185 & 192 & 200 & 208 & 217 & 225 & 235 & 244 & 254 & 264 & 275 & 285 \\
\hline Tunisia & 615 & 625 & 633 & 642 & 650 & 658 & 665 & 674 & 683 & 692 & 702 & 711 & 722 & 732 & 743 \\
\hline Uganda & 290 & 302 & 315 & 332 & 352 & 372 & 393 & 416 & 440 & 465 & 491 & 519 & 549 & 580 & 612 \\
\hline Zambia & 367 & 378 & 393 & 409 & 425 & 441 & 459 & 477 & 496 & 515 & 536 & 559 & 582 & 607 & 632 \\
\hline Zimbabwe & 413 & 423 & 432 & 436 & 438 & 441 & 445 & 450 & 455 & 461 & 468 & 475 & 483 & 492 & 501 \\
\hline
\end{tabular}

Table A3.4 Forest loss from charcoal production in Africa. ${ }^{\text {a }}$

\begin{tabular}{|c|c|c|c|c|c|}
\hline \multirow[t]{2}{*}{ Country } & \multirow[t]{2}{*}{$\begin{array}{c}\text { Above Ground Biomass } \\
\text { [tonne ha } \\
\end{array}$} & \multicolumn{2}{|c|}{$\begin{array}{l}\text { Wood burned }^{\mathrm{c}} \\
{[1000 \text { tonne }]}\end{array}$} & \multicolumn{2}{|c|}{$\begin{array}{c}\text { Forest loss } \\
\text { [ha] }^{\text {d }}\end{array}$} \\
\hline & & 2014 & 2030 & 2014 & 2030 \\
\hline Algeria & 50 & $2401-8003$ & $3167-10557$ & $48470-161566$ & $63938-213127$ \\
\hline Angola & 46 & $3880-12933$ & $8987-29956$ & $85061-283537$ & $197014-656715$ \\
\hline Benin & 35 & 910-3033 & $1629-5429$ & 26133-87109 & 46771-155903 \\
\hline Botswana & 48 & $246-821$ & $406-1352$ & $5175-17251$ & 8521-28402 \\
\hline Burkina Faso & 46 & $2123-7076$ & $3990-13300$ & $46060-153535$ & $86581-288602$ \\
\hline Burundi & 55 & $880-2933$ & $1790-5968$ & $16043-53477$ & 32639-108798 \\
\hline Ivory Coast & 36 & $4790-15967$ & $6350-21167$ & $134753-449177$ & $178639-595464$ \\
\hline Cameroon & 99 & $787-2622$ & $1839-6131$ & $7985-26617$ & $18670-62233$ \\
\hline Central African Rep & 77 & $689-2297$ & $1277-4256$ & $8900-29667$ & $16492-54973$ \\
\hline
\end{tabular}




$\begin{array}{rcrrrr}\text { Chad } & 65 & 1485-4950 & 2521-8404 & 22788-75960 & 38691-128969 \\ \text { Congo } & 88 & 687-2289 & 1073-3578 & 7764-25880 & 12136-40453 \\ \text { Dem. Rep. of the Congo } & 159 & 12677-42256 & 24140-80467 & 79765-265883 & 151895-506317 \\ \text { Djibouti } & 37 & 170-568 & 225-750 & 4574-15245 & 6037-20123 \\ \text { Egypt } & 95 & 4700-15667 & 5810-19367 & 49341-164471 & 60994-203315 \\ \text { Equatorial Guinea } & 131 & 33-111 & 84-279 & 254-848 & 639-2129 \\ \text { Eritrea } & 44 & 490-1633 & 1367-4556 & 11040-36801 & 30793-102643 \\ \text { Ethiopia } & 69 & 13726-45752 & 22633-75444 & 198752-662507 & 327738-1092460 \\ \text { Gabon } & 83 & 73-242 & 99-331 & 877-2922 & 1198-3994 \\ \text { Gambia } & 47 & 214-713 & 314-1048 & 4553-15176 & 6687-22291 \\ \text { Ghana } & 49 & 5734-19113 & 8300-27667 & 116046-386820 & 167983-559945 \\ \text { Guinea } & 36 & 1267-4222 & 1916-6387 & 35506-118352 & 53710-179034 \\ \text { Guinea-Bissau } & 44 & 235-782 & 296-986 & 5384-17948 & 6789-22629 \\ \text { Kenya } & 54 & 21291-70969 & 29800-99333 & 394369-1314565 & 551989-1839962 \\ \text { Lesotho } & 95 & 346-1155 & 478-1593 & 3638-12127 & 5020-16735 \\ \text { Liberia } & 70 & 905-3017 & 1555-5184 & 12941-43136 & 22238-74126 \\ \text { Libya } & 54 & 365-1217 & 459-1531 & 6819-22731 & 8582-28607 \\ \text { Madagascar } & 102 & 5200-17334 & 10790-35967 & 51144-170479 & 106121-353738 \\ \text { Malawi } & 64 & 1799-5996 & 3083-10278 & 28030-93434 & 48048-160159 \\ \text { Mali } & 46 & 570-1900 & 1023-3409 & 12516-41722 & 22456-74855 \\ \text { Mauritania } & 47 & 688-2292 & 1029-3431 & 14550-48500 & 21779-72597 \\ \text { Morocco } & 48 & 373-1244 & 485-1617 & 7796-25987 & 10128-33760 \\ \text { Mozambique } & 40 & 2383-7944 & 5180-17267 & 59230-197435 & 128733-429109 \\ \text { Namibia } & 47 & 483-1611 & 1104-3680 & 10337-34456 & 23611-78703 \\ \text { Niger } & 47 & 161-535 & 282-941 & 3400-11335 & 5982-19939 \\ \text { Nigeria } & 42 & 12813-42711 & 31153-103844 & 303806-1012688 & 738651-2462170 \\ \text { Rwanda } & 78 & 2033-6778 & 2411-8036 & 25979-86598 & 30800-102668 \\ \text { Senegal } & 45 & 31-102 & 44-148 & 761-2536 & 1100-3666 \\ \text { Sao Tome and } & 1657-5522 & 4010-13367 & 36520-121732 & 88397-294656\end{array}$




\begin{tabular}{rrrrrr} 
Sierra Leone & 62 & $1403-4678$ & $2047-6823$ & $22649-75498$ & $33038-110127$ \\
Somalia & 49 & $3787-12623$ & $9180-30600$ & $77878-259595$ & $188786-629286$ \\
South Africa & 49 & $2382-7940$ & $6463-21544$ & $48999-163329$ & $132953-443178$ \\
South Sudan & 49 & $37-122$ & $37-122$ & $746-2486$ & $746-2486$ \\
Sudan & 49 & $5320-17733$ & $8483-28278$ & $108424-361414$ & $172894-576315$ \\
Swaziland & 47 & $158-526$ & $413-1376$ & $3372-11239$ & $8814-29379$ \\
Tanzania & 46 & $6457-21522$ & $11917-39722$ & $139850-466168$ & $258113-860378$ \\
Togo & 36 & $2233-7444$ & $3653-12178$ & $61350-204500$ & $100358-334526$ \\
Tunisia & 50 & $693-2311$ & $931-3102$ & $13905-46350$ & $18665-62216$ \\
Uganda & 53 & $3458-11527$ & $7687-25622$ & $65235-217452$ & $145008-483360$ \\
Zambia & 45 & $3610-12033$ & $5893-19644$ & $79809-266029$ & $130288-434293$ \\
Zimbabwe & 49 & $30-100$ & $21-69$ & $609-2028$ & $419-1397$ \\
\hline
\end{tabular}

\footnotetext{
${ }^{\mathrm{a}}$ Ranges are due to the use of the reported range in earth kiln combustion efficiencies of 9-30\%. ${ }^{\mathrm{b}}$ The AGB is from Hengeveld et al.,

(2015). ${ }^{\mathrm{c}}$ Wood burned was calculated from charcoal produced. ${ }^{\mathrm{d}}$ Forest loss was calculated from wood burned and AGB.
} 


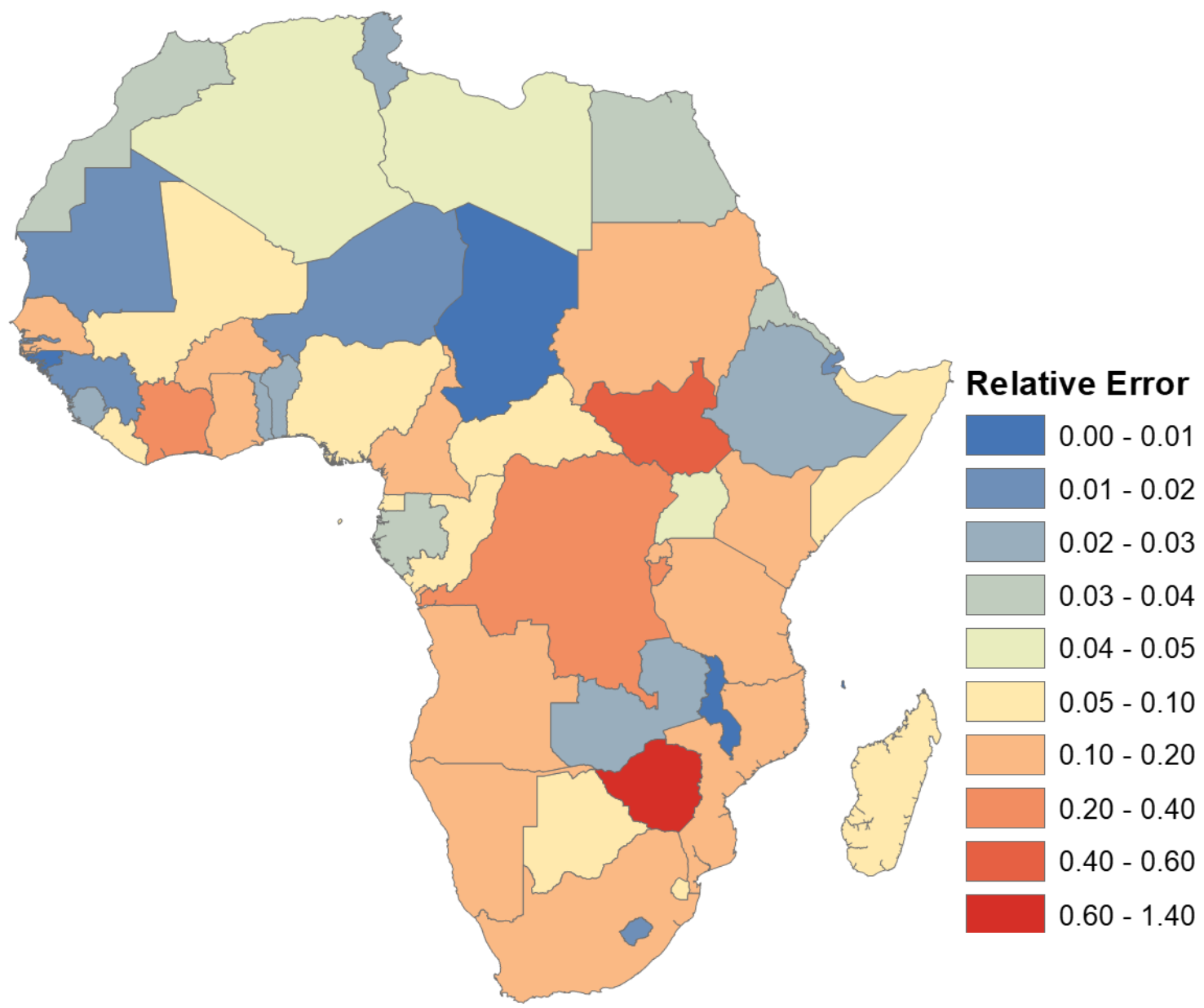

Figure A3.2 Uncertainty of regression. Map shows relative error in $\mathrm{Tg}$ (urban person) ${ }^{-1}$ $\mathrm{a}^{-1}$, associated with predicting future charcoal production in Africa in 2030 . 


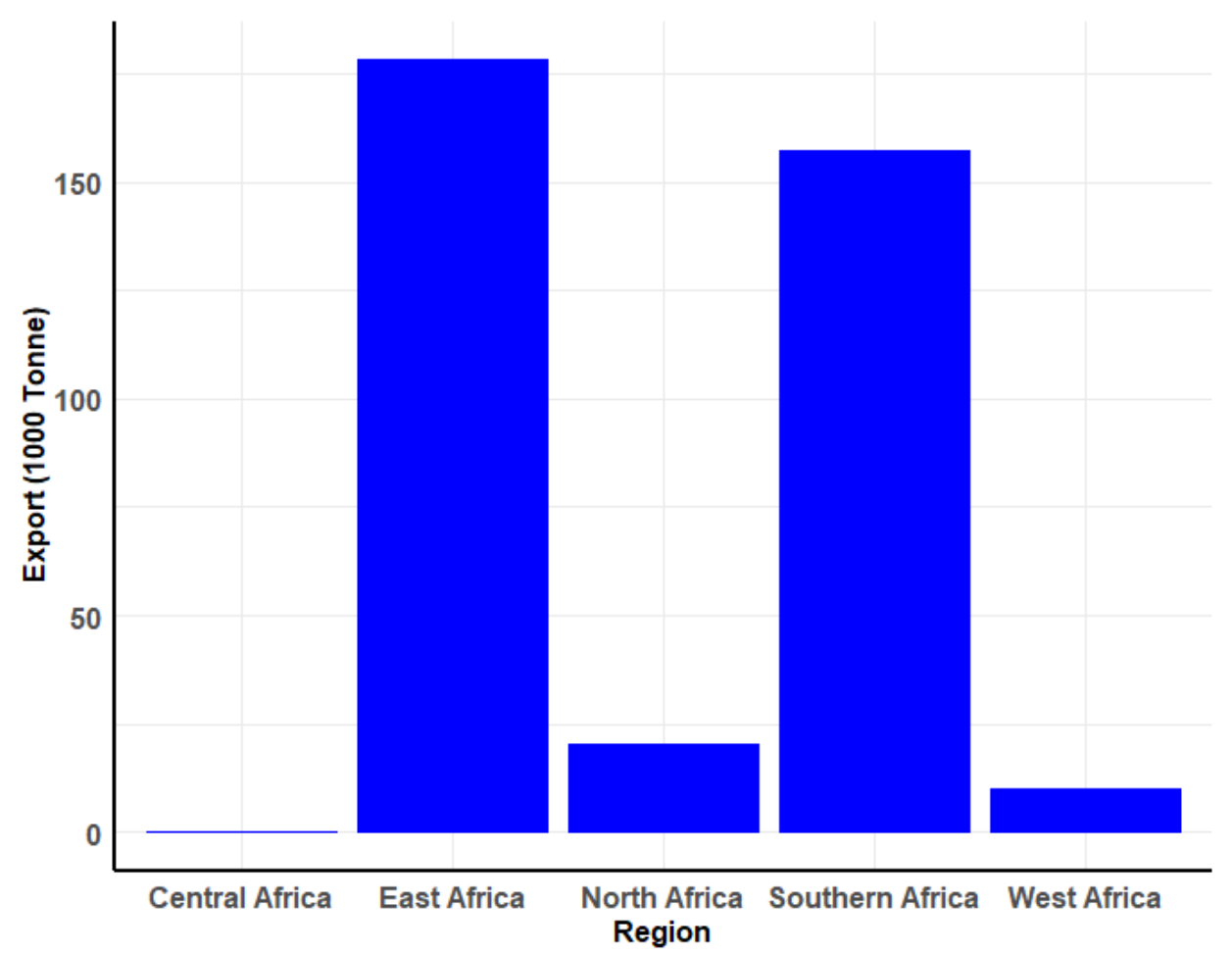

Figure A4.1 Charcoal export from Africa by region in 2014. Data source: (UN, 2017b).

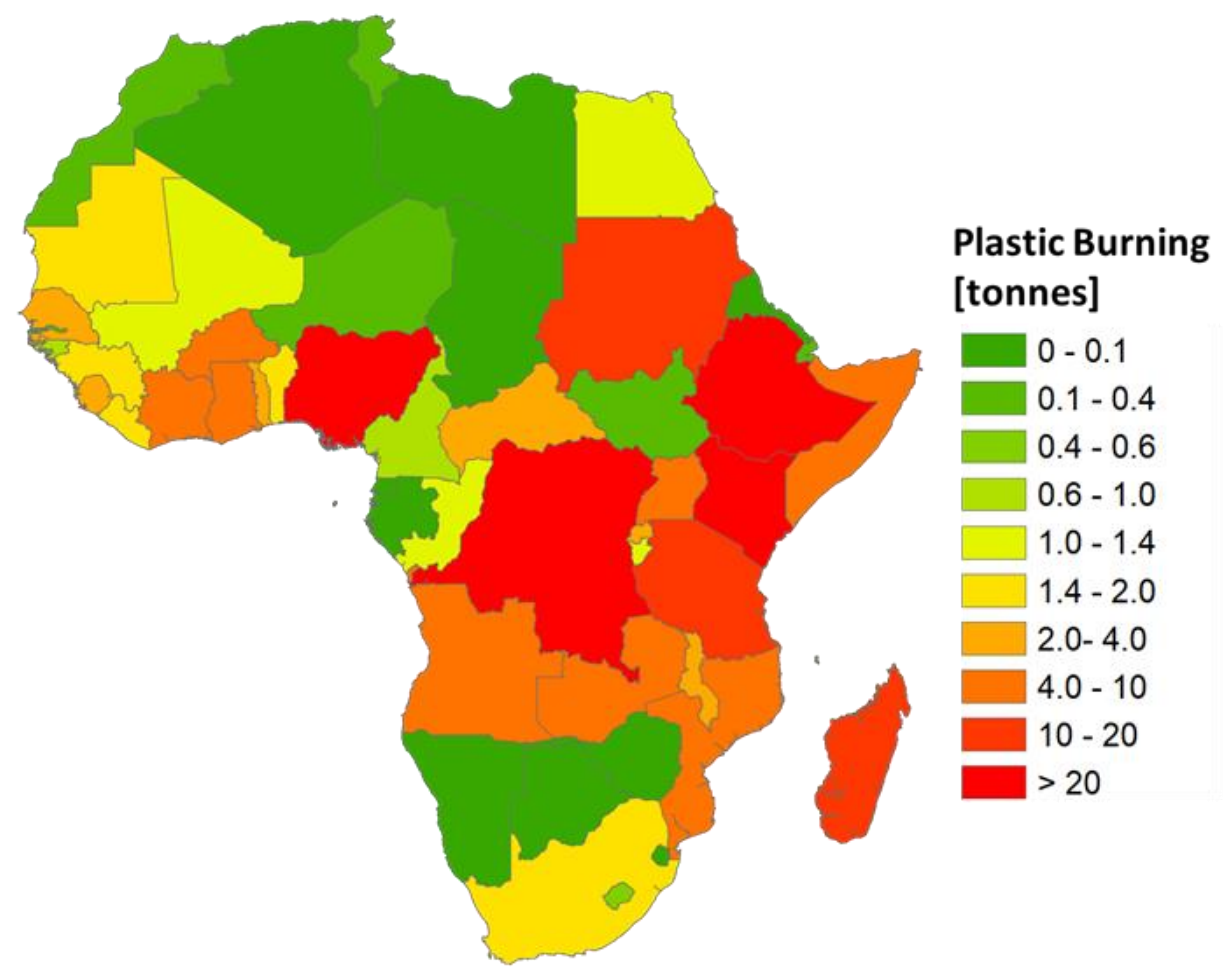


Figure A5.3 Plastic burned in 2014 to initiate combustion for charcoal use. Values are estimated as the product of the relative proportion of the urban population in slums, the quantity of charcoal consumed in each country, and a speculative guess of the amount of plastic used (4 $\left.\mathrm{g} \mathrm{kg}^{-1}\right)$ (see manuscript text for details). The 2014 total for Africa is 260 tonnes. 